\title{
Women's livelihood strategies in diverse contexts: Constructing feminist topographies in Appalachia and South Africa
}

Amy Danielle Pratt

West Virginia University

Follow this and additional works at: https://researchrepository.wvu.edu/etd

\section{Recommended Citation}

Pratt, Amy Danielle, "Women's livelihood strategies in diverse contexts: Constructing feminist topographies in Appalachia and South Africa" (2006). Graduate Theses, Dissertations, and Problem Reports. 2488.

https://researchrepository.wvu.edu/etd/2488

This Dissertation is protected by copyright and/or related rights. It has been brought to you by the The Research Repository @ WVU with permission from the rights-holder(s). You are free to use this Dissertation in any way that is permitted by the copyright and related rights legislation that applies to your use. For other uses you must obtain permission from the rights-holder(s) directly, unless additional rights are indicated by a Creative Commons license in the record and/ or on the work itself. This Dissertation has been accepted for inclusion in WVU Graduate Theses, Dissertations, and Problem Reports collection by an authorized administrator of The Research Repository @ WVU.

For more information, please contact researchrepository@mail.wvu.edu. 


\title{
Women's Livelihood Strategies in Diverse Contexts: Constructing Feminist Topographies in Appalachia and South Africa
}

\author{
Amy Danielle Pratt
}

Dissertation submitted to the Eberly College of Arts and Sciences, West Virginia University in partial fulfillment of the requirements for the degree of

\author{
Doctor of Philosophy \\ In \\ Geography
}

Committee:

Dr. Ann Oberhauser, Chair, West Virginia University

Dr. Cindi Katz, City University of New York

Dr. Kenneth Martis, West Virginia University

Dr. Calvin Masilela, Indiana University of Pennsylvania

Dr. Brent McCusker, West Virginia University

Department of Geology and Geography

Morgantown, West Virginia

2006

Keywords: feminist geography, socialist feminism, feminist materialism, gender and livelihoods, female-headed households, women in South Africa and Appalachia

Copyright 2006, Amy Danielle Pratt 


\title{
ABSTRACT \\ Women's Livelihood Strategies in Diverse Contexts: Constructing Feminist Topographies in Appalachia and South Africa
}

\begin{abstract}
Amy Danielle Pratt
This dissertation investigates the livelihoods of women heading households in rural parts of Appalachia and South Africa and develops a conceptual and methodological framework for transnational, comparative feminist research Situated within a feminist geographical framework that is informed by feminist materialism and livelihoods analyses, it focuses on both historical and contemporary socioeconomic, cultural, and political forces at various scales of analysis that either enable or restrict women's ways of 'making due' in the two regions. The study focuses on five counties in northern West Virginia in the Appalachian region and Limpopo, including the former bantustan of Venda, in South Africa and utilizes a qualitative methodology. Through individual interviews, focus groups, and survey data, the dissertation tells the stories of how women heading households in West Virginia and Limpopo piece together work in both the formal and informal economies; government assistance programs; subsistence agricultural activities; family and community support; and co-habitation and 'doubling-up' strategies to construct a livelihood that will support their families. With respect to their livelihood strategies, this research analyzes how they are accessed and utilized; associated benefits and drawbacks; and how they fit with women's productive and reproductive responsibilities. It is argued that while women's livelihood strategies in the two regions are embedded in specific contexts and local household and community relations, they are connected to broader socioeconomic and political processes that operate similarly across place. This research makes evident that the power to exclude or empower women is constituted through various institutions and processes at various scales of analysis and recognizes women's agency by examining the multiple and diverse strategies they create to combat unequal and oppressive relations and acquire sustainable livelihoods.
\end{abstract}


For Ava, my beautiful daughter. 


\section{Contents}

Illustrations $\quad$ vi

$\begin{array}{ll}\text { Acknowledgements } & \text { vii }\end{array}$

$\begin{array}{lr}\text { I. Introduction } & 1\end{array}$

II. Socialist Feminism and Topographical Analysis - Social and Spatial 16

A. Introduction 16

B. Contemporary Feminist Theories 16

1. Feminist Social Theory-Marxist, Radical, and Socialist Feminisms

2. Feminism and Postmodernism

3. Back from the 'Cultural Turn'? Critiques of Postmodernism

C. Reviving Socialist Feminism and a Materialist Approach

1. Defining Socialist Feminism

2. Contemporary Socialist Feminist Work

D. Feminist Topographical Analysis - A Geographical Framework for Social and Spatial Analysis and Comparative Feminist Research

1. Socialist and Postmodern Geographies

2. Feminist Topographical Analysis - A Framework for Comparative Feminist Research

E. A Livelihoods Framework-Conceptualizing Women's Economic Realities 58

$\begin{array}{ll}\text { F. Summary } & 64\end{array}$

III. A Socioeconomic History of Gender and Livelihoods in Limpopo, South Africa 68
A. Introduction
68
B. Defining Concepts and Terms
69
C. Gender and Livelihood Strategies in South Africa
72

1. Life in the Bantustans

2. African Women in Waged Labor

3. Collective and Informal Economic Activities

D. Limpopo: The Case Study Area

E. Democratization and Gender Policy in a 'New' South Africa 92

F. Summary 97

IV. Gender and Livelihood Strategies in Appalachia 99
A. Introduction

99

B. From Agriculture to Industry: early economic development in the Appalachian Region

C. The 'Making' of Appalachia

117

D. Women and Work in Appalachia

130

E. West Virginia: The Case Study Area 136

F. Summary 147

G. The Way Forward... $\quad 148$

V. 'Doing' Feminist Geography: Ethnographic Approaches and Feminist Topographies 151

A. Introduction 151

B. Feminist Methodological Approaches in Geography 153

C. Constructing Feminist Topographies-A Geographical Method for Analysis,
Comparative Work, and Activism

D. Statement of Research Objectives and Questions $\quad 170$

E. Methods Utilized to Research Women's Livelihoods 172

F. Experiences from 'the field' 179

a. The "I", the "Me", "the Researcher" 
G. Summary

VI. The Livelihoods of Female-Headed Households in Limpopo, South Africa and West Virginia, Appalachia

195

195

A. Introduction

B. Livelihoods in Limpopo-Women in Rural Households

1. Limpopo

2. Description of Sample

3. Female-Headed Households in Limpopo and their Livelihood Strategies
a. Community Producer Groups
b. Sewing, Knitting, and Craft Businesses
c. Informal Trade Activities
d. Subsistence Agriculture
e. Social Assistance
f. Family and Community Assistance

C. Livelihoods in West Virginia_-“On our own...," Women Heading Households in Rural Appalachia

1. West Virginia

2. Livelihood Strategies of Female-Headed Households in West Virginia
a. Work in the Formal Sector
b. Public Assistance and Child Support
c. Co-habitation and Doubling-up
d. Savings and Retirement and Life Insurance Benefits
e. Informal Activities
f. Co-strategizing
g. Family and Community Assistance

D. Summary

VII. Typologies and Topographies - Comparing the Livelihoods of Female-Headed Households 310

A. Introduction

B. A Typology of Livelihood Strategies

1. Formal Strategies

2. Informal Strategies

3. Government Assistance

4. Family and Community-based Strategies

5. Co-strategizing

C. Topographical Models, Contour Lines, and Countertopographies

344

D. Summary

VIII. Conclusion 


\section{Illustrations}

\section{MAPS}

Map 1: West Virginia and the Appalachian Region

Map 2: Limpopo, South Africa, and Continent of Africa 14

Map 3: The Appalachian Region 15

Map 4: Former Bantustans of South Africa $\quad 76$

Map 5: Former Venda Bantustan $\quad 87$

Map 6: West Virginia's Counties and Major Cities 104

Map 7: Communities of Respondents in Limpopo 202

Map 8: Communities of Respondents in West Virginia 241

\section{TABLES}

Table 1: Non-Farm Employment in West Virginia, Percent by Industry, by Decade, 1940-1999 140

Table 2: Summary Data for Respondents in Limpopo, South Africa 200

Table 3: Profile of Women's Community Producer Groups in Limpopo 209

Table 4: Comparative National, Regional, State, and County Level Data for Research Areas in West Virginia 230

Table 5: Summary Data for Respondents in West Virginia, Appalachia 240

Table 6: Current Use and History of Government Benefits Received by Respondents in West Virginia 269

\section{PHOTOGRAPHS}

Photo 1: Photo of Focus Group Discussion 296

Photo 2: Photo of Researcher with Respondents, Jaycie and Vera, in West Virginia 296

Photo 3: Photo of Dancing at Rambuda Stone Crushing Project 297

Photo 4: Photo of Venda Women Expressing Gratitude 297

$\begin{array}{lr}\text { Photo 5: Piggery } & 298\end{array}$

$\begin{array}{ll}\text { Photo 6: Eve working at the piggery } & 298\end{array}$

Photo 7: Eve making traditional mats $\quad 299$

$\begin{array}{ll}\text { Photo 8: Tshandama Bakery } & 299\end{array}$

Photo 9: Tshandama Jam Project: current work site 300

Photo 10: Women at Tshandama Community Stone Project 300

Photo 11: Rambuda Stone Project $\quad 301$

Photo 12: Photo of Sharon at sewing machine at Mvuleleni Sewing Project 301

Photo 13: Women with children at Tshandama Jam Project 302

Photo 14: Woven goods at Pfananani Community Center $\quad 302$

Photo 15: Baobob Kiosk $\quad 303$

Photo 16: Women working at Baobob Kiosk 303

Photo 17: Tshakuma Market 304

Photo 18: Anna's Home in Flemington, West Virginia 304

Photo 19: Wanda and her son $\quad 305$

Photo 20: Jane, Angie, and Karen's Home in Simpson, West Virginia 305

Photo 21: Tracy's Home in Simpson, West Virginia 306

Photo 22: Tracy and her two sons with their horses 306

Photo 23: Caroline's apartment in Bridgeport, West Virginia which qualifies as HUD housing 307

Photo 24: Wanda's farm that she inherited from her parents 307

Photo 25: Diane's "resource board” $\quad 308$

Photo 26: Vision Appalachia's Offices in Barbour County, West Virginia 308

Photo 27: The WorldVision Storehouse in Barbour County, West Virginia 309

FIGURE

Figure 1: A Topographical Model $\quad 347$ 


\section{Acknowledgements}

There are many people to thank for the completion and success of this project. First of all, I would like to thank my advisor, Dr. Ann Oberhauser, not only for her guidance and support, but also for her friendship. As a mentor, she has guided my educational development and demonstrated to me how one can excel in the teaching, research, and service duties of an academic professional. As a friend, she has been there to guide me through the trials of graduate school and becoming a mother and shown me how one can be a successful career woman and devoted mom. I truly appreciate and thank her for her guidance, patience, and constant faith and confidence in me as a student and researcher. I also thank her for the many opportunities she gave me as a graduate student, including the research assistantships and field experience in South Africa.

My most sincere thanks also goes to my committee members, Drs. Cindi Katz, Calvin Masilela, Ken Martis, and Brent McCusker. I deeply appreciate your time, patience, and support throughout the preparation of this work. Your insightful ideas and questions have truly strengthened this research project. Thank you for providing students with supportive environments where they can grow and develop as future teachers and researchers in geography.

I would also like to take this opportunity to especially thank Drs. Dan Weiner and Calvin Masilela. Since my undergraduate years, they both have encouraged me to pursue my love of southern African studies and geography and the confidence they both have in my abilities as a student has contributed greatly to my achievements. I truly value their experience and dedication to the southern African region and its people and it is through their support and hard work that I was able to realize my dream and conduct research in South Africa for the first time in 1997. I wish to thank them for their guidance, faith, and most of all, friendship.

Special thanks also goes to the Geography Program and the many faculty, staff, and students who have provided me with support, encouragement, and constructive debate, as well as friendship and comic relief. I would also like to thank Michael Walnoha for his cartographic assistance.

I would also like to thank the Office of International Programs and Center for Women's Studies for facilitating the funding I received for this project through the Global Education Opportunities Grant and the Velma Miller Scholarship. This funding supported the research in Limpopo, South Africa.

The field assistants for this project, Josephine Mudau, Virginia Maimela, and Madzinghe Nembudani, must also be recognized and thanked for their hard work. This work would not have been possible without their assistance. Their knowledge of rural communities in Limpopo, gender issues and women's livelihoods, and rural economic development was exemplary. They facilitated research with the women's groups with great ease and sensitivity and worked very carefully to ensure the correct translation of material throughout the interviews and focus groups. I would also like the Department of Geography at the University of Venda and most especially, Agnes Musyoki, for her help in facilitating this project and my stay in Thohoyandou. Agnes' efforts and dedication to building partnerships between the University of Venda and West Virginia University made it possible to conduct research in Limpopo and her hospitality, encouragement, and support is greatly appreciated.

I also want to thank my parents, Chuck and Carolyn Fowler, for their love and support. They have been a great example and source of strength in my life. They have made many sacrifices to provide my brother and me with the opportunities that they did not have. They are the kindest, most giving parents and I love them deeply. I also want to thank my younger brother, Jeremy, for our brother-sister relationship as well as friendship.

In addition, I have a wonderful extended network of aunts, uncles, cousins, and in-laws, close friends, and community and church members who have supported and encouraged me throughout this project. I also want to especially thank the "5ofus" (Tania, Edurne, Tina, and Jackie) for the special friendship we have. It has sustained me throughout the writing of this dissertation and I love you and cherish you all.

I also want to thank my husband, Gregg, for his confidence in me and support for my work on this project. Completing this dissertation has been a long process but with your help, I was able to finish this work with a toddler running around our house. Thanks for paying the bills, watching our daughter, and spending many nights alone while I worked. I also want to thank my beautiful daughter, Ava, for giving me yet another reason for wanting to make the world a better place for women. You are the best thing that has ever happened to me and I love you.

Finally, I would like to recognize and thank all of the women in Limpopo and West Virginia who participated in this study. Thank you for your time, patience, and insightful comments throughout the fieldwork portion of this work, for trusting me to tell your personal stories, and for letting me come into your homes and workplaces. I take full responsibility for any errors or misinterpretations. 


\section{Introduction}

Women in rural areas across the globe engage in diverse economic strategies to sustain a livelihood for their families. The concept of livelihood encompasses the varied ways of living that meet individual, household, and community needs (adapted from Ratner, 2000, May, 1999 and Chambers and Conway, 1992). In general, livelihoods depend on various types of 'capital' including human, social, natural, physical, and financial, as well as socioeconomic and political structures and processes (DFID, 1999). Structures and processes operate at all scales, from the household to the global, and within all spheres, from the most private to the most public.

Structures govern societies and determine access to capital, livelihood strategies, and decisionmaking power through processes, such as policies, legislation, institutions, culture, and power relations. Livelihood analyses that focus on women must therefore develop profiles of their livelihood strategies as well as analyze the multiple 'players' and 'practices' that either enable or restrict their livelihood options. Therefore, conceptual and methodological frameworks utilized in such analyses examine socioeconomic relations and specifically gender as a central analytic category in research on women's livelihood issues.

This research project specifically examines the livelihoods of women in diverse rural areas of the globe. Utilizing West Virginia, in Appalachia (Maps 1 and 3), and Limpopo ${ }^{1}$, in South Africa (Map 2), as case study areas, this project focuses on female-headed households and consequently asks: What particular livelihood strategies do women who head households engage in and are they sustainable? What factors affect their access to and control over resources and capital in their quest for sustainable livelihoods? How are women represented within the structures and processes that affect their participation in local economies and choice of

\footnotetext{
${ }^{1}$ Limpopo includes the former bantustan areas of Venda and Gazankulu. This research particularly focuses on the former Venda bantustan.
} 
livelihood strategies? What similar as well as differing issues affect the livelihoods of femaleheaded households in diverse geographic areas? And finally, how can understanding women's livelihoods transnationally contribute to global feminism?

To answer the questions highlighted above this project develops conceptual and methodological frameworks that are grounded in feminist materialism, geographical concepts of space, place, and scale, and global feminism. It is argued that unique local histories, specific socioeconomic and spatial conditions, and current political and economic restructuring issues have contributed to the rise of particular livelihood strategies among women in the two geographic areas (Bob, 2001; May, 1999; Oberhauser and Turnage, 1999; Mencken and Maggard, 1999; Oberhauser, 1995a; Seid man, 1993; Bozzoli, 1991; Preston-Whyte and Nene, 1991; Greene, 1990; Pudup, 1990; Cock, 1980). In Limpopo, the former apartheid regime, particular gender, race, and class relations, and current democratic and economic transition affect the nature of jobs available to women. A number of economic strategies often encompass the livelihoods of Black women in particular and may include both informal and formal sector work, subsistence agriculture, and pension and child grants.

In Appalachia, the historical economic context of resource extraction, cycles of unemployment and economic recession, rurality, and household gender relations affect women's participation in local economies. Strategies in the informal sector such as domestic labor and homework, raising livestock, and bartering coupled with employment in the rising low-paid and part-time service sector comprise the livelihoods of many women in rural areas (Mencken and Maggard, 1999; Oberhauser, 1995 a and b; 1993; Pudup, 1990; Greene 1990). It is argued that while women's identities and strategies in West Virginia and Limpopo are embedded in specific socioeconomic contexts and local household and community relations they are connected to 
broader capitalist, colonial, racist, and patriarchal processes. This work is particularly concerned with the effects of these regional and global processes, including economic and political restructuring, and local culture and gender relations on the lives of women who head households in the two areas. It makes evident that the power to exclude or empower women is constituted through various institutions and processes at various scales. Finally, this work recognizes women's agency by examining the strategies they create to combat unequal and oppressive relations and acquire sustainable livelihoods.

In order to understand women's livelihoods in these diverse places this work encompasses four main research objectives. The first research objective specifically aims to explore the socioeconomic and spatial conditions in West Virginia and Limpopo that have affected women's economic participation and contributed to the rise of female-headed households. Thus, the local socioeconomic histories of the two areas are explained and information concerning labor force participation, unemployment, and poverty rates, as well as sectoral data concerning employment in Limpopo and West Virginia is presented. Second, the research analyzes the particular livelihood strategies utilized by female-headed households in the two regions. Information concerning the types of income-generating activities or forms of employment that are available to women in the two areas is discussed and women's positions within formal and informal employment structures are addressed. An analysis of livelihood strategies used by women in this study is also presented with particular focus on sustainability, material and non-materials benefits and drawbacks, location, and organization of these strategies. The third objective examines the relationship between livelihood strategies within female-headed households and household and community gender relations in West Virginia and Limpopo. Issues around gender divisions of labor, women's roles and the distribution of power and 
resources within households and communities, and family and community resources utilized as part of women's livelihood strategies is explored. Finally, the fourth objective investigates how the livelihood strategies of female-headed households in the two regions are affected by broader processes such as global economic restructuring, political change, and economic development policy, that operate at regional and global scales. Here, information concerning democratization in South Africa and welfare reform in West Virginia as well as shifts in global capitalare discussed.

These objectives reflect the commitment made by this research project to recognize the importance of local context, but also broader socioeconomic structures and issues on women and their need to support families. Examining women's livelihood strategies in diverse contexts and making connections across space, place, and scale is a profoundly geographical project. Therefore, the particular conceptual and methodological approaches developed by this project utilize both topographical analysis, as developed within the field of feminist geography, and feminist materialism, including work by feminist theorists from various fields of study. As developed by geographer Cindi Katz (2001a and b), feminist topographical analysis enable s this study to examine and compare the rural economic context of the two case study regions, women's positions in both formal and informal economic structures and processes, and their subsequent livelihood strategies. Feminist materialism is related to topographical analysis and both seek to analyze material manifestations of power that result from particular socioeconomic structures and processes that occur at local, regional, and global scales, but are grounded in everyday life (Katz, 2001a and b; McDowell, 1997; Jackson and Jacobs, 1996; Smith, 1994). By rethinking the relationship between 'the local' and 'the global', these frameworks therefore analyze women's material realities and economic identities within their everyday lives and their 
connections to the broader workings of capitalism, colonialism, and patriarchy. These theoretical and methodological frameworks also realize that gender, class, and race relations are not only relations of 'difference' but also inequality made evident through institutionalized racism, legacies of colonialism and imperialism, and the international division of labor, for example. In recent years, the material foundations and consequences of these processes have been neglected by the postmodern turn within feminist theory despite the fact that we live within a global context characterized by extremely stark material inequalities. The economic oppression and marginalization of women has not gone away, and for many women the situation is worsening.

Constructing feminist topographies in West Virginia and Limpopo 'grounds' analyses of women's economic realities by considering the social and physical features of these diverse places and revealing the multiple socioeconomic structures and processes at all geographic scales that affect women's livelihoods (Katz, 2001a; Jackson, 2001and 1998; Liddle and Wright, 2001). Hence, issues around rurality, the heritage of apartheid and processes of underdevelopment, and political and economic restructuring are considered. Through these detailed and dynamic analyses of space, place, and scale, feminist topographies provide a more complete understanding of women's current economic situations and livelihood strategies.

In addition, topographical analysis allows for a comparative approach that reveals how specificities of different places are linked to socioeconomic realities of women. Methodologically, topographies provide the means for critically scrutinizing the material effects of capitalist, patriarchal, and racist processes, such as economic restructuring and uneven development, produced in diverse locations around the globe. Thus understanding the traces and connections of these processes and their effects on women's everyday lives are crucial to 
challenging them and allow for 'contour lines' to be drawn. The drawing of analytical contour lines between places and women that are based on a particular relation to the effects of such processes works toward the building of 'counter-topographies'. To illustrate this point, women in the Free Trade Zones of Southeast Asia and the maquiladoras of Mexico could find that they are connected to the process of global economic restructuring through their place within the international division of labor and potentially organize around issues concerning low wages, harsh working conditions, and lack of benefits. Counter-topographies consequently imagine different responses to the common problems and interests of women in places typically thought of as discrete and are ripe with possibilities concerning global feminist politics and organizing (Katz, 2001a and b). They are a long sought means for 'mapping' a translocal feminism that enables women to establish common needs, exchange information on strategies, and organize despite differences based on race, class, and place.

With regard to feminist materialism, recent work has (re)turned to empirically-grounded theorizing about the material conditions of women's lives within their social and historical contexts (Jackson, 2001 and 1998). Diverging from contemporary postmodern approaches within feminist theory concerning culture, women's subjectivities, and issues around identity, representation, and 'difference', this work (re)focuses on socioeconomic structures and processes, hierarchies of power, and women's strategies for change (Liddle and Wright, et al., 2001). Feminist materialism does not neglect analyses of difference and culture or reduce the material to the 'economic'. It does, however, seek to examine everyday social practices and material inequalities to better understand difference and the multiplicity of forces that either oppress or empower women (Jackson, 2001). It is argued here that all axes of difference, including gender, have a material basis or grounding that is connected to various ways of 
knowing, experiencing, and strategizing the world. Understanding and accounting for women's 'ways of knowing' treats women's knowledge and perspectives as primary and constitutive of a different point of view rather that 'subjugated' or 'disruptive' (Haraway, 1991; McDowell, 1991; Hartsock, 1990; Harding, 1986). Articulating these ways of knowing and strategizing the world through research projects such as this allows women to name and describe their diverse experiences and tease out their differences and commonalities. Fundamentally, this work highlights the need to bring together "the material" and "the cultural" so that differences constituted by structural inequality, hierarchical power relations, and culture can be realized (Liddle and Wright et al., 2001; Jackson, 1998). In addition, women are recognized as subjects that are not only constructed by, but also responding to, unequal relations of power through diverse types of mobilization, organization, and activism and gender can once again become the central analytic category for feminist research and activism (Butler, 2001; Hanscombe and Namjoshi, 2001; Liddle and Wright, 2001; Scott, 2001).

This research employs multiple methods, including surveys, interviews, and focus groups, as well as extensive library research, to construct feminist topographies of women's livelihoods in West Virginia and Limpopo. Information concerning the socioeconomic history of women in the two regions, current employment and economic participation data, and the factors that contribute to rising numbers of female-headed households is presented. This study also addresses the specificities of female-headed households concerning household and community relations, women's roles and responsibilities, and their particular livelihood strategies. The research develops a typology of women's economic activities in and between West Virginia and Limpopo and discusses their organization, location, material and non-material benefits and drawbacks, and viability. The common and differing issues concerning women's 
socioeconomic conditions and everyday material realities in the two areas is also presented and the information obtained is related to broader issues of restructuring, patriarchal relations, colonialism and apartheid, and economic and social policy, regionally and globally. The research involved fieldwork in both Limpopo and West Virginia. Transcripts from interviews, focus groups, and field notes were analyzed utilizing QSR INVIVO, a program for the analysis of qualitative data.

In sum, numerous studies have been conducted in the two regions concerning women's employment and socioeconomic history, as well as their participation in formal and informal work and development of strategies for economic, social and political justice (Francis, 2000; Oberhauser and Turnage, 1999; Mencken and Maggard, 1999; Oberhauser, 1995a; Robinson, 1994; Seidman, 1993; Bozzoli, 1991; Preston-Whyte and Nene, 1991; Greene, 1990; Pudup, 1990; Cock, 1980). Few studies have, however, illustrated the interconnections between women's informal and formal livelihood strategies, household and community relations, and broader processes of restructuring and capitalist economic development in and across these diverse rural places. This study contributes theoretically and me thodologically to feminist geography by advancing on-going discussions concerning the need to make connections and form alliances transnationally when working for the social and economic advancement of women.

The second chapter of this dissertation outlines the conceptual frameworks employed in this analysis: socialist feminism, including materialism, and feminist topographical analysis. These frameworks investigate issues of materiality and culture through a social-structural analysis and interrogate geographical concepts like space, place, and scale. Both frameworks seek to answer questions about women's oppression and subordination, attend to issues of 
difference and identity, and work for women's socioeconomic and political empowerment. Socialist feminism, in particular, allows this work to examine the socioeconomic structures of capitalism, patriarchy, and colonialism that are embedded within ideologies which establish men's and women's roles in society and legitimate power within socioeconomic and political institutions. Feminist topographical analysis works with socialist feminism to reveal how the socioeconomic structures of capitalism, patriarchy, and colonialism are manifested in space and place and at various scales of analysis and allows for a comparative approach. Fundamentally, these frameworks allow this project to interrogate and compare the capitalist, patriarchal, and colonial structures in Appalachia and Limpopo that work with local cultures to develop spatialized sets of social relations that construct place and identity and consequently affect women's livelihoods.

Chapter II also draws from the livelihoods approach to understand the various social, economic, and political factors and institutions that determine women's access to particular economic strategies that can sustain their families. This chapter defines the concept of a livelihood, the types of capital, structures, and processes that shape people's livelihood options, and discusses the importance of feminist analyses to work on livelihoods.

The third and fourth chapters provide background information concerning women's economic strategies in both South Africa and Appalachia. Chapter III defines concepts such as informal and formal economies and female-headed households before presenting a brief socioeconomic history of colonialism and apartheid in South Africa's former bantustans. African women's roles in the economy are then highlighted through an exploration of women's work in both the formal and informal economies. Limpopo, the case study area, is then described through maps, demographic, socioeconomic, and historical data, and a discussion of 
livelihoods in this Province. Democratization and gender policy in a 'new' South Africa are discussed in the final section and the various institutions and structures developed in the country to ensure and protect the rights of women are highlighted.

Chapter IV discusses gender and livelihood strategies in Appalachia by presenting a socioeconomic history of economic development in the region that explores both agricultural development and industrial change. The chapter also discusses the Appalachian Regional Commission (ARC) and its economic development role in the region. Women's productive and reproductive roles in the Appalachian economy are examined by highlighting the various formal and informal strategies they have historically utilized to support families. West Virginia, the case study area, is described through maps, physical descriptions, demographic, socioeconomic, and historical data, and a discussion of livelihood strategies used by people in the state. The chapter concludes by highlighting some of the parallels between West Virginia and Limpopo that led to the development of this comparative project.

Through a discussion of qualitative methodology and the development of feminist topographies within geography, Chapter V outlines the feminist methodological approach that is taken by this research. A qualitative research framework was designed for this project to explore women's roles as heads of households and their livelihoods in Appalachia and South Africa. Qualitative methodology seeks an interactive, more reciprocal relationship between researchers and subjects and interrogates issues around positionality and representation through a reflexive approach. Reflexivity is an essential part of feminist qualitative research because it seeks to challenge oppressive aspects of socially-constructed processes, combine the academic and political, and recognize the needs and wants of the research subjects. This chapter also highlights the specific research questions of the project and presents the methods utilized in data 
collection. It concludes with a discussion of the researcher's fieldwork in both Limpopo and West Virginia.

The sixth chapter presents the analysis of women's particular livelihood strategies in Limpopo and West Virginia. To describe the research areas and study samples it highlights regional statistics for both Limpopo and West Virginia and data gathered through socioeconomic surveys conducted with all of the respondents. It then describes the various and interconnected livelihood strategies of women heading households in the two study areas through data gathered in the socioeconomic surveys as well as individual interviews and focus groups. This chapter details the formal and informal work; public assistance benefits; family and community support; and co-habitation and 'doubling up' strategies that comprise the livelihoods of women heading households in the two regions. This analysis thus describes each livelihood strategy; how it is accessed and utilized by women in the study; how it fits with their household situation; and how it relates to other livelihood strategies. Through direct quotes and respondent profiles, every attempt is made to describe the livelihood experiences of women in this study in their own words.

The seventh chapter furthers the analysis of women's livelihoods in the two regions by first developing a typology of their strategies that facilitates the comparison of women's livelihood strategies between the two regions. It contributes to feminist topographical analysis as a conceptual framework by developing a topographical model. This model illustrates the various interconnected socioeconomic and political processes that affect women's livelihoods in Limpopo and West Virginia. It facilitates the drawing of the contour lines between the two regions and highlights the significance of countertopographies to feminist research on women's livelihood strategies. 
The concluding chapter highlights the theoretical and methodological contributions of this project to feminist and socialist geography. This chapter also outlines the contributions this project makes to literature on gender and livelihoods and the livelihood activities of women heading households in West Virginia and Limpopo. Further questions are raised and new horizons for feminist geographical research concerning rural women and female-headed households, livelihood strategies, and comparative work are discussed. 


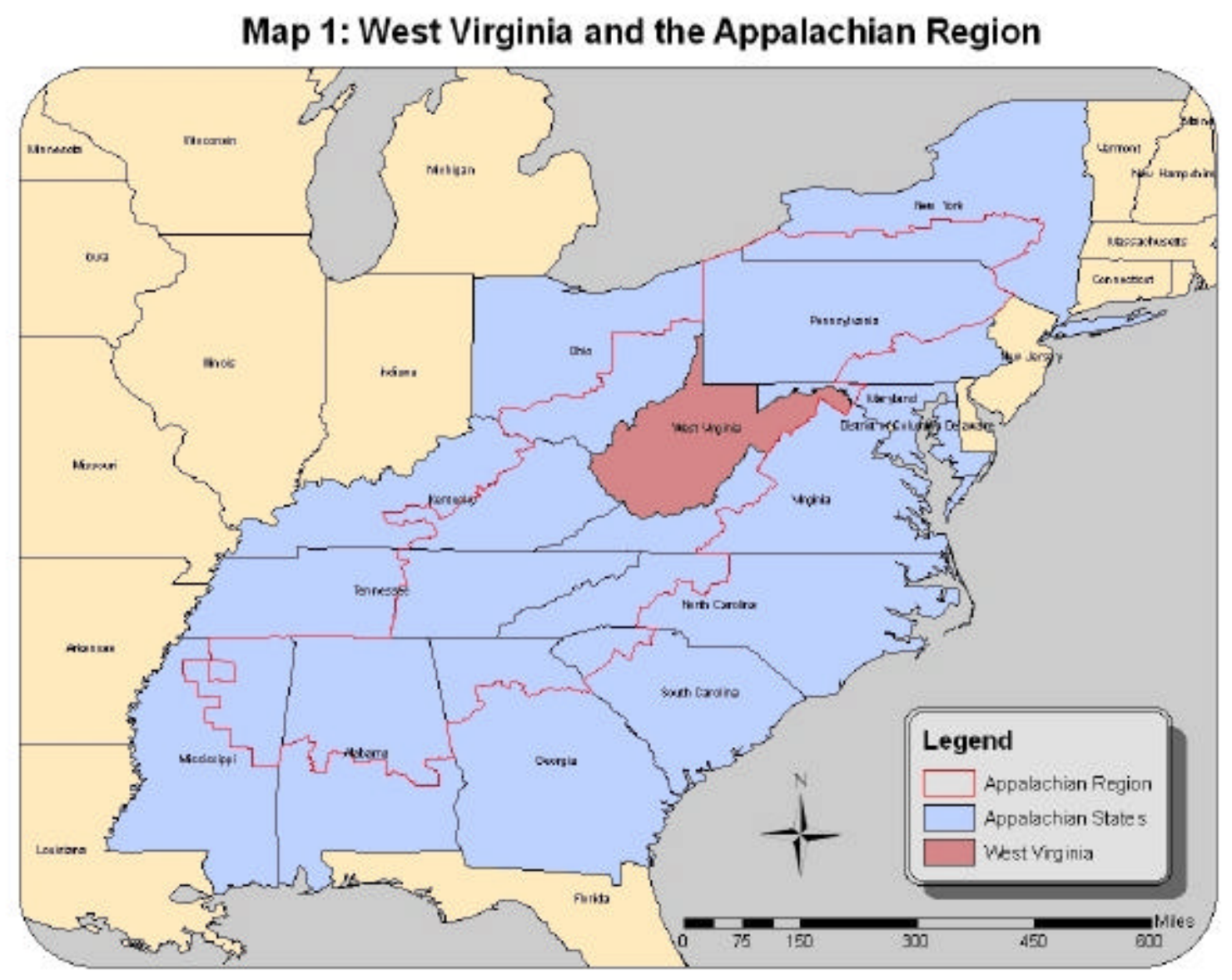




\section{Map 2: Limpopo, South Africa}

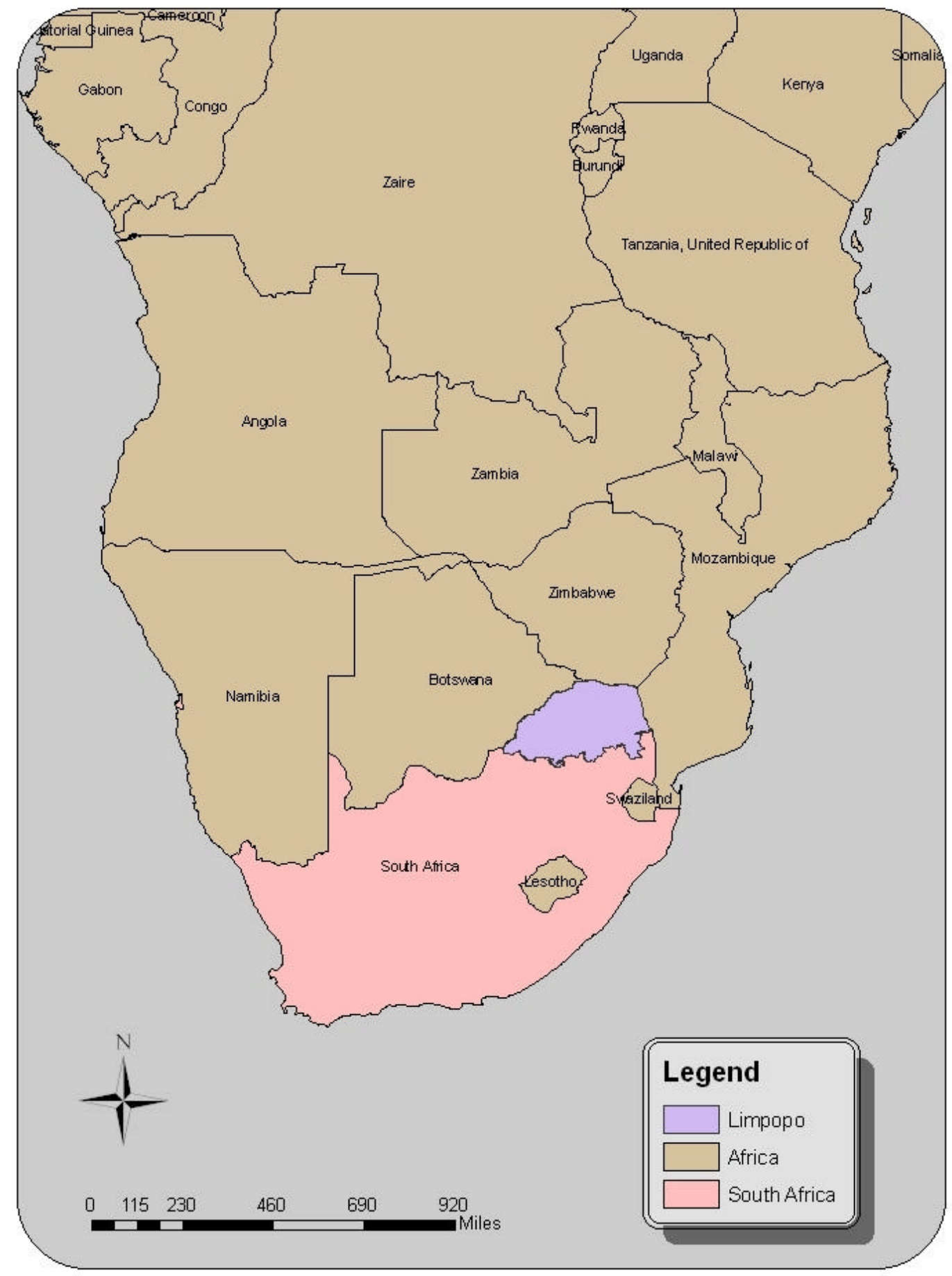




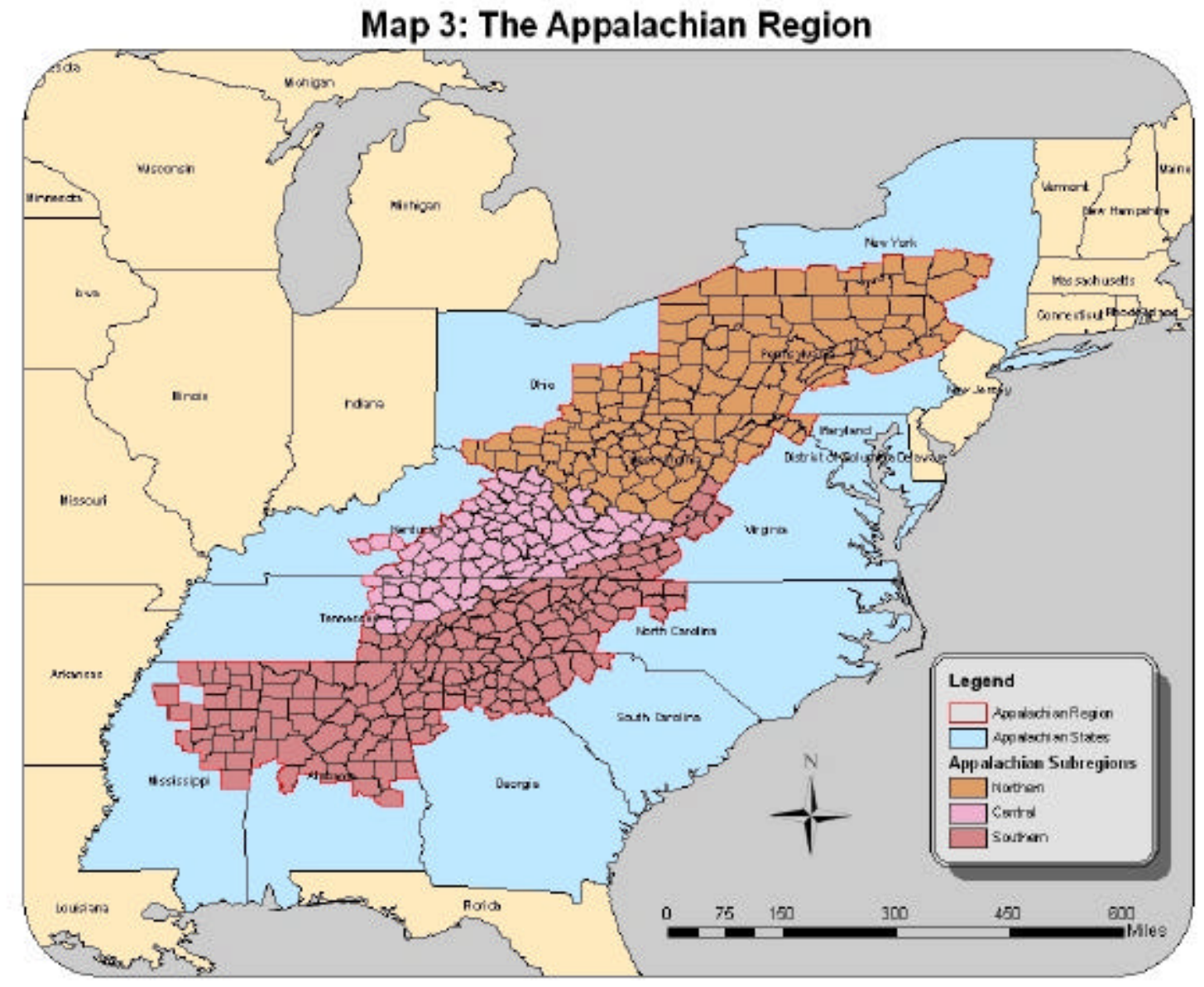




\section{Socialist Feminism and Topographical Analysis-Social and Spatial Frameworks for Feminist Research}

\section{Introduction}

The conceptual framework developed in this chapter draws on feminist scholarship that investigates issues of materiality and culture through a social-structural analysis and interrogates geographical concepts like space, place, and scale. First, the analysis highlights contemporary feminist theories, from Marxist approaches to postmodernism, with a focus on socialist feminist

perspectives. Second, the discussion addresses the theoretical strengths of socialist feminism and a materialist approach for analyzing the economic and social realities of female-headed households and their livelihood strategies. The third section explains how feminist topographies, as developed within feminist geography, are utilized to conceptualize the multiple socioeconomic processes at various scales of analysis that impact the livelihoods of femaleheaded households in Appalachia and South Africa. Topographical analysis also forwards a means for conducting comparative work within feminist research and activism more broadly. The fourth section explains the concept of livelihoods as utilized in this research project and highlights how feminists employ a livelihoods approach to better understand women, their social and economic roles and responsibilities, and how they 'make do' in the world today. Concluding remarks point to the importance of this study and its theoretical contributions for feminist research and activism.

\section{Contemporary Feminist Theories}

During the 1970s, feminist social theory was concerned with understanding inequality and power between men and women, arguing that male dominance derives from the social, economic, and political arrangements specific to particular societies. This mode of theorizing 
obtained its concepts and methods from the social sciences and focused on the material conditions of women's lives and the ideological processes which legitimize and perpetuate women's subordination. More recently, literary and cultural theory has become central to feminist thought. Michele Barrett (1992) has characterized this shift as a 'cultural turn' in feminist theory, a change of emphasis from 'things to words.' Initially, feminist theory was preoccupied by 'things' such as housework, inequalities in the labor market, or male violence, but it is more recently more concerned with 'words' and issues of subjectivity and representation (Jackson, 2001 and 1998).

However, while perspectives from the social sciences are less influential than they once were, they have maintained a significant presence within feminist theory. This dissertation argues that social science perspectives have much to offer feminism in the $21^{\text {st }}$ century concerning the need to analyze the economic and social realities of women in a globalizing world. As Nancy Holmstrom illustrates, ...women continue to bear a greater burden of labor throughout the world as social services are cut due to structural adjustment schemes in the Third World or so-called welfare reform in the United States. Women have been forced to migrate, are subject to trafficking, and are the proletarians of newly-industrializing countries. They continue to be subject to sexual violence and in much of the world, lack control of their own processes of reproduction... (2002: 2)

Feminist theory that is lost in theoretical abstractions or that minimizes economic realities will fail to understand these phenomena and most importantly, change them. This work therefore encourages feminists to (re)visit socialist feminist perspectives which analyze history and socioeconomic processes while seeking social change. By briefly tracing the development of feminist social theory, this section highlights the key points of contention between different feminist perspectives and why a (re)turn to a socialist feminist framework is appropriate for analyzing women's economic realities in a globalizing world. 
Feminist Social Theory—Marxist, Radical, and Socialist Feminisms

Throughout the 1970s and 1980s, feminists utilized Marxism as a conceptual framework for analyzing women's subordination. Marxism offered an analysis of oppression as systematic and social in origin, as well as a theory of social change (Holmstrom, 2002; Jackson, 1998). However, because Marxism was developed to explain capitalist class relations, it required considerable modification to accommodate analyses of gender relations.

Feminist reworkings of Marxism gave rise to intense theoretical discussions concerning capitalism and patriarchy (Stacey, 1993). The differing positions taken on this issue were related to political differences among fe minists, particularly concerning the relationship between women's liberation and class struggle. There was a continuum among those feminists who saw women's subordination as a consequence of capitalism; those who saw it as a consequence of patriarchy; and those who advocated a dialectical approach. Theorists from all of these perspectives drew on Marxism, but in rather different ways.

Patriarchy, in particular, was a highly contentious subject. While some Marxist feminists recognized male domination as a systematic feature of modern society, they insisted that women's oppression was rooted in capitalist social relations and were reluctant to conceptualize patriarchy as a separate social system co-existing with capitalism (Petty et. al. 1987). Some feminists maintained that the concept of patriarchy was ahistorical and not applicable to current times (Barrett, 1980; Rubin, 1975), while others cautioned that positing the existence of patriarchy as a system which long predated capitalism might lead feminists to a meaningless search for its origins (Rowbothom, 1981). Some feminists resisted its use as a transhistorical concept (Delphy, 1984) while others, in contrast, sought to historicize it (Walby, 1986). 
With no clear consensus among feminists on how to define or theorize patriarchy, disagreements about where the causes of women's subordination should be located ensued (Walby, 1986; Barrett, 1980). Many Marxist feminists argued for economic analyses that focused on productive relations. By analyzing productive and reproductive labor within the capitalist economy, these feminists examined issues such as women's positions in the labor market (Walby, 1986; Hartmann, 1981 and 1976; Beechey, 1979); the domestic mode of production (Delphy 1984, 1977, and 1976; Holmstrom, 1981; Kaluzynska, 1980; Molyneux, 1979; Dalla Costa and James, 1972; Benston, 1969); and job segregation and wage differentials (Amott and Matthaei, 1984). In contrast, radical feminists located women's subordination in social relations of reproduction and explored issues of motherhood (Barrett and McIntosh, 1979) and women's reproductive functions (Firestone, 1972); the historical development of social relations of reproduction (O'Brien, 1981); and sexuality, including critiques of heterosexuality and analyses of both sexual and labor relations (Wittig, 1992; Jefferys 1990; MacKinnon, 1982). Others, including socialist feminists, sought to replace dichotomous thinking between the social relations of production or reproduction with a dialectical approach that saw two theories of power, namely capitalism and patriarchy, as interrelated through the sexual division of labor ${ }^{2}$ (Eisenstein, 1979; Hartsock, 1979; Rubin, 1975; Mitchell, 1974). Understanding ideology, meaning the body of ideas that reflect the social needs and aspirations of an individual, group, class, or culture, within social systems was a subject of analysis within all of these feminist perspectives. Fundamentally, feminists working with Marxism to understand women's subordination analyzed productive relations, reproduction, and ideology.

\footnotetext{
${ }^{2}$ For socialist feminists, the sexual division of labor defines people's activity, purposes, and goals according to their biological sex and is at the base of patriarchy and capitalism. It divides men and women into their respective sex roles and structures their related duties within the family and economy.
} 
While Marx and Engels did explore women, domestic labor, and the family, they were defined only in relation to the capitalist mode of production and analyzed within a framework of class relations (Putnam Tong, 1998). ${ }^{3}$ Women were analyzed as a 'reserve army of labor' and as reproducers of the labor force. Discussed as part of the superstructure of capitalism, family was seen as an instrument of production based on capital gain and consequently, reflective of class society. ${ }^{4}$ Here, reproduction was not a unique object of analysis and although Marx and Engels refer to men as the bourgeois and women the proletariat, power relations between men and women were not addressed. Specifically, the sexual division of labor as the sexual definition of roles, purposes, and activities had no unique existence for Marx and Engels (Eisenstein, 1979) and they had little sense of women's biological reproduction or maternal functions as critical in creating a division of labor both within and outside the family.

Given this framework concerning work and relations of production, women's roles as producers and reproducers were neglected by Marxists. In addition, this framework was unable to explain the hierarchical sexual ordering of society and the fact that power emanates from both the relations of production and reproduction. Consequently, feminist theorists became dissatisfied with the gender-blind character of Marxist thought and questioned the power of other socioeconomic systems, including patriarchy (Jagger, 1986 and 1983; Young, 1980; Eisenstein, 1979; Rubin, 1975; Mitchell, 1974). The "categories of Marxists analysis,” such as capital, class, and worker, "are sex-blind," commented Heidi Hartmann and "give no clues about why particular people fill particular places. They give no clues about why women are subordinate to men inside and outside the family and why it is not the other way around" (1981: 1-41).

\footnotetext{
${ }^{3}$ For a comprehensive review of Marxism and Feminism see Holmstrom, 2002; Jackson and Jones, 1998; and Putnam Tong, 1998.

${ }^{4}$ For detailed explorations of Marx and Engels on women and family see Capital (1967), The Economic and Philosophical Manuscripts of 1844 (1964), The German Ideology (1947), and The Origin of the Family, Private Property, and the State (1942).
} 
In contrast to Marxist feminist analyses of production, radical feminism placed sex as its central analytic category. Early radical feminist approaches focused on the relations of reproduction within patriarchy, which was understood as key to the oppression of women. Here, patriarchy was viewed as a sexual system of power where males possess superior power and economic privilege. Radical feminists maintained that this male hierarchical ordering of society was rooted in biology through women's roles in reproduction and preserved via marriage and the family, the sexual division of labor, and ideologies of heterosexuality, marriage, and the family (Wittig, 1992; Jefferys, 1990; MacKinnon, 1982; Firestone, 1972). Moreover, the sexual division of labor expresses the most basic hierarchical division in our society between masculine and feminine roles and thus designates that social functions and individual power are determined sexually, rather than economically. Therefore, it is the biological family, the hierarchical sexual division of labor, and sex roles themselves that must be reorganized. Within early radical feminist analyses, women were seen as a "sex class" and patriarchy was analyzed as a generalized, ahistorical power structure (Firestone, 1972). While displacing class relations from their privileged place within Marxism and attempting an analysis of patriarchy, this perspective was criticized for reducing women's subordination to women's reproductive capacities and assuming a "natural" sexual division of labor.

Eventually, and largely through the work of those such as Kate Millet (1977) and Nancy Chodorow (1980), radical feminists moved beyond such biologically deterministic notions of sex to examine the social construction of gender and gender relations. Influenced by sociological and social psychological work, it was recognized that biological sex and social gender were separable concepts. Specifically, gender was the culturally, economically, and socially shaped cluster of expectations, attributes, and behaviors assigned to men and women by the society. The 
subordination of women was therefore enforced through the continued reproduction of gender ideologies that reinforced a separation between male and female roles. Understanding the social construction of gender, the functioning of gender roles, and the ideologies within capitalism and patriarchy which sustain them was to have a profound effect on socialist feminists and their attempts to analyze the connections between materiality and ideology within capitalist patriarchy.

Socialist feminism critiqued both Marxist and radical feminism's analyses of either capitalism or patriarchy as incapable of understanding the full reality and historical specificity of women's socioeconomic existence, exploitation, and oppression (Jackson, 1998; Putnam Tong, 1998). In order to understand the complexity of power in society, socialist feminists examined power and inequality in terms of their class origins and patriarchal roots. Here, capitalism and patriarchy were seen as neither autonomous not identical, but mutually dependent (Young, 1980; Eisenstein, 1979; Mitchell 1974 and 1971). According to socialist feminists, an analysis of capitalist patriarchy can break through the dichotomies of class and sex, public and private, domestic and wage labor, family and economy, ideology and material conditions, and the personal and political (Eisenstein, 1979).

In order to analyze women's positions and conditions within economic and patriarchal structures, socialist feminists sought to break down the division between material existence ${ }^{5}$ and ideology. According to socialist feminists, the sexual division of labor has both a material form and ideological reality that exist in an internal web. Here, attention was being drawn to the complex dimensions of women's oppression and exploitation and the interconnections of patriarchy and capitalism. Socialist feminists worked to analyze gender relations and how they

\footnotetext{
${ }^{5}$ For socialist feminists, a materialist approach must examine both women's economic existence, in relation to production, and sexual existence, in relation to reproduction, and how they affect particular formulations of women's oppression across time and place.
} 
are operationalized and sustained within capitalist patriarchy through gender roles and ideologies and how they are produced and reproduced through not only economics, but also culture, politics, and place. Hence, capitalist patriarchies are preserved through various institutions and relations of power (Rubin, 1975). The search for grand theory and macro-level explanations of women's oppression was being eroded and new forms of theorizing difference among women emerged.

\section{Feminism and Postmodernism}

The influence of postmodernism on feminist theory addressed the perceived failure of Marxism to deal with issues that were increasingly important to feminist analyses, such as subjectivity, sexuality, and difference among women. Historically, feminist debates had been almost entirely from a white, Western point of view and, consequently, women of color and from the 'Third World' began to denounce those perspectives that excluded their economic and social histories and realities (Brah, 1992; Spivak, 1987; hooks, 1984; Anthias and Yuval-Davis, 1983). Critiques around difference grew throughout the 1980s and it became clear that 'woman' was not, and could not be, a unitary category and any theory attempting to provide a single explanation of women's subordination was destined to exclude the experiences of the majority of the world's female population (Brah, 1992; hooks, 1984; Anthias and Yuval-Davis, 1983; Flax, 1990). Moreover, attention was increasingly being drawn to the complexities of women's lives in a post-colonial era concerning the global economy, colonial legacies, and political transformations. These concerns and critiques encouraged postmodern theorizing within feminist scholarship. Postmodernism was seen as a means for avoiding the exclusions of an 
assumed universal womanhood and the simplifications of economically or biologically deterministic causal modes of oppression within Marxist feminist approaches.

Developing throughout the 1980s and 1990s, postmodern feminisms examine the interrelationship between identity, knowledge, and power and have been influenced by a number of perspectives including: Marxism (particularly Althusser's theory of ideology); psychoanalysis (the work of Freud and Lacan); theories of difference and deconstruction (largely from Derrida); and theories of discourse and power (such as the work of Foucault) (McDowell, 1991; DiStefano, 1990; Flax, 1990; Weedon, 1987). Building on these various theories and approaches, feminist postmodernisms involve interrogations of language, discourse, difference, and deconstruction.

Postmodernists argue that language, as a system through which meaning is constructed and cultural practices are organized is the way people represent and interpret their world (Barrett, 1992; McDowell, 1991; Scott, 1988). Postmodern theorists therefore examine questions concerning how meaning is acquired and changed and its connections to power relations (Scott, 1988; Weedon, 1987). Questions such as these focus attention on specific contexts, culture, and social processes and imply that words or texts ${ }^{6}$ have no essential meaning. Thus, feminist postmodernists believe that analyses of language can facilitate an understanding of how social relations of gender, for example, are established and consequently, how they work in constituting feminine identities.

Discourse analysis draws primarily on the work of Michel Foucault and its critique of universality and rationality in Enlightenment theories to understand the relationship between language, social institutions, subjectivity, and power (Weedon, 1987; Hartsock, 1996 and 1990;

\footnotetext{
${ }^{6}$ Texts may include literature, historical documents, film, magazines, and pictures as well as other mediums such as art and cultural practices.
} 
Foucault, 1980). Interrogations of discourse highlight the power within dominant discourses to control meaning and define knowledge within writing and language, as well as institutions and organizations (Scott, 1988; Weedon, 1987). According to Foucault (1980), discourses are historically, socially, and institutionally-specific structures of statements, terms, categories, and beliefs. They are organized through institutions and social practices and consequently, offer individuals multiple modes of subjectivity.

Feminist discourse analysis such as the work by Spivak (1988) and Mohanty (1997b) concerning colonial and postcolonial theories has demonstrated both the masculine and Western biases in many of our understandings of women in third world places. Representations of "third world woman" as "poor, uneducated, tradition-bound, family-oriented, and victimized" is imbued with Western standards (Mohanty, 1997b: 258). It erases difference among women and perpetuates the hegemonic superiority of Western knowledge and feminine identity. Fundamentally, postmodern analyses seek to displace dominant discourses and transform our collective and individual understandings of the world.

With respect to difference, feminist postmodern work has called attention to the fact that unitary concepts, such as 'woman', are composed of oppositional categories, such as masculine/feminine, white/non-white, First World/Third World (Scott, 1988). Each concept is established in explicit opposition to another term in which the interdependence between the opposition is not one of equality, but rather a hierarchical relationship of dominance (Bondi, 1992 and 1990; McDowell, 1991). Oppositions therefore rest on metaphors and crossreferences. In patriarchal discourse, for example, differences between the 'masculine' and 'feminine' serve to encode or establish meanings that are unrelated to sex or the body (Poovey, 1988). Consequently, meanings of gender become tied to various cultural representations and 
practices, such as the veiling of women in some Islamic societies, female circumcision in parts of Africa, and foot binding in parts of China. These representations, in turn, establish the terms by which relations between men and women are organized and understood (Scott, 1988). By analyzing difference through the process of deconstruction, feminist postmodernists challenge oppositional and hierarchical categories in order to recognize the multiplicities within the category 'woman' and move away from analyses of only gender. These theorists feel that it is impossible to discuss gender without considering how it is constituted through other social categories, such as race, class, ethnicity, and sexuality, and emphasize the historical, cultural, and contextual specificities of feminine identities and the category 'woman'. Thus, postmodernism claims that it is impossible to identify and separate out different and distinct components of an individual's identity (Nicholson, 1990).

Drawing on the work of Jacques Derrida, deconstruction involves the dismantling of dualisms and oppositional categories and uncovering the nature of power relations in the operation of difference (McDowell, 1991; Bordo, 1990; Flax, 1990; Scott, 1988). Importantly, deconstruction illustrates that oppositions are not natural, but socially, economically, and politically constructed categories that exist for particular purposes in particular contexts (Bordo, 1990). Through analyses of difference and the method of deconstruction in feminist postmodernism, the subject 'woman' is therefore replaced by a new notion of 'decentered, partial, and fractured identities" and a "constantly shifting ground of emerging and dissolving differences" (DiStefano, 1990: 65). Feminist postmodernists reveal the mutual constitution of social categories, such as race, class, sexuality, and gender, and how identity production and the operation of difference are related to culture and specific contexts. 
In sum, feminist postmodernism shifted the focus from materiality and social relations to culture as depicted in language, meaning, discourse, and representation (Liddle and Wright, 2001). Feminist postmodernists critique Western, Enlightenment discourses that seek absolute truths and universality and foster essentialized notions of social, political, and economic phenomena, people, and places. They recognize and analyze difference and the construction of identities; question the salience of gender as the central analytical category within feminist studies; and see the subject as context-dependent, relational, complex, and variable. They seek to find the partial nature of knowledge and move away from dualistic notions and processes of 'othering' in conventional social analyses.

\section{Back from the 'Cultural Turn'? Critiques of Feminist Postmodernism}

Postmodernism reveals the diversity and complexity of women's lives around the world and encourages new investigations of identity, representation, difference, and discourse. The 'cultural turn' within feminist scholarship and political practice is, however, not without criticism. Fundamentally, critics claim that postmodern theory provides little direction for understanding and transforming the power relations that permeate socioeconomic structures and institutions and consequently affect the everyday material experiences and realities of women (Katz, 2001a and b; Jackson, 1998; McDowell, 1997; Jackson and Jacobs, 1996; Smith, 1994). Critics argue that postmodernism's preoccupation with deconstructing dualisms obscures the hierarchical nature of power between oppositional categories and ignores the fact that all axes of difference have a material basis or grounding that is connected to various ways of knowing, experiencing, and strategizing the world (Jackson, 2001). Postmodernism's focus on the fluidity of the subject and shifting subject positions also ignores women's agency and eliminates the 
possibility of constructing common knowledge among women. Women are not only constructed by, but respond to, unequal and oppressive relations that can lead to political mobilization, organization, and activism (Liddle and Wright et al., 2001). Women are both subjects and objects of history and their perspectives must not been seen as 'subjugated' or disruptive but as primary and constitutive of a different world (Hartsock, 1990).

Finally, other critics of postmodernism argue that it marginalizes through its inaccessible language, location within academia and intellectual communities, and lack of attention and cynicism toward social, political, and economic change (Appiah, 1996; Dirlik, 1994). This work specifically argues that this academization of feminism has located feminist theorizing and political practice within the walls of academic departments rather than the homes, communities, and workplaces where women live and work everyday. This has resulted in the displacement of gender as the central analytic category for feminist research and practice.

In response to these criticisms, many feminists have consequently called for reconstructed theories that direct attention to social structure and women's agency and focus on socioeconomic relations and hierarchies of power, the identities and meanings women give to their lives, and their social and economic strategies for change (Holmstrom, et al. 2002; Liddle and Wright, et al. 2001; Jackson and Jones, 1998; Hartsock, 1996). Navigating the strengths and weaknesses of the various feminist perspectives highlighted above has therefore raised important conceptual questions for this research: How do we analyze women's material realities and economic identities and their connections to the workings of capitalism, colonialism, racism, and patriarchy? How do we theorize difference while holding on to some notion of both gender as a central analytic category in feminist research and focus of political organization? How can a feminist academic project rethink the relationship between 'the local' and 'the marginalized' and 
the larger structures in which they are housed? And finally, how do we understand the diverse particularities of women's economic realities and find innovative conceptual and methodological ways of connecting them across space, place, and scale?

This research draws from feminist theory more broadly, concerning socialist feminist perspectives and a materialist approach, and feminist geography specifically, concerning feminist topographical analysis, to build a theoretical framework that can understand women's social and economic realities in a globalizing world. As presented below, this framework has the analytical power to analyze women's socioeconomic positions and conditions, their material realities and strategies, and the various social, economic, and political processes that affect them in and across diverse places. It prioritizes gender as its primary category for analysis without ignoring issues of race and class and forwards a comparative approach for feminist theorizing and political practice.

\section{Reviving Socialist Feminism and a Materialist Approach}

This project focuses on the livelihood strategies of women who head households in Appalachia and South Africa. Conceptually, therefore, the theoretical framework must be able to illustrate material manifestations of power such as women's disadvantaged positions in labor markets, unpaid domestic labor, unequal access to educational and training opportunities and productive resources, and lack of reproductive freedom, for example. The theoretical framework must also be capable of understanding women's identities as heads of households and how these identities are shaped by socioeconomic and cultural relations and gender, race, and class ideologies that are embedded in capitalist, colonial, and patriarchal structures. It must also account for women's agency and place prominence on how and why women develop certain 
livelihood strategies to fit their particular needs and socioeconomic situations. A materialist approach that is rooted in a socialist feminist perspective provides this work with an essential part of the analytical and practical power needed to understand these diverse cultural and material issues and how they affect the livelihoods of women who head households in West Virginia and Limpopo. This section of the conceptual chapter begins by briefly defining socialist feminism within feminist theory today. The discussion then turns to current work by highlighting a materialist discursive feminism and its emphasis on materiality and culture through a social-structural analysis. It emphasizes the importance of a socialist feminist framework for this research project and feminist theory more broadly.

\section{Defining Socialist Feminism}

While some would say socialist feminism is an artifact of the 1970 s, it is an on-going project that is alive and well today. It has been called Marxist and termed socialist feminism, womanism, materialist feminism, and feminist materialism. It is, fundamentally, according to Barbara Ehrenreich, "really socialist, internationalist, antiracist, antiheterosexist feminism" (1975). In a recent volume dedicated to socialist feminism, Nancy Holmstrom characterizes a socialist feminist as:

....anyone trying to understand women's subordination in a coherent and systematic way that integrates class and sex, as well as other aspects of identity such as race/ethnicity or sexual orientation, with the aim of using this analysis to help liberate women (2002: 1).

Fundamentally, this characterization puts forth the major elements of concern for a socialist feminist project including: women's subordination, read exploitation and oppression within capitalist, colonial, and patriarchal systems; coherent and systematic, read conceptually and methodologically sound and able to construct knowledge that is by, about, and for women; 
integration of class and sex as well as race and sexual orientation, read attention to difference and what constitutes feminine identities; and women's liberation, read attention to women's agency and working for socioeconomic and political justice and empowerment for women all over the world.

As stated in the previous section, early work within socialist feminism critiqued both Marxist and radical feminism's analyses of either capitalism or patriarchy. In order to understand the complexity of power in society, socialist feminists initially examined power and inequality in terms of its class origins and patriarchal roots in a mutually-dependent system called the capitalist patriarchy (Eisenstein, 1979). Within this framework, patriarchy provided order through the sexual hierarchical division of society and capitalism consequently fed off this patriarchal ordering. ${ }^{7}$ Therefore, concern for profit and societal control are inextricably linked and capitalism and patriarchy become an integral process that forms the political economy of the society. Here, Marx's political economy analysis was extended by feminists to include both productive and reproductive relations within capitalist patriarchy. According to socialist feminists, capitalist patriarchy is preserved through institutions and specific conceptualizations of the family and home, men and women's roles, productive and reproductive labor, and gender and class and they, accordingly, seek to challenge, destabilize, and redefine these conventional categories.

Through this framework and a historical materialist approach, feminists consequently understood that the destruction of capitalism would not necessarily mean a total transformation

\footnotetext{
${ }^{7}$ Within capitalist patriarchy, according to socialist feminists, the sexual division serves a specific purpose. It stabilizes the society through the family while it organizes 'work'-domestic labor, for which there is no pay (housewives) or limited pay (for houseworkers), and productive labor, for which there is unequal pay in the labor force. And, according to Eisenstein (1979), the second category shows the ultimate effect on women of the sexual division of labor within the class structure. Their position as a paid worker is defined in terms of being a woman, which is a direct reflection of the hierarchical sexual divisions in a society organized around the profit motive. This shows how relations and roles of production and reproduction work together in both spheres and further reinforce the social, political, and economic order.
} 
of patriarchal relations and called attention to the need to understand patriarchy cross-culturally and how it is produced and reproduced through not only economics, but also culture, politics, and place. Here, patriarchy is seen as actualized and maintained in differing ways for differing reasons through varying institutions and relations of power (Rubin, 1975). Attention was therefore drawn to the multiple and varying dimensions of women's oppression and exploitation. Socialist feminists sought to not only analyze women's roles, but also socioeconomic relations and how they are operationalized and sustained within the capitalist patriarchy through gender ideologies, social practice, and political organization ${ }^{8}$.

Specifically, in terms of theorizing and organizing, socialist feminists sought to develop conceptual tools that deal with the question of differential power among women. They did (and still do) not equate exploitation and oppression. Exploitation is analyzed as the economic reality of capitalist class relations for men and women in the labor force and oppression refers to women and minorities that are defined within the patriarchal, racist, and capitalistic relations that create hierarchies in society. Oppression thus reflects a more complex reality that is connected to socioeconomic and political systems, as well as culture and place, and their material and ideological dimensions. Importantly, exploring and understanding exploitation and oppression in this way has led to deeper understandings of difference among women and consequently, feminine identities, and how they are shaped by not only gender and class, but also race, sexuality, and place, for example. Fundamentally, socialist feminists recognize the differing

\footnotetext{
${ }^{8}$ It is interesting to note that the turn to postmodernism and poststructuralism within feminist theory is rooted in early Marxist feminist work on ideology and psychoanalysis. Drawing heavily on the work of French structuralists, including Althusser's Marxism, Lancan's psychoanalysis and Levi-Strauss's anthropological work on kin ship, some feminists began to analyze women's subordination as autonomous from economic relations and as primarily ideological. This created space to theorize women's subordination without having to relate it to the capitalist mode of production. Some analyzed ideology and how it was reproduced in our psyches between generations while others understood it as effective through the capacity of language to shape our thoughts and desires. Once the ideas of Michel Foucault were introduced to the mix, the emphasis shifted from linguistic and semiotic structures to a more fluid notion of discourse. Power was reconceptualized as diffuse and dispersed rather than concentrated into the hands of ruling classes and 'truth' was seen as determined by discourse.
} 
specificities of women's existence across time and space and call forth examinations of their everyday lives at particular, local scales, such as the ho me, community, and individual (Hartsock, 1979). Theoretically, they analyze the socioeconomic and political systems that govern women's lives, and the players, practices, and ideologies that define, protect, and maintain them.

\section{Contemporary Socialist Feminism}

Contemporary socialist feminists are breaking new ground with innovative ways to work within a socialist feminist framework and deal with the local and global complexities of women's lives in a contemporary world. They are extending materialist and political economy frameworks to provide a social-structural analysis that incorporates understandings of culturallyconstituted difference and inequality. Socialist feminism is an exciting and diverse field of feminist inquiry and one that this project argues is necessary to understand the realities of women's oppression and exploitation.

More recent work within socialist feminist scholarship has advocated a materialist discursive feminism to move beyond conventional Marxist conceptualizations and the search for grand theory and overcome critiques of economic determinism and essentialism (Liddle and Wright, et al. 2001; Jackson, 2001). This recent work within materialist feminism foregrounds the social, including social structures, relations, and practices, but does not reduce them to capitalism. Patriarchal or gendered structures are every bit as material as capitalist ones, as are those deriving from racism, colonialism, and imperialism. These, of course, intersect and interact at the micro, mezzo, and macro levels of society in often unpredictable and contradictory ways. Hence, adopting a materialist stance does not preclude awareness of difference among 
women because an understanding of those differences requires that we pay attention to material social inequalities and everyday social practices. Nor does materialism ignore issues of language, cultural representation, and subjectivity, but locates them in their social and historical contexts. A materialist discursive feminism thus integrates both the material and the cultural.

Within this framework, the concept of culture refers to language, meaning, discourse, representation, and practice and is used to analyze, for example, the presentation and performance of gendered identities, cultural production, processes of othering, and the exposition of alternative subjectivities as a stimulus for change. Materiality refers to social relations and practices, social structure, and institutions, and is used to analyze structural inequality and hierarchical power relations and their relationship to gendered identities and subjectivities (Liddle and Wright, 2001). The concept of materiality includes not only the economic, but also the physical and the sociopolitical (Cockburn, 1983) as well as the natural environment. Thus, this conceptualization moves beyond the reductive view of the material as simply "economic advantage' to recognize that political mobilization, organization, and activism are also part of the material basis of power.

Combining analyses of both the cultural and material allows this framework to emphasize the entire realm of the social that encompasses all aspects of social life, from structural inequalities to everyday interaction. The social realm is concerned with meaning, both at the level of our wider culture and as it informs our everyday social life. It includes subjectivity because our sense of who we are in relation to others constantly guides our actions and interactions and conversely, who we are is in part a consequence of our location within gendered, class, racial, and other divisions, and of the social and cultural milieux we inhabit ${ }^{9}$ (Jackson, 2001). Being able to explore the entire realm of the social is vital to this study in order to

\footnotetext{
${ }^{9}$ For a more detailed reading on the different facets of the social see Jackson, 2001.
} 
conceptualize all of the factors that affect women's abilities to engage in local economies and particular livelihood strategies and understand their roles and identities as heads of households.

Within a materialist feminist framework, it is possible to analyze the socioeconomic structures of capitalism, patriarchy, and colonialism that are embedded with gendered, racialized, and classed ideologies which define work, establish men's and women's roles in society and the economy, and legitimate power within socioeconomic and political institutions. The focus on these particular structures is deliberate because they work with local cultures in places such as Appalachia and South Africa to develop spatialized sets of social relations that construct place and identity and, consequently, affect women's access to particular economic strategies.

Capitalism, in particular, is a system of social relations of production and reproduction (Katz, 2001b). Production is a wage-labor relationship and social reproduction entails both the reproduction of the social relations that maintain capitalism as well as the reproduction of the material bases upon which social life is premised (Katz and Monk, 1993). Within contemporary capitalism, social reproduction of the material bases of society involves not only the large-scale physical infrastructure of capitalism, such as the delivery of services and the building of schools and roads, but the small-scale social, physical, cultural, and emotional infrastructure of the household where labor power is reproduced on a daily basis. This, of course, varies depending on the extent and scale that capitalism itself has penetrated a place and its economy.

An analysis of both production and reproduction and their associated processes must be accounted for when analyzing women's opportunities and constraints in local economies. This research is particularly concerned with capitalist processes in Appalachia such as economic restructuring and how global shifts in capital have transformed the rural economy and actually led to underdevelopment in certain parts of the region. In South Africa, it is concerned with 
economic development, for example, and how neoliberal policies are seeking to attract foreign investment by offering various economic incentives, few labor and environmental regulations, and of course, a cheap pool of labor that is largely Black and female. By analyzing these processes and the institutions that sustain and resist them, such as the state, economic development authorities, multinational corporations, and labor unions, too name a few, feminists can better understand how capitalism operates both locally and globally within our governments, communities, and even households.

Patriarchy is defined by many feminists as the unequal distribution of power and resources in society based on sex and gender (Kandiyoti, 2002). As indicated above, it has long been a focus of feminist work despite the fact that patriarchal analyses have been criticized for implying that women's oppression is universal and for being unable to handle historical change. This project argues that patriarchy is historically and geographically variable, but part of a contemporary world system that leads to unequal power relations between the genders and organizes societies hierarchically. ${ }^{10}$

By identifying six sites of patriarchal relations, including paid employment, household production, the state, male violence, sexuality, and cultural institutions, Sylvia Walby's (1990) work, in particular, provides a framework for analyzing how patriarchy is differentiated across time and place. The six sites of patriarchy are interrelated and therefore create different forms of patriarchy with particular social relations and spatialities. This framework reveals the various socioeconomic institutions involved in the maintenance of patriarchy such as the economy and labor relations when interrogating the realm of paid employment and the institution of marriage and other kinship relations when examining household production. Government and welfare and

\footnotetext{
${ }^{10}$ Patriarchy literally means a hierarchy — a rule of priests —in which the priest is a father. It describes an order of society that elevates men, particularly fathers, and then transfers power and authority through the paternal line (Gilligan, 2002). It is the hierarchies that patriarchy creates that have been forgotten in many feminist analyses.
} 
social programming can be examined when looking at the state and issues around domestic violence, rape, and wife-burning, to name a few, can be revealed when focusing on the site of male violence. Feminists can expose the tensions within institutionalized heterosexuality when investigating sexuality, religion, and ethnicity when exploring cultural institutions.

By dissecting the multiple sites highlighted above, feminists can reveal how patriarchy takes on both very public and private forms. This framework also facilitates an understanding of how patriarchy works with capitalism to create disarticulations such as gender segregation in the labor market, wage differentials, and the undervaluing of women's work in the home. This project is particularly concerned with the sites of paid employment and household production concerning women's access to different types of work and their productive and reproductive roles and duties; the state, with respect to social programming and family policy; and cultural institutions concerning the role of religion, ethnicity, and communal and kinship systems, for example, in establishing gender relations and ideologies about women, work, and the household. Colonialism is defined as the establishment and maintenance of rule, for an extended period of time, by a sovereign power over a subordinate and 'alien' people that is separate from the ruling power (Johnston, Gregory, and Smith, 1994). Characteristic features of the colonial situation include political and legal domination over an alien society, relations of economic and political dependence and exploitation between imperial power and colony, and racial and cultural inequality (Fanon, 1966). Colonial legacies of underdevelopment, corruption and patronage, disruptions in cultural and familial institutions and land tenure and livelihood systems, ethnic tensions, land conflicts, and gender, racial, religious, and ethnic discrimination have wreaked havoc on indigenous populations, especially women and the environment. 
Colonialism's form has changed, historically and geographically, and in current times it is often referred to as neo-colonialism or imperialism. Colonialism works with capitalism and patriarchy to establish rule and organize societies for the accumulation of capital, land, resources, and power. The ambitions of colonialism and capitalism are, and have always been global, and are revealed in the economic and social rhetoric and objectives of organizations such as the International Monetary Fund (IMF), World Bank, and World Trade Organization (WTO), for example, which dictate and police global economic and social development policies.

This work is particularly concerned with the effects of apartheid in South Africa and how colonial legacies of gender and racial discrimination and policies of separate development affect women's abilities to acquire a sustainable livelihood today. Appalachia is often termed an internal colony for resource extraction and cheap labor and this work is concerned with the capitalist and colonial processes summed up by Bob Tanner, a VISTA volunteer, in 1968 and their effects on the local economy today.

In West Virginia....as throughout Appalachia, we live in a system of absentee control by large financial and industrial corporations pursuing their economic ends without respect for the lives of the people in the state or region. The responsibility for the damagepolitical, economic, and social - can be attributed to these colonial exploiters...West Virginia is a rich state. Yet it is obvious that West Virginia is a poor state. Much wealth has been extracted from West Virginia's natural resources, but little of that wealth has remained in the hands of West Virginians. ${ }^{11}$

Fundamentally, the social relations manifested by capitalist, patriarchal, and colonial structures convert 'difference' into inequality and oppression resulting in institutionalized sexism and racism, gender discrimination and divisions of labor, and sexual and racial violence, for example. These manifestations have real, material effects for women such as wage differentials and job discrimination, poor working conditions, low pay, and few benefits, the feminization of

\footnotetext{
${ }^{11}$ Quoted in Helen Lewis, "Fatalism or the Coal Industry?" originally published in Mountain Life and Work (December 1970) and reprinted in Ergood and Kuhre, Appalachia, 155.
} 
poverty and welfare reform, the buying and selling of women within the sex tourism business, domestic violence and wife-burning. As feminists working for a more equitable distribution of the world's resources and power, we need to be able to interrogate these structures through a social-structural analysis. We must work to reveal the 'players' and policies involved, at various scales of analysis, including community leaders, politicians, and the state; national and international development and trade associations; and corporations, too name a few, and interrogate the rules, regulations, and laws that assist in the control and power of these various institutions.

Capitalist, colonial and patriarchal structures are potent social forces that work together to form a world system of inequality, exploitation, and oppression for the women of the world. In order to analyze this world system, this project takes both a local and global approach that addresses issues of materiality and culture and conceptualizes all of the factors that establish women's positions and conditions, affect their identities, and determine their abilities to acquire sustainable livelihoods for themselves and their families. This conceptual approach, which combines a materialist discursive feminism and feminist topographical analysis, does this by attending to how the social relations of global structures inflect upon local places and different women in both diverse and similar ways. The framework developed here does not advocate the building of 'grand theory' about women and the economy on a global scale. Rather it seeks what some sociologists have called "middle-range" or "middle order" theories that bridge the divide between the abstraction of grand theory, which is often remote from daily social life, and untheorized empiricism (Maynard, 1995). This type of theorizing focuses on the specifics of given social contexts, institutions, and relationships, offering grounded generalizations rather than universalistic, totalizing models of entire societie s (Jackson, 2001). It advocates making use 
of conceptual tools that are useful for a particular purpose rather than being guided by a rigid and inflexible set of concepts within one theoretical framework. Hence, we can analyze women's everyday existence and the meanings women give to their lives without losing sight of structural patterns of dominance and subordination. In addition, we can illustrate women's agency and recognize women as subjects that are not only constructed by, but also responding to, unequal and oppressive relations that can lead to political and socioeconomic mobilization, organization, and activism (Liddle and Wright et al., 2001).

\section{Feminist Topographical Analysis-A Geographical Framework for Social and Spatial Analysis and Comparative Feminist Research}

A feminist geographical approach, as outlined below, adds to the analytical and practical power of a materialist feminist perspective to examine the livelihoods of women who head households in Appalachia and South Africa. Women's identities as workers and heads of households and their livelihood strategies are affected by the socioeconomic histories of the different locales, contemporary economic and political restructuring, and household and community relations that are embedded in capitalist, patriarchal, and colonial processes. These processes are manifested in varying ways, across scale and place, affecting women's livelihoods in these diverse places differently, as well as similarly. To understand these complex connections, this section develops feminist topographical analysis to understand how socioeconomic relations and processes create spatialities and construct place. In addition, this approach realizes that while the material ground of women's abilities to acquire sustainable livelihoods is manifested locally, the multiple processes that affect this quest are translocal and working at local, regional, and global scales. This section therefore begins with a brief 
discussion of socialist feminist and postmodern perspectives within the field of geography and then moves on to geographical conceptualizations of space, place, and scale. It concludes by presenting feminist topographical analysis and highlighting its applicability to this research project.

\section{Socialist and Postmodern Geographies}

Geographers have long engaged with and extended the various theoretical perspectives discussed above. Specifically, Marxist and socialist feminist debates concerning capitalism and patriarchy were articulated within feminist geography throughout the 1970s and 1980s. At this time, feminist geographers began to recognize the importance of gender as a fundamental influence on societal-space relationships and questions concerning inequality between men and women and how and why these differences occur became central to the subfield. In 1984, the Women and Geography Study Group (WGSG) of the Institute of British Geographers advocated a "different approach to geography as a whole in which the influence of gender on relationships within space and society are treated with an importance equal to any other social and economic factor" (WGSG, 1984). This recognition marked a shift in focus within feminist geography that diverged from descriptive studies concerning housing, transport, and urban structure as experienced by women, as well as traditional Marxist approaches that reduced gender relations to "the economic" (Bowlby, et al. 1989).

In terms of understanding women's inequality, many feminist geographers espoused a socialist feminist standpoint that considered the influence of both class and gender in the development of social relations in society and acknowledged the importance of women's dual roles in production and reproduction (Little, 1986; Tivers, 1985; McDowell and Massey, 1984; 
Mackenzie and Rose, 1983). Recognizing that social categories, such as class and gender, are constructed in a way that is temporally and spatially specific, feminist geographers therefore enriched feminist studies by emphasizing spatiality ${ }^{12}$ and the place-based character of all objects of analysis (Massey, 1984; McDowell and Massey, 1984). Feminist geographers offered a contextual approach to feminist research that aimed to understand how social relations work differently across space, as well as how space is produced and reproduced as a gendered context that mediates social relations (Massey, 1994; Miller, 1991 and 1983; Mackenzie and Rose, 1983; McDowell, 1983). They emphasized the interdependent nature of social relations of power and encouraged researchers to construct more complete understandings of how context is defined. They focused on women's positions in relation to the domestic sphere and workplace and the interconnections between women's reproductive and productive roles (Little, 1987 and 1986; McDowell and Massey, 1984; Mackenzie and Rose, 1983).

Within a socialist feminist framework, feminist geographers also examined ideologies of gender, work, and place and called attention to their material 'grounding' in space, institutions, and gender roles. The diverse manifestations of capitalist and patriarchal structures and power relations within these structures vary over time and place and are based not only on gender and class, but also culture (Momsen and Townsend, 1987; Foord and Gregson, 1986; Bowlby, 1984). The inequality of social relations and their effects on women include, for example, access to and control over resources, the under-valuation of women's work, job segregation, and maledominated political structures (Little, 1986; McDowell, 1986; WGSG, 1984; Massey, 1983). Calling attention to space and place, studies in feminist geography have consequently assisted in encouraging new levels of analysis, such as the home, community, and individual, and signified

\footnotetext{
${ }^{12}$ The term spatiality is used by geographers to refer to socially -produced and interpreted space (see Soja, 1985).
} 
a move away from the search for generalizable knowledge concerning women's subordination to analyses of the differences based on class and gender, as well as space and place.

Feminist geographers have also engaged with postmodern theorizing and enriched analyses of location, positionality, borders, and boundary-making concerning analyses of difference, identity, and representation. Through postmodern work, feminist geographers have forwarded understandings of the complex and simultaneous interaction of gender and other social categories with space and place and how that interaction constructs differences among women and impacts identity, oppression, and resistance (Blunt and Rose, 1994).

With respect to the concepts of space, place, and scale, geographical definitions that rely on categorical and territorial notions have been displaced by geographers working with both socialist and postmodern theories and their attention to how spaces, places, and scales are made and maintained. Within feminist geography, space is seen as the medium, as well as the outcome of social action (WGSG, 1997). This relational understanding of space therefore conceptualizes space as structured by social, economic, political, and cultural aspects of social relations. ${ }^{13}$ According to Doreen Massey, 'social phenomena and space [are] constituted out of social relations, [such] that the spatial is social relations "stretched out" (1994: 2). Feminist geographers map various social relations but they have long been interested in the spatialities produced by the intersection of patriarchy and capitalism. For example, Mackenzie and Rose (1983) argue that production and reproduction, the related spheres of capitalist patriarchy, produce a specific spatiality because of a particular division of labor: a binary division of spaces into workplace and home, the spaces of productive and reproductive labor, respectively.

\footnotetext{
${ }^{13}$ For a detailed, early reading on the production of space see the work of Lefebvre, 1976a and b; 1977; and 1978 in French and 1991 in English. He is largely responsible for the observation that space is a social product.
} 
Many feminist geographers are further refining this argument by considering the spatialities made by other kinds of social relations including sexuality (Duncan, et al. 1996; Valentine, 1996 and 1992), 'race' (Preston et al. 1993; Peake, 1993), and dis abilities (Chouinard and Grant, 1996), for example, and how these spatialities affect women's identities and the construction of places. Gill Valentine's (1996 and 1992) work on sexuality and public space examines sexual dissidents: lesbians who perform acts of subversion and resistance that aim to renegotiate the heterosexuality of everyday public spaces like the street, restaurants, and shopping malls. This work emphasizes the political aspects of the performance of lesbian sexuality that disrupt binary gender identities which naturalize heterosexuality within public spaces. She demonstrates how lesbians can destabilize and renegotiate the heterosexual construction of public space through displays of affection, dress, and lesbian and gay pride marches.

Within feminist geography, place is also conceptualized in relational terms, as unbounded, unstable, and structured by social forces from the global to the most intimate scale (Massey, 1991; Smith, 1987). Doreen Massey's work (1994) on space and place has been central to forwarding "a progressive sense of place" where place is interpreted as the intersection of sets of social relations which are stretched out over particular spaces. The distinctiveness of place, therefore, is seen to rest in the combination of social relations juxtaposed together in place and the connections they make to elsewhere in the social world. Places are, therefore, bound up with social difference, power relations, and particular spatialities, and geographers, in particular, consider the various ways in which many of the meanings through which places are made are tied to social identities and struggles. 
Interrogating the 'maps of meaning' that are used to make sense of places reveal the particular power relations and power players, such as the media, government and development agencies, tourist boards, or community leaders, involved in the construction of places and how our images of place often depend on theirs. For example, if you don't live in Appalachia (or maybe if you do), your image of Appalachia as a place may echo not only the beautiful mountains, forests, wildlife, and rivers, but also images of gun-carrying men dressed in overalls or a 'beater' t-shirt, women 'knocked up' on the front porch, and children running around with no shoes in a backwoods 'holler' - images resulting from the 1960s War on Poverty, the development of the Appalachian Regional Commission (ARC), and more recently, political and socioeconomic debates around welfare reform(see Williamson, 1995). You may know 'the place' through media and government-driven depictions of poverty, joblessness, welfare dependency, and low education levels. Your images may not reflect, then, the local senses of place of people living in diverse locations within Appalachia, a region that stretches from northern Mississippi to southwestern New York. The ways in which places are made, both materially and culturally, and people's senses of places thus affect the construction of subjective identities and contribute to the process of 'Othering'.

According to postmodern geographies, 'the Other' is not understood in its own terms; rather, it is given all the qualities, positive or negative, understood as the opposite of those defining it (WGSG, 1997). 'Othering' is a process of boundary-making that constructs borders that separate you and me, us and them, here and there and is reflective of our everyday understandings of the social and geographical world such as masculine/feminine, white/black, and First/Third World. It should be said that spaces and places and the borders between them are, of course, open to contestation by different groups and individuals, many of whom are trying 
to question and redefine their meanings and boundaries (WGSG, 1997; Bell and Valentine, 1995; Smith and Katz, 1993).

Analyses of boundaries, positionality, and location challenge simple cartographic representations. Social and cultural boundary-making is dynamic and fluid, as well as intrinsically spatial. Human spatial boundaries are defined through social interaction when groups form geographically and differentiate themselves from one another based on linguistic, racial, or ethnic characteristics or religious, economic, or political interests, for example (Cohen, 1974). Boundaries such as these are expressed materially and maintained through various local and global power relations and gendered, racialized, and classed ideologies imbued with ideas and notions about appropriate behavior and values. They are, as articulated by Benedict Anderson (1983), oftentimes ambiguous and contested and more exclusionary than inclusionary. Fundamentally, boundaries and border-making, whether they are human or physical, are rooted in social processes and issues of territoriality, segregation, and community. Constructing boundaries and borders is related to the power to include or exclude by, for instance, establishing physical barriers, enforcing legal devices, or relying on constructions of difference. Importantly, human boundaries that are rooted in dichotomous categories, such as the masculine/feminine, white/black, First/Third World, and the process of othering reflect 'differences' based on gender, race, or place, but also a hierarchical relationship of material inequality.

Understanding the processes of boundary-making and 'othering', both materially and culturally, within our everyday spaces and places is key to understanding the development of the former bantustans in South Africa, for example. The racialized geography of the bantustan system was built on establishing both human and physical boundaries between people based on race and in the interest of economic and political advantage. Boundaries were sustained through 
a complex system of laws and regulations on spatial and social mobility and resulted in a hierarchical system of extreme inequality based not only race, but also gender. Importantly, the bantustans, where spatialized racism and sexism materialized, were contested and not only places of underdevelopment and oppression but also sites of political struggle and mobilization.

Within geography, scale theory focuses on understanding the processes that shape and constitute social practices at different levels of analysis ${ }^{14}$ (Harvey, 1984; Cox, 1995, 1996, 1998a and b; Smith, 1997, 1996, 1992a and b; Herod, 1997, 1991; Swyngedouw, 1997; Brenner, 1997; Howitt, 1998; Marston, 2000). According to this work, scale is not a preordained, hierarchical framework for locally, regionally, and globally ordering the world, but a contingent outcome of the tensions that exist between structural forces and the practices of social actors (Marston, 2000). Geographical advances reveal that scale should be seen as a relational element in a complex mix that also includes space, place, and environment and culture, history, economy, and geopolitics - all of which interactively make the geographies we live in and study (Howitt, 1998). To put it more succinctly, as Erik Swyngedouw has, scaled places are 'the embodiment of social relations of empowerment and disempowerment and the arena through which they operate' (1997: 169). As geographers, then, our goal with respect to scale is to understand how particular scales become constituted and transformed in response to social-spatial dynamics. Scale theorists have focused on how scale is made and changed around relations of capitalist production $^{15}$ and more recently, social reproduction and consumption (Katz, 2001a and b; Marston, 2000; Taylor, 1999) and issues of subjectivity (Smith, 1992a).

\footnotetext{
${ }^{14}$ For early, detailed readings on scale theory see the work of Peter Taylor, 1982; 1984; and 1987. Nearly all of the work on scale in geography that has been produced since the early 1980s is rooted in his 'materialist framework for political geography' that adapts Wallerstein's (1975) division of world space into three realms: the world economy scale (the scale of reality); the urban scale (the scale of experience); and the nation-state scale (the scale of ideology).

${ }^{15}$ See the work of Harvey, Smith, Herod, and Swyngedouw in particular.
} 
The particular ways in which scale is constructed are tangible and have real material consequences. Like the production of space and place, there are many players and socioeconomic processes at multiple levels of analysis involved in the construction of scale. Scale construction is a socioeconomic and political process endemic to the ordering of our world and local, regional, and global framings of scale are often contradictory and contested and not necessarily enduring (Smith, 1992b). In fact, the making of Appalachia as a 'region' illustrates the multiple players involved and the material consequences that result from scale-making.

The Appalachian Regional Commission (ARC), a federal, regional development agency, was created in 1965 (see Map 3). Targeting the run down, isolated coal fields in the center of the region, the old rust belt, heavy manufacturing area to the north, and exhausted agricultural areas of the south, this agency was designed to appropriate funds for infrastructure and economic development and conservation and resource management efforts. The region currently contains 410 counties in 13 states and a political process involving pressure from local and state politicians and a mix of metropolitan and county-level data is utilized to establish membership into the region. The competition for funds between development districts, states, and the ARC and economic development strategies of the ARC emphasizing highway development and growth-center theory has resulted in uneven development across the region. Central Appalachia, in particular, has not reaped the benefits of ARC membership because many of its market towns and service centers did not conform to what regional economists would identify as growth centers in the early years of the Commission. We could go a step forward in the analysis of Appalachia as an exercise in scale-making and acknowledge that ARC regional development policies have encouraged subregional (clusters of counties, development districts, and metropolitan areas) and supranational territorial scales (local, regional, and global political 
economic linkages such as those with the North Atlantic Free Trade Agreement NAFTA, manufacturing shifts within global economic restructuring, and the more recent outsourcing of jobs in the United States) of uneven development. Thus, scales are made and changed by local, regional, national, and global forms that are in a constant state of transformation.

While much of the work on scale has been focused on how the making of scale is so intertwined with capital and political-economic structures, Neil Smith (1992a) argues for the incorporation of issues of subjectivity into a theory of scale construction. Smith identifies the negotiation between difference and different subject positions as one of the central challenges of postmodernism and its focus on the fluidity of the subject and its championing of the local against the global, indigenous against the universal, and place against space. He demonstrates that scale is the main axis around which geographical difference is organized. Thus, rather than yield to difference as an individuallevel construction, Smith insists upon materially anchoring difference and the subject through a theory of scale where positionality is the product of contest and negotiation around socially-demarcated boundaries that are established at a particular scale and that may or may not be permeable. Positionality, then, reflects more complex notions of difference and inequality and encourages interrogations about where individuals are 'located' within social hierarchies and the implications of these social locations. Positionality emphasizes that one's identity and socioeconomic and political realities are shaped by issues of gender, race, and class and, most importantly, how these differences are appropriated at various levels of analysis by socioeconomic structures and agents for particular purposes. According to Smith, "once identity is seen as being dependent upon the scale at which it is established...the question of who is included and who includes themselves as 'black' [for example] can be recast as a 
question of the socially constructed scale at which a black social and political identity is established" (1992a: 74).

In South Africa, for example, we can see the contested nature of Black identity as it is constructed at various scales of analysis. For example, Black identity is intimately connected to ethnicity at the individual and community level depending on if you were born Venda, Xhosa, or Ndebele, for example, and is connected to language and cultural differences. Under apartheid, black identity, as well as white, Indian, and colored, was defined at the national level to create a hierarchical system. This system positioned blacks socially and geographically by marginalizing them with regard to access to various types of work, educational opportunity, and political participation, for example, and dumping them in numerous, poverty-stricken and fragmented areas called bantustans. During the anti-apartheid movement, black identity was embraced by many people of color at local, national, and even global levels for the purposes of liberation. Here, we can see how the making of place and identity is constructed at multiple scales and through cultural and social structures, as well as political and economic ones.

\section{Feminist Topographical Analysis—A Framework for Comparative Feminist Research}

By forwarding new conceptualizations of basic geographical concepts within socialist and postmodern geographies, feminists within the field are revealing the unstable nature of dichotomous categories and emphasizing the contested nature of subjects, subject positions, and borders and spaces, places and scale. Feminist geographers critique the gendering of dichotomous categories used to create space and places, the boundaries which these set up, and the ways in which boundaries work to define some people and practices as being 'in bounds' while others are located 'out of bounds' (WGSG, 1997). Feminist geographers, in particular, 
must continue to work for a 'geography of [and for] ${ }^{16}$ women' and reclaim the side of the binary category that has been less valued by non-feminist geographical analyses and make previously hidden processes, patterns, and experiences more visible. Finally, they must continue to work with the concept of scale and forward a feminist politics that allows women to tease out their differences but also establish commonalities (McDowell, 1996). This political project will involve building bridges between women who are differently 'positioned', both in the literal and metaphorical sense, to create what Chandra Talpade Mohanty has called an 'imagined community'.

Imagined not because it is not 'real' but because it suggests potential alliances across divisive boundaries, and 'community' because in spite of internal hierarchies it nevertheless suggests a significant, deep commitment to what Anderson, in referring to the idea of the nation calls 'horizontal comradeship'... such imagined communities are historically and geographically concrete, [but] their boundaries are necessarily fluid (1991: 4).

By considering social and physical features, attending to history, and revealing the multiple socioeconomic processes at all geographic scales that work to produce place and space, feminist topographies 'ground' analyses of inequality among women and reveal its materiality in everyday realities and practices (Katz 2001a and b). This approach focuses on women's identities as heads of households and their livelihoods strategies, which have a very local material grounding, without losing sight of the regional and global processes and players that impact upon and connect them. Feminist topographical analysis allows us to more powerfully integrate the material and the cultural, as articulated by a materialist discursive feminism, through its attention to space, place, and scale. This framework also outlines a spatialized feminist politics and provides the conceptual ground and practical solutions for comparative

\footnotetext{
${ }^{16}$ Phrasing added by author.
} 
feminist work that overcomes the boundaries of cultural and geographical differences concerning women's identities and place.

As defined by Katz (2001a) and according to the Oxford English Dictionary (1971), topography is "the accurate and detailed delineation and description of any locality" (1214). Topographies are descriptions or representations of "the features of a region or locality collectively" and part of the "mincing of the world into particular places" (Fuller, 1642: 75; Katz, 2001a: 1214). This particular exercise in the specialized study of places, conducted both within and outside the field of geography, has always been purposive and partial and usually conducted for political leaders and military commanders. Topographical data has long been fed into maps, and more currently, Geographic Information Systems (GIS) and other global databases to facilitate resource extraction and surveillance and organize place. The local and global knowledge produced through topographies facilitates rule imposed by those in positions of power. Thus, "if topographical knowledge is so integrally important to various agents of domination and to the maintenance of their associated power processes, its appropriation should be important to countering them" (Katz, 2001a: 1215).

Geographer Cindi Katz (2001a) appropriates the concept of topography to develop a means for "examining some part of the material world, defined at any scale from the body to the global, in order to understand its salient features and their mutual and broader relationships" (1228). Because topographies incorporate both 'natural' and social features of a landscape, they embed a notion of process, of places made and nature produced. Producing a critical topography makes it possible therefore to account for history and situate places in their broader context and in relation to other areas or geographic scales. Fundamentally, Katz's form of topographical analysis makes it possible to "excavate the layers of process that produce particular places and to 
see their intersections with material social practices at other scales of analysis. Revealing the embeddedness of material practices in place and space in turn invites the revelation of socioeconomic and political difference and inequality” (Katz, 2001a: 1228).

In her case study (Katz, 2001a and b), Katz conducts a critical topography of Howa, Sudan to illustrate the ways globalization affects a particular place. By focusing on three processes of globalization, including economic restructuring, 'time-space expansion', and Sudan's civil war, Katz reveals that it is not simply globalization that is important, but its encounter with existing social relations and material social practices in particular places. She highlights, for example, how modernization programs, including a state-sponsored agricultural project, transformed local farming and land tenure systems to disrupt the livelihoods of local people. By encouraging the development of a cash economy of laborers and producers, this project commodified the basic means for social reproduction in Howa and intensified the work of women and children, limited access to educational opportunities, led to food shortages, and created new forms of corruption and patronage. The disruption of people's livelihoods by attempts to 'modernize' the rural sector and the civil war has led to the out-migration of village residents and the alteration of family and community relationships, thus creating what Katz calls 'time-space expansion'. By constructing a topography of Howa, Katz is able to reveal how the material social practices associated with globalizing capitalist relations of production and reproduction intersected with volatile political circumstances, disintegrating economic conditions, and a deeply troubled historical geography of racialized religious and ethnic difference and made them all worse. Hence, the traces of 'local' globalization can be seen in the landscape and 'doing' a topography brings them into sharp relief to expose their tensions, contradictions, and affiliations (Katz, 2001a). 
Topographical analysis which is informed by socialist feminist and geographical conceptions of space, place, and scale, seeks to understand the socioeconomic relations and processes that shape and constitute material practices at different scales. Challenging hierarchical and fixed geographic definitions, space is seen as the bearer and reinforcer of social relations and scale as socially produced and relational, rather than hierarchical (Katz, 2001a; Marston, 2000; Howitt, 1998). Place is understood, therefore, as structured by social, spatial, and physical forces from the global to the most intimate. Specifically, topographies are able to account for varying socioeconomic histories, such as colonialism; contemporary processes, such as economic restructuring; and the operation of culture, such as religion or tribal relations, for example. Topographies illustrate how power, within this complex web of processes and relationships, is reconstituted over time, through space, and at different scales. Constructing critical topographies consequently reveals the importance of analyzing the structures of capitalism, patriarchy, and colonialism which are embedded with gendered, racialized, and classed ideologies and producers of unequal socioeconomic relations. In addition, topographies recognize that these ideologies and relations have particular spatialities that create place, construct identity, and affect material practices among women. Finally, topographical analysis also understands that these socioeconomic relations and processes work differently, as well as similarly, at local, regional, and global scales.

Katz's emphasis on materiality is deliberate in her construction of critical topographies, however, she points to the fact that there are productive metaphorical entailments of topographical analysis as well. Within this framework, topography is associated not just with the description of place, "but with measurements of elevation, distance, and other structural attributes that enable the examination of relationships across space and between places" (Katz, 
2001a: 1229). The social and economic processes of globalization, or patriarchy or colonialism for that matter, have translocal effects that are commonly experienced across different locales and between various groups and individuals. Understanding these connections between places and people is crucial to challenging them effectively.

Topographical analysis does not, therefore, negate the importance of 'situatedness' or context but sees the local, regional, and global working together to produce particular geographies that are connected along 'contour lines'. Contour lines, as established by Katz (2001 a and b), are the means for metaphorically connecting specific topographies that are affected by certain social and economic processes in analogous ways. In traditional topography, contour lines are utilized to connect places at precisely the same altitude to reveal a terrain's three-dimensional shape. Here, in the metaphorical sense, Katz imagines a politics that maintains the distinctiveness of the particular conditions of a place but recognizes that it is "analytically linked to other places along contour lines that represent not elevation but a particular relation to a process" (2001a: 1229). To illustrate this point, contour lines are able to situate particular places, such as the maquiladoras of Mexico and Free Trade Zones in Southeast Asia, to particular social and economic processes, such as restructuring, for example. Once the contour line is drawn associated issues, such as the informalization of work, and consequent material conditions and practices, such as harsh and demeaning work environments, low wages, and lack of health and retirement benefits are revealed and information on strategies designed to combat these issues can be exchanged. Such connections are "precise analytic relationships, not homogenizations" highlighting the "connectedness of vastly different places made artificially discrete by virtue of history and geography but reproducing themselves within common politicaleconomic and sociocultural processes" (Katz, 2001a: 1229). By constructing precise 
topographies at a range of scales, from the local to the regional and beyond, we can analyze a particular issue, like the informalization of work, in and across place, mapping sites connected along 'contour lines'.

The larger intent of topographical analysis and the drawing of contour lines is the building of 'counter-topographies' that "link different places analytically and thereby enhance struggles in the name of common interests" (Katz, 2001a: 1230). Because topographies are a means for elucidating the intersections of historical social processes and their geographies with others elsewhere, they inspire a different kind of politics: one in which crossing space and ‘jumping scale’ are obligatory rather that overlooked (Marston, 2000; Smith 1992a). This grounded but translocal politics offers the possibility of countering the ways processes of global capitalism, for example, build upon gendered, racialized, and class axes of oppression and inequality in different historical geographies. We can then ask: What politics might work the contours connecting sweatshop New York, maquiladora Mexico and the Free Trade Zones of Southeast Asia: or, the trafficking of women in Southeast Asia, Eastern Europe, and Russia to the United States and Western Europe: or, women heading households in underdeveloped areas of South Africa and Appalachia?

Importantly, the building of counter-topographies moves beyond place-based politics to provide feminism with a more productive and spatialized understanding of the problems resulting from the disarticulations of capitalism, legacies of colonialism, and the local and global workings of patriarchy as simultaneous and intertwined. They work toward a politics of scale that allow, as Lynn Staeheli asserts, “oppositional movements... to take advantage of the resources at one scale to overcome the constraints encountered at different scales in the way that more powerful actors can do..." (1994: 388). They create new 'sites' of engagement at local, 
regional, and global scales that are based on the understanding that women's identities and socioeconomic and political roles and abilities to participate in societies are dictated by both local and global forces and that it is, as John Berger (1974) states, "space, not time that hides consequences from us." Therefore, let women reveal the hidden, common consequences of capitalist, colonial, and patriarchal processes in their local lives and spaces through topographical analysis, connect them across culturally-constituted difference and place by drawing the contour lines, and thus construct counter-topographies that are able to appropriate power and resources at local, regional, global scales and work for a global feminist praxis.

In sum, topographies encourage feminists to theorize both analytically and politically about local places, people, and material practices, the various socioeconomic processes and institutions of power that affect them, and their relationships to one another. They forward realizations of agency in women's struggles against oppression and inequality and by dissecting the differences that space, place, and scale make, they also work to establish connections, based on the relationships people and places have to particular processes, and their consequent material realities. In fact, the drawing of contour lines could facilitate the development of 'imagined communities' that unite women around common issues and result in activism that transcends cultural and geographical differences. Geographically-informed theories and analyses such as this make it possible to establish common needs, exchange information on strategies, and organize across our differences. Through comparative feminist analyses, a more complete understanding of the local and global geographies of women will be achieved. 


\section{A 'Livelihoods' Framework—Conceptualizing Women's Economic Realities}

This section outlines a framework for a livelihoods approach to understand the particular economic strategies of female-headed households which is the focus of this research. The discussion develops a framework to help describe what women actually do to support households and understand the various social, economic, and political factors and institutions that either enable or restrict their abilities to 'make due' in Appalachia and South Africa. This collection of both productive and reproductive activities including those that feed and care for the kids, pay the bills, keep the house, and plan for the future is conceptualized as women's livelihoods in this project. This section of the chapter defines the concept of a livelihood, as utilized in this research, the types of capital, structures, and processes that shape people's livelihood options, and discusses the importance of feminist analyses to work on livelihoods. There are many debates going on within the livelihoods literature that are beyond the scope of this research. A brief overview of the livelihoods approach, which focuses on those aspects that are relevant to an analysis of the livelihoods of women who head households, is outlined below.

The livelihoods approach to understanding development processes was first introduced in the mid 1980s by Robert Chambers (1983) and has become increasingly popular in academic research and practice over the past decade (Rakodi and Lloyd Jones, 2002; Schafer, 2002, Francis, 2000). A livelihoods approach to development is one that is people-centered involving an analysis that begins with people's livelihood strategies and continues by including those people fully in the development process. It is also holistic and dynamic, involving an analysis of the constraints to and opportunities for people's livelihoods that are played out at all scales and within various social, economic, and political institutions. This approach builds on people's strengths and works for environmental, economic, social, and institutional sustainability. Thus, a 
livelihoods framework is both a goal: that works to create new ways of living that enable people to meet their varied and interwoven needs without compromising the ecosystems that support them and their community; and an approach: that is rooted in particular people in specific places making decisions about sustaining themselves and their families (Carney, 1998).

For the purposes of this research project, a livelihood is defined as the varied ways of living that meet individual, household, and community needs (adapted from Ratner, 2000; May, 1999; and Chambers and Conway, 1992). A livelihood may, therefore, include agricultural work for one's own consumption or sale; small and micro-enterprise development; wage labor; and claims against the state. It may also include unpaid domestic labor, illegitimate activities, bartering and labor exchanges, or non-income-generating measures. According to Frank Ellis, livelihoods encompass "the assets (natural, physical, human, financial, and social capital), the activities (strategies of use), and the access to these (mediated by institutions and social relations) that together determine the living gained by the individual or household" (2000: 10). People's abilities to engage in particular livelihood strategies depend on various types of capital, as well as structures and processes. Capital includes human, social, natural, physical, and financial and positive livelihood outcomes result from combining these various types of assets in different ways (Rakodi and Lloyd-Jones, 2002; Ellis, 2000; DFID, 1999). Human capital refers to skills, knowledge, the ability to labor, and good health, while natural capital includes resource-based activities such as farming, fishing, and gathering as well as land allocation systems, natural resource use patterns, and natural capital stocks. Physical capital refers to infrastructure and producer goods that are required to support livelihoods and include affordable transport, shelter, adequate water supply, clean and affordable energy, access to information, and tools and equipment for productive functioning. Financial capital denotes 
accessibility of cash, or its equivalent, for the pursuit of livelihood strategies and includes: available stocks, especially savings which may be held in banks or in liquid assets like jewelry, livestock, or through credit provision and regular flows of money including earned income, welfare and other transfers from the state, or remittances. Finally, social capital is the most contentious type referring to the "social resources upon which people draw in pursuit of their livelihood objectives" (DFID, 1999). Social capital is therefore developed through:

?networks of connectedness, which may be vertical, such as patron-client, or horizontal, as with individuals with shared interests, that facilitate working together and access to institutions;

? more formal group membership with associated rules, norms, and sanctions;

?and trust, reciprocity, and exchange which facilitates co-operation, reduces transaction costs, and which can be a basis for informal safety nets among the disadvantaged.

Thus, social capital can be important in improving efficiencies in economic relations, income, and rates of return; improving the management of common resources and maintenance of shared infrastructure; and stimulating improvements in human capital where it enables innovation and the sharing of knowledge.

The structures and processes that affect livelihoods operate at all scales and influence access to various types of capital, certain livelihood strategies, and decision-making; the terms of exchange between different types of capital; and both the economic and social returns to any given livelihood strategy (Ellis, 2000; Francis, 2000). Structures include all public and private organizations that set and implement policies and legislation; deliver services; purchase goods and services; trade; and perform all other functions that affect livelihoods. As Jim Bingen (2000: 3-4) has identified, structures include familial or cultural institutions that cover a range of 
descent or kin-based (clan, lineage, tribe) relations and practices; communal institutions, which are often more relevant in rural rather than urban areas, involving practices associated with shared physical and natural resources; and social institutions which comprise 'codes of conduct' reflecting particular social interests. These three groups of institutions shape the 'social norms' or unwritten rules that influence people's constraints and opportunities within their households and communities. In contrast, collective and policy/government institutions constitute the 'formal rules' by which societies are structured. Collective institutions are various types of contractual arrangements while government/policy institutions correspond to the constitutional and juridical setting (Bingen, 2000; Folbre, 1994).

In order to function, structures require processes, such as policies, legislation and institutions. Analyzing the operation of these processes is vital to understanding how structures relate to one another and how they impact women and their quest for sustainable livelihoods. To the extent that livelihoods are derived from assets and access to them through particular structures and processes, they are inextricably linked to social power, which is reflected in and exercised through the production and control of space at various scales of analysis. Socio-spatial relations are, of coarse, gendered and vary across class, race-ethnicity, and place.

Unfortunately, many livelihood analyses ignore the role of gender and few feminists have embraced a livelihoods framework when investigating women's economic activities and their productive and reproductive roles (see for exception Oberhauser, Mandel, and Hapke, 2004; de Haan et al. 2002; Whitehead and Kabeer, 2001; and Francis, 2000). Similar to Carney's (1999) work on livelihoods, this research adopts livelihood analyses as a goal: to meet basic needs, foster economic opportunity, transform gender relations and power structures, and ensure sustainability for the social, economic, and political empowerment of women; and an approach: 
that involves women, in their particular places, making decisions, establishing priorities, and building strategies about sustaining themselves and their families. A feminist livelihood framework involves analyzing how what women do to support households is affected by their access to various types of capital and how this access is shaped by the gendering of socioeconomic and political structures and processes. This involves a dynamic feminist approach that can account for the micro, mezzo, and macro scales in which these structures and processes occur and inter-relate. By adopting a gendered livelihoods framework, this research can reveal the multiple and interrelated structures and processes, occurring at various scales of analysis, that affect women's abilities to support households in West Virginia in Appalachia and Limpopo, South Africa.

By embracing a livelihoods framework and infusing it with a feminist geographical analysis, this study will be able to more adequately illustrate women's multiple roles and duties in society and overcome dichotomous notions of productive/reproductive and paid/unpaid labor and the division of home/work spaces. Livelihood analyses allow feminists to investigate the overlapping issues of housework and domestic responsibilities within homes and communities and occupational segregation within the labor market and their effects on women. This framework is, therefore, able to articulate the constraints, as well as opportunities, in all the spheres of women's lives that determine their livelihood options. This framework also fits with this project's focus on female-headed households because these women, whether they are single, married, or widowed, manage both the productive and reproductive duties of the household. For them, constructing a livelihood is not simply about monetary support but also the care-giving of children and oftentimes elderly or disabled family members, cleaning and maintaining a home, subsistence farming and community and religious activities, for example. 
As will become evident in the following chapters, this research argues that livelihoods, as conceptualized here, are a representation of economic activity within contemporary capitalism and society that is shaped by socioeconomic and political factors and institutions at various levels of analysis. Livelihoods include both capitalist and non-capitalist activities and the need to piece together a variety of income, subsistence, social welfare, and family-based strategies to sustain a household has evolved out of contradictions within capitalism. These contradictions result from both macro-level processes, including global capitalism and economic restructuring, as well as local factors, such as welfare reform, migrant labor, and changes in family structure. As feminists, we know that it has always been difficult for women to meet the needs of a household through reliance on a single activity or income source, however, the new forms this is taking in rural parts of the world today must be revealed.

This research project because it can captures the dynamic, historical, and relational processes that inform the intricate array of activities that comprise women's ways of 'making do' in a contemporary world. Because it begins with people's strengths and attends to the differing goals of diverse community members, it is able to demonstrate that women are active agents that develop their own unique strategies to deal with social and economic change in their daily lives. This framework also seeks to both analyze and overcome power differentials that exist within households and communities and between individuals, communities, non-governmental organizations, funding agencies, and the state that affect access to resources and authority. It acknowledges that every woman is situated within a household, community, and region that have distinct livelihood options and constraints that are shaped by social, political, cultural, economic, and geographical forces that operate in both different and similar ways across places. Finally, a livelihoods framework provides the means for linking macro-level processes to micro-level 
outcomes and responses which provides this research with a view into how women are coping with or adapting to global socioeconomic processes, such as economic restructuring.

To conclude, the livelihoods framework developed here analyzes the role of gender in determining differential access to and control over productive and reproductive resources and reveal the specific barriers to sustainable livelihoods women face in the two regions. By investigating the particular livelihood activities in which women engage, this study reveals how these women negotiate these constraints and develop their own particular strategies. It also exposes how women's particular strategies are embedded in space and place while illustrating how broad social and spatial processes impact upon women in different and similar ways across the globe. Finally, it demonstrates how women's economic activities are couched in diverse social identities such as gender, class, race, and place and how multiple scales are represented and constructed in community and individualbased livelihood strategies.

\section{Summary}

This dissertation seeks to reveal the many ways women who head households in rural parts of the world mediate their multiple roles and negotiate the various economic opportunities and constraints they face in their quest for sustainable livelihoods. It analyzes the particular livelihood strategies women adopt to support households and recognizes the ir contributions to rural economies. The conceptual framework developed here consists of feminist materialism, topographical analysis, and a livelihoods framework.

A 'materialist discursive feminism' forwards empirically-grounded theorizing about the material conditions of women's lives within their social and historical contexts (Jackson, 2001 and 1998). By bringing together 'the material' and 'the cultural', this framework analyzes 
socioeconomic relations and hierarchies of power, issues of identity and the meanings women give to their lives, and finally, their strategies for change. It moves beyond conventional, hegemonic notions embedded in capitalist discourses, economic restructuring analyses, and gender ideologies concerning women, work, household production and reproduction and women's social and economic identities. It does not negate analyses of difference but examines everyday social practices and material inequalities to better understand how difference is constructed through a multiplicity of forces that occur at the household, community, national, and global scales (Jackson, 2001).

This materialist discursive feminism relates to the concept of 'topography' within feminist geography (Katz, 2001a and b) and the position that socioeconomic processes, relations, and ideologies are rooted in space and place but operationalized at various scales (Marston, 2000; Massey, 1994; Smith 1994 and 1992). Topographical analysis, as developed by geographer Cindi Katz (2001a and b), dissects the historical, cultural, and spatial processes that assist in the production of place and affect the contemporary socioeconomic relations and economic practices among women. Articulating the importance of local, regional, and global scales of analysis, topographies enable feminists to examine the micro-levels, such as the household, at which power is deployed and resisted, as well as the macro-levels of systematic domination, such as the state. This non-hierarchical approach to the consideration of scale thus demonstrates how global socioeconomic processes work with local cultures and intersections of gender and other social categories to produce diverse forms of women's oppression and varying material realities, gendered identities, and livelihood strategies. Topographical analysis and feminist materialism partner with livelihood analyses within the framework developed here to identify the multiple 'players', at all scales of analysis, that are involved in dictating women's 
economic roles and opportunities. This conceptual framework demonstrates how the power to exclude or empower women is constituted through various institutions and processes that function at and across different scales, including the global, regional and local.

Finally, the conceptual framework developed here has very practical goals concerning both local and global feminisms. Topographies, in particular, imagine a translocal politics whereby places and women are analytically linked due to their relationship to particular processes and consequent material realities. Here, the diverse strategies women adopt to deal with the common politicaleconomic and socio-cultural processes they experience can be shared, fostering solidarity around particular issues rather than place or identity-based politics. The construction of feminist topographies thus facilitates comparative feminist work concerning women and the differing socioeconomic contexts within which they live and work. By moving beyond a case study approach and connecting women and their economic issues and strategies by drawing contour lines across place and space, feminist countertopographies can be constructed.

The construction of countertopographies relates to the prospects for a transnational feminist research and political praxis and the call for

... a comparative methodology which moves beyond the case study approach and illuminates global processes which inflect and draw upon indigenous hierarchies, ideologies, and forms of exploitation to consolidate new modes of colonization. The local and global are indeed connected through parallel, contradictory, and sometimes converging relations of rule which position women in different and similar locations...(Mohanty, 1997: 6).

This comparative research and its theoretical framework is therefore a building block to the realization that women working to support households all over the world are embedded in common socioeconomic structures that affect their abilities to acquire a sustainable livelihood for themselves and their families. This realization and the articulation of common needs and 
concerns forward transnational connections and a broader movement for socioeconomic justice and empowerment for women. 


\section{A Socioeconomic History of Gender and Livelihoods in Limpopo, South Africa}

\section{Introduction}

This research constructs feminist topographies to reveal the multiple and binding socioeconomic structures and processes at various scales of analysis that impact the livelihood strategies of women who head households in West Virginia, Appalachia and Limpopo, South Africa. To construct feminist topographies, this study accounts for the particular gendered, socioeconomic histories of the two places and presents an analysis of the varying ways women have participated in both productive and reproduc tive labor. In particular, topographical analysis allows this study to interrogate the socioeconomic, political, and cultural systems and institutions of these places that either enable or restrict women's livelihood options.

This and the following chapter lay the foundation for the two topographies by providing detailed analyses of the historic socioeconomic and spatial conditions in the two regions that affect contemporary women's livelihoods. In South Africa, this portion of the topography considers the history of apartheid and colonialism, traditional institutions and both national and local gender relations, economic development policies, democratization, and issues around HIV and AIDS concerning women's livelihoods and their roles as heads of households. In Appalachia, discussed in the following chapter, the feminist topography includes an analysis of its labor and economic development histories and institutions, issues around welfare and social services, economic recession and restructuring, and religion and family values concerning women's access and abilities to engage in certain livelihood strategies and head households.

This chapter and Chapter IV therefore address the character of rural economies in the two regions, women's positions in both formal and informal economic structures, and the types of 
work women have historically participated in as background material. First of all, however, it is necessary to define informal and formal economies and female-headed households, as conceptualized in this research. The chapter then turns towards the development of the topography on the livelihoods of women who head households in Limpopo by exploring the various socioeconomic and spatial conditions that affect rural women's economic participation in the region. The chapter presents a detailed analysis of colonialism, apartheid, and women's roles in both the formal and informal economy in South Africa as well as particular case study data concerning Limpopo. It also includes information on democratization and current gender policy in a 'new' South Africa.

\section{Defining Concepts and Terms}

In recent years, new consideration has been given to the diverse nature of rural economies globally (Cloke and Little, 1997; Crow, Bernstein, and Johnson; 1992; Fitchen, 1991; Preston-Whyte and Rogerson, 1991). While many rural workers engage in agriculture, others may work in industries and construction, artisan production, community services, or trade. In addition, high numbers of people in rural regions are often self-employed or participate in the informal economy. Rural women, in particular, often undertake multiple and seasonal economic activities.

The formal economy is that portion of natural, human, manufactured, and entrepreneurial capital utilized to meet human wants and needs (Ratner, 2000). It is counted through measures such as the rates of unemployment and inflation and Gross National Product. These measures assist in the tracking and monitoring of economic performance and viability and consequent development of economic programs and policies. 
The informal economy consists of everything from household production and consumption of goods and services, both paid and unpaid, to inter-household bartering and sharing, volunteer work, subsistence production, unpaid labor and labor exchanges, unreported business transactions, and care- giving (Ratner, 2000). Of course, what is considered informal economic activity varies, depending on location, time, and social and economic context. As well, informality is not an inherent property of specific activities. According to Williams and Windebank (1998), whether or not an activity is considered 'informal' is a social construction. They argue that all goods and services can be distributed either formally or informally. The diversity of activities in the informal sector makes it difficult to define and its connection with 'formal' manufacturing, services, and agriculture makes it hard to draw clear boundaries when examining rural economic issues and concerns.

Activities in the informal sector are becoming increasingly important as formal sector activities, agriculture, or welfare provisions are not able to provide jobs and economic well-being for rural people who are increasingly marginalized from land and access to other resources such as education, training, and credit (ILO, 1987). The informal economy is part of everyday life and household survival strategies, but remains poorly understood and largely ignored by scholars, practitioners, and policy makers.

Women's participation in informal activities is growing and often utilized to either support households or supplement incomes (Oberhauser and Turnage, 1999; Oberhauser 1995a and 1993; Hays-Mitchell, 1993; ILO, 1987; Tripp, 1992). In fact, feminist analyses have highlighted that by treating household work and wage labor as separate issues, the full range of household economic strategies has been blurred and the continued importance of work which takes place outside formal employment has been undermined (Leonard, 1998). Disputing 
dichotomous notions of productive and reproductive work and recognizing that both formal and informal economies are complementary parts of rural economic systems are of utmost importance to this research. This conceptualization also relates to the importance of utilizing a livelihoods framework and its comprehensive approach to understanding the diverse informal and formal activities and their interconnections which comprise women's ways of 'making due' in the world today.

This research focuses on the livelihoods of women who head households in rural areas of West Virginia and Limpopo. Rural women living in these areas, of course, are not homogenous and the pressures on and ambitions of rural women vary from region to region depending on various socioeconomic and spatial factors. It has been argued that the principal factors contributing to uneven social and economic development among rural women are unequal access to income; especially waged employment and migrant remittances, natural resources; especially land, water, and wood, and education, training, and child-care facilities (Whatmore, Marsden, and Lowe, 1994). In addition, isolation may be greater in rural areas because of distance, poor transportation networks, and lack of communication means and fewer public services often exist. Finally, patriarchal, class, and race structures intersect and serve to exclude women socially, economically, and politically in varying degrees (Adepoju and Oppong, 1994). All of these factors affect women's participation in rural economies and contribute to their quality of life.

Rural women in parts of Appalachia and the former bantustans of South Africa face many of the same issues and concerns highlighted above within their own regional context. In the case of Limpopo, it is necessary to examine the former apartheid regime, particular gender, race, and class relations, and the nature of jobs available to black, African women ${ }^{17}$. These socioeconomic

\footnotetext{
${ }^{17}$ It is important to note here that all of the respondents who participated in the study in South Africa were black.
} 
and spatial conditions have contributed to the economic marginalization of many women and subsequently, the rise of particular livelihood strategies in rural areas of South Africa. In the case of West Virginia, the research analyzes how the historical economic context of resource extraction, contemporary economic restructuring, rurality, and household gender relations affected women's participation in the Appalachian economy.

For the purposes of this research, female heads of households include widows, unmarried mothers, divorced or separated wome n, or women whose husbands are temporarily away (Ingstad, 1994; Whitehead, 1994). They also include women heading households due to their ability to earn more income or unemployment or disability issues affecting husbands or other household members. In addition, grandmothers who are responsible for children, who are unmarried or temporarily away, and grandchildren are also included (Ingstad, 1994). Women heading these households are primarily responsible for acquiring and performing both the productive and reproductive resources and tasks necessary to sustain the household. However, many do not have decision-making power and control over resources within the household. This broad conceptualization of female-headed households addresses the multiple econo mic, demographic, and cultural issues both within and between the diverse contexts.

\section{Gender and Livelihood Strategies in South Africa}

Livelihood strategies in Limpopo are embedded in the socio-historical context of traditional African societies, colonialism, apartheid, and capitalist development. African women's historical exclusion from property rights, educational and training opportunities, and financial resources are material manifestations of the unequal social relations that developed under these institutions (Morema, 2000). These institutions have worked to maintain 
'traditional' and conventional understandings of gender through racist and sexist policies and programs and by exploiting African women's labor. They have effectively limited the livelihood options of African women in the former bantustan areas and their legacies threaten the current restructuring process and quest for social, economic, and political justice in the country.

Therefore, to understand the socioeconomic history of African women and their quest for sustainable livelihoods this section of the chapter begins with a discussion of the apartheid system and explores issues concerning life in the bantustans, forced removals, and the migrant labor system. Secondly, the opportunities and constraints for African women with respect to waged employment are outlined and women's roles in the informal economy are discussed. This section moves beyond hegemonic notions of apartheid concerning the subordination and oppression of African women and also discusses the role of capitalism as well as patriarchy, household and community relations, and geographic isolation This part of the chapter also describes the case study area by highlighting particular socioeconomic characteristics and data as well as demographic information from Limpopo. It concludes with a discussion about democratization in the country and its effects on gender policy.

Life in the Bantustans

\section{WHAT WILL THEY EAT?}

There was stormy panic

When the police came

To round up polltax defaulters.

Once more the knowing forest

Hurriedly beckone

To hide in its bosom

Men of the village.

But uncle was again betrayed 
By his arthritic limbs.

Women wailed

Hearts seized by apprehension

And cousin cried

Fear in his little heart.

We had never seen a handcuffed person.

The police returned one day

And we craned our necks for uncle.

But he was not there.

For a long time,

Lasting almost the day,

Grandpa and grandma

Argued with the white policemen.

There was a black one

Well known for torturing

Standing away near the kraal

Like a skullpanda .

For the first time I saw tears

In granny's dark face,

Grandpa so furious

It was coming through his nose.

That day no tea,

Cookies or sour milk were served.

In the afternoon the guests left.

Granny was in grief

Parroting a recital,

"What will they eat?

What will my children eat?"

In the evening a man came

To herd all three suckling cattle,

Their calves and a pregnant cow.

He drove them away.

He herded away our wealth,

Our source of nutrition,

Grandfather's status and pride.

Their value would pay for his son's freedom.

A complete invalid.

Grief was choking my throat.

Would they know their special names?

Would they graze them in lucerne?

Give them chaff and salt?

What of the green acres at home? 
The calabashes,

Would they now be turned upside down?

What would we milk, feed the dogs on?

We would never again

Watch them grazing in the field.

For many seasons

Our home lay

Under the roof of sorrow.

Now I know

That from a dog's withered back

You can tell that

There's hunger in a home.

This poem was written by South Africa poet, Mzi Mahola, and is from When It Rains, Carapace Poets, Snailpress, South Africa.

For nearly a century, the apartheid structure and colonial regime sustained a system of oppression and exclusion based on race, class, and gender in South Africa. This system marginalized African women both economically and politically, and shaped and conditioned their everyday roles and realities. The apartheid system divided the land and people of South Africa into separate groups. Whites were the privileged and powerful minority and the black majority was divided into three principle groups: 'African', 'Indian', and 'Colored'. The African majority was excluded from participation in central government and assigned to live in numerous, poverty-stricken, and fragmented areas officially know as homelands ${ }^{18}$. These areas were presented as the territories of separate national states and declared "independent" in the advanced stage of grand apartheid (Map 4). Upon independence, the majority of Africans allocated to that bantustan lost their South Africa citizenship.

\footnotetext{
${ }^{18}$ In this analy sis these areas will be called bantustans so as to avoid apartheid language.
} 


\section{Map 4: The Former Bantustans, South Africa}

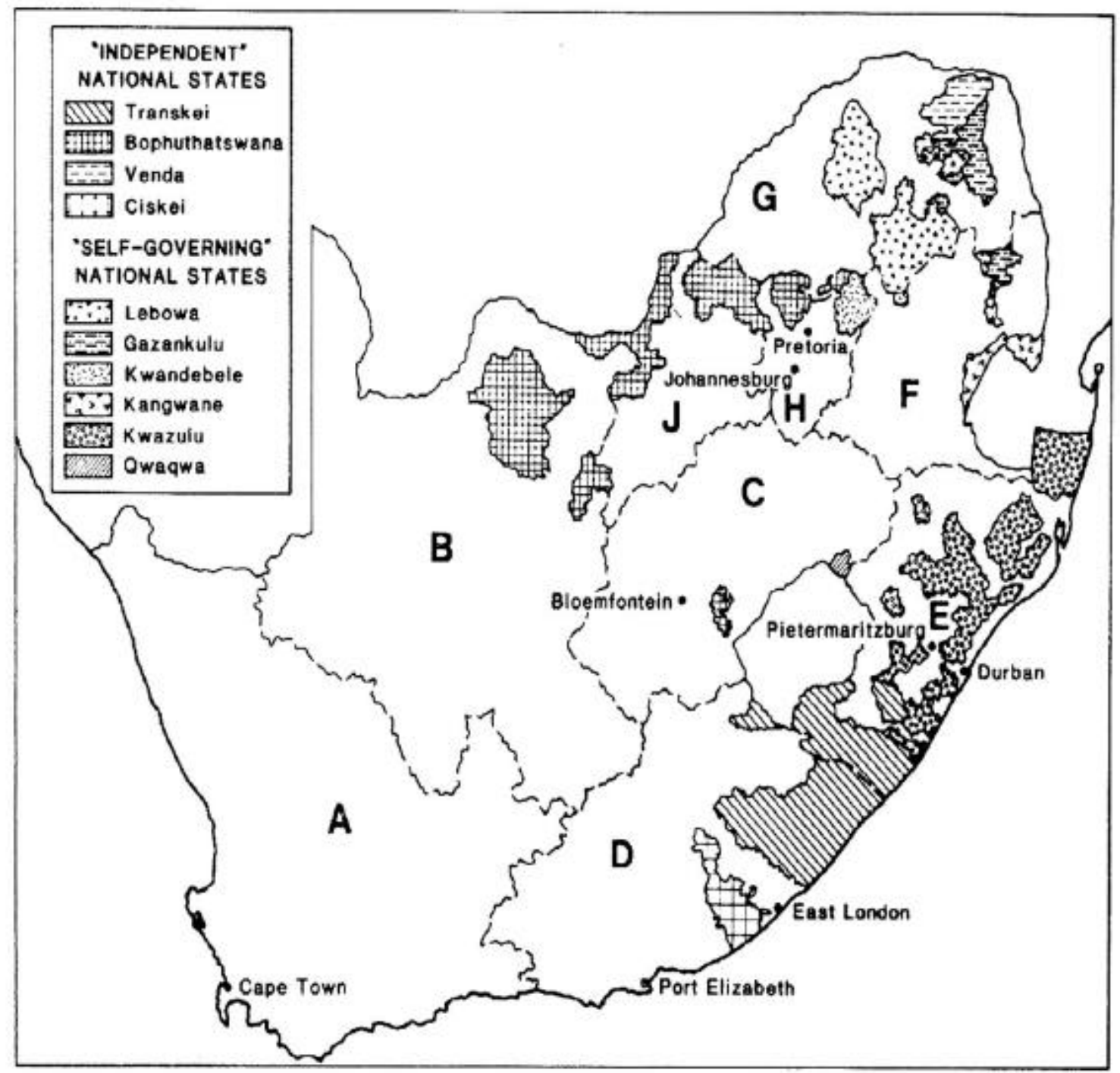

Source: Pickles, J. and Weiner, D. eds. "Rural and Regional Restructuring in South Africa." Special Edition of Antipode-A Radical Journey of Geography 23(1): 1991.

For African women, life in the bantustans was particularly severe. Beginning with colonialism, when commercial and capitalintensive industries such as plantation agriculture and extractive mining industries rapidly grew, local labor, community, and family structures began to be transformed. Under apartheid and its program of separate development and policies including the migrant labor and bantustan systems, this transformation was reinforced and accelerated. 
The apartheid government made a parody of traditional institutions, such as the cheiftancy, to serve the conservative and repressive white government. African women were consequently imprisoned within a complex interlacing web of customary and common law and often remained perpetual minors to their husbands and fathers (Walker, 1990; Bernstein, 1985). They were unable to own land in their own right, enter into contracts without the aid and consent of their male guardian, or act as guardians to their own children. Under this regime, the political structures were undemocratic and male-dominated, despite the fact that most households in the bantustans were headed by women (Bob, 2001; May et al., 1995; Pickles and Weiner, 1991; Bernstein, 1985). Therefore, in the absence of husbands and fathers, many women became de jure heads of households and assumed financial and decision-making responsibilities, as well as most of the care-giving and domestic duties (Bob, 2001; Sharp and Speigel, 1990). In 1993, approximately $27 \%$ of all households were reported as being headed, de jure, by women (Posel, 2001).

The bantustans were reserves, from which the apartheid government could draw supplies of labor at will and reservoirs, in the sense that they were the holding ground for the unemployed, the old, the disabled, and all those women and children who had no function within the operation of apartheid and the white economy (Bernstein, 1985). Until rapid industrialization and consequent increasing urbanization took hold in the 1960s and 1970s (see Seidman, 1993; Mabin, 1989; Hindson, 1987; Pillay, 1985), it was extremely difficult for African women to obtain work both inside and outside the bant ustans due to household responsibilities, denied access to education, and legal restrictions on mobility.

Under the bantustan system, spatialized racism and sexism were achieved by forced removal or eviction and regulated by the migrant labor system. The entire structure of apartheid 
was essentially built on these programs and for African people this meant strict controls on their movement, where they lived, and where they worked (Beinart, 1994; Beinart and Bundy, 1987; Bernstein, 1985). Africans were forcibly removed when the government designated land for another group, which was usually white, or when the regime sought to reduce the number of fragments of land that made up the bantustans. People were evicted from white-owned farms and squatter settlements in urban areas. Towns and cities were divided into commercial, residential, and industrial zones by the Groups Areas Policy and movement of only the African population was controlled by a system of regulations know as Pass Laws (Beinart and Bundy, 1987; Bernstein, 1985; Legassick, 1974 and 1975). This practice of Influx Control was linked to the exploitation of African labor and movement of that labor was monitored (Wolpe, 1980). Through these various programs and policies, accommodations were destroyed and people were driven into the bantustans or sharply segregated regional townships, far from city centers and economic opportunity.

Initially under the migrant labor system, nearly all migrants were male and African women were left behind socially, as well as economically and geographically (Seidman, 1993). Women were expected to conform to their 'traditional' roles as wives, mothers, and caregivers in the bantustans and to remain working in subsistence agriculture while waiting for male migrants to send their wages home (Walker, 1990; Murray, 1987). It is true that many households receiving migrant remittances did better that those without, however, because of both legal restrictions and overcrowding, peasant agriculture was oftentimes undermined and other economic alternatives were limited (Bob, 2001; Lucas, 1987). In the early 1980s, 57 percent of South Africa's African women legally resided in the bantustans (Simkins, 1984: 6). Therefore, few households were able to expand cattle holdings and migrants' wages could only rarely 
increase productive capacity (Beinart, 1994; Beinart and Bundy, 1987). Many African women experienced grinding poverty, increased agricultural labor which was frequently part-time or temporary and persistent dependence on oftentimes unreliable migrant remittances. Many women were forced to accept whatever they could get from their husbands, however little, without question. According to Hilda Bernstein, "In Winterveld it was common to find women who starved themselves to feed their husbands and children because there was so little money..." (1985: 23).

The apartheid system, including the migrant labor system and program of forced removals, deprived African women of their most elementary and fundamental rights. By the creation of a gendered and racialized migrant labor stream, little opportunity was left for employment or education and women were denied access to essential means of production such as land and water. In addition, because of the powerlessness and exploitation experienced by migrant workers, wife-beating, child abuse, and rape were common. It was virtually illegal for many African women and children to live with their husbands and fathers in town, therefore family and community relationships were profoundly transformed. Migrant labor and forced removal made a mockery of family and community life, disrupting all personal relationships and hindering cooperation, unity, and support.

Through the institutionalization of the apartheid regime's policy of separate development via a vast array of oppressive programs, policies, and laws, white domination was sustained. In addition and because the segregated groups (African, Indian, and Colored) were administered differently, the fragmentation and control of the black population was achieved and enforced. Consequently, the South African landscape was distorted by sharply contrasting employment and educational opportunities as well as harsh variations in living conditions and mobility. The 
apartheid regime's discriminatory policies based on race, class, and gender, both socioeconomically and spatially marginalized Africa women.

\section{African Women in Waged Labor}

...I showed them that being unmarried you can live and do lively things like there in the fields, I showed them there. I showed them through my children. My children are very good. I have disciplined them....These children I paid for their education up to the secondary.... So these four can live well while I'm unmarried and without any husband to help me.... I try to show a person that it is not correct to think you can earn a living by relying on another person. You have eyes, brains and hands. You must do something. Whatever you can do, try and make it a success. ${ }^{19}$

Apartheid legislation, combined with sexist cultural and customary practices, limited the activities of African women with particular respect to employment (Bob, 2001 and 1997;

Seidman, 1993; Walker, 1990; Mager, 1989; Bernstein, 1985; Cock et al. 1983; Lapchick and Urdang, 1982; Cock, 1980). The economic, social, and political spaces in which African women were allowed to penetrate were intensely controlled. African women were physically and emotionally placed in a situation of dependence on a male-dominated society and relegated to the lowest paid and unskilled occupations (Bob and Musyoki, 2002; Martin and Rogerson, 1984).

As seen above, education, employment, and status, as well as everything affecting personal relations, were predetermined by race, class, and gender. Hence, on the backs of African women rested a vast superstructure of laws, policies, and customs, in which the habits and institutions of an old pastoral society were cemented into a modern industrialized state (Bernstein, 1985).

Specifically, in examining the opportunities and constraints in employment for African women under apartheid and today, it is true that most were, and still are for that matter,

\footnotetext{
${ }^{19}$ Quote from an interview with Phyllis Nokoyi, Keiskammahoek, May 17, 1989 from Anne Kelk Mager's work entitled Gender and the Making of a South African Bantustan: A Social History of the Ciskei, 1945-1959, page 89.
} 
employed in domestic service and agriculture. However, capitalist transformation throughout the 1980s and 1990s brought about an increase in women's participation in manufacturing and various other professions such as secretarial work, retail, education, and health care. At this time, many of the stringent controls on African people's mobility were relaxed in order to sustain and expand the white economy. In turn, the expansion of capitalist relations increased the need for wage labor within households, contributing to the growth of petty commodity production while exacerbating the social differentiation between classes (Levin et al. 1997). At this time as well, more and more African women began participating in the informal sector, such as the making of crafts and selling of vegetables, as well as illegal activities, such as beer brewing and prostitution. Despite their prevalence, however, these flexible and sometimes non-monetary activities have been largely overlooked in the bantustan literature, especially with respect to women (see for exception Francis, 2000; Preston-Whyte and Rogerson, 1991).

In examining agricultural employment, the policy of forced removal and changes in large-scale farming in the 1970s and 1980s forced many labor tenant families off land, out of their homes, and into the bantustans. This phenomenon was essentially brought about by the spread of capitalism and modernist development policy that sought to increase output through mechanization and industrial decentralization. Migrant and seasonal labor further increased and women, in particular, were denied access to land and domestic employment on farms that supplemented their living. At this time, women also began to constitute most of the casual workers on farms and were forced to travel long distances to work. In 1980, about 17 percent of employed African women worked on large-scale, commercial farms (Marcus, 1989: 100-112; Barrett, 1985: 20). Their share of the total labor force in commercial agriculture doubled in the early 1980s, reaching 24 percent (Seidman, 1993). 
Moreover, it was generally impossible for women agricultural workers to find other employment because under the migrant labor system they were registered as farm employees and unable to change their status. They received extremely low wages (an average of five to ten US dollars per month in most regions) and lacked social security benefits (Bernstein, 1985). They were not protected by industrial legislation and had no bargaining power.

In addition to the agricultural worker, black domestic servants played an important part of the economic and racial structure of South Africa. In 1980, a quarter of all employed women were domestic servants and the majority (86 percent) were African (Bernstein, 1985). Black women were responsible for the domestic and subsistence duties in their own homes and at the same time performed these functions within white households. They were often separated from their families, received low wages, and were also excluded from protective legislation. Domestic workers often worked long hours, seven-day weeks and many were the sole breadwinner and support of the family. Viewed as marginal to the labor force, domestic servants were situated at the convergence of gender, race, and class inequality. These divisions, according to Jacklyn Cock (1980), facilitated and intensified African women's exploitation.

In manufacturing, African women were concentrated in those sectors related to the 'traditional' concept of 'women's work' under apartheid, as well as from the social construction of gender and patriarchal domination. The 1970s and early 1980s brought a tremendous increase in African women's employment in secondary industries such as food preparation, clothing, textiles, and footwear (Seidman, 1993; Mager, 1989; Lawson, 1986; Bernstein, 1985; Martin and Rogerson, 1984). Border industries, in particular, employed African women and because of their lack of skills, illiteracy, and inability to speak English or Afrikaans, the pay was very low, the working conditions were poor, and the work itself was labor-intensive. Set up on the fringes of 
the bantustans, these factories were part of the planned process to keep Africans out of the 'white' areas while at the same time making the maximum use of the cheapest labor possible (Bernstein, 1985). Until 1981, South African law actually permitted employers to pay women twenty percent less than men in the same job category. While that law was changed, pay scales varied and Black women generally remained in low-paid occupational categories (Lawson, 1986).

Facilitating the expansion of capitalism, the apartheid government offered companies financial assistance, tax remissions, and various exemptions from some of the provisions of the industrial labor laws, such as the minimum wage determinants, to establish businesses in these semi- urban areas. Border industries encouraged the growth of sprawling urban slums, lacking infrastructure and economic viability of their own.

Since the 1960s many Colored, Indian, and some African women moved into various occupations such as teaching, nursing, secretarial work, sales, and banking in addition to university, medical, and law professions. However, most African women, especially in rural areas, have remained in agricultural and low-paid domestic work as migrants or on temporary contracts. According to the Central Statistical Service in their 1995 October Household Survey, 50 percent of employed African females were working in elementary occupations such as cleaning, garbage collection, and agricultural labor. 19 percent of African females were in semiprofessional occupations, such as nursing assistants, only 3 percent occupied professional jobs, and only 2 percent were in managerial positions (Central Statistical Service, 1995: 19 and 20). These statistics reveal that most African women remain in low-paid, low skilled occupations. 


\section{Collective and Informal Economic Activities}

Accordingly, it can be said that capitalist transformation and the increased need for waged labor brought about the decline of family production, the demise of many rural households, and the increased need for women's paid labor throughout the twentieth century. Therefore, because of rural African women's lack of opportunities with respect to sustainable waged labor due to apartheid policies, patriarchal structures, unequal access to various means of production, and the intricate relationship between production and reproduction, informal economic activities became an attractive alternative for many African women.

The informal sector, as articulated above, includes a wide range of activities such as selling fruits and vegetables, taking in washing and sewing, making textile goods, and beerbrewing and prostitution as well as bartering, volunteer work, subsistence production, unpaid labor and labor exchanges, and care-giving. Flexible forms of accumulation, such as cooperatives and networks for marketing, training, and production purposes, can also be included in this discussion.

In the South Africa rural economy, informal activities have provided alternative incomegenerating activities for unemployed women while also enabling them to cope with poverty and local community problems (Oberhauser and Pratt, 2004; Bob, 2001; Lipton et al. 1996).

Through informal activities, many of the contradictions created by capitalism and the market in the bantustans, including the need for waged income and unequal access to essential means of production, could be mediated by sharing domestic and subsistence duties, bartering for food, and engaging in co-operative work or collective saving, for example. Likewise, many of the problems associated with the racist apartheid state such as harsh and demeaning working conditions, lack of education and training, and strict regulations on mobility could be resolved 
within the informal economy. By performing collective work in the community or in someone's home, exchanging skills through social or training networks, and selling or bartering goods on an informal basis to other local people and communities, many households and communities were sustained. Additionally, many of the obstacles associated with women's reproductive duties could be overcome by the adaptable work environments, flexible time and work schedules, and the sharing and exchange of duties that many informal strategies afforded. Lastly, some informal strategies, especially co-operatives, networks, and savings clubs, allowed for the formation of economic, social, and political space for African women to discuss issues and raise awareness around household, community, and even national problems (Oberhauser and Pratt, 2004; Pratt, 1999).

The realities and important, life-sustaining contributions of informal sector activities to women and their families is only beginning to be revealed in the South Africa literature (see for example, Oberhauser and Pratt, 2004 and Francis, 2000). Scholars and development practitioners need to interrogate the gendered aspects of the informal economy in rural South Africa and investigate issues such as: the particular informal activities women engage in; their abilities and reasons for engaging in informal work; access to skills, capital, productive resources, and markets, improvements in income and overall well-being; how household and community dynamics are affected; and how women's informal activities could be better supported through development policies. 


\section{Limpopo: The Case Study Area}

Situated in the northern-most region of South Africa, Limpopo has a history of relative isolation from major urban and industrial centers of the country. Limpopo comprises part of the former Northern Transvaal that includes the former Bantustans of Lebowa, Gazankulu, and Venda. This research focuses on livelihoods in the former Venda bantustan, one of the four bantustans designated as 'independent' by the South Africa apartheid government in the early 1980s (Map 5). Housing a university and parliamentary complex, the regional capital of Thohoyandou was largely controlled and subsidized by the South Africa government (Wilson, 2000). Many local chiefs and traditional authorities worked in collaboration with the apartheid government, giving some black Africans access to land and other resources. Today, local authorities continue to influence community political and economic activities within a system of headmen, local councils, and civic organizations (Hendricks and Ntsebeza, 1999).

The concentration of black Africans in these environmentally and economically marginalized bantustans has had important implications for women's livelihood strategies. Under apartheid, the migrant labor system moved many men to industrial and urban areas to work in the mines and factories (Beinart, 1994). As indicated previously, some Black women also migrated to work as domestic servants or as agricultural laborers on white farms. The gendered nature of labor migration in South Africa left may women to cope with extreme economic and social hardships in rural areas such as the former Venda bantustan (Mager, 1999; Meer, 1997, Levin, 1996; Bozzoli, 1991). This system also established a strong dependence on migrant remittances, which remains one of the main sources of income for rural households today (Levin and Weiner, 1997). Overall, colonial impacts on access to both productive and 
reproductive resources and property rights, in addition to apartheid's territorial segregation, created a situation in Limpopo that makes sustainable livelihoods difficult, especially for women.

\section{Map 5: The Former Venda Bantustan}

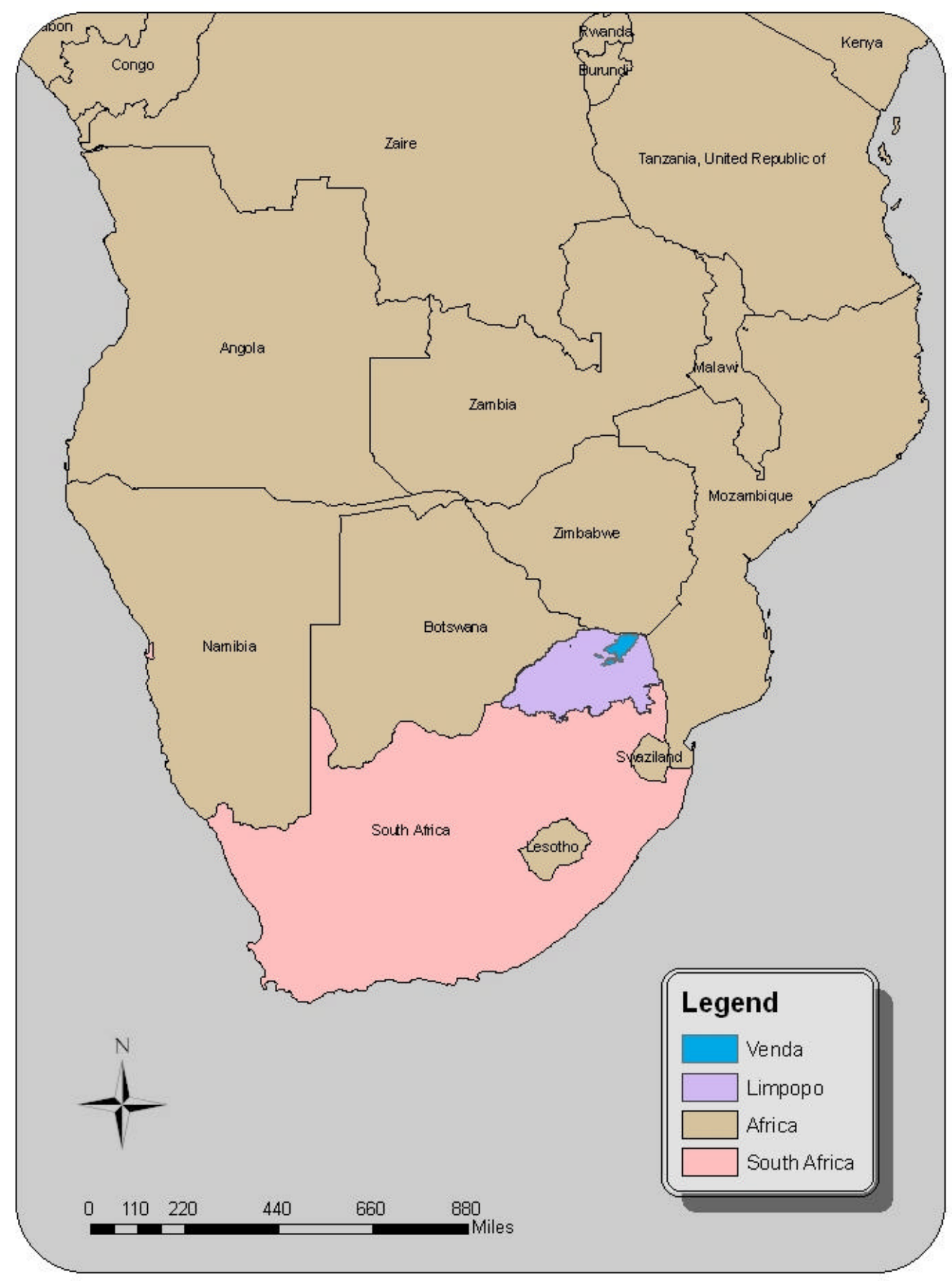


Socioeconomic inequalities in this region are particularly acute with respect to poverty and women's status. Without access to adequate employment opportunities and burdened by the legacy of apartheid, Limpopo is the poorest and most rural province in the country. The province contributes only around 3.7 percent to the national budget and the unemployment rate is 49 percent (Statistics South Africa, 2003; Republic of South Africa, 1999). It is estimated that in 1996, 78 percent of individuals lived in poverty without any permanent source of income (DBSA, 1998). The situation was particularly desperate under apartheid, when two-thirds of the population reported no income whatsoever in 1991 (DBSA, 1993). Women, in particular, suffer from economic marginalization with unemployment rates of 64.9 percent, compared to 35.1 percent among men in 1995 (DBSA, 1998). In addition, nine out of ten unemployed females are located in rural areas of the province. This rate is particularly significant since 89 percent of the approximately 4.9 million people in the province live in rural areas, compared to 46 percent for South Africa as a whole (DBSA, 2000).

The types of livelihood strategies in this region are affected by the gendered nature of poverty and employment described above. A recent provincial study reported that the informal sector is the largest contributor to total economic output while the community and social services sector is the second largest contributor and agriculture the third (LAPC, 1995). Given women's marginalization from formal sector jobs and the dependence of many households on often insufficient and irregular remittances from migrant laborers, informal activities provide one of the only means of income for rural women (Oberhauser and Pratt, 2004; Bob, 2001 and 1997; DBSA, 1998; Kirsten, 1996). In their analysis of how informal, petty-commodity production is related to gender, patriarchy, and social differentiation, Levin et al. state:

The interrelationship between wages and rural livelihoods has reconstructed rural patriarchy while contributing to social differentiation through unequal access to such 
wages. In order to understand this process, it is necessary to distinguish between access to cash through migrant remittances... and access to cash through petty commodity production (1997: 128).

The issue of social differentiation is a significant issue among women in rural areas ${ }^{20}$. African women in Limpopo are not a homogenous category and there are many factors that must be considered when attempting to understand social differentiation and how it impacts livelihood formation. These factors include access to land and other natural resources, marital status, relationship to the cheiftancy, number of dependents, age, and access to formal employment and/or wage labor remittances. Furthermore, a range of factors such as race, class, ethnicity, religious affiliation, location, and historical experiences affect social differentiation. The different contexts and realities of women's lives in Limpopo impact on the position they hold in a particular place and at a particular time. Social differentiation in the South Africa context is thus affected by historical factors, such as legacies of apartheid, traditional institutions, such as the cheiftancy, and household and community gender relations. Analyzing social differentiation among African women is critical to understanding the conditions faced by different groups of women, particularly those who head households, and their abilities to acquire a sustainable livelihood.

The issue of patriarchy in South Africa is an important one that needs critical and careful attention when analyzing women and their livelihood strategies in Limpopo. Racist ideology and traditional practices have set up a unique and extremely powerful form of patriarchy in Black communities. To a large extent, it was only in the home that Black men could assert power. Women were disempowered by the state, within communities, and in their homes and the physical, emotional, and sexual abuses that women faced under these conditions have remained.

\footnotetext{
${ }^{20}$ For a detailed reading on social differentiation among women in South Africa see the work of Urmilla Bob, 2001 and 1997.
} 
This is worse if men are unable to find employment and fulfill, even in a limited way, their allocated patriarchal responsibilities of financially taking care of their family.

Patriarchal and lineage relations often determine how power and authority are deployed in the household and in the community within Limpopo. The intersection of patriarchy and class helps to reinforce differential access to capital, natural resources, and facilities such as education and health care services in rural areas. Patriarchal and lineage relations influence the levels that women participate in political and social activities in community organizations and household decision-making processes and subsequently affect women's social positions in the household and community. According to Bob (2001), the major factors that reinforce patriarchy and lineage relations are the presence of a spouse or partner (women-headed households are relatively poorer than male-headed households), kinship and familial ties (relation to chief or head of household), generation and age, breakdown of traditional extended family, and cultural attitudes about women that are influenced in part by religion and tradition. Thus, patriarchy in the community and household takes on a number of forms and because it is inextricably linked to cultural and religious doctrines, male hegemony is regarded as normal and rarely contested. Summing up the marginalization that Black women in rural South Africa have suffered under apartheid, capitalist development, and patriarchy, Linda Kompe (1992) states that "rural women face oppression from four sides -because they are black, because they are women, because they are poor, and because they live in rural areas" (Land Update, 18: 6).

Research has clearly shown that women's presence in decision-making structures such as local land, agricultural, and water committees and district councils and civic organizations in rural South Africa is limited (Bob, 2001 and 1999; Department of Land Affairs, 1998). This is 
an important concern since women lack the power to make decisions concerning access to resources and ultimately, more diverse and productive livelihood options.

Demographic characteristics of Limpopo also play a role in the gendered nature of livelihood strategies. The migrant labor system has contributed to an uneven distribution of population whereby the percent of females is greater in every age category above 15 years old and females make up 55 percent of the total adult population (Statistics South Africa, 2003). Other research has suggested that almost 67 percent of households in the former bantustan areas are headed by women (Bob, 2001; Marcus, et al. 1996; May et al. 1995; Pickles and Weiner, 1991). Given these figures, women have by necessity been heavily involved in constructing their own livelihood strategies and continue to be the backbone of rural households. As stated by Morema (2000: 173), women in Limpopo "maintain households, sustain agricultural production and are responsible for the day to day running of the rural communities."

In addition to migration, the demographic profile of this province and the livelihoods of rural households are significantly impacted by the prevalence of HIV/AIDS. Studies have indicated that rates of HIV/AIDS infection are highest in poor rural communities, such as the case study area, with a history of migrant labor (UNDP, 2000). In regions with a high incidence of HIV/AIDS and inadequate health services, women end up caring for extended family and supporting additional household members (DBSA, 2000). The impact of HIV/AIDS and its assault on the most productive portion of the population in South Africa must be considered in any analysis of rural livelihoods in the country. 


\section{Democratization and Gender Policy in a 'New' South Africa}

Remember all our women in the jails

Remember all our women in campaigns

Remember all our women over many fighting years

Remember all our women for their triumphs, and for their tears.

From the Women's Day Song, South Africa, quoted in H. Bernstein, 1985.

Gender concerns were included in nationalist debates during the democratization period in South Africa. In his inauguration speech in 1994, Nelson Mandela stated that a 'new' South Africa would be both a "non-racist and non-sexist" democracy. The guiding principle for gender ideology in South Africa is enshrined in Clause Nine of South Africa's Bill of Rights stating that, "Everyone is equal before the law. Neither the state nor any private person or juristic person may unfairly discriminate directly or indirectly against anyone on one or more grounds including race, gender, sex, pregnancy, marital status, ethnic or social origin, color, sexual orientation, age, disability, religion, conscious, belief, culture, language, and birth" (Commission on Gender Equality, 1999). In probably the most progressive constitution ${ }^{21}$ in the world today, South Africa makes provision for affirmative action to protect or advance persons who have been disadvantaged and includes clauses that guarantee freedom and security with respect to one's body and mind, and equality with respect to culture and religion. In addition, the democratic South African state is required to "progressively realize" a number of socioeconomic rights, all of which are fundamental to gender equality and ensuring a sustainable livelihood for all of South Africa's citizens. These include housing, health care (including reproductive care), food, water, social security education, and children's rights.

\footnotetext{
${ }^{21}$ South Africa's first democratically designed constitution was adopted in 1996.
} 
Going beyond constitutional mandate and law, gender ideology, constitutional rights, and an understanding and commitment to equality for women has been further institutionalized within some key policies and programs developed and adopted by the South African government and its citizens. These include the Women's National Coalition (WNC) and the Women's Charter, the Beijing Declaration and Platform for Action, and the Commission for Gender Equality (CGE).

The WNC was formed in 1994 and conducted a nation-wide participatory research project that surveyed women's needs across the racial and political divide of South Africa. The priorities expressed were for land, water, electricity and telephones, as well as the abolition of polygamy and the resolution of many other issues emanating from customary law (Women's National Coalition, 1994). In turn, this project played a key role in bringing about the constitutional provisions for gender equality articulated above and to the consequent development of the Women's Charter.

The Women's Charter for Effective Equality states that the "principle of equality underlies all our claims in the charter and recognizes that the achievement of social, economic, political, and legal equality is indivisible" (Commission on Gender Equality, 1999). This charter understands that women suffer disadvantages in all spheres of life and realizes that similar treatment of women and men may not result in true equality. It is stated that the promotion of gender equality will sometimes require distinctions but confirms that no distinction should be made that disadvantages women.

In addition to the WNC and Women's Charter, soon after the Fourth World Conference on Women in Beijing the South African government ratified this United Nations Convention, seeking the end of discrimination against women. The outcome of the Beijing Conference was 
the development of a Platform for Action that addresses twelve critical areas affecting gender equality and empowerment. The Platform aims at removing all obstacles to women's participation in all spheres of public and private life through a full and equal share in economic, social, cultural, and political decision-making. Consequently, many South African ministries committed themselves to implement various actions laid out in this Platform. For example, the Ministry of Land Affairs pledged to take legislative and administrative measures to give women and men equal rights to economic resources such as access to ownership and control over land and other properties, credit facilities, natural resources, and appropriate supporting technology (Department of Land Affairs, 1999).

Finally, the CGE is one of six institutions established for the promotion of democracy under Chapter Nine of the Constitution. The Commission is an independent statutory body tasked with promoting "respect for gender equality as well as the protection, development, and attainment of gender equality" (Commission for Gender Equality, 1999). By exposing gender discrimination in laws, policies, and practices, advocating changes in sexist attitudes and gender stereotypes, and instilling respect for women's rights as human rights, it seeks a transformation of society. The CGE targets those living on the periphery, especially African women in rural and peri-urban areas and in domestic and agricultural employment and informal settlements. Additionally, it embraces issues concerning education, law and justice, safety and security, and economic and political empowerment.

As is quite evident, the South African government committed itself to gender needs and concerns in the early years of the new state. This can be seen in the Constitution as well as the various policies and mechanisms highlighted above. Through the establishment of "gender machinery" the South African government sought to ensure that the constitutional provisions 
were translated into action (Commission on Gender Equality, 1999). By being a state party in several regional and international frameworks, such as the Beijing Convention Platform, it committed itself to the implementation of activities articulated by these instruments. It also agreed to report and be monitored on its progress and achievements towards gender issues and equality. Additionally, the South Africa government realized the importance of forming partnerships and alliances with civil society, such as non-governmental organizations, women's organizations, the private sector, and academic institutions (Commission on Gender Equality, 1999).

By mid-2000, however, the CGE was in disarray and South Africa's feminist project was in crisis. The institution standing at the peak of the new democracy's efforts to give women equal citizenship was unclear about its goals, immobilized by internal dissent and disillusion, and unable to even coordinate activities to commemorate South African Women's Day in August, 2000. The organization was plagued with issues concerning institutional design, political pressures, tensions around racial identity, cultural traditions, and political perspectives, and how to deal with both strategic and practical gender concerns (Seidman, 2003).

With respect to institutional design issues the Commission was divided on how they could deal with representing women's voices within state policy-making discussions and the importance of mobilizing wider support, both within civil society and the ge neral population, for feminist concerns. These concerns created tensions within the Commission itself and between feminist professionals and grass-roots groups. Questions concerning identity and social differentiation also plagued the Commission due to the vast differences of class, race, and urban/rural location among South African women and the diverse challenges these differences create. Lastly, the Commission was also divided on how to deal with both strategic and practical 
gender concerns. Clearly, there was a need in the country for what Joyce Piliso-Seroke, appointed chairperson of the Commission in 1999, called "strategic" feminist interventions that would challenge gender hierarchies and power relations and work to transform gender relations in the country (Seidman, 2003). However, women had practical, everyday life needs as well around poverty alleviation, housing, access to land, water, and other resources, and employment, education, and training issues, for example. The Commission continually tried to balance the need for service provision and strategic intervention.

By mid 2001, the South Africa Gender Commission began to move out of its stalemate through the appointment of new commission staff combined with renewed efforts by nongovernmental feminist activists to re-engage with the Commission (Seidman, 2003). Several strong feminist activists were appointed to the Commission, giving it greater credibility within activist feminist circles and helping rebuild its links to already mobilized feminists in South Africa. At the same time, the Commission seemed to be taking stronger stances on some of the more controversial issues, including challenging the government's policy in key issues such as the HIV/AIDS epidemic. Feminist interventions are controversial. They challenge basic social patterns of gender relations, inequality, and power. In the absence of broad support for feminist goals therefore, it is necessary for feminist policy makers to strengthen support both from within and outside the state for feminist ideals across local, national, and international scales.

In conclusion, this research embraces the ideals articulated by the organizations, policies, and programs highlighted above. It also realizes the need in the country to translate these principles to women in their everyday lives so that their situations may be improved. According to Weiner, Levin, and Chimere-Dan (1997), there is considerable confusion about rural people today. Broad generalities about the socioeconomic status of rural black people dominate post- 
apartheid policy statements and practices and the tendency to homogenize rural people and their economic activities, for example, ignores the most oppressed and exploited rural groups, including women. Through its examination of women's livelihood strategies, this project seeks to provide knowledge gathered at the local level concerning the socioeconomic situation in South Africa for women heading households. As frameworks for feminist analysis and practice, socialist feminism and feminist topographies have much to contribute to gender policy and the empowerment of women. Recognizing the historical and contextual oppression and marginalization of African women, these frameworks identify unequal power relations that operate within the family and community to the highest social, political, and economic levels. They reveal the power relations in societies and the gender, race, and class ideologies that sustain them. Finally, and most importantly, these conceptual frameworks identify women themselves as active agents of change in socioeconomic transformation.

\section{Summary}

With the transition to democracy in the mid-1990s, the South African government and local authorities have implemented measures to improve many of the socioeconomic conditions described above. Although economic policies of the post-apartheid government tend to target macro-level economic development, provincial and community initiatives are increasing in areas such as Limpopo. Local chiefs and civic organizations are playing a significant role in stimulating the rural economies of their areas through partnerships with extension agents and the provincial government to establish community economic groups, build infrastructure, and attract business (Oberhauser and Pratt, 2004; DBSA, 2000). 
In sum, the material inequalities and everyday social practices of women in rural South Africa are embedded in the political economy of gender, as well as power relations that reflect differences in class, race, and place. The challenges that stem from a history of apartheid and migrant labor combined with extreme socioeconomic inequalities, deeply rooted patriarchal structures, and the prevalence of HIV/AIDS underscore the growing importance of investigating women who head households in rural areas and their livelihood strategies. The emphasis on democratization and gender equity in post-apartheid South Africa presents opportunities for rural black women to expand their livelihood options to better support households. Studies such as this provide a window into what women are actually doing to sustain households as well as encourage the development of innovative policies and programs designed to improve existing livelihood strategies and develop new ones. 


\section{Gender and Livelihood Strategies in Appalachia}

\section{Introduction}

In Appalachia, rural women weave together a variety of both formal and informal economic resources to support households. Labor exploitation and rural isolation have contributed to the economic marginalization of many Appalachian women and rural households (Oberhauser and Turnage, 1999; Oberhauser, 1995a and b and 1993; Green, 1990), as parts of the region have been historically dependent on extractive industries and other related economic sectors. Similar to South Africa, employment in the formal sector has also been historically divided along gender lines (with some important exceptions), with men working in the mines, mills, and factories, and women largely involved in related service sector employment, household reproductive labor, and informal activities (Greene, 1990; Pudup, 1990a and b). More recent employment associated with economic restructuring and the recession of the 1980s has, however, brought about layoffs and shutdowns in manufacturing, coal mining, and related industries. These economic shifts have produced high unemployment rates and a rising service sector, which is largely low-wage, part-time, and female-dominated. The diverse nature of women's economic activities is embedded in local contexts, but also connected to broader processes of regional and global economic change.

In conjunction with Chapter III, this chapter begins the construction of the topography on the livelihoods of women who head households in West Virginia in Appalachia by providing detailed historical and contemporary socioeconomic data on the region. In order to understand the socioeconomic history of women in rural Appalachia and the various factors that have affected their livelihood strategies, this chapter begins by discussing its labor and industrial history. Secondly, the 'making' of Appalachia as a 'region' is discussed as well as the 
contemporary issue of economic restructuring. Third, women's participation in wage labor and the informal economy are highlighted. Fourth, this chapter presents socioeconomic and demographic data on West Virginia, the particular case study area. To summarize the two case study chapters, this chapter concludes by emphasizing the importance of utilizing a feminist geographical framework that can analyze women's everyday material realities and their connections to structural and ideological forces that occur across place and scale.

From Agriculture to Industry: early economic development in the Appalachian region

\section{Dark as a Dungeon}

Come and listen you fellows, so young and so fine, And seek not your fortune in the dark, dreary mines. It will form as a habit and seep in your soul, 'Till the stream of your blood is as black as the coal.

It's dark as a dungeon and damp as the dew, Where the danger is double and pleasures are few, Where the rain never falls and the sun never shines It's dark as a dungeon way down in the mine.

It's a-many a man I have seen in my day, Who lived just to labor his whole life away. Like a fiend with his dope and a drunkard his wine, A man will have lust for the lure of the mines.

It's dark as a dungeon and damp as the dew, Where the danger is double and pleasures are few, Where the rain never falls and the sun never shines It's dark as a dungeon way down in the mine.

The midnight, the morning, or the middle of day, Is the same to the miner who labors away. Where the demons of death often come by surprise, One fall of the slate and you're buried alive. 
It's dark as a dungeon and damp as the dew,

Where the danger is double and pleasures are few,

Where the rain never falls and the sun never shines

It's dark as a dungeon way down in the mine.

I hope when I'm gone and the ages shall roll,

My body will blacken and turn into coal.

Then I'll look from the door of my heavenly home, And pity the miner a-diggin' my bones.

Originally recorded by Merle Travis, August 8, 1946, Hollywood California, Capitol Records

Recently recorded by Vince Gill with the Chieftains on Down the Old Plank Road: The Nashville Sessions, 2002, RCA Records

In Appalachia, as in the rest of the country, the early 1900s were years of profound social, economic, and environmental transformation. Vast tracts of land were purchased for industrial development throughout the region, initiating a process of social and spatial marginalization upon the local population. Traditional ways-of-life in the region were gradually, yet significantly being usurped as agrarian relations of production were heavily impacted by the penetration of industrial capital.

The coming of railroads, the building of towns, and the general expansion of industrial employment sent mountain agriculture into serious decline. While the size of the average mountain farm was about 187 acres in the 1880s, by 1930 the average Appalachian farm contained only 76 acres, and in some counties the average was as low as 47 acres (Eller, 1982; US Department of the Interior, Census Office, 1880 and 1930). This decline occurred throughout the region but was most pronounced in the coal fields and other areas of intense economic growth. Land was being 'bought up' throughout the region by timber and mining companies and the Appalachian region's ways of 'makin' due' that relied on the land and the family as an independent, productive unit were transformed. 
Farm production and income drastically changed during this time. While farm production had been the major, and usually the sole, source of income in 1880, by 1930 most mountain farms had become part-time units of production and the major source of income had shifted to non-agricultural employment in mining, logging, textiles, and other forms of public work (Eller, 1982; US Department of Agriculture, 1935). It was largely men who were sent into the mines, mills, and factories and women were left to subsistence activities on the family farm or associated reproductive work such as taking in laundry or sewing, housekeeping, and child care.

Along with the decline of agriculture came changes in the demographics of the region as well. Whereas mountain society in the 1880 s had been characterized by a diffuse pattern of open country agricultural settlements located primarily in the fertile valleys and plateaus, by the turn of the century the population had begun to shift into non-agricultural areas and to concentrate around centers of industrial growth (Eller, 1982). Between 1900 and 1930, the urban population of the region increased fourfold and the rural non-farm population almost twofold (Gray, 1933). It is important to point out that many of the new industrial centers were company towns of the mining and mill industries. In fact, over six hundred company towns were constructed in the southern mountains during this period, and in the coal fields they outnumbered independent incorporated towns more than five to one (Eller, 1982; US Congress, 1925).

This rising urban population provided a base for the emergence of a more modern political system in the mountains, one increasingly dominated by corporate interests and business-minded politicians. Where the traditional political order had relied largely on kinship, personal contacts, and a broad-based party structure, after the turn of the century the level of citizenship participation declined and the average farmer or laborer became isolated from the 
political process. As early as the 1890s, industrialists such as Stephen B. Elkins in West Virginia had begun to gain control of the political organizations in the mountains and to turn the powers of state and local governments toward the expansion of commerce and exploitation of the region's resources (Williams, 1972). As a result, there emerged in Appalachia a constricted political system based upon an economic hierarchy. This hierarchy allowed those in power to exploit the region's natural wealth for their own personal gain. It was a male-dominated, classed system dominated by wealthy politicians, industrialists, and mineral and timber businessmen. The loss of local political control distressed many mountain people, plunging the region into prolonged industrial violence and social strife (Eller, 1982; McKinney, 1977).

Behind this transition in political culture lay the integration of the region into the national economy and the subordination of local interests to those of outside corporations. Nowhere was this process more evident than in the concentration of large amounts of mountain land in the hands of absentee owners. Beginning in the 1870s, northern speculators and outside businessmen carved out huge domains in the rich timberlands and mineral regions of Appalachia. By 1910, outlanders controlled not only the best stands of hardwood timber and the thickest seams of coal but a large percentage of the surface land in the region as well. The situation was particularly worse in the coal fields and according to the West Virginia State Board of Agriculture in 1900, outside capitalists owned 90 percent of the coal in Mingo County, 90 percent of the coal in Wayne County, and 60 percent of the coal in Boone and McDowell counties (Map 6). In 1974, absentee corporations still controlled more than half of the total land area in the nine southernmost counties of West Virginia and in 1994 approximately half of the land in Pendleton and Randolph Counties in the state was controlled by outside corporations and 
federal and state agencies (Rasmussen, 1994). The Appalachian Land Ownership Task Study quotes one Randolph County resident as saying:

West Virginia is thoroughly used to being exploited by outsiders whether they come from Philadelphia or Japan, that's immaterial...We are in sad need of land reform. We have haciendas, we just don't call them that. (1980: 271).

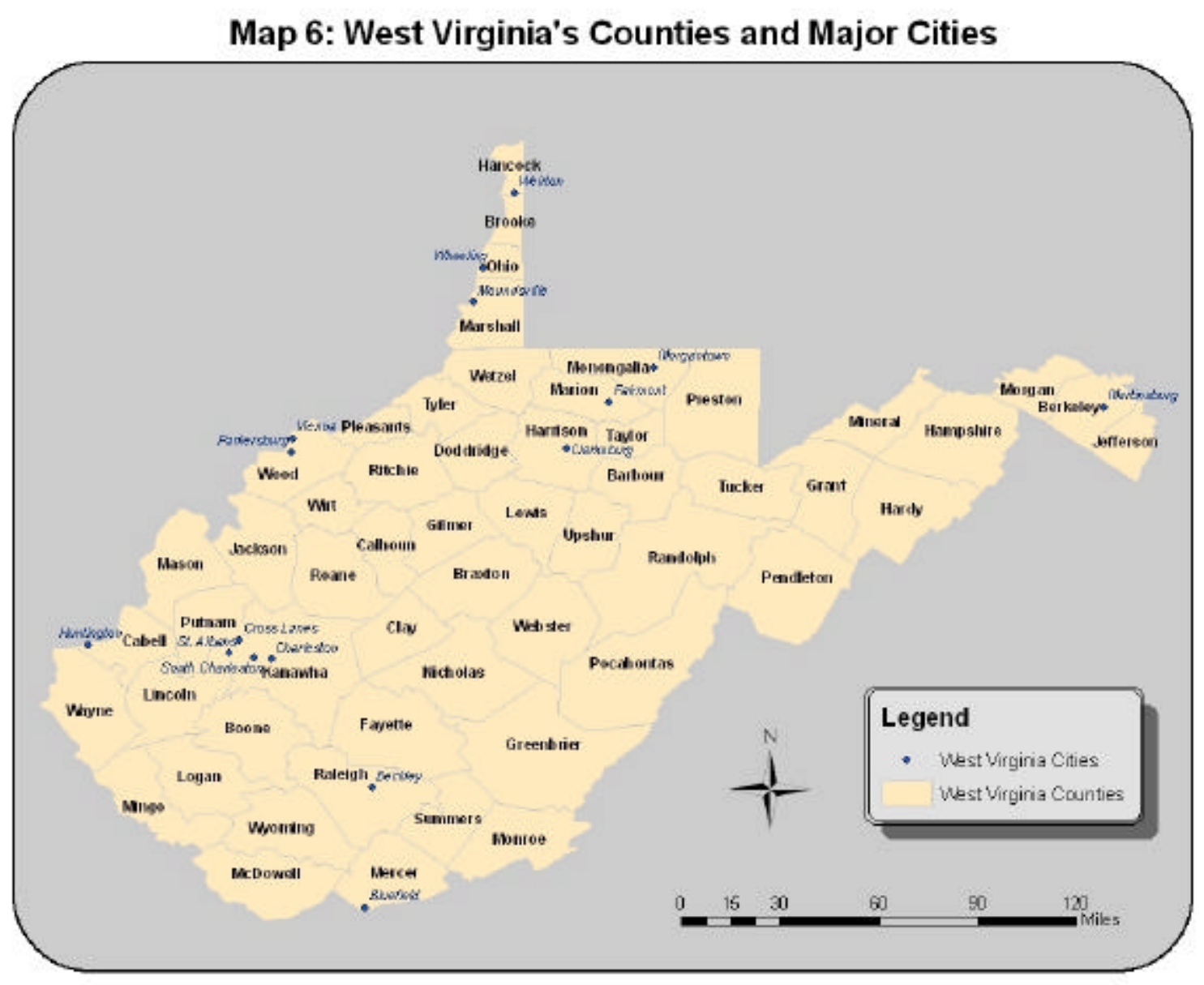

Such an uneven distribution of land ownership has prevented the diversification of local economies and decreased the tax base by shifting the tax burden to local residents. The federal government, which owns a large part of the land in counties such as Randolph and Pendleton in the Mountain State today, pays no taxes on that land. Absentee ownership has prevented reinvestment into local communities and access to natural resources resulting in the socioeconomic and spatial marginalization of many Appalachian communities. 
The early and immediate effect of absentee ownership was to dislodge a large part of the region's people from their ancestral homes. A few former landowners managed to remain on the land as sharecroppers or tenant farmers, but a great number of the displaced mountaineers migrated to the mill villages and mining towns where they joined the ever-growing ranks of the new industrial working class. Uprooted from their traditional way of life, some individuals were unable to reestablish permanent community ties, and they became wanderers drifting from mill to mill, company house to company house, in search of higher pay or better living conditions.

Many mountaineers found themselves unable to escape their condition of powerlessness and dependency. By coming to a coal mining town, for example, the miner had exchanged the independence and self-sufficiency of the family farm for subordination to the coal company and dependence on a wage income. He lived in the company house, he worked in the company mine, and he purchased his groceries and other commodities from the company store. He sent his children to the company school and patronized the company doctor and company church. The company deducted rent and school, medical, and other fees from his monthly wage and under the 'scrip' system, he occasionally ended the month without cash income. He had no voice in community affairs or working conditions and he was dependent upon the benevolence of the employer to maintain his rate of pay. ${ }^{22}$

Work in the mills and mines was difficult and dangerous. In the early years of mining, for example, almost all of the work was done by hand. The average pick miner could earn about two dollars a day at the turn of the century and was paid not by the hour, but by the tonnage of coal that he mined per day ${ }^{23}$ (Eller, 1982). There was always the threat of roof falls, fire and

\footnotetext{
${ }^{22}$ See Eller (1982) for a detailed discussion of life in the company towns.

${ }^{23}$ A pick miner in West Virginia was paid an average of 38.5 cents per ton in 1912 for run-of-the-mine coal, while the statewide average was 48 cents. In the coal fields of Ohio, Indiana, Illinois, and Pennsylvania, miners' wages
} 
explosions, and haulage accidents and the miner was not paid for setting the timber safety props that supported the ceiling of the mine or for the loading of his coal. Work areas were extremely cramped and wet and the miner was exposed to methane gas and coal dust. Miners vented their discontent in almost unceasing efforts to unionize the mountain coal fields as evidenced by the bloody mine wars that rocked every decade from 1893 to 1933 . Although wages and working conditions were important factors in these strikes and organizing efforts, the elimination of mine guards, overpricing at the company store, assembly and visitation restrictions, and other issues of civil liberty related to living in the company towns were almost always major areas of concern.

Conditions in the company towns, as in the mines, varied from community to community. After 1900, coal operators increasingly required their employees to live in the company towns and since the coal and land companies owned much of the land around the mines, this became the living situation for many miners and their families. The company towns were directly related to coal production but were also used to maintain profits, enforce company discipline, and control the miners when they were off-the-job. Housing was generally poor and small with no running water or sanitary equipment. The houses were usually located on the lower slopes and valley floor between two high ridges, making town development very confined and congested. Dwellings nearest to the coal tipple received a daily shower of coal dust and because there were few surfaced roads a layer of mud, black from the run-off waste of the mine, covered the ground during much of the year. The absence of sanitary facilities and the refuse from mining operations polluted land and water resources, causing serious health problems among the miners and their families as well as disrupting supplemental food sources, such as wildlife for hunting

ranged from 57 cents to $\$ 1.27$ per ton. Rates in the southern coal fields were also based on "long tons" of 2,240 pounds but those in the northern coal fields were based on "short tons" of 2,000 pounds, making the wage differential even greater (Cubby, 1962). 
around the mining areas. There was little productive land to plant a garden or maintain even a few chickens.

In addition, the power of the mine operator was pervasive, extending to all facets of town affairs. If a miner was selling home-brewed wine or a woman was cheating on her husband he would "learn of it," give them a warning or send them out of town. He divided the community into an "immigrant town," a "colored town," and an "American town" and enforced social barriers between the groups (Eller, 1982). He regulated access to the town and restricted movement within it, inspected the miners' homes, and evicted "undesirable" residents or visitors and those "makin' trouble". It was a closed community and the operator ruled without opposition or debate.

As indicated previously, miners patronized the company store for everything from food to home furnishings, all of which could be purchased on credit or with company 'scrip' money. Churches and schools were also controlled by the coal companies. The coal company usually provided the school building and supplies and contacted the teacher and then deducted an “education fee" from the miner's monthly wages (Eller, 1982; Wolfe and Collins, 1916). The construction of churches followed the same pattern, with companies matching funds raised by the miners for the purpose of building a church but retaining ownership of the property to ensure its proper use. ${ }^{24}$ Some coal operators did provide amenities such as movie theaters, bowling alleys, and gymnasiums, which were available to the miners and their families for a small fee. Unfortunately, these social amenities were only available to a very small fraction of the mining population and there was little opportunity for a sense of community to develop in the company towns.

\footnotetext{
${ }^{24}$ Coal company schools were only nominally controlled by country school systems where they existed. Also, many mining towns did have independent churches, despite the threat of company control.
} 
Company towns were also affected by social disorder such as theft, drinking, gambling, and prostitution. Coal producers simply laid the blame for lawlessness and poor living conditions on the "class" of miners employed in the field — the immigrant from Italy, Hungary, and Poland; the black from the central and deep South, and the native mountaineer, fresh from the backwoods farm (Eller, 1982).

Industrialization introduced rigid class, as well as racial, ethnic and gender, distinctions into the mountian culture. Traditional status distinctions had always existed but there were few economic differences within the rural population. Status distinctions in remote mountain communities where economic differences were minimal were based on personality characteristics or such traits as sex, age, and family group. ${ }^{25}$ Measures of social prestige were based on the value systems of local communities and the rural social order was divided into 'respectable' and 'nonrespectable' groups (Eller, 1982). The lack of overt class consciousness was reflected in the presence of strong egalitarian attitudes and beliefs. "The mountain farm family," wrote one observer "recognizes no social classes either in the community or out...each family feels itself as good as the best people in the state" (Miller, 1935). Hence, the mountain expression "I'm as good as you are."

With the coming of the industrial age, however, the separation between employer and employee and the emerging professional, middle class became all too apparent. In the coal company town, the miners lived in small dwellings in the hollow near the tipple, while mine

\footnotetext{
${ }^{25}$ It is important to note here that class distinctions did exist before industrialization took a firm hold on mountain life. More visible in communities in the larger valleys and county seat towns, wealthier, landed families had both economic and political power in the region. Many of these families had acquired large land holdings through Revolutionary War grants. They often controlled local, comme rcial enterprises and were involved in both state and local politics. Thus, their political influence, access to resources, and contacts with the outside mountain elites placed them in strategic positions to benefit from economic change. As intermediaries between local culture and outside business interests, they came to play an important role in industrialization in the mountains by purchasing land and mineral rights from local people for resale to outsiders, advertising and promoting the development of mountain resources, and encouraging the construction of roads and railroads (Eller, 1982).
} 
operators and superintendents often built palatial structures high on the hillside overlooking the town (Eller, 1982; Gillenwater, 1972). In some communities, the railroad track literally divided the town in two, separating the more substantial residences of the managing class from the miners' shacks. Hence, the expression from the mountains for those who are socially and economically undesirable, "he/she is from the wrong side of the tracks" (Eller, 1982).

On the farm, the mountaineer had been master of his own fate, the social equal of any man in his community. In coming to the mining camp or mill town, he had exchanged that independence for subordination to the coal or timber company and dependence on a cash income. The mountaineer no longed owned land or a home and was always subject to eviction. The company controlled or owned the land and furnished the houses, stores, churches, and schools, especially in the mining towns. There were no public agencies to provide for social welfare, and residents had little voice in the management of public affairs.

There was a small middle class that developed in the region that was largely made up of lawyers, bankers, doctors, large landowners, and public officials. Assuming a fairly conservative position on economic and social issues in the region, they favored development that would bring greater returns from natural resources or enhance their own power and gave only limited support to human social and economic concerns (Eller, 1982). Unlike the miners and mill workers who were constantly moving from place to place looking for a better life, this mountain middle class retained a degree of stability that allowed for the crystallization of their power in local communities. The social gap between the classes thus increased with industrialization as company managers and professional personnel developed lifestyles and formal institutions different from those of the working class. 
With regard to ethnic and racial distinctions, thousands of blacks and European immigrants were brought to the region to supplement the local labor supply or serve as strikebreakers in times of labor strife. Attracted by glowing descriptions of comfortable housing and steady work at good wages, this influx of Italians, Poles, Hungarians, and Slavs as well as southern blacks, drastically changed the ethnic and racial composition of the mountains.

Blacks had worked in the mines of southern Appalachia from the opening of the first collieries in the 1850s. However, the black population was never very large in the mountains until coal operators began to recruit extensively in the southern states. By 1920, 43 percent of the black miners employed in the United States worked in the southern coal fields of West Virginia (Eller, 1982; Spero and Harris, 1931). McDowell County, for instance, had the largest concentration of blacks in the Appalachian coal fields. At the height of the coal boom, over 45 percent of the miners in McDowell County were black and one of the major towns of the county, Keystone, was predominately black (Eller, 1982; Thurmond, 1964).

Blacks were recruited for work in the mountains by labor agents hired by railroads, a coal company, or group of companies. Once the new recruits reached the mining towns, they were segregated into "Colored Towns" that consisted of the least desirable houses in the camp and segregated schools, churches, and recreational facilities. They were often restricted to the ranks of pick miners and loaders of coal and had few opportunities for upward mobility on the job. Blacks in West Virginia, however, could vote and black lawyers and doctors wielded a degree of political influence in these communities.

Social relationships with white miners were often ambiguous. Incidents of racial violence were not uncommon and the fact that black miners were often brought to the region as strikebreakers did not ease the tensions. The coal operators chose to recruit black miners as a 
means of creating a "judicious mixture" of whites, blacks, and immigrants, in order to forestall unionization by segregating the men and playing one group off another (Eller, 1982; Bailey, 1973; Thomas, 1971). Nevertheless, a relatively high degree of harmony existed between the races at a personal level. Working side by side in the mines, the men came to depend on each other for their own safety and the lack of major differences in housing, pay, and living conditions mitigated caste feelings and gave rise to a common consciousness of class. Many of the white mountaineers had never developed a deep prejudice against blacks and had often extended them a measure of social equality. White and black miners freely visited each other's homes, churches, and physicians and the races mixed openly at rallies, recreational events, and union meetings (Minard, 1952; Laing, 1936; Semple, 1910). In fact, a higher level of racial and ethnic mistrust existed between blacks and immigrants whose cultural backgrounds were more clearly diverse.

Immigrants composed the final third of the ethnic mix in the region during industrialization, especially in the coal fields. Their presence was most noticeable in the newer coal districts of eastern Kentucky, the Logan and Winding Gulf fields of southern West Virginia, and the Clinchfield area of southwest Virginia (Eller, 1982). Many coal operators preferred immigrant labor to native white or black workers because, they believed, the immigrants would work harder and were more easily controlled (Lantz, 1964). The mine owners of southern West Virginia claimed that their immigrant miners worked from five to ten hours per week longer and produced a higher daily tonnage of coal than any of their American miners (Thomas, 1971). Between 1900 and 1915, the mines of the southern mountains eagerly accepted all of the immigrant laborers they could obtain and some larger companies predominately employed foreign-born miners. Almost two-thirds of the work force at the U.S. Coal and Oil Company's 
mines in southern West Virginia, for example, were recent immigrants (Eller, 1982; Watson, 1963).

The methods of recruiting immigrant labor were similar to those used to lure southern blacks. During periods of labor scarcity or strife, coal companies hired age nts to go to Europe and eastern cities in the United States to attract potential miners. Once the new miners reached the coal fields, however, they lived under the constant presence of armed guards until they had "worked out" the cost of their transportation. In some instances, companies who were hard pressed for labor used extreme levels of intimidation and force to keep the men in the mines.

The largest ethnic group to immigrate to the mountains was the Italians, although large numbers of Poles, Hungarians, and Slavs arrived as well. The high point of Italian immigration was the decade from 1900-1910 when over two million Italians arrived in the United States (Eller, 1985; Wolfe, 1975). These immigrants also worked on railroad construction, in the timber industry, and eventually, northern Appalachian industries such as steel and manufacturing.

In terms of gender relations, pre-industrial mountain society was most certainly patriarchal. Adult white males held the greatest power, privilege, and freedom within the social order. Men controlled the political system, held most of the property, and made most of the financial decisions in family matters. They were responsible for the heavy work around the farm and were the principal traders and negotiators with the outside world. In times of special need, women might assist in activities supposedly allotted to men but men were expected almost never to do women's work.

Women's roles were more clearly confined to the home. They seldom traveled and in addition to the daily activities of cooking, cleaning, spinning, weaving material for clothes, 
knitting, and making quilts and blankets, the mountain woman fed and milked the cows, slopped the hogs, fed the chickens, hoed the garden, carried water from the spring, washed clothes, gathered and chopped wood, and tended to the children ${ }^{26}$ (Eller, 1985; Semple, 1910). Though this life was hard, the woman in pre-industrial Appalachia was the most important figure in the basic social unit, the family. Her role within the domestic realm granted her significant authority over the household, respect in the community, and a strong sense of identity and personal gratification. The men were often away for weeks at a time working, trading, or hunting and the women were left to run the family farm. Social gatherings such as church, dances, quilting bees, cabin and barn raisings, and corn shuckings provided numerous opportunities for social interaction and helped to develop a strong sense of community and interdependence among women.

The move of families into the mine and mill towns of industrial Appalachia profoundly disrupted mountain society in terms of gender roles and relations (Eller, 1982). The noise, congestion, and filth of the industrial communities was in striking contrast to the environment of the mountain farm and the sultry, thin-walled company houses were hardly an improvement over many mountain cabins. On the farm women had made the cabin bright with coverlets, patchwork quilts, and dried fruits and vegetables. Grass and wildflowers grew in the doorways, trees provided shade, and a garden plot provided fresh vegetables. In the company towns, the house was often dull and lifeless, surrounded by dust and dirt. Women gave up their handicrafts as the family purchased garments and other goods from the company store or mail-order

\footnotetext{
${ }^{26}$ In her younger years, it was not uncommon for a woman in the mountains to bear a child a year and be responsible for the health and discipline of ten to fifteen children.
} 
catalogues, there was little land for garden plots and raising livestock ${ }^{27}$, and because of the transient nature of company towns, few strong community and kin ties (Armstrong, 1935; Thomas, 1926). Health and social problems were magnified in the company towns with epidemics of smallpox, typhoid fever, and intestinal diseases. Children suffered from pellagra and other dietary deficiencies (Eller, 1982; Thomas, 1971; Department of Labor Children's Bureau, 1923). Mining and timber accidents were also common and upon a miner's death, for example, a women and her family were immediately evicted from company housing. It was not uncommon for women to lose not only husbands, but also fathers and sons, in a mining explosion or roof collapse. Alterations in family roles and the decline of communal or family work activities often increased personal and family tensions and contributed to the rise of divorce, delinquency, and child desertion (Eller, 1982; Cressey, 1949; Armstrong, 1935).

Patriarchy was reconstituted with industrialization and the rising dependence of women on a male wage earner in mountain society. Women were further confined to the domestic sphere and reproductive labor but lacked the basic means of production and reproduction they had previously relied upon. Some women did enter the formal economy as wage earners themselves, particularly in the southern textile industries, but their opportunities were limited. Approximately 80 percent of the workers in most mills during the late 1800 s were women and children who worked from 65-72 hours a week (Eller, 1982; Manufacturer's Record, 1897). As will become evident below, others engaged in the informal economy through agricultural work, bartering, and labor exchanges.

\footnotetext{
${ }^{27}$ Although there was little land, women and children did raise garden crops and animals for their own use in the company towns (Lewis, 1993 and 1989; Green, 1990; Trotter, 1990). The agricultural landscape of the mountains persisted, despite its transformation.
} 
The boom cycle of coal and timber was to come to an end in the mountains. As early as 1916, the Appalachian timber industry began to waver and move to the virgin wilderness of Oregon and Washington states. In addition, cotton mills closed and the minerals industry collapsed in the 1920s due to the loss of foreign markets, intense competition, and the Great Depression. Miners, millhands, and loggers and those employed in associated service and transportation industries found themselves without work, land, and a place to live. ${ }^{28}$ Entire communities disappeared and many migrated out of the region to industrial centers.

The federal relief programs passed by the New Deal congresses did bring some relief to those left in the region during the 1930s. The National Industrial Recovery Act restored earnings for many coal diggers ${ }^{29}$, but unemployment remained high. Conservation programs, price supports, and crop subsidies established by the Agricultural Adjustment Act, the Tennessee Valley Authority (TVA), and other agencies improved the conditions on many mountain farms. It is true, although, that by 1936 over 47 percent of all mountain families were on federal relief rolls (Eller, 1982; Gray, 1936). Government intervention further complicated the desperate conditions in the mountains by shifting the region's dependency on the federal government. Programs of land acquisition by the federal government for parks and hydroelectric dams further displaced people and their ways of life and a growing dependence of federal relief funds and programs increasingly characterized people's livelihoods. Only with the coming of World War II did conditions improve in the mountains with many Appalachians moving in mass migration to the booming war industries in the North and East Coast and for military service.

\footnotetext{
${ }^{28}$ The 1920s was a time of general prosperity in the United States however the three "sick" industries of that decade were agriculture, textiles, and bituminous coal—the backbone of the mountain economy.

${ }^{29}$ The average per capita income of coal miners declined from \$851 in 1923 to \$588 in 1929 and an unbelievably low point of \$235 in 1933 (Parker, 1940).
} 
William Wirt, a mountain farmer from east Tennessee summed up the dramatic events of industrialization, modernization, and New Deal legislation on his mountains in a letter to a northern friend in 1938:

One day we were the happiest people on earth. But like the Indian we are slowly but surely being driven from the homes that we have learned to love, and down to the man we are not a friend of the Government for the simple reason that every move they have made has increased our poverty.

We were told that if we kept the fire out of the forest that we would have plenty of range for our cattle, but we found that after a few years that there is no range left. We were also told that we would have plenty and increasing flow of water in our mountain streams furnishing an abundance of fish for sport and food. But I've found that our streams are drying up and the fish in the ponds that are left are all dying, and at times you can smell them are you pass along the highway. Fifteen years ago you could have seen in the forest here thousands of cattle, sheep, and hogs. Today you never see one out of the forest, and if you do his head and horns is the heaviest part of him.

Now what are we going to do, move on and try to fit in where we do not belong or undertake to face the situation and gradually starve to death? In the little mountain churches where we once sat and listened to the preaching of the gospel with nothing to disturb us, we now hear the roar of machinery on the Sabbath Day. After all I have come to believe that the real old mountaineer is a thing of the past and what will finally take our place, God only knows. ${ }^{30}$

Industrialization and modernization came like a storm over the ridges, profoundly disrupting the social and economic structure of mountain life. The legacies of external land ownership, extractive mining and timber industries, disrupted agricultural and livelihood systems, and lack of social investment were to have a profound effect on the future social, economic, and political development of the region.

\footnotetext{
${ }^{30}$ William and Wilma Wirt to Peggy Westerfield, 19 September, 1938. Peggy Westerfield Papers, No. 1430, Southern Historical Collection, University of North Carolina, Quoted in Eller (1982).
} 


\section{The 'Making' of Appalachia}

For over a century, Appalachia has been considered a region of social, political, and economic backwardness plagued by underdevelopment. This expansive mountainous areawhich extends from northeast Mississippi to southern New York (Map 3)—has historically been associated with deep poverty and 'less developed' living conditions. In accordance with this modernist assumption came a number of models intended to both explain and ameliorate Appalachian underdevelopment. These explanations include the culture of poverty, internal colony, and internal periphery models ${ }^{31}$. These models have exerted significant influence on how the region is perceived and serve as a basis for the vast majority of regional economic development policies and programs, including the development of the Appalachia Regional Commission (ARC) (Billings and Blee, 2000; Isserman, 1997; Bradshaw, 1992; Conn, 1983; Watts, 1978; Whisnant, 1981; Branscome, 1977; Walls, 1976; Bray, 1975). As will become evident below, the construction of Appalachian as a distinct region has had both positive and negative effects concerning its social, economic, physical, and political landscape.

The culture of poverty explanation, a form of modernization theory, gained popularity in the 1960s. This theory assumes that underdevelopment and poverty in the region are caused by regional cultural traits which are common among Appalachian people. This theory is rooted in Appalachianography that emerged during the late nineteenth century by writers such as James Lane Allen and John Fox, Jr. This distinct genre of local color fiction simultaneously created, exploited, and tried to explain images of the mountains as a place that was vastly out of step, culturally and economically, with the progressive trends of industrializing and urbanizing late nineteenth-century America (Billings, Pudup, and Waller, 1995). A discourse on Appalachia

\footnotetext{
${ }^{31}$ See the work of Billings and Blee, 2000; Lewis and Billings, 1997; Gaventa, 1980; Fisher, 1979; Nyden, 1979; Lewis et al. 1978; Walls, 1976; Billings, 1974; and Ball, 1968.
} 
that constructed the region as a "retarded frontier" 32 plagued with moonshining, feuding, and backwardness because of its supposed geographical, socio-cultural, and economic isolation was consequently created. As Henry Shapiro’s (1978) intellectual history of the idea of “Appalachia," Appalachia on our Mind: The Southern Mountains and Mountaineers in the American Consciousness, 1870-1920, has ably shown, such early writings about life in the mountains contributed to the social construction of Appalachia as "a coherent region inhabited by a homogenous population possessing a uniform culture.” Regardless of how people in the mountains defined or identified themselves, the popular representations that created "Appalachia" stressed sameness and identity to the neglect of locality differences and population diversities. Hence, the enduring image of Appalachia as a region apart, an 'other' in the heart of America (Billings and Blee, 2000).

The internal colony model attributes Appalachia's developmental lag to the nature of its integration with, not isolation from, the U.S. corporate economy and unequal patterns of natural resource ownership and poor terms of trade resulting from economic exploitation from outside capitalist interests. The internal periphery model also links Appalachian underdevelopment to spatial exploitation but views the region as a semi-periphery which is not politically autonomous, as is the case with third world nations (Walls, 1976). These models, although on opposite ends of the political spectrum, helped to place Appalachian poverty on the national political agenda and publicized the poor living conditions found within the region. They contributed to early reform efforts, such as the settlement house programs and other urban-based strategies of benevolence and education, aimed at "modernizing" and "civilizing" the mountaineer and the

\footnotetext{
${ }^{32}$ See the work of George Vincent, 1898. Vincent's work was influenced by the writings of William Goddell Frost, president of Berea College in Kentucky at the turn of the century. Frost was one of the most influential creators of the discourse on Appalachia (see Frost, 1896 and 1899).
} 
development of the Appalachian Regional Commission (ARC), a large-scale regional development program that was designed to socially and economically transform the region.

The ARC evolved during the 1960s, a time of both economic and social change in the United States. While the U.S. was still the dominant hegemonic power among capitalist industrial countries at this time there was increasingly successful economic competition from overseas (Shannon, 1984). U.S. companies could no longer 'buy' labor peace and industrial discipline with high wages and then pass those higher costs on to consumers. Corporate behavior was changing along with the world economic system and major corporations began to seek new locations for their operations, both domestically and overseas (Frank, 1980).

As a result of these economic changes, Appalachia's role in the domestic division of labor began to change. Coal and light industry remained important, especially in Central Appalachia with the beginning of the revival of the coal industry in the 1970s and many parts of Appalachia began to play a new economic role involving the development of manufacturing operations. David Gordon (1977) argues, however, that the transfer of manufacturing to the region was a limited one, involving "satellite" industrial plants that specialized in those operations in which low-wage, semi-skilled workers offered major cost advantages. Operations involving skilled workers tended to stay in the more industrialized and urban areas of the North and managerial functions around design, marketing, and finance remained where they were.

At the same time, the political environment of the 1960s created pressures on the state and federal governments around social issues, such as poverty and race. Heightened public awareness of and concern for blacks and the poor combined with and was reinforced by rising expectations and militancy on the part of the disadvantaged. Certain political events and campaigns, such as the 1960 Kennedy campaign in West Virginia and the War on Poverty, 
increased Appalachia's visibility as a "disadvantaged" region and further legitimated the development of the ARC for economic and social change in the region.

The ARC was born with the passing of the Appalachian Regional Development Act of 1965. The development of this Commission was part of the War on Poverty and charged with "preparing a comprehensive action program for the economic development of the Appalachian region" (President's Appalachian Regional Commission, 1964). The ARC is a planning effort that now ranks with the Tennessee Valley Authority (TVA) as one of the United States' only two sustained national regional development programs.

Targeting a 200,000 square-mile area that follows the spine of the Appalachian Mountains, the ARC was specifically designed to appropriate funds for infrastructure and economic development, conservation, and resource management efforts. The region currently contains 410 counties in 13 states including all of West Virginia and parts of Alabama, Georgia, Kentucky, Maryland, Mississippi, New York, North Carolina, Ohio, Pennsylvania, South Carolina, Tennessee, and Virginia (Map 3). The population of the region is around 23 million and 42 percent of the population is rural, compared to 20 percent of the national population (ARC, 2005). The ARC has divided the region into three sub-regions: Northern Appalachia, which stretches from New York through most of West Virginia, is the most populated and urbanized portion; Central Appalachia, including parts of West Virginia, Kentucky, and Tennessee, is the smallest, poorest, and least populous sub-region; and Southern Appalachia, which extends from Virginia to Mississippi.

The Commission is an exercise in American federalism involving cooperation between the ARC, which is made up of state governors and representatives and a federal co-chairman, Appalachian states, and local development districts. The Commission was designed to serve as 
the forum for developing regional plans and priorities and the states were to be responsible for developing plans and priorities to be implemented within their boundaries. The local development districts ${ }^{33}$ are made up of counties and the underlying premise for their creation was that economies of scale and the scarcity of resources made it essential for counties and municipalities in a local area to work together, rather than compete with each other, for economic and social development resources (Widner, 1990).

A political process involving pressure from local and state politicians and a mix of metropolitan and county-level data is utilized to establish membership into the region. When the Appalachian region was initially defined, the go vernor of each state had the responsibility and power to decide which areas were to be included and which were not. For example, the natural urban market center for much of Appalachian Virginia, Roanoke, was not included in Appalachia because the governor believed that only the most distressed counties should be included. Yet, other governors recommended inclusion of centers similar in size and function, such as Winston-Salem, North Carolina, and Greenville, South Carolina. The consequence of this inconsistency is that a considerable number of local development districts around the region's periphery are part of multi-county development organizations based outside of Appalachia, a clear indication that the states themselves failed to follow any consistent principles in defining the area (Widner, 1990). As it has turned out, some counties included in Georgia's definition, for example, became thriving suburbs of Atlanta and, by hindsight, probably should not have been included. ${ }^{34}$

\footnotetext{
${ }^{33}$ The local development districts include elected officials, business people, and other local leaders from the member counties.

${ }^{34}$ Forsyth County, Georgia, located just north of Atlanta is an ARC county however it bears few of the characteristics that warrant it in need of 'development'. In 2000, per capita income in the county was $\$ 34,608$ compared to $\$ 29,469$ for the national population. The poverty rate was only $5.5 \%$, compared to the US rate of $12.4 \%$, for the same year. The unemployment rate for 2001 was only $2.3 \%$ compared to the national unemployment
} 
In the initial legislation, Mississippi, New York, and South Carolina were not included in the region defined as 'Appalachia'. However, at the insistence of Senator Robert Kennedy, thirteen New York counties were included and six counties in South Carolina were added as a result of local pressure on the state's congressional representatives. Two years after the act was passed, the governor of Mississippi petitioned for participation in the program and eighteen counties in that state were finally admitted.

The ARC's approach to regional economic development is, and always has been, comprehensive. The original 1965 Act appropriated funds for highways, hospitals and treatment centers, land conservation and stabilization, mineland restoration, flood control and water resource manage ment, vocational education facilities, and sewage treatment. The basic strategy combines physical infrastructure development, social programs, and regional coordination. In its early years, the Commission emphasized highway development and the use of growth center theory for development.

The 1965 Act earmarked more than 85 percent of the appropriated funds for highways and authorized an Appalachian Development Highway System of up to 2,350 miles (Isserman and Rephann, 1995). The President's Appalachian Regional Commission contended:

"Development activity in Appalachia cannot proceed until the regional isolation has been overcome...by a transportation network which provides access to and from the rest of the nation and within the region itself...The remoteness and isolation of the region, lying directly adjacent to the greatest concentrations of people and wealth in the country, is the very basis of the Appalachian lag. Its penetration by an adequate transportation network is the first requisite of its full participation in industrial America (1964: 32).

rate of $4.8 \%$. In contrast, if one looks at Lumpkin County, Georgia, which is just north of Forsyth County but outside of "greater-metro Atlanta," a different picture is revealed. Per capita income in 2000 for Lumpkin County was only $\$ 22,279$ and its poverty rate was $13.2 \%$. Like Forsyth County, it had a lower than national average unemployment rate for 2001 at $2.3 \%$. However, its local economy is not as diverse nor does it include the higherwage occupations that Forsyth and other metro-Atlanta counties (Data obtained from the ARC, Regional Data, 2005). 
Highway construction has remained prominent on the ARC agenda. In fact, between the years of 1965 and $1990 \$ 3.6$ million dollars was spent on highway construction in the region. This figure is more than the total spent, $\$ 2.1$ million, on non-highway projects including health, child development, education, community development, energy and enterprise development, natural resources, special initiatives, housing, development districts, and research and technical assistance (Widner, 1990). The authorized mileage for the highway system in the region persistently increases and the ARC continues to provide the dominant share of the highway funds (68 percent) and a smaller share of the others ${ }^{35}$ ( 29 percent) to the states (Isserman and Rephann, 1995). The ARC has seen no dichotomy between infrastructure and social programs and the highway system was, and still is, designed to open areas with economic developmental potential and improve local access to educational, health, recreational, commercial and industrial facilities. Moving Appalachia Forward: the ARC Strategic Plan, 2005-2010 remains committed to highway development for economic development by including "the building of the Appalachian Development Highway System to reduce Appalachia's isolation" as one of its four goals for the future (ARC, Strategic Plan, 2005-2010, 2005).

The growth center strategy for development in Appalachia evolved out of the 1965 Act as well as criticisms from politicians that the ARC could just amount to a federal "hand-out" program. The Act required that programs be concentrated "in areas where there is a significant potential for future growth, and where the expected return on public dollars will be the greatest." Thus, the ARC designated both growth centers where investments would be made and other "rural, isolated areas which would not qualify for investments" (ARC, 1985: 28) through the work of a consultant, Litton Industries. 125 growth centers were identified and ARC proponents

\footnotetext{
35 This would include funds for education, community development, energy and enterprise development, health, research and technical assistance, local development district planning, housing, and administration.
} 
argued that this strategy allowed for a "rigorously managed" initiative in which investments would be placed very carefully to achieve the greatest possible benefit (Widner, 1990).

Many have debated the effects of the ARC's development strategies on the region. The growth center strategy clearly did not work for the most economically disadvantaged areas of Appalachia. In 1990, Ralph Widner ${ }^{36}$ pointed out that in Central Appalachia, where problems were, and still are for that matter, most severe, market towns and service centers of 5,000 to 7,000 people serve rural areas of 250,000 or more and thus can maintain urban services even though they hardly constitute what regional economists would identify as growth centers. Definitions of growth centers dictated by regional economics disqualified major sub-regions in Appalachia and thus denied them funds. Local development staff characterized the growth center concept as "irrelevant, inappropriate, and inapplicable" (Bradshaw, 1992: 82) to the socioeconomic development needs of most of the region. This approach is a legacy that is left to be undone in many parts of the region, especially Central Appalachia, which remains relatively 'underdeveloped'.

Thus, the ARC's approach to development is, and has always been, controversial. While highway construction has improved access to services, facilitated commuting, and restructured the patterns of development and settlement in parts of the region, highways have not been the primary tools for attracting investment to the region. The premise that highways would bring branch-plant development from high-cost metropolitan areas into non- metropolitan areas along major transportation corridors has proved inaccurate. Since the 1960s, economic trends have changed and manufacturing has been internationalizing in its search for reduced labor, tax, and environmental costs. Critics have also denounced the enormous costs associated with highway

\footnotetext{
${ }^{36}$ Ralph R. Widner served as the first executive director of the Appalachian Regional Commission from 1965-1971.
} 
development at the expense of human social development and argued that highway planning and route selection has sacrificed economic considerations for political ones. Others claim that highway development has ignored small communities and primarily benefited those areas outside Appalachia by providing more efficient and rapid systems for passing through the region. $^{37}$

Other critics, particularly those from an Appalachian Studies perspective, argue that ARC programs have failed to benefit the Appalachian people. This critique comes from scholars and practitioners working within the region and focuses on the central roles that coal mining, external ownership, local politics, environmental degradation, and outsiders who are misguided, naïve, self-interested, or malevolent have played in the region's development history (Gaventa, 1980). Others have argued that while the ARC was designed to deal with the problems of poverty and stimulate economic development in the region, it has functioned in a way that is consistent with patterns of corporate investment and attempted to subsidize that investment (Shannon, 1983).

Despite continued attempts by the federal government to abolish the ARC, it is still the main economic development program in the region. It has helped to cut the region's poverty rate in half; double the percentage of adults age 25 and older with a high school diploma; create numerous rural health facilities; construct miles and miles of new highways; provide water and sewerage services; create vocational and technical educational programs that in some areas serve as a model to the nation; and cut the number of severely distressed counties ${ }^{38}$ from 223 in 1960

\footnotetext{
${ }^{37}$ For some detailed readings on early critiques of the ARC, particularly from a regional science perspective, see Hansen, 1966, 1969, and 1970; Friedmann, 1966; Miernyk, 1967a and b; Munro, 1969; Cumberland, 1971; Gauthier, 1973; Britt, 1971.

${ }^{38}$ Definition of distressed counties 2004: Distressed counties have a three-year average unemployment rate that is at least 1.5 times the U.S. average of 4.3 percent; a per capita market income that is two-thirds or less of the U.S. average of $\$ 25,676$; and a poverty rate that is at least 1.5 times the U.S. average of 12.4 percent; or that have 2 times the U.S. poverty rate and qualify on the unemployment or income indicator (ARC, Distressed Counties in the Appalachian Region, 2004).
} 
to 91 in 2004 (ARC, Strategic Plan, 2005-2010, 2005). It remains committed to increasing job opportunities and per capita income in the region; strengthening the capacity of people in the region to compete in the global economy; developing and improving Appalachia's infrastructure; and building the Appalachian Development Highway System (ARC, Strategic Plan 2005-2010, 2005). These goals are very similar to the objectives laid forth in the late 1960s, however, the approaches are a bit different. The ARC is currently working toward more 'homegrown' solutions and establishing connections between federal and state agencies as well as non-profits and other civic organizations.

Despite the gains made in the region since the 1960s, it still lags behind when one looks at jobs, income, and economic diversification, poverty, and education, especially at the state and county levels. For example, per capita income in Appalachia for the year 2001 was $\$ 24,912$ compared to U.S. per capita income of $\$ 30,413$ (ARC, Regional Data Results, Personal Income Rates in Appalachia, 2001). However, for states such as West Virginia and Mississippi, per capita income was only $\$ 22,862$ and $\$ 21,653$, respectively, just 75.2 percent and 71.2 percent of the national average (ARC, Regional Data Results, Personal Income Rates in Appalachia, 2001). Great disparity can also be seen when examining poverty rates at the state level. The poverty rate for the U.S. in 2000 was 12.4 percent and the Appalachian region, 13.6 percent, reflecting a difference of only 1.2 percent (ARC, Regional Data Results, Poverty Rates in Appalachia, 2000). States such as Kentucky, Alabama, West Virginia, and Mississippi, however, had poverty rates of between 15.8 and 19.9 percent for the same year while others, such as Maryland, Virginia, Ohio, and Pennsylvania, had rates between 8.5 and 11 percent (ARC, Regional Data Results, Poverty Rates in Appalachia, 2000). Many have argued that disparity in educational attainment between the region and other parts of the U.S. is one of the fundamental development challenges 
for the region in the future (Widner, 1990). Again, only 14.8 and 16.9 percent of the population in West Virginia and Mississippi had college degrees compared to 24.4 percent of the U.S in the year 2000 (ARC, Regional Data Results, Education—High School and College Completion Rates in Appalachia, 2000). Those that receive a college degree in areas such as West Virginia, eastern Kentucky, western Virginia, and Mississippi are oftentimes forced to leave because the local economies are not diversified enough to provide these graduates with employment. This aspect of educational attainment further compounds the economic development problems of these areas by forcing valuable resources, including knowledge and capital, out of the region. As is evident, regional development policy has not dealt with the great diversity and disparity in Appalachia and the ARC itself is just beginning to prioritize development for the most economically distressed counties in the region.

In addition, $\mathrm{ARC}$ and other regional development policies have not been able to effectively deal with the effects of economic restructuring on the region. Between 1979 and 1984, 11.5 million workers nationwide lost their jobs as company officials shut-down or relocated plants in search of lower labor costs, fewer environmental regulations, and better tax incentives (Gaventa, Smith, and Willingham, 1990). In such economic restructuring, the jobs in traditional sectors such as mining, manufacturing, and agriculture, the backbone of Appalachia, declined the most (U. S. Congress, 1986). Accompanying this loss in mining, manufacturing, and agricultural jobs has been the rise in low-paid, often part-time service sector employment. In fact, between 1979 and 1985, 44 percent of new jobs created in the United States paid povertylevel wages (U.S. Congress, 1986). In areas of Appalachia that lack economic diversification, workers from the higher-paid occupations in mining and manufacturing have been forced into lower-paid, often part-time work with few benefits. They lack the training and education for 
higher-paid service sector work in education, finance, communications, and health occupations. These profound economic changes have been magnified by a political assault on poor and working class people with federal reductions in social welfare programs—-from Aid to Families with Dependent Children (AFDC), now Temporary Assistance to Needy Families (TANF), ${ }^{39}$ to housing and from job training to student aid—and have further whittled away the narrow base of resources by which many people survive. In addition, participation in social movements for civil, welfare, and women's rights and labor activism and unionization has declined leaving many people in the region with no mechanism for voicing their concerns (Couto, 1994; Obermiller and Philliber, 1994; Gaventa, Smith, and Willingham, 1990). All of these changes were consequently occurring as more and more women were entering the labor force and have led to the increased feminization of low-wage work in the region and coincide with the feminization of poverty (Couto, 1994). Mediating structures, such as the family, community organizations, and the church, are meeting the needs of local communities and 'cushioning' people socioeconomically through various types of social programming for basic needs, such as clothing, food, and utility payments, education, and health issues. These structures are the supportive institutions that come between individuals and large-scale social and public institutions and forces, such as the state and issues around economic restructuring and decreased social spending (Couto, 1994).

To conclude, the 'development' and 'underdevelopment' rhetoric that was utilized to justify the development of the ARC has politically and economically defined the region of Appalachia and had both positive and negative effects on this beautiful part of the United States. Future economic and social development efforts in the region must account for and work toward

\footnotetext{
${ }^{39}$ Under the 1996 federal welfare law, The Personal Responsibility and Work Opportunity Reconciliation Act, AFDC was changed to TANF. Both of these programs provide cash assistance to the poor.
} 
ameliorating the extreme disparity that exists within the region. It must also be attuned to the local histories of development in the region and the role that local politics and state development have played in shaping Appalachia's political economy ${ }^{40}$. Importantly as well, many analyses on the economic and social history of Appalachia have left "Appalachians" themselves out of the picture. Both the wealthy and powerful and the 'common folk' have struggled to shape and/or resist the economic, social, and political changes that have swept across the region. Scholarly attention should be paid to those Appalachians so rarely mentioned, including women and African Americans, concerning their social, economic, and political roles in both past and contemporary Appalachia. In addition and because the U.S. and world economic systems have changed, it may be time for a 'redevelopment' and 'rethinking' of regional development policy and it's institutions, including the ARC. Finally, analyses that consider contemporary social and economic processes, such as economic restructuring, changes in family structure, such as the rise of female-headed households, and civil society, including the role of community service organizations in local economic and social development, can inform economic development approaches in the region. This is a project for Appalachian scholars and development practitioners from a variety of disciplines that can use their skills and knowledge to maintain the beauty of the region and work for the people of Appalachia.

\footnotetext{
${ }^{40}$ The Road to Poverty-The Making of Wealth and Hardship in Appalachia (2000) by Dwight B. Billings and Kathy M. Blee is an excellent study into Appalachia's early agricultural history and the role of state development and local politics in influencing economic development and the making of wealth and poverty in Appalachian Kentucky.
} 


\section{Women and Work in Appalachia}

\section{Mama}

Mama got married when she was fifteen

She was sixteen when her first child was born.

Mama woke up before the sun did.

Mama washed her clothes on an old washboard by the river.

Mama made all our clothes.

Mama knew secrets.

When we were sick, she would take a knife and skin the bark down and make a batch of tea, hot as we could stand.

Everything would be all right then.

Mama smiled all the time. Mostly.

Daddy came in from work and sat in his chair to read.

He didn't talk much.

We would hoe corn, pick beans, string beans, peel apples, peel tomatoes, chop wood, carry water...

We had a big garden.

Mama put food on the roof to dry.

We went to town for sugar and coffee.

Mama was a member of the Ladies' Aid.

I never did learn how to milk a cow.

Mama made sure I knew how to churn.

We slaughtered hogs in the winter.

Mama canned the meat.

Mama and I made soap from the scraps.

In the winter, Mama pieced quilts.

She told us ghost stories.

We never did have any money.

My Mama never stopped moving. Never stopped working.

"I won't stop until the day I die," she said.

"It's all I know how to do."

Mama never stopped cooking, scrubbing, canning, and quilting...

Until the day Mama died.

This poem was written by the Ivanhoe Theater Group for the community theater production It Came from Within ${ }^{41}$.

As discussed above, industrial capitalism penetrated Appalachia's predominately agricultural economy in the form of timber, oil, gas, and coal industries during the late nineteenth

\footnotetext{
${ }^{41}$ For more information on the Ivanhoe Theater Group and Civic League see M. A. Hinsdale, H. M. Lewis, and S. M. Waller (1995) It Comes from the People: Community Development and Local Theology, Temple University Press.
} 
and early twentieth centuries. Many small subsistence farmers were forced to relinquish their land to absentee corporate owners and thus became rural industrial workers (Billings, Blee, and Swanson, 1986; Eller, 1982; Maggard, 1981). Although the social and economic changes associated with the creation of an industrial labor force have received considerable attention from scholars of the region, women's roles in local economies have often been neglected ${ }^{42}$.

In pre-industrial Appalachia women were confined to the home yet heavily involved in many spheres of economic activity, especially subsistence activities that sustained the household as both the productive and reproductive unit (Pudup, Billings, and Waller, 1995; Pudup 1990b; Eller, 1982). In addition to the cooking, cleaning, sewing, and tending to the children, women fed and milked the cows, slopped the hogs, fed the chickens, planted and hoed the garden, carried water from the spring, gathered and chopped wood, and engaged in informal trading for agricultural and household goods and money.

Households experienced significant shifts in their productive and reproductive activities and social divisions of labor with the move of men into waged labor and families into the mine and mill towns of industrial Appalachia. As extractive industries in mining, timber, oil, and gas developed within the region, production became a sphere of male domination; men directed the ownership and management of land, natural resources, technology, and capital and new jobs within the region's primary industries were considered “men's work" (Pudup, 1990a). The company towns offered limited opportunities for women to engage in waged work, further confining many women to the domestic sphere while denying them the basic means of production and reproduction they had once relied upon. The types of jobs that were available to women in the new industrial spaces of Appalachia often drew upon women's roles as caregivers

\footnotetext{
${ }^{42}$ See for exception work by Greene, 1990; Halperin, 1990; Pudup, 1990a and b; Anglin, 1993; Isserman and Rephann, 1993; Oberhauser, 1993; 1995a and b; Oberhauser, Waugh, and Weiss, 1996; Oberhauser and Turnage, 1999.
} 
and nurturers, essentializing criteria that segregated them in nursing, teaching, and domestic work (Maggard, 1994). Some women were employed in textile and knitting mills, glassware shops, and tobacco factories (Anglin, 1995; Hensley, 1990) and access to formal, waged employment did vary among women in the region according to certain demographic characteristics. Both black and immigrant women migrated to larger population areas in search of wage labor and found work in factories, inns, private houses, and laundry services. In contrast, white, native-born females who comprised the majority of West Virginia women, for example, tended to remain in their rural communities and did not seek employment outside the home. Overall, women's opportunities in the wage economy were limited.

Women's participation in the formal economy was restricted due to capitalist ideology about gender, the household, and economic practice as well as local patriarchal relations. Because of these limitations and the rural isolation experienced by many communities, many women engaged in the informal economy. Several of these informal economic activities reinforced the relationships among women of the same and different economic classes within the region. For example, many working-class women in coal camps generated income by performing domestic work such as laundering, housekeeping, and child care for more socially prominent families in the camps (Greene, 1990). Others raised chickens, tended gardens, sold butter and eggs, and took in borders for income. Recent immigrant women in the camps baked bread in communal ovens, while women who were native to the region provided traditional health-care services by working as midwives as well as herbal healers (Barney, 1995; Greene, 1990). This reliance on informal activities provided women and their families with cash and other goods and was a safety net that proved vital in a region where employment has historically been based on the boom and bust cycles of extractive industries (Halperin, 1990; Beaver, 1986). 
The informal exchange of goods and services between women in the company towns also allowed women to avoid the inflated prices at the company store. By trading and bartering with each other, the women escaped this economic exploitation while establishing and strengthening intra-class relations within the camps.

Despite the particular gendered division of labor that developed with Appalachia's transition to an industrial economy and excluded women from certain types of public work, women engaged in economic strategies within their own communities (Salstrom, 1996). Women's participation in both formal and informal economic activities has been, and still is, the backbone of many local, Appalachian economies.

Contemporary economic restructuring has further impacted upon women's employment and household economic strategies in Appalachia. The globalization of capital has contributed to the loss of jobs in manufacturing and mining and the rise of the service sector in the region (Wood and Bischak, 2000). The region has functioned as a layover on capital's flight to cheaper labor and resources, as industries fleeing the [U.S.] South are purchasing one-way tickets to Taiwan and other exotic destinations just as readily as they used to depart Akron, Ohio for Opelika, Alabama (Cobb, 1986). The increased mobility of firms has left laid-off manufacturing workers and miners with bleak prospects for obtaining new jobs that have similar levels of security, wages, and benefits (Gaventa, 1994). In West Virginia alone, nearly 70,000 jobs in manufacturing and mining were eliminated between 1979 and 1987 (U.S. Bureau of Labor Statistics, 1990). While those jobs averaged $\$ 20,000$ to $\$ 36,400$ annually, they have been replaced by retail and other service sector jobs that pay $\$ 13,500$ to $\$ 15,000$ a year and specifically target a female labor force (U.S. Bureau of Labor Statistics, 1990). 
Layoffs and plant closings in mining and manufacturing and the shift to a more servicebased economy have consequently resulted in an increase in women's participation in the formal economy. Women in the Appalachian region are primarily employed in the service sector and the flexibility of this work has been especially attractive to working-class women who maintain the majority of the household responsibilities (Oberhauser, Waugh, and Weiss, 1996). However, the positions many of these women find as secretaries, schoolteachers, waitresses, and retail clerks tend to offer low wages and few, if any, benefits compared to male-dominated occupations. Furthermore, service-sector jobs are not readily available in the region's more rural areas (Rogers, Mencken, and Mencken, 1995). The lack of social capital or social support systems in rural areas, particularly day care, often prevents women from seeking employment in those jobs that do exist. Lack of access to transportation, domestic responsibilities, inadequate job training, and lack of previous work experience also deter many working-class wo men in Appalachia from entering the formal workforce (Oberhauser, Weiss, and Waugh, 1996). Educational levels in the region remain low with, for example, only 14.8 percent of adults over the age of 25 having a college degree in West Virginia in the year 2000. It is true that women in the West Virginia labor force tend to be more educated than men however; their average earnings are markedly lower than the average male wage (Hannah, 1995). Thus, few women have access to a higher-paying job with health and retirement benefits.

In response to the barriers highlighted above, may women continue to rely on the informal sector as an important component of their overall livelihood strategy. According to studies conducted by Oberhauser (2002; 1995a and b; 1993), Pudup (1990a), and Greene (1990), strategies such as domestic work, raising livestock, taking in boarders, baking in communal ovens, bartering, and participating in economic co-operatives or networks have proved vital in a 
region where employment has been historically based on the boom and bust cycles of extractive industries. Increases in the informalization of labor are also connected to the regional and global economic shifts discussed above, as manufacturers flee for lower labor costs and fewer regulations in the US and Global South (Mencken and Maggard, 1999; Fitchen, 1991; Benton, 1990). Many argue that informal strategies allow households to replace lost wages within mining and manufacturing, as well as supplement the relatively low wages earned within the region's rising service-sector economy (Mencken and Maggard, 1999). For women in particular, these activities often provide the necessary support and resources to care for children or elderly people and maintain other aspects of the household. The social dimensions and gender relations of informal economic activities, as manifested at the household level, have been largely ignored (Phillips, 1994). In addition, little attention has been paid to the connections between informal activities, formal economic structures, and broader socioeconomic processes (for exception see Oberhauser and Turnage, 1999; Fitchen, 1991; Halperin, 1990).

The realities of women's participation in the Appalachian economy are only beginning to be revealed by Appalachian scholars from a variety of disciplines. In fact, Pudup (1990a) claims that Appalachian women have been 'doubly hidden from economic history' due to their almost total exclusion from market production and exchange and the failure of analysts to recognize the importance of unpaid labor and home-based work. Her historical work outlines women's evolving roles in paid and unpaid labor since the pre-industrial era in the region. In addition, Maggard's (1990) work highlights women's roles in political activities, such as the coal strikes of the 1970s. Halperin's (1990) research focuses on non-capitalist livelihood strategies such as family subsistence farming, independent commodity production, and the informal economy while Oberhauser's geographical studies (2002; 1995a and b; 1993) highlight women's roles in 
home-based work through their involvement in economic networks and co-operatives. Finally, Fitchen (1981) and Tickameyer and Tickameyer (1986) explore the connections between rural poverty and broader economic processes by focusing on regional economies, gender relations, and changing family composition. This research seeks to build upon this existing literature by highlighting the livelihood strategies of women who head households in the region and contribute to Appalachian literature on gender and the economy.

\section{West Virginia: The Case Study Area}

West Virginia is centrally located in Appalachia (Map 3 and 6). Sharing many of the social and economic characteristics that define the Appalachian region, West Virginia is the only state that lies totally within the boundaries of the ARC. It is one of the most rural states in the United States with approximately 54 percent of its population living in settlements with less than 2500 people, compared to just 21 percent nationally (U.S. Census Bureau, 2000a). Charleston and Huntington to the south, Parkersburg to the west, Clarksburg-Bridgeport and Morgantown in the north-central region, Martinsburg in the eastern panhandle, and Wheeling in the northern panhandle comprise the state's main metropolitan areas (Map 6). Charleston is the capital of the state and Huntington and Morgantown house the state's largest universities, Marshall University and West Virginia University. Parkersburg has historically been part of the chemical, steel, and power plant industries of the Ohio Valley while the Clarksburg-Bridgeport area, formerly dependent on the coal industry, has become a major economic center for the north-central region. Wheeling has historically depended on the steel industry while Martinsburg has recently been part of the growing suburbs of western Maryland and northern Virginia, which lie in close proximity to Washington, D.C. This study focuses on the north-central part of the state including 
Taylor, Monongalia, Marion, Preston, Harrison, and Barbour counties (Map 6). The physical geography of the state is mountainous, with the Appalachian Mountains running down the central to eastern part of the state (Map 6). These mountains contribute to the great beauty of West Virginia, but have also isolated many communities and made economic development difficult in many places.

Rural Appalachia and West Virginia in particular have been described as peripheral regions in a core country (Couto, 1988; Nyden, 1979). The state industrialized relatively late in the nineteenth century, partly as a result of its remoteness and often impassable terrain. Its position as an economically marginal area is also related to the predominance of natural resource extractive industries during the late nineteenth and early twentieth centuries (Lewis, 1993; Pudup, 1990b; Simon, 1979). Although manufacturing was important to the state's economic development, it has been confined to a few urban areas.

The expansion of railroads in the late nineteenth century facilitated investment by timber, coal, and natural gas companies which were soon extracting a seemingly endless supply of raw materials throughout the region. During this period, many West Virginians had their land ownership taken away by the coal and timber companies and became economically dependent on these industries for jobs (Lewis, 1993). According to the West Virginia State Board of Agriculture, outside capitalists owned 90 percent of the coal in Mingo and Wayne Counties and 60 percent of the coal in Boone and McDowell counties in 1900. In 1974, absentee corporations still controlled more than half of the total land area in the nine southernmost counties of West Virginia and in 1994 approximately half of the land in Pendleton and Randolph Counties was controlled by outside corporations and federal and state agencies (Rasmussen, 1994). As mentioned previously, such an uneven distribution of land ownership has prevented the 
diversification of local economies and decreased the tax base by shifting the tax burden to local residents. The federal government, which currently owns large tracts of the land all over the state, pays no taxes on that land. Absentee ownership has prevented reinvestment into local communities and access to natural resources resulting in the socioeconomic and spatial marginalization of many West Virginia communities.

The rural nature of West Virginia, its early agricultural and industrial histories, and the issue of land and land ownership also impact social networks within communities. Communities are oftentimes more insular and self-contained and local community structures, such as churches, schools, and civic organizations, and familial ties are the backbone of mountain society ${ }^{43}$. Social networks that are made up of neighbors, church members, and family are very important in everything from finding employment to puttin' up hay on the farm. These networks are vital resources in rural West Virginia that sustain communities both economically and socially and have often been overlooked in scholarly economic analyses. They combat certain conditions in rural areas such as lack of economic diversity and an underdeveloped public sector and tax base that would otherwise provide employment opportunitie s and social investment. Home, family, and the land are powerful social and environmental forces that bind rural communities.

In recent decades, West Virginia has been 'adjusting' to the process of economic restructuring. Since the late 1970 s, the state has suffered tremendous economic setbacks and population out-migration as employment in the primary and secondary sectors has plummeted (Dorsey, 1987). Increased mechanization and rising international competition in the coal industry led to the loss of more that half the state's coal mining jobs in the 1980s. Many rural mining counties have experienced severe economic and social decline as a result of this

\footnotetext{
${ }^{43}$ For more information on the role of community structures, the church, and the family in Appalachian communities see Halperin, 1990 and Couto, 1994.
} 
tremendous job loss. At the peak of West Virginia's economic recession in 1983, official unemployment rose as high as 18 percent and in 1990 was among the highest in the nation at 12 percent (U.S. Bureau of Labor Statistics, 1990). While unemployment in the state in the year 2000 was down considerably to 5.5 percent, it was still above the national rate of 4 percent and the second highest in the Appalachian region (ARC, Unemployment Rates in Appalachia, 2000).

The economic shift from a mining and manufacturing-based economy in West Virginia has transformed the structure of employment and the labor force. As Table 1 indicates, the proportion of non-farm employment in goods-producing industries has decreased steadily since 1940, falling from 57.2 percent in 1940 to just 18.8 percent in 1999. Mining and manufacturing, in particular, have experienced significant job losses since 1940 when they accounted for 29.6 and 24.9 percent of the non-farm employment in the state, compared to just 2.9 and 11.2 in 1999. In contrast, employment in the service-producing industries has increased dramatically from just 42.9 in 1940 to 81.2 percent in 1999. Services, which include nursing aides, cooks, waitresses and other similar occupations, has more than quadrupled from 6.9 percent in 1940 to 30 percent in 1999. In January of 2005, the service-producing sector as a whole accounted for 84 percent of all non-farm jobs in West Virginia with only 3.2, 4.4, and 8.6 percent of jobs coming from mining, construction, and manufacturing respectively (West Virginia Bureau of Employment Programs, 2005). 
Table 1: Non-farm Employment in West Virginia, Percent by Industry, by Decade, 1940-1999

\begin{tabular}{|l|l|l|l|l|l|l|l|}
\hline Industry & $\mathbf{1 9 4 0}$ & $\mathbf{1 9 5 0}$ & $\mathbf{1 9 6 0}$ & $\mathbf{1 9 7 0}$ & $\mathbf{1 9 8 0}$ & $\mathbf{1 9 9 0}$ & $\mathbf{1 9 9 9}$ \\
\hline ALL & 100 & 100 & 100 & 100 & 100 & 100 & 100 \\
\hline $\begin{array}{l}\text { GOODS- } \\
\text { PRODUCING }\end{array}$ & 57.2 & 52.2 & 43.3 & 39.7 & 33.8 & 23.8 & 18.8 \\
\hline Mining & 29.6 & 23.4 & 12.2 & 9.7 & 10.2 & 5.7 & 2.9 \\
\hline Construction & 2.7 & 3.7 & 4.0 & 5.5 & 5.5 & 4.2 & 4.6 \\
\hline Manufacturing & 24.9 & 25.1 & 27.1 & 24.5 & 18.1 & 13.9 & 11.2 \\
\hline $\begin{array}{l}\text { SERVICE- } \\
\text { PRODUCING }\end{array}$ & 42.9 & 47.6 & 56.8 & 60.2 & 66.1 & 76.3 & 81.2 \\
\hline TCPU* & 9.7 & 10.2 & 9.7 & 8.0 & 6.7 & 6.0 & 5.2 \\
\hline $\begin{array}{l}\text { Wholesale \& } \\
\text { Retail Trade }\end{array}$ & 13.6 & 15.8 & 18.4 & 17.7 & 20.0 & 23.2 & 22.5 \\
\hline FIRE** & 2.0 & 1.9 & 2.9 & 3.0 & 3.4 & 3.9 & 4.1 \\
\hline Services & 6.9 & 8.4 & 11.1 & 12.9 & 15.4 & 23.2 & 30.0 \\
\hline Government & 10.7 & 11.3 & 14.7 & 18.6 & 20.6 & 20.0 & 19.4 \\
\hline
\end{tabular}

*Transportation, Communication, and Public Utilities

**Finance, Insurance, and Real Estate

Sources: West Virginia Bureau of Employment Programs, 2005; West Virginia Bureau of Employment Programs, 2001; U.S. Bureau of Labor Statistics, 1990; WV Department of Employment Security, 1990.

The livelihoods of people in West Virginia have consequently been transformed and gender divisions of labor play an important role in the economic restructuring outlined above. In West Virginia, most of the increase in employment is in female-dominated sectors such as retail and trade, while most of the decline is in male-dominated sectors such as mining, construction and manufacturing. Indeed, between 1988 and 1994, 97 percent of the 65,000 additional jobs in West Virginia were filled by women and women's labor force participation has increased from 33.5 percent in 1977 to 49.4 percent in 2002 (West Virginia Bureau of Employment Programs, 1995 and 2004).

Although women's employment in West Virginia has risen dramatically, they tend to be concentrated in a few occupations which are generally lower paid, lower status, and represent more part-time work that male-dominated occupations. This occupational segregation translates into wage differentials between men and women. In 2000, women earned 32 percent less than men in West Virginia. Translated into median annual incomes, the 2000 Census reported that 
women in West Virginia earned $\$ 21,154$ that year compared to $\$ 31,299$ for men (U.S. Census Bureau, 2000b).

The restructuring of employment, as discussed above, combined with decreases in the provision of social services and public assistance has consequently made it more difficult for families to construct a livelihood in West Virginia. During the years of 1982 and 1983, when West Virginia led the nation in unemployment, the state was losing federal aid at the rate of $\$ 479$ per person, which was the fifth highest rate in the nation (Couto, 1994). West Virginia ranked fifth in per capita losses in social services; sixth in per capita losses in health services, rehabilitative services, and wastewater services; second in per capita losses in Social Security benefits for the disabled; and seventh in per capita losses in food stamps (AFSCME, 1984). Further cuts in the 1990s with so-called 'welfare reform' have removed the safety net of many families. People are no longer able to supplement low wages, layoffs, or seasonal employment with public assistance. Devastating social conditions, such as poverty, have consequently resulted.

Poverty is not new to West Virginia, yet economic restructuring in the 1980s and declining social spending produced severe economic and social crises in a state already reeling from significant cutbacks in manufacturing and extractive industries. In 1992, more than 320,000 West Virginians, approximately 18 percent of the state's population, lived in poverty, a slight decline from the mid 1980s when the poverty rate was approximately 22 percent (U.S. Census Bureau, 1992). In 2000, the poverty rate for the state was again, 18 percent, compared to just 12 percent nationally with little changing during the economic boom of the 1990s (ARC, Regional Data Results, Poverty Rates in Appalachia, 2000). Poverty rates are particularly high in the central counties and southern coal fields where lumber, coal, and natural gas were once big 
employers and little economic diversification exist. For example, in the central counties of Barbour, Calhoun, and Webster poverty rates in 2000 were 23, 25, and 32 percent, respectively. In the southern part of the state and former coal fields, poverty rates in Mingo and McDowell counties were as high as 30 and 38 percent for the same year (ARC, Regional Data Results, 2000). Poverty strikes especially hard among single parent families, many of whom are femaleheaded. In 1999, 49 percent of female-headed households with children under the age of 18 in West Virginia lived below the poverty level. If we count only those female-headed households with children under the age of 5, the rate rises to an astonishing 63 percent (U.S. Census Bureau, 2000b).

West Virginia's dependence on extractive industries and issues around economic restructuring, occupational segregation, wage differentials, and poverty have important implications for women's livelihood strategies in the state. Women in West Virginia have always been active in local economies; however, their roles in both productive and reproductive labor have not always been recognized ${ }^{44}$. Women's work within households and in the informal economy, for example, is difficult to measure and quantify, yet crucial to these spheres of economic activity.

In the transition from pre-capitalist to capitalist production, households in West Virginia experienced significant shifts in their economic activities and social divisions of labor. For example, most of the jobs in the extractive industries were only available to men; thus domestic and farms tasks became the primary responsibility of women. Work for women in the former coal and timber towns was limited however, they constructed economic strategies, such as taking in borders, bartering for goods, selling eggs and produce, and doing housework and childcare to

\footnotetext{
${ }^{44}$ See for exception work by Greene, 1990; Halperin, 1990; Pudup, 1990a and b; Anglin, 1993; Isserman and Rephann, 1993; Oberhauser, 1993; 1995a and b; Oberhauser, Waugh, and Weiss, 1996; Oberhauser and Turnage, 1999.
} 
contribute to the household (Greene, 1990). More recently, women in West Virginia have increasingly entered the wage labor force, primarily in the service sector, despite challenges such as low pay and few benefits, occupational segregation, transportation barriers, as West Virginia is the most rural state, domestic responsibilities, inadequate training or work experience, and domestic violence (Oberhauser, Weiss, and Waugh, 1996). Domestic violence, in particular, limits women's access to the emotional and material resources needed to seek gainful employment. Since 1989, domestic violence complaints to law enforcement agencies in West Virginia have increased by 400 percent and between 1990 and 1997 the number of domestic violence petitions processed by magistrate courts in the state tripled (Criminal Justice Statistical Analysis Center, 1998). Thus, gendered power relations within households impede the economic progress of women and when combined with poverty, make it extremely difficult for women to escape abusive situations.

Many women in the state of West Virginia also engage in the informal economy. Informal strategies are often able to combat some of the challenges highlighted above for women such as lack of available jobs, the need to care for children or elderly family members, issues around rurality and transportation, lack of training and education, and rigid work schedules. The rich and insightful work by Oberhauser (2002; 1997; 1995a and b; 1993), Oberhauser et al. (2001 and 1999) and Halperin (1990) on women's participation in the informal economy in rural Appalachia highlights both the benefits and drawbacks of informal work. Oberhauser's work, in particular, on women working 'at home' through their participation in economic networks and co-operatives illustrates how homework allows women to balance their productive and reproductive duties through flexible work schedules and work environments, few transportation requirements, the ability to be their own boss, and earn their own money. Women's participation 
in these economic networks and co-operatives has provided women with training and education around business ownership, finance, and credit issues and fostered entrepreneurship among women in rural parts of West Virginia. Other informal strategies that women in the state engage in include: craft, textile and food production; the selling of goods and produce at flea markets and road-side stands; in-home childcare and eldercare; subsistence farming and the bartering of goods; casual farm labor; bookkeeping; and housekeeping; too name a few.

In conjunction with work in both the formal and informal economies, women utilize public assistance and community social services to help support households. Transfer payments, such as the former Aid to Families with Dependent Children (AFDC) and the new program called Temporary Aid to Needy Families (TANF), and Medicaid and Food Stamps are the main public assistance programs used by many women. Despite the notion that people can 'live off' welfare, it is and always has been difficult to 'get by' on these programs. These welfare benefits are usually means-tested and the "the family as well as the recipient must become demonstrably poor even to be eligible to receive them. Savings must be exhausted, and property reduced to the bare minimum necessary for survival" (Pearce, 1986: 159). To qualify for the former AFDC benefit in West Virginia, individuals could not own more than $\$ 1000$ in real or personal property or a vehicle worth more than $\$ 1500$. The resource limit for Food Stamps is $\$ 2000$ for a household and up to $\$ 3000$ if the household has someone over 60 years old. The "blue book" value of the car cannot be over $\$ 4550$ (Grinberg and McHenry, 1995).

Handler and Hasenfeld (1997) state that "Between 1972 and 1992, the combined value of AFDC and food stamps declined from $\$ 874$ to $\$ 649$-a 26 percent reduction" (p. 44) for welfare recipients in the United States. About 10 percent of all families in West Virginia received some type of public assistance in 1991. A 1993 random sample of AFDC and Food Stamp recipients 
in West Virginia found that women made up about 78 percent of this population (CPI, 1995). This research also found that the average take home pay for these respondents at their last job was on average $\$ 983$ per month for males and $\$ 480$ a month for females. For those currently employed, female respondents averaged $\$ 5.10$ an hour compared to $\$ 6.40$ an hour for their male counterparts (CPI, 1995). The average recipient in West Virginia (i.e., a white woman with two children) receives approximately $\$ 226.64$ a month in benefits. These benefits alone would amount to $\$ 2,719.68$ a year, which is "half the amount needed to survive, according to the West Virginia Department of Health and Human Resources, and was only 26 percent of the federal poverty level" (Hannah, 1995: 50).

Overall, welfare provides "only the most minimal support necessary to meet basic needs" (Pearce and McAdoo, 1981: 23). It is used by low-wage and part-time employees to subsidize the low wages found in secondary sector jobs and industries. Many women, in particular, have combined AFDC and food stamps because employment in the formal economy often does not offer high enough wages to meet the childcare and transportation costs associated with the lowpaid, part-time jobs in the formal economy. Other women have utilized AFDC as an economic bridge out of a violent relationship or to 'get by' after the death of a spouse.

With the work requirements and time limits on benefits associated with federal welfare law of 1996, the Personal Responsibility and Work Opportunity Reconciliation Act, the safety net of AFDC and Food Stamps has been pulled out from under many women. The limited lifetime benefits (60 months total) and the increased work requirements for both TANF and Food Stamp recipients will be particularly difficult for women and men in a state with high unemployment like West Virginia. To receive benefits, TANF recipients must be in a workrelated activity within 24 months. Thirty percent of single parent families had to participate at 
least 20 hours a week in a work-related activity in 1998, 25 hours a week in 1999, and 50 percent of these families had to be working 30 hours a week in 2002. The comparable rates for twoparent households were 75 percent in 1998 and 90 percent working 35 hours per week by 2002 . If the state was unable to meet these requirements, the federal government would reduce the welfare money it provided to the state (Sharlip et. al. 1998).

Pregnant women are temporarily exempt from the work requirement during the last three months of pregnancy and up to the first six months after the birth of a child. If the child is a first birth, the woman may take the three months prior and six months after the birth. Otherwise, women have only six months total that are exempt from the work requirement. Single parents with a child under 6 who are unable to obtain suitable childcare can also get a temporary exemption. Lack of transportation does not appear to be a legitimate reason for exemption under West Virginia Works. Individuals attending college are not given a temporary exemption. This is particularly problematic in a state where the majority of its labor force needs to increase their educational attainment to recruit new or retain old industries. College students must participate in a work activity after two years of benefits. The federal TANF legislation did contain a Family Violence Option (FVO), which West Virginia adopted, that temporarily releases victims of domestic violence from meeting certain requirements or they can receive special assistance in areas such as time limits, work and residency requirements, child support cooperation requirements, and family income provisions.

In terms of Food Stamps, individuals can receive Food Stamps for three months without having to meet a work requirement. After the first three months, able-bodied adults 18-50 years old must work an average of 20 hours a week to receive benefits. The unemployment rate has been so high in West Virginia that 46 counties have been exempt from this work requirement. 
This federal exemption is not automatic or permanent and the state must continue to reapply for each county to continue to receive this exemption.

Because of the many cuts in benefits, work requirements, and time limits now associated with social services and welfare, many local and regional civic organizations such as church charities, food pantries, and the Salvation Army are offering a variety of services from food and clothing provision, to utility payments, to job training. Some of this help is also means-tested while others require no information concerning income, property, or household status. The relationships between local Department of Health and Human Resources in West Virginia and local civic organizations, churches, and charities is an interesting aspect of women's livelihoods in the state and one that will be explored further in Chapters VI and VII. These organizations work together in local communities to supplement one another and assist families in their day to day struggle to 'get by'.

\section{Summary}

Despite federal, state, and local economic development efforts, many parts of rural West Virginia have not been able to overcome the legacies of external land ownership and history of extractive industries. Combine these legacies with the process of economic restructuring and welfare reform and you have people in rural areas struggling to find jobs that provide a living wage and benefits and are close to home. For women, especially those heading households, finding a sustainable, well-paying job is further complicated by factors such as occupational segregation, wage differentials, and the need to care for children and the household. The job market in the state continues to provide low-wage, often part-time service-sector work in many 
areas and women can no longer depend on the welfare system in a time of need. All of these factors indicate that women in West Virginia face great obstacles in constructing a livelihood.

This research emphasizes the need for analyzing how women who are heading households in rural Appalachia are supporting their families. A livelihoods approach, which is a more comprehensive and inclusive framework for understanding how women 'make due' in rural West Virginia, provides interesting insight into the multiple factors highlighted above that affect women's participation in both the formal and informal economies. In addition, this framework illustrates the intricate ways in which women utilize waged employment and informal and subsistence activities, as well as social services and family and community resources, to construct a livelihood.

\section{The Way Forward...}

Chapters III and IV provide historical, geographical, and socioeconomic background information about and begin to draw parallels between West Virginia and the former bantustans of South Africa. Local histories of land and labor exploitation in the two places reveal the disarticulations of outside land ownership and control over resources and their effects; such as the underdevelopment of many Appalachian counties and the former bantustans of South Africa. The legacies of this underdevelopment are made evident in the lack of economic diversification and poor infrastructure in these areas and the marginal skills of the local workforces and high poverty and unemployment rates. Historically, women in both places have been excluded from full participation in the formal economy, yet highly involved in supporting households and devising their own livelihood strategies. 
Exploring the background information, as laid out by these two chapters, is essential in the construction of the topographies on women who head households and their livelihood strategies in Limpopo and Central Appalachia and a comparative analysis of women's situations in the two regions. The construction of the two topographies continues in Chapters VI and VII when the fieldwork portion of the research is outlined and an analysis of women's particular livelihoods today is presented. Once topographies of the two places are complete the author will begin to draw the analytical contour lines that reveal the common socioeconomic processes women in both places are embedded in, their particular outcomes, and establish their relationships to one another. This will be done to 'connect' women's common livelihood concerns and needs, as well as exchange information on social and economic strategies. It is hoped that this work will be a model for other comparative feminist research that seeks to build bridges between women who seem to occupy different 'positions' but, in reality, have commonalities.

To conclude, it is argued that livelihood strategies and women's socioeconomic conditions and positions in local rural economies can be understood within a geographic framework. As advocated in the previous theoretical section, this framework emphasizes multiple and interrelated economic, social, and political structures and processes that occur at household, community, national, and global scales. Analyses of women's everyday material realities cannot be divorced from structural forces such as capitalism, colonialism, and patriarchy and the ideological notions of gender, race, and class embedded within them. Feminist geographical theories on space, place, and scale provide the necessary framework for understanding these complex connections. In addition, they can forge new feminist insight, both theoretically and methodologically, about global and local processes that affect female-headed 
households, both locally and globally, and their quest for sustainable livelihoods in rural areas. Analyses such as this are critical in the exploration of avenues for change and economic justice for women in South Africa and Appalachia. 


\section{V. 'Doing' Feminist Geography: Ethnographic Approaches and Feminist Topographies}

\section{Introduction}

Methodology is a theory and analysis of how research does or should proceed (Harding, 1987). It describes how the general structure of theory finds its application in particular disciplines and studies actual techniques and practices used in the research process (Fonow and Cook, 1991; Harding, 1987). Feminist methodologies, in particular, transcend masculinist perspectives that have dominated social science. Feminists argue that conventional methodology, which is rooted in positivist empiricism ${ }^{45}$ and focused on the search for universal truths through logical, value-free research, is consistent with a male, androcentric point of view (McDowell, 1992b; Mies, 1991). Conversely, feminist methodologies challenge researchers to recognize the gendered basis of all social life and to rethink concepts concerning gender and other social relations and their connections to broader structures. They forward women's 'ways of knowing ${ }^{46}$ by advocating a feminist value position and perspective and challenge conventional notions of objectivity, rationality, and truth. In addition, feminist methodological approaches are often action-oriented and working for social change.

For many feminist researchers, qualitative methodology is able to "give voice" and reflect the subjective, personal experiences, and knowledge of women through more inclusive, interactive, and in-depth approaches, such as case studies, ethnography, and participatory methods (Cancian, 1995; Reinharz, 1992; Acker, Barry, and Esseveld, 1991). Here, new sites of

\footnotetext{
${ }^{45}$ Positivism is associated with many specific social theories, including structural-functional and rational choice theories. Positivist researchers prefer precise quantitative data and often use experiments, surveys and statistics. They seek rigorous, exact measures and "objective" research and they test hypotheses by carefully analyzing numbers from the measure. Positivism sees social science as an organized method for combining deductive logic with precise empirical observations of individual behavior in order to discover and confirm a set of causal laws that can be used to predict general patterns of human activity (Neuman, 1997).

${ }^{46}$ Women's ways of knowing may include, for example, oral histories, storytelling, long, intensive interviews, poetry, or even drama.
} 
investigation, such as the individual, home, community, and workplace, are advanced and attention is paid to how socioeconomic relations of gender and power permeate all spheres of social life, including the research process (Ahrentzen, 1997; Falconer-Al Hindi, 1997; Oberhauser, 1997). Feminist researchers consequently rely on a wealth of qualitative methods, such as interviews, focus groups, oral histories, textual analysis, and participant observation. The more inclusive and interactive nature of these methods is attractive to many feminist researchers who wish to pay critical attention to socioeconomic and cultural relations and determine how they manifest themselves in women's everyday lives and in particular places.

Finally, feminist methodology has generated critical debates around power relations between 'the researcher' and 'researched' and subsequently encourages analyses of issues such as positionality through a reflexive approach. In addition, representation, including the ways of writing and presenting research, has entered methodological discussions and feminists have encouraged greater attention to the relationships between researchers and academia, research objectives and questions, research subjects, and the reader/audience ${ }^{47}$.

This chapter presents the methodological framework developed for this research project on the livelihoods of women who head households in West Virginia, Appalachia and Limpopo, South Africa. While largely employing a qualitative, ethnographic approach, this research relies on certain quantitative methods to answer questions concerning women and the economy. Emphasis is placed on the importance of utilizing methods that recognize context and everyday life but are also able to address the particular objectives and questions of the research project.

The following section of the chapter discusses methodological approaches within feminist geography by highlighting how feminist geographers actually "do" research. Emphasis

\footnotetext{
${ }^{47}$ Issues on positionality, reflexivity, and representation will be discussed in greater detail in the following sections.
} 
is placed on the importance of utilizing qualitative methodology and a plurality of ethnographic methods that are attentive to place, context, and women's everyday lives, as well as power relations and the various complexities in fieldwork. Issues around reflexivity, positionality, and representation are important aspects of feminist geographical research and this particular project.

The third section discusses how this research constructs feminist topographies as methodological tools to reveal the complexities of women's livelihoods within West Virginia and Limpopo, but also compare and connect them across scale and place. The fourth section outlines and explains the specific research objectives and questions comprising this research project while the fifth section presents the particular research methods utilized to meet and answer those objectives and questions. The sixth section offers fieldwork experiences from the actual research conducted in both West Virginia and Limpopo and pays critical attention to the researcher's role in the research process. The conclusion emphasizes the importance of this research in recognizing the livelihoods of female-headed households in the two areas and the importance of developing a methodological framework for comparative feminist work.

\section{Feminist Methodological Approaches in Geography}

Feminist geographers claim that the research process must place an emphasis on space, place, and scale, the significance of everyday life, and recognize and overcome power relations between the researcher and the researched. In many feminist geographical analyses, these elements, which are essential in conceptualizing the different and varying experiences of women, are addressed through a qualitative methodology (Katz, 1994 and 1992; Kobayshi, 1994; McDowell, 1992b). According to Kobayashi (1994), qualitative methodology highlights "the processes producing a particular event and promotes detailed understandings of socio-spatial 
experiences" (74). In addition, a qualitative framework forges links between the theoretical and 'the practical' and challenges oppressive aspects of socially-constructed processes by combining the academic and political through mutual understanding and learning during the research process. Reciprocity and overcoming power relations between researcher and subject is also accomplished through various research methods that are consistent with feminist goals and guided by the conceptual framing of the research project (Dyck, 1993). Finally, qualitative feminist research practice, in its critique of positivist empiricism, recognizes the personal and subjective in the research process and shows that the world is full of contradic tions and complexities that are in turn based on various social and spatial contexts.

Within feminist geography, a qualitative framework for research primarily utilizes qualitative methods that are intensive, place-based, and context-specific. Qualitative methods, including ethnographic approaches, are based on detailed case studies rather than large data sets and seek a non-hierarchical, more reciprocal relationship between the researcher and the research subjects (Nast, 1994; England, 1994; Gilbert, 1994; Rose, 1993). These types of methods are sensitive to issues of reflexivity, positionality, and representation discussed below.

Ethnography is a particular methodological approach that diverges from the androcentric, detached, and objective nature of positivist empiricism. It seeks to provide alternative or nonpositivist ways of interpreting the world by including and recognizing that both 'the researcher' and 'researched' are active participants in the research process. Therefore, ethnography relies on the researcher's immersion in social settings and aims for inter-subjective understanding between researchers and the person(s) being studied (Gilbert, 1994; Reinharz, 1992). It involves studying and learning about a person or group of people in their own environment in order to achieve a detailed understanding of their everyday circumstances. Ethnographers often conduct 
qualitative, multi-method research that may involve participant observation, interviews, focus groups, or archival analysis and ethnographic accounts are, therefore, both descriptive and interpretive. Descriptive, because their detail is so crucial to the research, and interpretive, because the ethnographer must determine the significance of what she observes without gathering broad, statistical information (Glossary on Ethnography, 2000).

According to Reinharz (1992), ethnography is consistent with three goals of feminist research: 1) documenting women's lives and activities; 2) understanding the experiences of women from their own point of view; and 3) conceptualizing women's behavior as an expression of social contexts. Documenting women's lives through participant observation or interviewing, for example, allows one to see women as full members of their social, economic, and political worlds. Understanding the experiences of women from their own point of view corrects the male biases of non-feminist observation that oftentimes trivializes the activities or thoughts of women or interprets them from the standpoint of men and the male researcher. In addition, ethnographic approaches are tools that enable the researcher to question their own positionality and 'give voice' to the experiences of women that have been ignored, spoken for, or interrupted in other research. Feminists, in particular, also see ethnographic approaches as mechanisms for destabilizing power relations within local, social contexts and the research process and interpreting the socioeconomic, geographical, and political contexts of women's lives. Feminists argue that paying attention to context reveals differences in behavior, opportunity, and responsibility by gender, as well as race, ethnicity, sexuality, and class, for example.

Issues around positionality, power relations, and representation are related to the reflexive approach within ethno graphic feminist research. Kim England (1994) argues for a feminist geography in which reflexivity plays a central role in methodological analyses, stressing that 
"reflexivity is self-critical sympathetic introspection and the self-conscious analytical scrutiny of the self as researcher" (England, 1994: 82). Reflexivity is the process by which the researcher critically examines the initial assumptions of the research project and the way the research is carried out. It is a process that is continuous throughout the project, constantly forcing the researcher to confront and question her own approach to doing fieldwork. England (2000 and 1994) asserts that reflexivity can lead to new insights and hypotheses about research questions and methods. Such self-critical introspection is a necessary part of addressing one's positionality in the field and of how this may impact field relationships and research findings.

With respect to field relationships and power relations within the research process, England (1994) also reminds us that "Fieldwork is inherently confrontational in that it is the purposeful disruption of other people's lives" (85). It is very difficult to create a situation of equal power relations between the researcher and researched and fieldwork can be intrusive and exploitative for both parties involved. Thus, field relationships may be "reciprocal, asymmetrical, or potentially exploitative; and the researcher can adopt a stance of intimidation, self-promotion, or supplication" (England, 1994: 82).

Feminist researchers choose the role of supplicant and seek reciprocal relationships based on empathy and mutual respect, often sharing the knowledge gathered with those they research. From this perspective, the researcher explicitly acknowledges her dependence on whoever is being researched for information and guidance. As England (1994) suggests:

Fieldwork for the researcher-as-supplicant is predicated upon the unequivocal acceptance that the knowledge of the person being researched (at least regarding the particular questions being asked) is greater than that of the researcher. Essentially, the appeal of supplication lies in its potential for dealing with asymmetrical and potentially exploitative power relations by shifting a lot of the power over to the researched (82). 
Supplication, reciprocity, and overcoming power relations in fieldwork are affected by the researcher's positionality. Demographics, race, class, and ethnicity and whether a researcher is an "insider" or "outsider" to the research subjects affect the researcher's positionality in the field and her relationships with the research subjects. Melissa Gilbert (1994) addresses positionality within the research process by addressing the 'insider/outsider' issue in her work on low-income women workers in Worcester, Massachusetts. She argues that, as an insider, the researcher is embedded in some of the everyday contexts of the women being studied. For example, being a single mother and/or working a full-time job may be points of commonality which enable the researcher and researched to relate to one another. Conversely, the position of outsider is experienced when research is performed on a group of people to which the researcher can only minimally relate.

In his work on resource ownership, access, and use in rural Appalachia, geographer Todd Nesbitt (2000), utilizes the reflexive approach to reflect on how his positionality as an insider and outsider constantly shifted throughout the research process and was dependent on a complex set of field relationships, how he identified himself, and geographic location. For example, Nesbitt had natural access to Glady Fork, West Virginia and its residents because Nesbitt's family owns land in the Randolph County area. Residents easily identified with Nesbitt, often seeing him at the local post office, cutting firewood, or having a beer at the local bar, and viewed him as actively participating in their culture and way of life. In contrast, conducting research in neighboring Pendleton County was a bit more difficult and Nesbitt soon realized that the geographic scale at which local residents consider one an insider or outsider is very small. Nesbitt's access to residents in Pendleton County was dependent on his relationships with a few select 'gatekeepers' in the community and these relationships were dependent on how he 
identified himself as either the husband of one who worked for a local non-profit, largely composed of outsiders with outside views and opinions, or as the grandson of a farmer and stone mason from the neighboring county. Nesbitt's identity as 'the grandson' and his relationships with two local Pendleton County families ultimately provided him access to local residents and acceptance within the community.

Thus, the reflexive approach allows the researcher to analyze how their own positionality affects access to and relationships with respondents and power relations within the research process. It acknowledges and discusses the inherent and complex relationships present in fieldwork and that both researcher and subject are active participants in the research process. Feminist geographers have argued that reflexivity encourages a more interactive, inclusive research process and collaboration through a reciprocal relationship between researcher and researched (Kobayashi, 2003; England, 1994; Gilbert, 1994; Rose, 1993). This non-hierarchical relationship is believed to 'ground' feminist work and challenge positivist methodology that specifies a strict dichotomy between researcher and subject. Finally, the reflexive approach can also strengthen the research findings because it encourages the researcher to reflect on both the respondent's interpretations, as well as their own. Fundamentally, the reflexive approach encourages the questioning of how knowledge is constructed, how lives are represented, the context in which the research is conducted, and to what ends (Kobayashi, 2003; Katz, 1994 and 1992; McDowell, 1992b; Mohanty, 1991).

Through qualitative methodological analyses, feminist researchers have also encouraged critical discussions around representation. Feminist geographers, in particular, have also problematized 'the field' itself and recognized how it is always constituted through various sets of power relations. Concerning representation, feminists raise questions concerning "who 
speaks" and "for whom," as well as how much power the researched has in the design, process, and outcome of research projects. For example, postcolonial critics such as Chandra Mohanty (1991) criticized Western feminism's representation of women in the third world and called attention to how the practice of ethnography has oftentimes marginalized certain groups. She argues that women in the third world have been portrayed as victims lacking agency and that research has emphasized the negatives such as disempowerment, colonial processes, male violence, and religious oppression. Consequently, a totalizing, essentialist view of women in the third world is constructed and this representation does not show the diversity of women's lives or their various forms of resistance to oppression.

The issue of representation and the question "who speaks and for whom?" are vital considerations to the broader feminist goals of social change and equality. Methodological analyses of representation within the research process reveal that women do not form one constituency and address the fact that research that empowers one category may in fact disempower another. Women, of course, are affected by various forms of oppression and consequently, different women will challenge these issues in diverse ways with varying feminisms.

The development of local feminisms involves both social and spatial processes and illustrating them is a methodological project for feminist geography. Feminist work is often considered "action research" because projects are often guided by locally-constituted needs, lending potential for meaningful change and empowerment for those involved (Wolf, 1996; Mies, 1991). In order to conduct this type of research, Audrey Kobayashi (1994) states that "we (as researchers) need direct engagement with those who people the world of our concern. This is not to say that (our) subjects are part of (our) project, but that we are part of theirs" (78). 
Kobayashi points out that feminist projects advocate for the researched and treat them as people and not mere mines of information to be exploited. She goes further to say that the researcher's task "is to understand how discourses are produced and sustained, by uncovering and engaging social constructions on the very sites where they are produced and nourished..." a project, she argues, "that is profoundly geographical" (1994: 78). This liberating of women's 'places' reveals the importance of 'locality' contexts in illustrating the differences among women, their diverse experiences and survival strategies, and the social and spatial conditions that help to explain gender, race, and class processes.

When considering the geographical aspects of fieldwork, feminist geographers have revealed that 'fields' are not static, but constructed, defined, and dominated by various political, economic, and academic projects and interests (Katz, 1994 and 1992; Mohanty, 1991). This methodological consideration acknowledges the blurred boundaries between fields and the fact that researchers occupy multiple positions as they operate in 'the field'. In her methodological discussions, Cindi Katz (1992 and 1994) articulates this point by stating:

I am always everywhere in 'the field.' My practices as a politically engaged geographer-feminist, Marxist, anti-racist—requires that I work on many frontsteaching, writing, and non-academy based practice_-not just to expose power relations but to overcome them... This task requires recognition that as an ethnographer and as a woman my subject position is constituted in space of betweeness ${ }^{48}$.

As indicated in this quote from Katz, fields may include, for example, the academy, a political community, an identity-based community, and/or a place-based community. Katz (1994

\footnotetext{
${ }^{48}$ The metaphor of betweeness is mentioned by Katz, Kobayshi, and England (1994). Betweeness highlights the fact that we can never not work with "others" who are separate and different from ourselves because difference is an aspect of all social interactions that requires that we are always everywhere in between or negotiating the worlds of me and not-me. Sometimes differences are culturally, socioeconomically, or politically so great such that researcher and researched find little between them to establish personal or social common ground. But even where differences are small, we are positioned simultaneously in a number of fields and always, at some level, somewhere, in a state of betweeness, negotiating various degrees and kinds of difference - be they based on gender, race, class, ethnicity, sexuality, and so on. Betweeness thus implies that we are never totally outsiders or insiders.
} 
and 1992), Kobayashi (1994), Gilbert and Masucci (2004) and Gilbert (1994), in particular, specifically discuss the fluidity of boundaries and occupation of 'spaces of betweeness' concerning these 'fields'. These feminist geographers acknowledge their varied and changing relations to their research subjects as researchers, activists, and community members through reflexivity. In addition, they critically analyze their politics and research, as well as positionality concerning socioeconomic status, race, gender, and age.

In order to understand the complexity of women's lives, their differences, and how identity is linked to both social and spatial processes other feminist geographers have highlighted other 'fields,' such as the home, community, and workplace (Ahrentzen, 1997; Falconer-Al Hindi, 1997; Oberhauser, 1997). By positioning these spaces or places as 'field,' dichotomous masculinist assumptions can be challenged, underlying social processes can be grasped, power and control mechanisms can be understood, and gender roles and divisions of labor can be resolved. This is consistent with Kobayashi's point made above that research must be conducted on the "very sites where social construc tions are produced and nourished" (1994: 78). Importantly as well, these 'fields' call attention to everyday life and the multiple dimensions of social spaces and how they relate to broader social structures (Oberhauser, 1997). They also forward the quest to overcome power relations in the research process by allowing one to engage with participants on their own terms, in their own space.

In sum, reflecting upon issues around positionality and representation through reflexivity is an essential part of feminist qualitative research because it seeks to challenge oppressive aspects of socially-constructed processes, combine the academic and political, and recognize the needs and wants of the research subjects. By exploring positionality through the reflexive approach, the researcher is provided with the ability to deal with his or her own biases and 
interpretations of the world and explore the intimate and complex relationships involved in fieldwork. By exploring issues around representation, feminists can better understand the varying gender, race, and class processes that construct identity and either empower or impede women in their daily lives. Dealing with the politics of representation in the research process also encourages feminists to develop more insightful and respectable ways of representing and supporting women and their diverse issues and concerns. Finally, qualitative methodology remains consistent with the conceptual basis of feminist research that articulates the importance of self-determination in developing and meeting the needs and wants of the research subjects to help overcome power relations in the research process.

Before concluding, it should be mentioned that while this project largely relies on qualitative methods within an ethnographic framework, it embraces quantitative methods as well. Early feminist geographical research, such as the work done by Massey (1984), McDowell and Massey (1984), and Hayford (1974), demonstrates the importance of integrating empirical analyses of gender and place with broader structures through the use of multiple methods ${ }^{49}$. The particular methods utilized in a research project must be appropriate to the research question being asked and should meet the needs articulated by those involved (WGSG, 1997). Additionally, using multiple qualitative and quantitative methods allows the researcher the flexibility to be more open to the challenges of fieldwork (Opie, 1992; Hondagneu-Sotelo, 1988) because 'the field' is constantly changing (England, 1994). A research method is a technique for gathering evidence (Harding, 1987) and in a "social world that is culturally constructed and peppered with contradictions and complexities" (England, 1994), this can be a difficult task.

\footnotetext{
${ }^{49}$ See also Epstein Jayaratine, 1991 and Rose, 1993.
} 
As articulated above, feminist researchers have argued that quantitative methodology distorts women's experiences and results in a silencing of women's own voices. Specific criticisms of quantitative methodology from feminist researchers have included: the selection of sexist and elitist research topics and the absence of research questions of central importance to women; biased research designs, including the selection of only male subjects; an exploitative relationship between the researcher and subject; the illusion of objectivity, especially associated with the positivist approach; the simplistic and superficial nature of quantitative data; improper interpretation and overgeneralization of findings; and inadequate data dissemination and utilization (Epstein Jayaratine and Stewart, 1991: 86). Given these criticisms, however, feminist researchers are working to overcome criticisms of quantitative methods and the quantitativequalitative dichotomy.

Advocates of both qualitative and quantitative methods specifically warn that the abandonment of all aspects of traditional methodology may carry political and scholarly costs (Epstein and Jayaratine and Stewart, 1991; Mattingly and Falconer-Al-Hindi, 1995). Therefore, many feminist researchers have come to advance a more inclusive viewpoint that takes the form of promoting the value and appropriate use of both types of methods as feminist research tools. The emphasis here is that researchers must use methods that can best answer particular research questions that are, of coarse, consistent with feminist goals and ideology (Epstein and Jayaratine and Stewart, 1991; Mattingly and Falconer-Al-Hindi, 1995; McLafferty, 1995; Lawson, 1995). They argue that there can be no single, prescribed method or set of methods consistent with feminist values. Feminist researchers must be critical of both quantitative and qualitative research that is used against women and be able to marshal the richest and most persuasive evidence in the service of women (Epstein Jayaratine and Stewart, 1991). 
One strategy for overcoming the qualitative-quantitative divide, according to Epstein and Jayaratine (1991), is the combing of methods through triangulation. First of all, triangulation, permits researchers to capture a more complete, holistic and contextual portrayal of the research project and subject, as well as counter balance the weaknesses of one method with the use of another ${ }^{50}$. This encourages feminist researchers to see research projects as involving a group of separate procedures or methods and consequently reconceptualize each procedure as located on a qualitative-quantitative continuum. Secondly, the use of multiple methods also overcomes the essentializing of the female voice as only qualitative which, according to Epstein Jayaratine and Stewart (1991), "ignores difference among women and makes the differences invisible by an exclusive focus on inter-sex differences" (89). Finally, Rose (1993) articulates that the use of multiple methods allows feminist methodology to seek and bring together both subjective and objective ways of knowing the world. For feminists, subjectivity recognizes roles, values, and attitudes. Usefully as well, objectivity has the ability to provide tests or theories and consequently encompasses the power to change opinions. This is essential if feminists are going to correctly and effectively direct their energies and target problem areas for change (SpalterRoth and Hartman, 1995). Importantly as well, feminist researchers must be familiar with mathematical and statistical skills and be able to evaluate and critique their use because they are so widely used as research tools (Epstein Jayaratine and Stewart, 1991). Oftentimes, they can lead to misleading findings and false generalizations. ${ }^{51}$

Fundamentally, feminist researchers must develop realistic and pragmatic strategies that allow for various implementations of feminist perspectives. Strategies may include, for example:

\footnotetext{
${ }^{50}$ For example, the true nature of rape cannot be captured in statistics so it is necessary to use qualitative methods such as interviews. However, counting rape or other sexual crimes can be useful in influencing public awareness as well as policy and program development.

${ }^{51}$ For detailed discussions about and examples of triangulation and the use of mu ltiple methods see Lawson, 1995; Rocheleau, 1995; and Rose, 1993.
} 
the critical interrogation of research topics and their potential to help women; the proposition of methods that are both appropriate to the questions being asked, the information needed, and the audience targeted; and, realizing and working to overcome the problems with both qualitative and quantitative methods. Feminists should also take critical time and effort to conduct quality research and ask what different interpretations of research results, that are of course consistent with the findings, might encourage or discourage positive changes in the lives of women.

Finally, feminists should always attempt some political analysis of research findings and actively participate in the dissemination of research results.

In conclusion, feminist methodological frameworks allow for the possibility of women's voices and experiences to be heard and seek a supportive environment for other ways of knowing. Through the use of multiple qualitative and quantitative methods and a reflexive approach that attends to issues of positionality and representation, feminist research can collect and present data that give a fuller picture of women's many activities and better analyze and work to overcome constraints on their participation and opportunities. This research contends that working for improved methodological approaches to research is just as important as theoretical work within feminist research. Methodological discussions and certain research methods often build consciousness and awareness for both researchers and the researched and contribute to the development of more effective solutions for women's empowerment.

Being reflexive, insightful, and thoughtful about the research process and both the researcher's and subject's roles in that process is of utmost importance to this research project. Because this project explores the livelihoods of women in diverse socioeconomic and geographical contexts, it is comparative, and the researcher constantly moves between the position of 'insider' and 'outsider', this methodological framework utilizes multiple methods and 
emphasizes the importance of being reflexive about the research process and attentive to issues around positionality and representation within both the research process and writing and presentation of research findings.

\section{Constructing Feminist Topographies-a Geographical Method for Analysis, Comparative}

\section{Work, and Activism}

As highlighted previously, feminist methodologies transcend masculinist perspectives that have dominated social science and challenge researchers to recognize the gendered, racialized, and classed biases of all social life. Feminist geographical analyses specifically seek a better understanding of economic, social, and cultural processes that construct people's everyday lives and encourage researchers to make connections across scales in order to reveal the complexities of women's lives and their multiple roles (Katz, 1994; 1992). Feminist geographers therefore argue that while the research project and its goals are oftentimes socially, geographically, and politically context-specific, "non- local" forces should not be ignored. According to feminist geographers, place-based, context-specific studies must connect with historically situated political-economic analyses of the material and cultural forces that structure gender and other socioeconomic relations and operate at a variety of scales (Katz, 2001; Staeheli

and Lawson, 1994; England, 1994; Mohanty, 1997b). In order to attend to issues of space, place, and scale concerning both the local and non-local forces that impact the lives of women who head households, this research mobilizes the concept of topography as a distinct research tool. This tool allows this project to reveal the specific socioeconomic and political processes and relations that affect women's livelihoods in particular places. It also allows for a comparative approach, through the construction of contour lines, which links women and particular places to 
common processes and reveals their common effects. Finally, this tool has a political component known as the counter-topography which works for a feminist praxis that can unite women globally.

Cindi Katz states, "to do a topography is to carry out a detailed examination of some part of the material world, defined at any scale from the body to the global, in order to understand its salient features and their mutual and broader relationships" (2001a: 1228). Topographies incorporate both social and physical features, attend to history, and reveal the multiple processes and material social practices, at all geographic scales, which work to produce place and space. Place and space embody social relations of gender, race, and class and 'doing' topographies can therefore 'ground' analyses of social, economic, and political difference and inequality. Through this method, Katz (2001a and b) imagines projects that maintain the distinctiveness of the particular conditions of a place, but recognize that it is analytically connected to other places along 'contour lines'. As indicated in Chapter II, these contour lines situate distinct locales in relation to particular social practices and processes, such as women's informal labor and restructuring, respectively.

Therefore, topographies are a means to illustrate the intersections of material practices and socioeconomic processes in and between places and thereby inspire a different kind of politics; one in which crossing space and 'jumping scale' are obligatory rather that overlooked (Katz, 2001; Marston, 2000; Smith, 1992a and b). Constructing precise topographies at a range of scales, from the local to the regional and beyond, enables feminists to analyze particular issues, such as the informalization of female labor, in and across place. The sites of these issues, whether they be households or free trade zones, for example, can then be mapped and connected along contour lines. These connections can then lead to the construction of feminist counter- 
topographies, which analytically and politically link different places and thereby enhance struggles in the name of common interests.

Utilizing topographies as research tools and working to construct counter-topographies through the research process relates to the construction of what Katz (1994) terms a "politics of engagement" and committed scholarship. Katz writes,

if there can be mutual learning about, and meaningful differences and workable affinities in, our positions vis-à-vis the structures of dominance, perhaps we-all participants in the work-can appropriate knowledge in ways that strengthen us in our encounters with these structures, and allow us the possibility of connecting across class, race, or gender to confront their manifestations in everyday life (70).

As research tools, topographies work to reveal socioeconomic processes and relations and how they are materially manifested in particular places and spaces but mobilized by common local and global forces. Topographies, therefore, allow feminist research to move beyond organizational and political dilemmas concerning place and identity-based politics. Constructing feminist topographies allow connections and strategies that are based on precise analytic relationships to particular structures, such as global capitalism, and its associated processes, such as economic restructuring to be developed. Once these connections are established, associated issues, such as the informalization of work, and their material manifestations, such as poor working conditions, low wages, no health benefits, and few labor regulations, can be revealed. A politics of engagement is consequently established around particular issues and concerns, rather than place or identity, and strategies designed to combat these can be developed and exchanged.

Utilizing topographies as research tools and working for a politics of engagement also reveal the importance of conducting comparative, feminist work. Women in various parts of the world are embedded in common capitalist, colonial, and patriarchal structures that restrict their social, economic, and political abilities and opportunities. These structures establish social 
hierarchies and power relations and have very real, material consequences that place women in precarious and oftentimes desperate situations, such as the sex-tourism business, free-trade zones, under 'the veil', and as heads of households. Comparative work and a global feminist praxis are empowered by geographical feminist work, such as topographical analysis. This type of work can reveal the similar consequences of capitalist, colonial, and patriarchal processes in women's local lives, spaces, and places and connect them across culturally-constituted difference and place by drawing contour lines. Counter-topographies, that are able to appropriate power and resources at local, regional, and global scales and work for a global feminist praxis, can then be established.

This research will employ topographical analysis through both quantitative and qualitative research methods such as surveys, interviewing, and focus groups. It specifically aims to construct feminist topographies of women's livelihood strategies in West Virginia and Limpopo and begin to map the sites of women's participation in rural economies today. This form of inquiry is useful to this research project as it attends to the multiple processes and relations that affect the material realities of female-headed households and their economic practices. With respect to this research, feminist topographies can address the rurality and physical geography of the case study areas and the production of the Appalachian region and bantustan areas as distinct places that are affected by common global processes.

Topographies also enable the research to examine the historical economic geography of women's marginalization in West Virginia and Limpopo and reveal the interconnections between socioeconomic and cultural struc tures of apartheid, patriarchy, and capitalist economic development and current processes of regional and global economic restructuring. By realizing the embeddedness of social relations in space and place, topographies also allow for local, 
context-specific studies within households and communities that are connected to 'non-local'

forces. Topographies reveal the 'interrelatedness' of local, regional, and global processes and deconstruct scale as the organizer of geographical difference. In sum, feminist topographies address the research questions and objectives highlighted below and forward new theoretical and methodological discussions concerning female-headed households and their socioeconomic positions, economic strategies, and concerns across diverse rural contexts. This research intends to assist in the construction of a feminist counter-topography that recognizes common interests and concerns among female-headed households and their attempts to 'make it' in rural parts of the world today.

\section{Statement of Research Questions}

Embracing a feminist methodological framework, this research seeks to provide an analysis of women's roles in rural economies and how they are affected by socioeconomic and spatial conditions that operate at household, community, regional, and global scales. It specifically focuses on the socioeconomic processes that affect female-headed households and their economic participation and livelihood activities in parts of Appalachia and South Africa.

In relation to the research objectives outlined in Chapter I, the research answers the following questions:

1) What are the specific socioeconomic and spatial processes that affect women's participation in rural economies and contribute to women heading households in West Virginia and Limpopo? Specifically, what is the historical socioeconomic background of these two regions?

2) What is the social differentiation both within and between women in the two regions? Where are women situated within formal and informal employment structures and how have these structures changed in recent years? What sorts of income-generating activities 
or forms of employment are available to women in these regions and what conditions contribute to female-headed households and their social, economic and political realities?

3) What are the livelihood strategies of female-headed households in rural West Virginia? In Limpopo? In particular,

a) How are the activities organized and where are they located?

b) How do they contribute to household incomes and what is the time spent on these activities?

c) Do the activities provide women with access to education, training, childcare, credit, or health and retirements benefits? And,

d) What are the material and non-material benefits and drawbacks of women's activities?

4) What is the relationship between women's livelihood strategies and household and community gender relations and community and family networks of support? Specifically,

a) What do women see as their primary roles within households and communities and how do wo men value their contributions?

b) What is the distribution of power and resources within households and communities?

c) What family and community resources are utilized within women's strategies? And, how vital are these resources to issues of well-being?

5) Finally, what is the relationship between livelihood strategies utilized by women heading households and the effects of restructuring and changing economic and social policy in West Virginia and Limpopo? Particularly,

a) Are women in the two areas utilizing current social or economic policies, programs, or initiatives? If so, how are they working? If not, why not?

b) According to the women involved, what role, if any, should the government play in assisting them in acquiring a sustainable rural livelihood?

c) What do women involved in the study identify as the particular barriers or opportunities to building sustainable livelihoods for themselves and their families?

These questions reflect the commitment made by this research to recognize the importance of local context, but also broader socioeconomic structures and issues. Examining women's socioeconomic situations and strategies in diverse contexts and making connections across space, place, and scale is a profoundly geographical project. Therefore, this research requires multiple research methods to achieve topographical analyses of women's livelihood activities in rural West Virginia and Limpopo. 


\section{Methods Utilized to Research Women's Livelihoods}

Analyzing women's roles in local economies and their livelihood strategies involves examining gender relations, that is the relations between men and women in particular locations and times, and leads to new understandings of differences in power, divisions of labor, and differences in perspective which influence all aspects of social life. Analyses such as this interrogate women's participation in local economies, as well as the institutions that support those economies, such as the state and family. These types of analyses examine statistical information such as labor force participation rates and income and occupational and unemployment data as well as poverty rates, social service data, and educational attainment information among and between women and men as well as conduct fieldwork with women about how they 'make due' on a daily basis.

Consequently and in order to achieve the objectives and answer the questions highlighted above, this research project utilized a variety of research methods. First, the researcher compiled detailed background information concerning the socioeconomic history of women in Limpopo and West Virginia. This was conducted to provide a conceptual understanding of the processes that affect women's economic participation and livelihood activities in the two regions. This information was obtained from extensive library research conducted in South Africa and Appalachia and is presented in a comprehensive literature review (Chapter II), the background chapters (Chapters III and IV), and also within the analysis section (Chapter VI). Including both statistical and textual data, this research includes a review of both academic and government studies on women's economic participation and livelihood activities in the two regions. It examines and compares labor force participation, unemployment, and poverty rates, as well as sectoral data concerning employment among and between women in Limpopo and West 
Virginia. The United States Census Bureau and West Virginia Bureau of Employment Programs, concerning women in West Virginia, and the Central Statistics Service (CSS) and Development Bank of Southern Africa (DBSA), concerning women in Limpopo, are utilized as secondary data sources. This information is utilized to make comparative comments and discern some general trends relating to women's socioeconomic conditions in Central Appalachia and the former bantustans of South Africa.

Second, the researcher engaged in qualitative fieldwork conducted in West Virginia and Limpopo to assess the livelihood strategies of female-headed households. Selected through snowball sampling, twenty-one women in Limpopo and eighteen women in West Virginia were interviewed and the sample population adhered to the definition of female-headed households put forth in Chapter III. In South Africa, all of the women resided in what was formerly the Venda bantustan and is now, Limpopo. They were all black and members of the Tshivenda community. They covered all ages and engaged in a variety of livelihood strategies to support their families. In West Virginia, the women interviewed were from Harrison, Marion, Monongalia, Preston, and Taylor counties in the north-central part of the state. They also covered a wide-range of age groups, from 19 to 75 years of age, and income categories, from between $\$ 10,001-15,000$ to over $\$ 30,000^{52}$. All but one respondent was white. Contacts acquired through previous research in the two regions were used to facilitate the initial process of contacting women to participate in the study.

The fieldwork portion of this study included a socioeconomic survey concerning demographic, household, educational, and income and employment data and in-depth, semistructured individual interviews. Separate surveys and interview questions were developed for

\footnotetext{
${ }^{52}$ The socioeconomic and demographic characteris tics of the women interviewed are explained in great detail in the following analysis chapter.
} 
West Virginia and Limpopo in conjunction with local researchers who had particular insight into the specific research sites and women's roles in the local economies. The individual interviews focused on the particularities of women's livelihood strategies concerning organization, location, material and non-material benefits and drawbacks, access to resources, and viability. The interviews also addressed the relationship of these activities to women's status as heads of households and in the context their rural locations. In addition, the interview process sought information concerning household and community relations, women's roles and responsibilities, and familial and community resources and support. Finally, the interviews addressed women's involvement in economic and social programs, the role of government in the provision of social and economic resources, and barriers to and opportunities for women economically in the two regions. The survey was conducted at the beginning of the interview process and was followed by the more semi-structured, individual interview. The entire process, including the survey and interview, required one to three hours of the respondent's time depending on the time available and the relationship between the researcher and respondent.

In addition to the surveys and individual interviews, the fieldwork consisted of group interviews and focus groups in West Virginia and Limpopo. The researcher was a field assistant to Dr. Ann Oberhauser's work on women's producer groups in Limpopo during the summer of 2001. During this time, the researcher was able to collect the data for this project and be a part of this related research. Oberhauser's research conducted thirteen focus groups with women's producer groups in Limpopo and the researcher assisted in the collection of this data and was granted access to the data for this research project. The twenty-one individual interviews for this project were facilitated through the focus groups and included women working with these 
producer groups. Individual interviews were conducted at the worksites of the producer groups with women who volunteered to be interviewed.

The focus groups, in particular, reflected a variety of women's livelihood activities in the region including agricultural production and trade, manufacturing, food processing, sewing, and construction work. The focus groups were conducted with representatives from each of the thirteen groups studied and the representatives were self-selected and generally comprised the chair or manager of the project, as well as others who were working at the time of the visit. The focus groups involved four to six members and all of the discussions were conducted on scheduled work days, allowing the researchers to observe the daily operations of the projects. The focus groups were facilitated by the researchers who gave project members the opportunity to guide the discussion (Photo 1). Topics included background information such as date of establishment, number of members, and location; materials, production strategies and markets; decision-making and organization of the groups; financial support and training; and future plans $^{53}$. Due to high unemployment rates, the incidence of migrant labor, and death, many of the women in these producer groups were the heads of households. For example, when the members of the Tshandama Community Bakery were asked how many were the heads of the household, eight out of the ten female members raised their hands (Focus Group, Tshandama Community Bakery, July 12, 2001). Thus, the focus groups provided an additional forum of exchange between the researcher and respondents and further information concerning the livelihood activities of women who head households in Limpopo ${ }^{54}$. The research in South Africa also

\footnotetext{
${ }^{53}$ For a detailed reading on this work concerning women's producer groups in Limpopo see Oberhauser and Pratt, 2004.

${ }^{54}$ For the extensive time required to conduct both focus groups and individual interviews, a donation was made through Dr. Oberhauser's National Science Foundation (NSF) Grant (\#SBR 9906626) to all of the producer groups that participated in the study. It is only through the support of Dr. Oberhauser that the South Africa component of this research was possible.
} 
included an interview with a local chief. This was not an intended aspect of the fieldwork but a result of the interviews and focus groups conducted. It provided valuable information on local economic development, land use, the current role of the chieftaincy in the democratic government, and the role of women in the local culture and economy.

The research conducted in Limpopo required research assistants and interpreters and their knowledge about local customs, local environmental conditions, and livelihood activities in the area were critical to the success of this component of the project. They attended all research meetings and were responsible for the initial identification of women's producer groups. As members of the Tshivenda community, they described the project and introduced its participants at every site visit, focus group, and individual interview, translating the discussions and interviews from the regional languages (sePedi and Tshivenda). All of the research assistants were also paid for their participation in this project ${ }^{55}$. Most of the interviews and focus groups were taped and transcribed. Extensive field notes were taken by the researcher and research assistants for all focus groups and interviews, as well as photographs.

In contrast to the collaborative research process that took place in South Africa, the fieldwork in West Virginia was conducted by the researcher alone. As stated above, eighteen women were individually interviewed. Sixteen of the interviews were conducted in the respondents' homes and two at a local restaurant ${ }^{56}$. Every effort was made by the researcher to respect the busy schedules of these women and their families. The researcher was welcomed

\footnotetext{
${ }^{55}$ The researcher would like to personally thank Agnes Musyoki, Virginia Maimela, Madzinghe Nembudani, Josephine Mudau, and Reuban Ramudzili for their hard work and support. Their dedication to and knowle dge of gender issues and rural economic development in Limpopo is exemplary. The researcher would also like to acknowledge the members of the community groups that participated in this study and thank them for their time and patience during the fieldwork.

${ }_{56}$ The researcher would like to personally thank all of the women in West Virginia who participated in this study. Their time was greatly appreciated and their thoughts, ideas, and experiences added tremendous insight and credibility to this research project.
} 
into the homes of these women and was sensitive to their living situations and duties while conducting the interviews (Photo 2). Children were almost always around and their needs had to be tended to over the interview. In addition to the individual interviews, two group interviews were conducted. Interestingly, the group interviews were conducted with multiple women who were either divorced, widowed, never married, or the primary breadwinner for their family and living together for support. This was not an intended aspect of the fieldwork but an interesting household strategy discovered through the fieldwork.

The fieldwork in West Virginia also included an interview with a West Virginia Department of Health and Human Resources (DHHR) employee that had particular insight into the many state-sponsored social programs utilized by many of the women interviewed. The research also included site visits to and phone interviews with staff at several non-profit and charitable organizations, such as Heart and Hand, the Salvation Army, and Vision Appalachia. These organizations were mentioned and also utilized by women interviewed. Again, interviewing a DHHR employee and visiting and learning about non-profit and charitable organizations operating in the research area were not intended aspects of the fieldwork set forth in the research proposal. However, they were important outcomes of the interview process that had to be explored further. All of the interviews conducted in West Virginia were tape-recorded and transcribed by the researcher. Extensive notes were taken after visiting and talking with the various non-profits and charitable organizations and certain promotional material from some of the organizations was obtained. With permission, the researcher also took photographs of many of the women interviewed as well as their children, homes, and communities. The photographs provide this research with a visual record of the research setting, respondents, and wider 
community and are utilized with great respect for the respondents and their community members. The fieldwork in West Virginia began in October of 2001 and concluded in August of $2004^{57}$.

Finally, the fieldwork component of this project also included observations and reflections from the researcher. These observations and reflections concerned the content addressed in the interviews and focus groups, relations with participants, and information on the research setting and local community and environment as well as the researcher's personal feelings and issues about the respondents and research process. These reflections and observations were notes made by the researcher at various points in the research process.

Concerning data management and analysis, the surveys were compiled and analyzed utilizing Microsoft EXCEL. Again, the interviews and focus groups that were taped, were transcribed. The content analysis of all interviews, focus groups, and the researcher's field notes was done utilizing QSR NUDIST, a statistical program that assists with the management and compilation of non-numerical data. As will be seen in Chapter VII, the research develops a typology of women's economic activities in and between West Virginia and Limpopo and analyzes common and differing issues concerning women's socioeconomic conditions and everyday material realities in the two areas. The information obtained is related to broader issues of restructuring, patriarchal relations, colonialism and apartheid, and economic and social policy, regionally and globally.

The following section describes various field experiences from the view of the researcher. This section is based on the field notes of the researcher and discusses the very personal and intimate issues involved in qualitative fieldwork. It utilizes the reflexive approach

\footnotetext{
${ }^{57}$ The extended period taken to complete the fieldwork in West Virginia was do to the fact that the researcher no longer lived in the research area and had to make various trips to organize and complete the interviews.
} 
to discuss issues around positionality and representation and the research process in both Limpopo and West Virginia.

\section{Experiences from 'the field'}

The "I", the "Me", "the Researcher"

While qualitative research is a very intrusive and personal journey into the lives of the respondents it is also oftentimes a very personal process for the researcher. For feminists, the research topic often reflects the researcher's own concerns and political views about a place, people, or issue. This particular research is intertwined with my, as the researcher, analyst, and author of this work, own personal convictions and concerns for women and love for West Virginia and South Africa. Consequently, I feel is it necessary to first reflect upon my own history and personal life as it connects to this research project.

I was raised in Simpson, West Virginia, a very rural community in Taylor County (Map 7). I am the first in my family, on both sides, to be college-educated and the first of the grandchildren on both sides to move out of the state. My dad is a trained welder but due to economic recession in the early 1980s resulting in a lay-off from Ingersol Rand, a manufacturer of large equipment, he now works construction. My mom worked on and off over the years selling real estate and doing social work but was mostly a stay-at-home mom to my brother and I. Both my grandfathers were coal miners and my dad's father, William Fowler, was killed in a mining explosion in 1963 when my father was senior in high school.

Growing up, we were middle-class in our community but certainly lower-class by United States standards. We never received what my Grandpa Zirkle called 'relief' and we always had 
what we needed. My mother and father made every sacrifice possible to provide my brother and me with food, clothing, and opportunity. There was little left for savings and I put myself through college by getting student loans and working a couple of jobs at a time.

School, church, family, and community activities kept our family busy. My mother has six brothers and sisters, my dad has two brothers, and I, consequently, have lots of cousins. We were very involved in church activities such as choir, Sunday school, and youth groups and my mom was the youth director and my dad a trustee at our church, Union Baptist. My dad also started a community sports league called the Taylor County Youth League, which is still operating today, that organizes a baseball league in the summer and basketball league in the winter for kids of all ages. He worked to get funding for the construction of baseball fields, basketball courts, and tennis courts in our community and devoted years to the operation of the Youth League. I grew up with big family dinners on Sundays, huge holiday and birthday celebrations, and lots of summer picnics.

I went to a very small high school in Flemington, West Virginia. I had only fifteen students in my class and many of the teachers taught at the school when my parents attended there in the 1960s. It was very supported by the community and the students had close, mentor relationships with many of the teachers. It was a very supportive learning environment with dedicated teachers, parents, and students working together. As is quite evident, I grew up with an extended network of family, teachers, and church and community members who loved and supported me. Love and concern for family and community was instilled in me at a very young age and has led to my interest in feminist research that is concerned with improving the lives of women in rural areas and community development issues. 
I also have a great love for Appalachia and West Virginia, in particular, as a place. When I drive home (yes, West Virginia is still 'home') from Atlanta, Georgia and hit 77 north into the mountains I just breathe in and think, "I'm home". It is a love for the beauty of the place and its people - a love that comes from the way places are long made in our psyche through the geography of life.

My interest and love for South Africa came later during my undergraduate years at West Virginia University. During that time, I was an International Studies major with a focus on Africa and the Middle East. I found my way to geography through the interdisciplinary nature of international studies and soon realized that it was only through geography that the world made any sense. I met Dr. Dan Weiner through an introductory World Regions course and he and his teaching assistant, Urmilla Bob, who was from South Africa, encouraged me to take Geography of Africa the next semester. It was through this course and Dan's teaching that I knew I had to get to Africa, particularly South Africa. I continued to take courses in geography and after I had a graduate course on Regional Development as a senior, I knew I wanted to attend graduate school. Dan encouraged me to pursue graduate work and to continue to focus on Southern Africa.

During my first year of graduate school I became interested in women's issues and wanted to explore women's roles in economic development in South Africa. I became close with Dr. Ann Oberhauser and she encouraged me to design my thesis project around women and their participation in economic co-operatives in South Africa. She was also interested in these issues and had long been doing work in rural Appalachia with women and their participation in cooperatives and economic networks. It was through Ann, Dan, and Dr. Calvin Masilela and their connections in South Africa that I was able to conduct my thesis research in the country. 
I went to South Africa during the summer of 1997 to conduct the fieldwork for my Master's thesis. It was a life-changing experience for me that deepened my love for the country, its dramatic history, and beautiful people and landscape. I spent most of my time in the former bantustan area of Bophuthatswana doing my research and was humbled by the generosity and kindness of people. This experience made me reflect upon who I was and my place in the world. I realized what it was like to be the 'different one,' 'the outsider,' and was confronted head-on with my 'whiteness,' my gender, and my geography: American, first world. I realized both the 'connectedness' and 'disconnectedness' of the world; how what we do and think, consume and throw away, care about and discard, and talk about and ignore impact those elsewhere in the world and that time, space and place, and scale often hide their consequences from us if we are not aware or concerned.

I had overwhelming academic and personal experiences on this first trip to South Africa. I was continually struck by the stark physical and human geography of the country: modern cities, beautiful residential neighborhoods, and then sprawling shacks with raw sewerage running in the streets; fields upon fields of fruits and vegetables, nuts, and cattle but people without land and food to eat; black people, white people, coloured people, and Indian people but very few intermingling to enjoy a laugh or handshake. I admired the women I interviewed in Mathateng in the Molopo River region who were paying the local school teacher, who had not received a paycheck from the government in weeks, to stay and teach their children. I was overwhelmed by the little children at a crèche inside the township of Alexandria just outside of Johannesburg who wanted to touch my skin and hair because it was so different from theirs. I cried when I held a baby boy, adopted by a professor at a local university, who had been left at a garbage dump. I was shocked when the house I was staying in with some university professors was robbed. I 
marveled at the sight of wild elephants, rhino, and lions in their natural habitats. I enjoyed shopping at the local stands for fresh produce and crafts and getting to know the local traders and shop owners. I was astounded by the presence of the Mmabatho Sun, a plush hotel with a casino, in the middle of the former 'Bop' bantustan. I fell in love with my host family, the Drummonds, especially their little girl, Fiona. I laughed, ate and drank, and danced at the many braai's held to welcome me into the community. South Africa had, for so long, been that 'imagined' place, revealed to me only through books, pictures, and those who had been there before. It was now mine to embrace, ${ }^{58}$ if only for a short time, and it became 'that place' made real in my mind and heart through these wonderful experiences I knew that this was not my last trip to this amazing country.

I finished my thesis in 1999 and went on to pursue a $\mathrm{Ph} \mathrm{D}$. I continued to be interested in South Africa and began to think more about the 'connectedness' and 'disconnectedness' of women in the world. I had seen the parallels between Appalachia and South Africa concerning the processes of development and underdevelopment, the exploitation of land and labor, and women's marginalization from economic participation. I began to critically think about how a research project could both analytically and methodologically compare and contrast women's participation in Appalachia and South Africa. Then, feminist geographer Cindi Katz visited the Departments of Geography and Women's Studies at West Virginia University and delivered a talk on feminist topographical analysis. She had developed a path for feminist comparative work that I could work with and utilize for my own comparative work. Dr. Oberhauser was also beginning her own work on women's producer groups in Appalachia and South Africa and

\footnotetext{
${ }^{58}$ A South African barbeque.
} 
offered me the opportunity to serve as her research assistant and return to South Africa. Hence, this dissertation research project was born.

\section{Limpopo: doing fieldwork abroad}

Conducting fieldwork in a different country is always a daunting task. There are major logistical issues, such as travel, accommodations, funding, and time, that can delay or totally derail a research project abroad. There are also, oftentimes, cultural and racial differences, as well as language barriers, that must be attended to when working in a different country. Fortunately, the South Africa portion of this project was facilitated by my previous research experience in the country, Dr. Ann Oberhauser's NSF grant, and the West Virginia UniversitySouthern Africa Linkage Program that has established research and student exchange partnerships between West Virginia University and the University of Venda. Collaboration with the University of Venda through the Linkage Program helped to facilitate travel arrangements and living and work accommodations in Thohoyandou, the largest city in the area and home to the University, as well the hiring of research assistants and a driver for the fieldwork.

Conducting interviews and focus groups about very personal issues in a woman's life, such as finances, their household and household duties, family, and even HIV/AIDS, requires sensitivity and respect on the part of the researcher and her assistants. It is only through the help of the field assistants that this research could delve into those difficult issues with careful consideration of and sensitivity to local culture and gender relations. Consequently, much time was spent developing a relationship with the research assistants. Work began before I even arrived in South Africa through emails that outlined my research interests and role with Dr. Oberhauser's project. Once at the University of Venda, many research meetings and site visits 
took place before the fieldwork began. This gave us insight into the community and fostered a collaborative relationship with the research assistants. The research assistants described the field site areas, Venda culture and customs, and provided valuable feedback on the socioeconomic survey and questions for the focus groups.

My positionality, as Dr. Oberhauser's research assistant and student, allowed me to be seen not as someone in charge but as more of an equal to the other research assistants. However, my 'whiteness' and geographic location, as first world/United States, always seemed to place a distance between us. Perhaps a longer stay and deeper relationships with these fieldworkers in Limpopo would have bridged this distance. I thoroughly enjoyed working with them and both admired and appreciated their patience, knowledge, and sensitivity during our fieldwork.

The fieldwork for this project was difficult but very rewarding and informative. Much time was spent traveling around the greater Thohoyandou in the University van giving us plenty of time to get to know our field assistants, the area, and reflect upon the research itself. Our field assistants were eager to work and very comfortable talking with community people. Virginia, one of our field assistants, had done research for her Master's Thesis in Matangarie, one of the areas we were working in. All of the research assistant were Venda and from the greater Thohoyandou area.

With regard to the respondents, as recorded in my research notes:

People have been very willing and easy to talk to but there are very few whites around and I can't help wondering what they must think of us. We are quite an entouragewhite and black women traveling around together in van with notebooks and cameras and asking all kinds of questions. People stare, as can be expected (Research Notes, July 10, 2001).

Because our field assistants were so comfortable and adept at introducing us and the project to the many women we worked with, it was easy to organize time for interviews and 
focus groups. Ann and I were very careful and non-intrusive, letting the field assistants take charge of the introductions and organizing at every site visit. It was absolutely essential to this project that we trust and have full confidence in their abilities and that we be seen as respectful guests in these communities. The language barrier, however, made it difficult to develop one-onone relationships and really engage with the respondents and we relied upon the field assistants to communicate with us about each interview and focus group and the dynamics. Concerning these dynamics, my research notes state:

In the group interview (at Mvuleleni Sewing Group), there was a strong woman articulating issues about women's situations and rights. Josephine and Virginia, who were interpreting the focus group, were calling her a feminist...The research process is interesting here. While doing work in the United States, we often become close and develop relationships with our respondents. Here however, we are developing strong relationships with our field assistants. We rely so much on them to communicate about not only the content of the interviews and focus groups but also the tone and nuances of the conversations-language is a major barrier in this context-making it very difficult to connect with the respondents and have long conversations about issues raised (Research Notes, July 16, 2001).

Despite the fact that the interviews and focus groups were tape recorded, Ann and I took careful notes during the interviews and focus groups. This helped to further document the interviews and focus groups and provided information that could be reflected upon between the two of us and with the field assistants at research meetings.

Visiting the many communities in Limpopo and talking with the women about their lives and livelihoods was a rewarding, yet humbling experience. We were continually amazed by the many women organizing themselves into economic groups and small businesses and their resourcefulness in devising diverse strategies to feed, clothe, and educate their families. One group of women had formed a community bakery where they sold baked goods as well as sodas, candy, coffee and tea, sugar, and milk. They had received funding from the Limpopo government and had a nicely-equipped building with a storefront, large kitchen with numerous 
appliances, ovens, refrigerators, and tables, and an office. They were taking home a profit and seeking to expand the business. In contrast, we were humbled by the scarcity of productive and reproductive resources that are available in theses communities, women's living and working conditions, and the impacts of HIV/AIDS. For example, at a stone crushing project in the community of Tshandama, we were astounded by the labor conditions. Women carried stones from the riverbed to a structure made of sticks and cloth where other women crushed them with a mallet by hand. It tried it — the mallet was very heavy and crushing the stones into small gravel like pieces was not only difficult but dangerous. One woman had a large gash in her shin from gravel flying around in this small area. These women work everyday from 8am to 4pm and are putting all money earned back into the business to buy stone-crushing machinery. This was a very humbling time for me and an experience I will never forget.

We would end everyday with many more questions and some frustration with the language barrier. We were always a little unsure of where we stood with the communities and never felt like we were 'insiders', despite our closeness with the field assistants. We were white, which always makes you suspicious, but not South African Afrikaans or English. Many of the respondents were curious, because we were from the United States, and wondered why we thought their lives and communities were so interesting. Many also thought we had access to money in the form of grants or loans and that we were connected to the government or international funding organizations. We constantly had to emphasize that we were from the University and that this was purely a research project. We did pay all of the groups for their time and this often created quite a scene, as recorded in my research notes:

As we were leaving the Rambuda Stone Crushing Project, Ann handed the group some money in appreciation for the ir time. Well, this created quite a scene. The women began dancing and singing (Photo 3) and laying on the ground in the traditional Venda way of expressing thanks and gratitude (laying on one's side, with hand in the prayer position) 
(Photo 4). They were so jubilant over this, we couldn't believe it. They thanked us over and over again. We took lots of pictures and were happy we could give them something. Some of them chased the van as we were leaving (Research Notes, July, 13, 2001).

It was moments such as this and the interesting women we met and stories heard that makes research abroad such a wonderful and rewarding experience.

West Virginia: doing fieldwork 'at home'

Doing research at 'home' in one's own place- the place where you were born, reared, and shaped—conjures up a mixture of feelings. It can be both comfortable and uneasy and familiar and strange. It is an experience that forces you to reflect upon a place, its people, and yourself in ways that you have never done before. You are required to be the 'researcher' and critical 'thinker' about a place and its people that are so familiar to your life and close to your heart.

My home, meaning the house I grew up in, was the base for this research project and contact was made with respondents in a variety of ways. Initial contact was made with a few respondents and then a snowball sampling method was used to identify additional women to interview. I also interviewed women that I knew personally or ones who were referred to me by friends and family who had knowledge of the project. A mixture of respondents that I knew personally, had a minor acquaintance with, and total strangers made for interesting fieldwork experiences and affected how I was viewed by each respondent and consequently, the information gathered. I was familiar with the geographic area where all of these women lived. I grew up in Taylor County, had worked in Harrison County, and had lived and went to school in Monongalia County. 
Finding women to interview was easy however finding the time to sit down with them for a couple of hours to conduct an interview was difficult. These women have very busy lives: they are raising children and taking care of homes, largely alone; many are working more than one job and must also attend to their reproductive duties; many participate in church and other community activities; and sometimes, they need to sleep. I fully respected their schedules and was, of course, willing to work around their lives in order to hear their stories. Consequently, some of the interviews were conducted during a lunch hour at a local restaurant or over dinner with the kids around. I was most always in the respondent's home and this provided unique insight into their lives and livelihoods. I also took my one-year old daughter to a couple of the interviews and this encouraged great dialogue between me and the respondents regarding childcare and childrearing. I am very grateful and appreciative of the time these women gave me and their honesty and insightfulness about women in Appalachia and their livelihoods.

It is important to note that between the fieldwork in South Africa and Appalachia, my life had totally changed. My husband had graduated with his Ph D in Chemistry and we had moved from Morgantown, West Virginia to Kansas City, Missouri and then to Atlanta, Georgia. We were no longer poor graduate students living is a small house but professionals with a great salary, big house, and nice cars. We had also become parents and my new role as a mother greatly increased my sensitivity toward women and their struggles to provide for their families.

I initially thought that having conversations about women, their jobs, and raising a family in West Virginia would be easy. I had prior research with women in the State and thought that I was a well-informed researcher. I was about half right and half wrong. I did have an understanding of the economy in West Virginia, women's roles in that economy and households, and also daily life in these communities. What I was not prepared for was the stories about how 
these women became heads of households and the emotional aspects of those circumstances.

Stories about divorce and extramarital affairs, domestic violence and child abuse, the death of a spouse and becoming a widow, and poverty were heartbreaking and resulted in many tears, hand holding, and hugs during these interviews. I oftentimes left interviews with feelings of not only sorrow and concern for this women but also anger at myself for asking them to reveal so much of themselves. From my research notes:

I got in my car and just put my head on the steering wheel and cried with not only sadness but also anger at and disappointment with myself. Tracy's ${ }^{59}$ husband had died just a few months ago and here I was intruding on her grief for my own benefit. This interview was painful...she cried, I cried, her boys cried... about all that had been lostnot only a husband and father but also the breadwinner. Times were tough... and they were just getting by emotionally, physically, and financially (Research notes, August 9, 2004).

Despite the emotional aspects of their lives, women were very open and willing to talk to me about their employment situations and family and community lives. I was welcomed into their homes and oftentimes they had just as many questions as I did about the research, other women I had talked to, information I was getting, and why I found their lives so interesting. We all had things in common concerning our backgrounds and where we were from and we were all mothers. Like myself, all of the respondent's, except one, were white and we all, of course, spoke the same language.

The interviewing dynamics were interesting in this context. My positionality when interviewing strangers was always fluctuating. One moment, oftentimes because we had similar upbringings in West Virginia, I was very much an 'insider' into their lives. However, when the conversation turned to particular family and household situations or livelihood strategies, I oftentimes could not identify with their situations and felt very much as an 'outsider'. After all, I

\footnotetext{
${ }^{59}$ To protect the privacy of the respondents, all names have been changed in all explanations of the data gathered.
} 
was college-educated, upper class, and a professional-in-training when most of my respondents were high-school educated, low income, and working non-professional-type jobs. One respondent told me: "you're a smart girl, you got your education and got the hell out of here...there's nothing here, no jobs and certainly no good men." (Research notes, April 20, 2002). In some of the interviews, I was reluctant to reveal a great deal about myself because my current life and socioeconomic situation was so different from theirs, despite my similar upbringing and social class as a young person.

When interviewing people that I knew personally, the interview was oftentimes more complex and oftentimes more detailed. With these respondents, less time was needed to cover background material and clear up logistics, such as marital situations, household composition, and even work histories, before moving on to detailed discussions about how they manage their households, their work situations and community life, and their future. I could probe more indepthly into the personal lives of these respondents because I knew them well and was comfortable with them. For example, one of the respondents I interviewed had divorced a few years before I interviewed her due to her husband's extra- marital affair. I knew all of the very personal details of this very messy divorce prior to the interview. At the interview, therefore, we could really delve into the emotional and financial issues around this divorce and their impacts upon her and her family without having to cover all of the background information about the divorce. She felt comfortable talking with me about these issues because I was familiar with the situation. She would say things, like, "Well, you know how Matt (the ex-husband) is... or "Do you remember when this happened...?" and I could easily follow along. Many of these interviews were very long and I always hated to cut people off when they so graciously offered their time to me. 
When interviewing people I knew personally, I also tended to know when a subject might be off limits for discussion due to certain circumstances in their family or work situations or body language. Many of the respondents that I knew personally also felt comfortable saying to me, "that is something I don't like or want to talk about." My changed socioeconomic situation didn't matter to these people because they all knew me 'when' and I was an 'insider' to not only their communities, but also their lives.

Conducting research 'at home' was both rewarding and humbling for me. It was rewarding because I felt like I was gathering accurate, personal information about women in Appalachia and would have the ability to tell their stories 'in their own words'. I was also able to reconnect with some old friends and revisit some community members and community issues. It was also a humbling experience for me. I interviewed women my age with children in middle school and because they had children so young, were never able to go to college. I just kept thinking, "I could be them and they could be me" and pondering the differences in our lives. I was also disturbed by the profound struggles that women are facing today in their attempts to support households concerning the West Virginia economy, the Department of Health and Human Resources, and society at large. I was continually frustrated by the lack of commitment we, as a society, have toward family and our children. I hope that the information gathered through this research project tells the stories of these women in such a way that the myths of lazy, welfare, single mothers, are dispelled and that it leads to a better understanding of women's complex socioeconomic roles in Appalachia and their profound dedication to their families. 


\section{Summary}

This chapter presented the research design of this project. It highlighted the conceptual basis for qualitative fieldwork, as set forth by feminist geographical work, and how feminist topographies are utilized as methodological tools. It also presented the research questions being asked by the research project and discussed the particular research methods utilized to collect the data. Finally, it included a discussion of the fieldwork from the view of the researcher, highlighting the importance of utilizing a reflexive approach in qualitative fieldwork.

In sum, this research collected data that give a fuller picture of women's diverse livelihood activities in West Virginia and Limpopo and analyzes the various processes, locally, regionally, and transnationally, that affect their quest for sustainable livelihoods. The data collected and analysis are presented in the following chapter which details the lives of women heading households in West Virginia and Limpopo. It tells the stories of women working to support themselves and their families and the many challenges they face. It describes encounters with the state, community figures, and family members in wo men's daily struggles to and triumphs in making a living for themselves and their families. It highlights the nature of rural economies in these areas and women's conditions and positions within these economic spaces. Importantly as well, it demonstrates the strength and resiliency of women and highlights their own unique ways of 'making due' in rural parts of the world.

As will become evident, there are significant differences between women in the two regions. However, this study begins to construct a feminist 'politics of engagement' that allows women to communicate their common issues and concerns and exchange information on strategies through topographical analysis, the drawing of contour lines, and the construction of 
counter-topographies. It is only through comparative work that a true understanding of women's geographies, both locally and internationally, will be achieved. 


\section{The Livelihoods of Female-Headed Households in Limpopo, South Africa and West Virginia, Appalachia}

\section{Introduction}

Livelihoods of female-headed households encompass the material realities and ideological processes that shape and are shaped by economic strategies in diverse geographical locations. This research examines women's multiple livelihood strategies in two geographically and socioeconomically diverse places, South Africa and Appalachia, within the context of global restructuring. This analysis shows that despite differential, place-based opportunities and constraints, similarities exist in women's livelihood approaches within and across these different geographic locations.

A livelihoods approach, introduced in the mid 1980s by Chambers (1983), accounts for resources (what people have), strategies (what people do), and outcomes (the goals people pursue). This approach offers a people-centered perspective that allows detailed insight into the impacts of changing macro-level economic circumstances on local communities, households, and individuals (Francis, 2000). As indicated in Chapter II, the conceptual framework provides a basis for analyzing, understanding, and managing the complexity of livelihoods (Carney, 1998), through its efforts to capture the dynamic, historical, and relational processes that inform the ‘diverse ways people make a living and build their worlds' (Beall, 2002; Bebbington, 1999 p. 2021). Furthermore, a livelihoods approach facilitates the disaggregation of households according to the different goals they pursue and shows people to be active agents responding to social and economic change within the circumstances in which they find themselves (Oberhauser et al. 2004; Beall and Kanji, 1999). Because it provides a means to link macro-level processes 
and micro-level outcomes and responses, a livelihoods approach also provides us with a view into how people are coping with or adapting to both global and local socioeconomic processes.

This chapter presents the fieldwork conducted for this project and initially discusses the case study areas through socioeconomic and geographic data. The discussion then describes the sample populations by highlighting data gathered through socioeconomic surveys conducted with the respondents. The final discussion addresses particular livelihood strategies women have adopted to support their households in the two areas. This information was obtained through socioeconomic surveys, individual interviews, and focus groups and covers issues such as income, access to resources, and the organization of households; the balancing of productive and reproductive duties; and family and community life. The fieldwork in Limpopo was conducted during the summer of 2001 and the fieldwork in West Virginia was conducted between 2001 and 2004. Respondent profiles are utilized throughout the chapter to bring out the voices, social and economic situations, and individual perspectives of the women themselves.

\section{Livelihoods in Limpopo-Women in Rural Households}

\section{Limpopo}

This section of the analysis highlights specific socioeconomic and geographic data concerning the study area in South Africa. It highlights population and household characteristics, income and employment information, and poverty and educational data on Limpopo.

Limpopo is the fifth largest of nine provinces in South Africa with a population of 5.3 million (Statistics South Africa, 2003) (Map 2). It includes the former bantustans of Lebowa, Gazankulu, and Venda (Map 4), is 97 percent Black, compared to 79 percent for South Africa as 
a whole, and has the largest female population in the country at 55 percent (Statis tics South Africa, 2003). The dominant languages of the Province are Sepedi, Xitsonga, and Tshivenda and the average household size is 4.3 , compared to 3.8 for the country as a whole. The 1996 Census showed that 52 percent of the households in Limpopo, then named the Northern Province, were female-headed (Statistics South Africa and the World Bank, 2000). However, other research has suggested that the numbers could be as high as 67 percent in the former bantustans, including the case study area (Bob, 2001; Marcus et al. 1996; May et al. 1995; Pickles and Weiner, 1991). In the focus group interviews conducted for this project women frequently mentioned the prevalence of female-headed households in the case study region. For example, eight out of the eleven members of the bakery where two of the respondents worked were the head of their households. Likewise, the majority of members from the Tshandama Community Project, where many women were working in gravel production, were the head of the family.

Limpopo is the poorest province in the country. It has a provincial poverty level ${ }^{60}$ of around 38 percent, which is the third highest in the country, and the former bantustan areas in the Province have poverty levels between 40 and 59 percent (Statistics South Africa and the World Bank, 2000). The mean household income is $\mathrm{R} 1,234^{61}$ per month and is the lowest in the country and almost 80 percent of the population reported incomes below R250 per month, which is well below the poverty line in the country (Statistics South Africa and the World Bank, 2000). It is also the most rural province in South Africa with 24 percent of its households residing in non-urban areas (Statistics South Africa and the World Bank, 2000).

Employment in Limpopo is located in a few, usually low-paid, seasonal, and insecure, economic sectors including: community, social and personal services (24 percent); agriculture,

\footnotetext{
${ }^{60}$ The household poverty line in South Africa is based on consumption expenditure at R800 or less per month (Statistics South Africa and the World Bank, 2000).

61 The exchange rate as of August 2005 was 1 US dollar is equal to 6.5 Rand (R), the South Africa currency.
} 
hunting, fishing, and forestry (18 percent); wholesale and retail trade (14 percent); and private household employment (11 percent) (Statistics South Africa, 2003). In fact, examining occupation by province statistics reveal that 33 percent of the employed in Limpopo are located in elementary occupations, which is the second highest in the country (Statistics South Africa, 2003). The 49 percent unemployment rate is the second highest in the country, compared to 41 percent nationally (Statistics South Africa, 2003). In 2001 the Labour Force Survey reported that 57 percent of the population in Limpopo was not economically active, the highest in the country. On the subject of unemployment, Agnes, a widow in Matangarie stated: "With the present unemployment, I am worried that my children might not get jobs after their education. Many kids have education in the village, but not jobs.” (Individual Interview, Matangarie, July, 13, 2001). Margaret, in Rambuda, reiterated this point by saying, "the problem is there are so many educated ones who have no work." (Individual Interview, July 13, 2001). Joann, in Shayandima, also discussed the problem of jobs, the local economy, and education: “...the government must supply people with jobs because in our country many people are educated but they are not employed... Here in our village, Shayandima, there are many industrial firms that are closed down, the government must open them so people can get jobs." (Individual Interview, Shayandima, July, 17, 2001). Since Joan's husband lost his job and has been unable to find work in the formal economy, she has been heading the household:

Joan became head of the household when her husband lost his job in 1999. Joan's husband previously worked as a migrant worker at a resort. He had worked at the resort for 20 years and when he was laid off he was the Kitchen Supervisor and making R1,500 per month. He received six months salary as a pension payment for his time served and Joan and her husband utilized this money to purchase a three room house and start a small clothing business. Joan's husband utilizes public transportation to travel to Johannesburg to purchase clothing, which he sells informally in surrounding villages. Joan began working at Rambuda Stone Crushing Project in May of 2000 and is now the primary breadwinner and caretaker of the household. Joan and her husband have four children. The income earned from the stone crushing project and her husband's clothing 
business is very irregular and she reported a monthly household income of less than $R 200$ per month. When asked what she considers her most important contribution to her household, Joan stated "providing money...I use money earned at the stone project to buy food, pay school fees, and pay utilities.... Joan reported that it was "hard being the head of the household, it has a lot of pressure" but concerning her future, she stated that "I am optimistic that this project will grow and we will have enough to support our families" (Individual Interview, Rambuda, July 13, 2001).

Educational statistics relate to the employment data above with 33 percent of the population in Limpopo reporting no schooling at all, which is the highest in South Africa. Only 14 percent of the population in Limpopo reported a Grade 12/Standard 10 education and only 7 percent received any form of higher education (Statistics South Africa, 2003). For women in Limpopo, educational statistics are even more disturbing. 38 percent of women in the Province reported that they have received no schooling at all, only 25 percent had some secondary education, only 13 percent completed Grade 12/Standard 10, and only .06 percent had any type of higher education (Statistics South Africa, 2003).

Issues around poverty, rural location, a lagging provincial economy, and poor educational levels affect women's abilities to acquire and sustain a livelihood for themselves and their families in Limpopo. Their struggles and triumphs to do so are discussed in the following pages.

\section{Description of the Sample}

This section presents data gathered through a socioeconomic survey of the respondents interviewed in Limpopo and presents information concerning the location, age, educational levels, household status, and income of the study sample. Table 2 provides a summary of socioeconomic information concerning the respondents and can be used as a reference guide throughout this and the following section of the Chapter. 
Table 2: Summary Data for Respondents in Limpopo, South Africa

\begin{tabular}{|c|c|c|c|c|c|c|c|}
\hline NAME & LOCATION & AGE & EDUCATION & $\begin{array}{l}\text { MARITAL } \\
\text { STATUS }\end{array}$ & $\begin{array}{c}\text { NO. } \\
\text { IN } \\
\text { HH } \\
\end{array}$ & $\begin{array}{c}\text { MONTHLY } \\
\text { HH INCOME* }\end{array}$ & HH LIVELIHOOD STRATEGIES $* * * * *$ \\
\hline Diane & Mukondeni & $70+* *$ & Primary & Widowed & 6 & $\mathrm{R} 401-600 * * *$ & Potter, Pension Grant, Subsistence Agriculture \\
\hline Frances & HaMashamba & 61 & None & Married & 6 & R401-600 & Potter, Pension Grant, Subsistence Agriculture \\
\hline Hope & Tshandama & 36 & Some Secondary & Married & 5 & R5000 & Teacher, Food Production, Subsistence Agriculture \\
\hline Janet & Tshandama & $* * *$ & Grade $12 / \mathrm{Std} .10$ & Married & 5 & R1001-3000 & Food Production, Welding, Pension Grant, Subsistence Agriculture, Double-up \\
\hline Louise & Tshandama & 50 & Primary & Widowed & 7 & R201-400 & $\begin{array}{l}\text { Food Production, Child Grant, Informal Trading, Subsistence Agriculture, Family } \\
\text { Assistance }\end{array}$ \\
\hline Margaret & Rambuda & $40^{* * *}$ & Primary & Widowed & 7 & R201-400 & Gravel Production \\
\hline Joan & Rambuda & 36 & 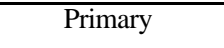 & Married & 6 & $<\mathrm{R} 200$ & Gravel Production, Informal Trading \\
\hline May & Nesengane & 40 & Primary & Married & 8 & R401-600 & Bakery Worker, Pension Grant \\
\hline Tina & Tshino & 45 & Grade $12 /$ Std. 10 & Widowed & 3 & 0 & Bakery Worker \\
\hline Eve & Matangarie & $60^{* *}$ & $\begin{array}{l}\text { Primary } \\
\end{array}$ & Married & 5 & $<\mathrm{R} 200$ & Agricultural Worker, Subsistence Agriculture, Traditional Mat Making \\
\hline Agnes & Matangarie & 53 & Primary & Widowed & 5 & R201-400 & Agricultural Worker, Subsistence Agriculture \\
\hline Carol & Lwamondo & ** & Some Secondary & Single & 6 & R201-400 & Informal Clothing Sales, Subsistence Agriculture \\
\hline Joanne & Shayandima & 45 & Grade $12 / \mathrm{Std} .10$ & Married & 11 & R1001-3000 & Sewing Business, Pension Grant, Doubling-up \\
\hline Beth & Tshisaulu & 28 & Grade $12 / \mathrm{Std} .10$ & Married & 5 & R3001-5000 & Teacher, Sewing Business, Subsistence Agriculture \\
\hline Sharon & Tshisaulu & 51 & Primary & Married & 9 & R601-800 & Sewing and Beadwork Business, Delivery Business, Pension Grant, Doubling-up \\
\hline Joy & Tshakhuma & 53 & Primary & Widowed & 6 & R1001-3000 & Agricultural Sales, Pension Grant, Doubling-up \\
\hline Ruth & Tshakhuma & 50 & $\begin{array}{l}\text { Primary } \\
\end{array}$ & Widowed & 4 & R201-400 & Agricultural Sales, Subsistence Agriculture \\
\hline Helen & Hamutsha & 27 & Grade $12 / \mathrm{Std} .10$ & Married & 6 & $<\mathrm{R} 200$ & Sewing Business, Informal Agricultural Sales, Child Grant \\
\hline Mary & Tshakhuma & $50^{* *}$ & None & Widowed & 3 & $<\mathrm{R} 200$ & Sewing and Knitting Business, Pension Grant \\
\hline Sarah & Malonga & 49 & $\begin{array}{l}\text { Primary } \\
\end{array}$ & Widowed & 6 & $<\mathrm{R} 200$ & Agricultural Worker, Subsistence Agriculture \\
\hline Nancy & Malonga & $60^{* *}$ & None & Widowed & 3 & R401-600 & Agricultural Worker, Subsistence Agriculture, Pension Grant, Family Assistance \\
\hline
\end{tabular}

*Monthly income is measured because of the fluctuations in income that people in Limpopo experience

**Exact age unknown

***The exchange rate at the time of the research was 10.42 Rand per 1 US dollar.

****Italicized text shows strategies of household members other than respondent. Bold text shows government programs. 
All of the respondents interviewed for this project were Black and reside in villages that were formerly part of the Venda bantustan (Map 7). All but one respondent had lived in their current village for over ten years, with over half residing in their current village their entire lives. The majority of the sample, 71 percent, is over 40 years of age. Five respondents are between 40 and 49 years of age, six are between 50 and 59, four are over 60 and two did not know their age. Only two respondents are between 30 and 39 years of age and another two are between 20 and 29. All of the women speak Tshivenda, one speaks some English and another, some Shongon. Eleven of the twenty-one respondents had only attended primary school, two had some secondary education, five had completed Grade 12/Standard 10, one had attended technical school, and three had no schooling at all. As is evident in Mary's story, a few of the respondents reported attending initiation schools, which are part of the Venda culture and only for young girls.

Mary, a widow in her 50s, is supporting herself, her brother's orphaned child, and an inlaw by selling textiles and knitwear that she makes. The in-law receives a pension grant but Mary does not control that money. She makes, on her own, less than R200 per month. Mary attended an initiation school and it was the only education that she received. On this subject, Mary said, "we were told that girls didn't go to school. Women were not allowed to go to school because they were having the belief that they would go crazy. They told us to go to the traditional (initiation) schools in order to be taught how women behave in their own families and how to treat men and tolerate the burden of marriage. In the initiation school, we were told that the grave of the woman is in the husband's house" (Individual Interview, July 16, 2001).

At the household level, ten of the respondents are married, ten are widows, and only one is single and has never been married. Fifty-two percent of the households in this study have six to eight members and two households have more than eight household members. Six households, which are 28 percent of the households in the study, have four to five household members and only two have three or less. The household size for this sample population is well above the average household size for the Province of 4.3. Household members include 
husbands, children, grandchildren, parents, and in-laws as well as siblings and nieces and nephews. Four of the households have disabled members.

\section{Map 7: Location of Respondents in Limpopo}

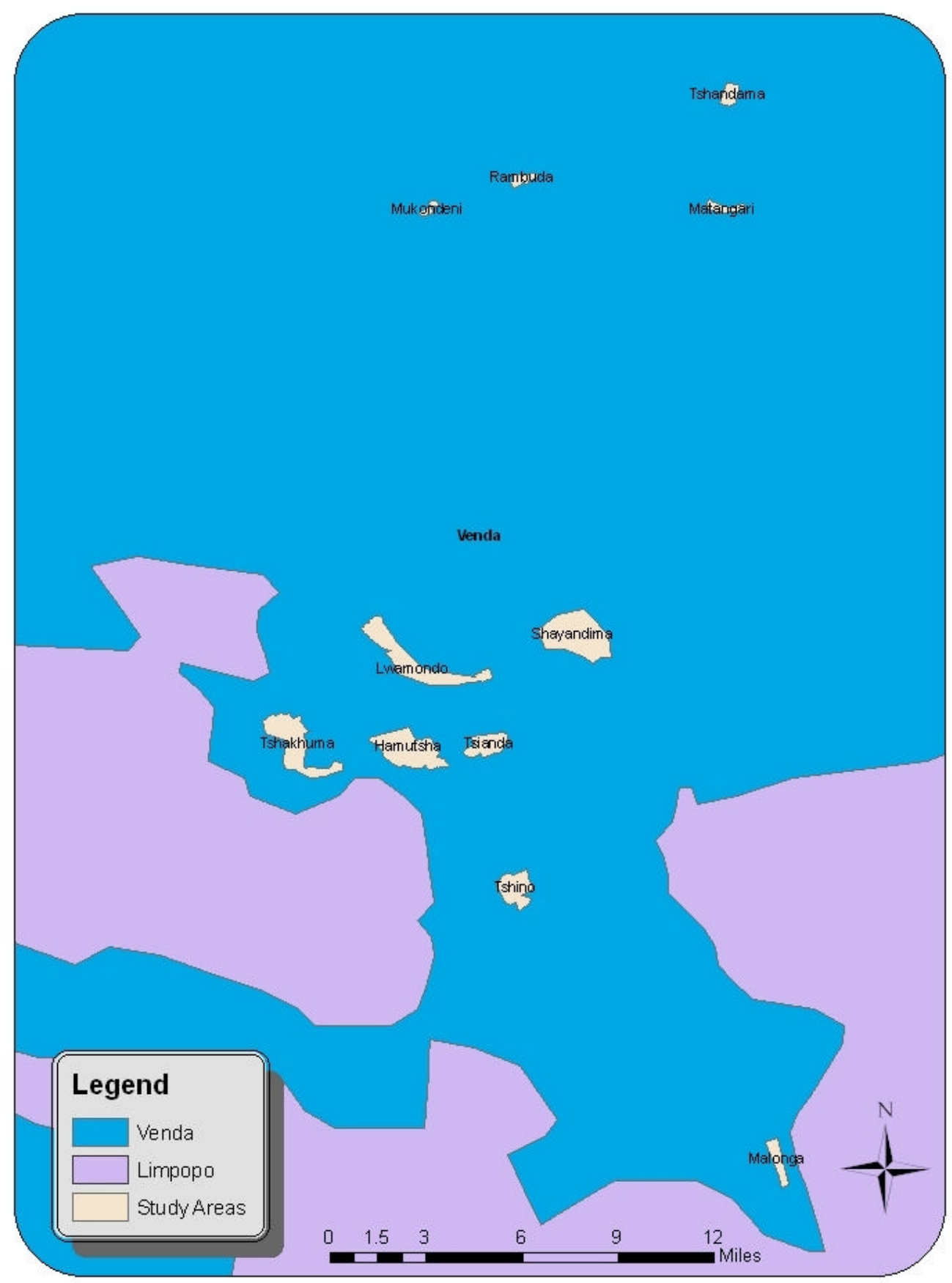


The majority of the respondents have monthly incomes below the poverty level in South Africa, with sixteen respondents reporting monthly incomes of below R800. Three have household monthly incomes of R1001-3000, one has an income of R3001-5000 per month, and one has a monthly income of over R5000. These higher income households have members who were professionals and trade workers. Fifteen of the women interviewed were contributing more than 50 percent of the total household income, with nine contributing 100 percent of the household income. Ten households reported that only one individual is contributing to the household income, seven households have two individuals contributing, and four households have three household members contributing to the household income. According to Posel (2001), "female-headed households in South Africa have fewer income-earners, are more reliant on the income earned by women, and therefore are more likely to be in lower income groups than households headed by men" (p. 669). On the subject of heading the household Tina, in Tshino, states:

Being the head of the household is very difficult because I didn't have a job (before joining the bakery)...it was very difficult for me. There are no jobs here and I can't support my children. (Being the head of the household) since my husband passed away forces me to be confident and hope that God will be on my side (Individual Interview, July 24, 2001).

Concerning a question asked in a focus group on economic opportunities and people's livelihood strategies in general, one woman responded:

The biggest problem (concerning access to economic opportunities) is faced by women because they are the ones who support the families here...women have to be stronger than men...they are the head of the families and they have to support their children (Focus Group Interview, July 16, 2001).

Livelihood strategies for these households include self-employment, participation in community economic groups, professional occupations, temporary/odd jobs, informal trading, pension and 
child grants, subsistence farming, and family assistance. Interestingly, none of the respondents reported any income from migrant remittances.

Sixty-two percent of the respondents reported having access to land for food production but none reported having animals to graze. Eight respondents get their water from a private tap, eight use a public tap, only three have piped water, and four respondents get their water from a dam, river, or small stream. In terms of energy sources, the majority either use wood or electricity for heating, cooking, and lighting. Seventy-one percent of the respondents use wood for cooking and heating, two households use wood for cooking only, and one for heat only. Two households use electricity for heating and cooking; one uses electricity for heating only; and one for cooking only. Six households use electricity for lighting. Only one household uses paraffin. Through the socioeconomic survey it was consistently revealed that women in this study lacked the means to access basic services, such as water and electricity:

Ruth, in Tshakhuma: "I need free water and electricity." Sarah, in Malonga: "I can't afford to pay the bills...I need free water and electricity." Mary, in Tshakhuma: "I have a problem with electricity, and I need free water, I can't manage to pay the bills."

Tina, in Tshino: "I had electricity before, but because of unemployment I had to close it down because I can't afford to pay the bill."

Frances, in Hamashamba: "We are in need of free electricity and water...we spend many days a month without water and travel a long distance to reach Nwanndi River to fetch water."

May, in Nesengane: "Our tap often dries up and we have to buy water from those who have boreholes."

In terms of sanitation, nineteen of the households use a pit toilet and only two have flush toilets inside their homes. Five of the respondents have access to a public telephone, six to a community Vodacom, one has a home phone, and three have a cell phone. Seven respondents have no access to any means of telecommunication at all. Nine of the respondents have access to a television and sixteen to a radio. Seven of the respondents utilize a public motor vehicle while 
six have access to a private motor vehicle. In terms of health care for themselves and their families, the majority, seventeen of the respondents, use a public clinic. Six use the provincial public hospital, two utilize a private clinic, and only one had utilized a private hospital or private doctor. Only one respondent reported using a traditional healer and one used a mobile clinic.

In terms of community activities, eighty-one percent of the respondents reported being involved in religious activities, one was involved in school activities, and one was in a savings club for women.

\section{Female-Headed Households in Limpopo and their Livelihood Strategies}

The research for this project was conducted seven years after South Africa's transition to democracy and the livelihoods that women were engaging in reveal the complex realities of both historical and contemporary local and global processes. Understanding women's livelihoods in the South African context and at the household level involves linking the dynamics of gender relations within households to broader structural changes going on at the local, regional and national levels and to the operation of state, market, and cultural institutions. These processes have socioeconomic, legal, political, and ideological dimensions that influence women's livelihood strategies.

The livelihoods of female-headed households in Limpopo today are embedded in persistent barriers that have marginalized women from control over land rights and access to viable employment. Under the apartheid regime, black women were denied equal access to land and other agricultural resources as well as educational and employment opportunities. ${ }^{62}$ They were often confined to the Bantustan areas, relying on migrant remittances for financial support. With the transition to democracy, however, women are empowered at the national level by a

\footnotetext{
${ }^{62}$ See Chapter III for a detailed discussion of women's positions and conditions under apartheid.
} 
Constitution and Gender Commission that mandates both a "non-racist and non-sexist society". The South African state makes provision for affirmative action to protect or advance persons who have been disadvantaged and is required to "progressively realize" a number of socioeconomic rights, such as housing, land, food and water, health care, education, and social security, all of which are fundamental to ensuring a sustainable livelihood.

Current development policy at the national and regional levels unfortunately runs contrary to these progressive goals. In particular, the Growth, Employment, and Redistribution (GEAR) Program that has emerged as the main macro-economic development strategy in South Africa prioritizes reduced spending and market-driven policies and seeks to attract foreign investment to further integrate South Africa into the global economy (Bob, 2001). It is also increasingly apparent that rural development and the restructuring of the former Bantustans are not high priorities for the current government (Lehulere, 1997). The closing down of the Reconstruction and Development Programme (RDP) (African National Congress [ANC], 1994) Ministry, the political home of rural development initiatives, and the shift to GEAR has created a vacuum (Bob, 2001). Little investment is being made in human capital and the provision of employment, infrastructure, and basic human needs, especially in the rural periphery. In addition, the voice of the rural poor remains weak and disorganized.

As will become evident below, local people, especially women, are engaged in economic development and creating employment opportunities for themselves and their communities into their own hands through the creation of grassroots livelihood strategies, such as community producer groups. They are also adopting multiple livelihood strategies that work together and suit their household situations. Women in Limpopo are, and always have been, sustaining rural households. 
The livelihood strategies among women in this study are immediately affected by the local economy, the physical environment, women's individual household situations, and women's access to human, physical, financial, and social capital. ${ }^{63}$ They are also affected by familial and cultural institutions, including the cheiftancy; communal institutions, such as civic organizations; social institutions, such as extended families; and collective and policy/governmental institutions, including economic development authorities, welfare agencies, and local, provincial, and national government bodies. ${ }^{64}$ The respondents interviewed for this project reported that women and men in Limpopo engage in a variety of livelihood activities to support their households. Men, for example, work on commercial farms and in construction; they cut trees and sell bulk firewood; they are police, teachers, and soldiers; they create and sell wood carvings, tend to animals, and sell fruits and vegetables in bulk. Many, unfortunately, have also been retrenched and are currently unemployed. Women are agricultural, crèche, ${ }^{65}$ and domestic workers; they do light construction activities such as thatching roofs, fencing, brickmaking, digging toilets, and stone crushing; they do sewing, knitting, and beadwork; they informally sell firewood, fruits and vegetables, and snacks; and they brew and sell beer. According to the respondents, few men and women migrate to find work in more urbanized areas.

Women's livelihood strategies identified in this sample and described below include participation in community producer groups; the informal selling and trading of goods; sewing, knitting, craft, and clothing businesses; subsistence agriculture; social assistance programs; and family and community assistance. Women, such as Louise, rarely engage in only one of these

\footnotetext{
${ }^{63}$ To revisit definitions for these various types of capital see page 59 in Chapter II.

${ }^{64}$ To revisit definition for these various structures see page 60 in Chapter II.

${ }^{65}$ Childcare.
} 
activities and usually combine one, two, or sometimes all of these strategies to create a livelihood for their families (Table 2).

Louise, who was widowed in 1993, combines almost all of the strategies identified in this study to create a livelihood for her family. She supports a household of seven including herself, her four children, a daughter-in-law, and one grandchild. She is the leader of the Tshandama Jam Project, where she works with other women to produce jellies and peanut butter to sell locally, and she farms her own land where she grows produce for her own consumption and for sale. Her son, a professional teacher, is unemployed. He works temporary jobs and occasionally contributes to the household income. Her grandchild receives a child grant from the government totaling R110 per month. Her monthly household income is between R200 and R400 per month. Louise's daughter-inlaw is a big help around the house. Louise states, “...I am growing old ...I need for this business (the jam project) to grow and for my son to find employment...” (Individual Interview, July 12, 2001).

\section{Community Producer Groups}

The most innovative livelihood strategies studied in this project were the community producer groups. Women involved in these projects engage in food preparation (baking and jam and peanut-butter production), agricultural activities (raising pigs and growing vegetables), sewing and traditional crafts (traditional Venda clothes, weaving, knitting, pottery and other handicrafts), and construction work (manual and machine gravel production) (Table 3). These activities are generally very labor-intensive with minimal capital input and are also common among women in other areas of sub-Saharan Africa (Francis, 2000; Aspaas, 1998). Many community producer groups have been established in South Africa since the democratic transition in 1994 due to eased restrictions on their organization and increasing support from local and state institutions, such as the chieftaincies, local civic organizations, and provincial economic development and extension departments. When questioned about women's economic status under apartheid compared to the current government, members from the Tshandama Community Stone Crushing Project responded that "women can now create their own jobs" 
(Focus Group, Tshandama Community Stone Crushing Project, July 13, 2001). Involvement in these projects represents a step towards women empowering themselves and improving their abilities to provide for their households and communities.

Table 3: Profile of Community Producer Groups in Limpopo

\begin{tabular}{|l|l|l|c|c|}
\hline Name of Group & Products and Activities & Location & $\begin{array}{c}\text { Members } \\
\text { Female }\end{array}$ & $\begin{array}{c}\text { Date } \\
\text { Es t. }\end{array}$ \\
\hline Tshandama Jam Project & Peanut Butter and Jam & Tshandama & $12(100 \%)$ & 1998 \\
\hline Tshandama Bakery & Baked goods & Tshandama & $13(77 \%)$ & 1995 \\
\hline Matangari Piggery & Hogs and piglets & Matangari & $11(64 \%)$ & 1995 \\
\hline Rambuda Stone Crushing & $\begin{array}{l}\text { Machine crushed stones for } \\
\text { gravel }\end{array}$ & Rambuda & $15(73 \%)$ & 2000 \\
\hline Tshandama Stone & Hand crushed stone for gravel & Tshandama & $31(90 \%)$ & 2000 \\
\hline Pfananani Community Center & Weaving, Knitting, and Sewing & Tshianda & $14(100 \%)$ & 1972 \\
\hline Mvuleleni Sewing & $\begin{array}{l}\text { Sewing and Crafts-Traditional } \\
\text { Venda clothes and beadwork }\end{array}$ & Shayandima & $16(100 \%)$ & 2000 \\
\hline Fulufhelo Community Garden & Grow Vegetables & Malonga & $22(100 \%)$ & 1993 \\
\hline Tshino Confectionary Group & Baked goods & Tshino & $14(100 \%)$ & 2001 \\
\hline Mukondeni Pottery Project & Pottery & Mukondeni & $13(100 \%)$ & 1998 \\
\hline
\end{tabular}

These community projects usually function similar to a co-operative. They are jointly owned and operated by the group members and each member, if there is profit, receives an equal monthly income. The projects range from eleven to approximately thirty-one members in size (Table 3). Group membership is constantly fluctuating due to women's inability to pay project fees and basic expenses, disagreements among members, and low wages.

Earnings from community producer groups vary between 200 and 400 Rand per month for each member (Table 2). Reasons for these relatively low earnings are their recent establishment and the need to reinvest the profits back into the business to purchase supplies and equipment. For example, the Pfananani sewing and weaving group uses earnings from their 
sales to purchase wool, dye, and yarn. The piggery also puts most of its earnings into materials. Located on an irrigation scheme in Tshiomo village, members of the piggery contribute R20 per month to buy piglets, equipment, petroleum to run the water pump, and building materials (Photo 5). In response to a question about profits, one respondent noted, "All we can say now is that the pigs we have sold have brought us some profit, but since we use the money to buy feed we find ourselves without a profit" (Individual Interview, Matangari, July, 13, 2001). As the head of the household, Eve combines her work at the piggery with informal activities and subsistence agriculture to construct a livelihood:

As the head of the household, Eve is supporting herself, her husband, two children and one grandchild by working at Matangarie Piggery (Photo 6), making traditional mats (Photo 7), and subsistence farming activities. Eve's husband is unemployed but had previously worked in Johannesburg as a telephone line worker and then as a domestic worker. When her husband was retrenched he received a sum of pension money from the telephone company, which they used to build a four room house. Her husband and son assist with the subsistence farming activities. Eve makes very little income at the piggery and from making mats, around R10 per month, and they produce most of their own food. In addition to her work at the piggery, mat making, and agricultural activities, she is responsible for most of the household duties including cooking, collecting firewood and water, laundry, and house cleaning. Concerning her involvement with the piggery and the future, Eve stated, "I hope the piggery will grow... I feel confident and I am determined to continue with this business..." (Individual Interview, Matangarie, July13, 2001).

Transportation costs are also required to ship raw materials from urban areas or finished goods to markets. The need to purchase raw materials, especially in relatively small quantities, combined with the costs of equipment, facilities, and transportation often uses most of the earnings of these groups.

Differences among the groups in terms of equipment, facilities, raw materials, and access to transportation are partly due to their ability to access various types of financial and physical capital. For example, the Tshandama Bakery received funding from Eskom, a large utility 
company in South Africa, for training and machinery, including ovens, mixers, and refrigeration equipment, and the RDP, for the construction of their building (Photo 8). Rambuda Stone Crushing Project received a grant from the Premier's Office and was able to purchase stone crushing machinery thereby reducing the labor intensity of the work and increasing their gravel production. Operation Hunger sponsored Fulufelo Community Garden and helped them build the reservoir and obtain equipment and other materials such as hoses, fertilizer, seeds, taps and pipes. The Pfananani Community Center received funding from a Roman Catholic organization for the construction of their building. Many of the groups also had land granted to them by local chiefs to set up their businesses or obtain natural resources.

Many of the groups have business plans and expressed interest in acquiring funding to expand their businesses. For example, the Tshandama Jam Project has detailed architectural plans for a new building and storefront to both produce and sell their products (Photo 9). They had recently applied for funding from numerous corporations and government and nongovernmental sources. In contrast, many of the groups are cautious of loans and lack the means to access grant opportunities and economic development funds. The Tshandama Stone Project needs funds for stone crushing machinery; Fulufhelo Community Garden needs money for a water pump; Mukondeni Pottery Project needs to fence its property and a borehole for water; and Tshino Confectionary Project needs ovens and other baking equipment, repairs done to their building, and a vehicle for delivering baked goods. The capital required to meet these needs is minimal, however, women in these groups have limited assets to use as collateral for credit. This problem is linked to their lack of knowledge about grant and credit programs and previous status as minors under apartheid. 
Because many of these activities require minimal capital input and few resources they are oftentimes very labor-intensive. Carrying stones from the riverbed, crushing them by hand with a mallet, and shoveling gravel into dump trucks is heavy, difficult, and dangerous work at Rambuda Stone and Tshandama Stone Crushing Projects; plowing fields, hoeing weeds, and carrying water is back-breaking work at Fulufhelo Community Garden and Mapile Community Project; collecting clay in large buckets, gathering firewood, and carrying water from the river to make and fire pottery at Mukondeni Pottery Project is time-consuming and strenuous.

At Tshandama Stone Project, where women crush stones by hand with a large rubber mallet, one woman had a large gash in her shin from gravel flying around in the small workplace (Photo 10). At Rambuda Stone Project where rocks were carried from the nearby riverbed and crushed by machinery, no one wears protective head or face gear (Photo 11). The labor intensity of this work combined with their reproductive duties at home with regard to collecting firewood and water, maintaining their own garden plots, cooking, cleaning, doing laundry, and tending to children and the elderly makes for a long and tiring day for these women. Many of these women are not young and women at the Fulufhelo Community Garden commented on the unwillingness of young women to join and keep up with their project ${ }^{66}$. They claim that young women in their community do not want to engage in the difficult labor involved in the garden project (Focus Group, Malonga, July 24, 2001). Nancy and Sarah, who were both beyond middle age, work at the community garden for a cash income and the ability to grow their own food:

Nancy is a widow who supports herself and two grandchildren by working at Fulufhelo Community Garden. She receives a pension grant and some assistance from her son, whose children she is caring for, who does odd jobs in Johannesburg. Her son's wife, who is also in Johannesburg, is a professional teacher but out of work. Nancy's pension grant and work at the garden project provides her with a monthly income of around

${ }^{66}$ The youngest in this group is 41 years old and the oldest is 75 years old. 
R580. ${ }^{67}$ In addition to the community garden, the project provides all of the members with their own plot to grow food for their own consumption or to sell as individuals. In an interview with Nancy, she stated that she could not make it without the community garden and the food it provided her family. She has to pay school fees for the children and purchase other food, such as mealie meal, clothing, and household items with her small income. She said she often runs short on basic things such as tea and bread. "We are suffering...there is little money...I pray for God to bless me so that I can support my grandchildren” (Individual Interview, Malonga, July 24, 2001).

Sarah is also a widow who supports herself and her children by working at the Fulufhelo Garden Project. She stated that her income for the entire year was less than R200. Since her husband passed away in 1997, Sarah had found it very difficult to support her children. Working with the garden project provides some food for her family but she had no cash income for other needed food, household items, utilities, school fees, and clothing. Sarah stated that her children cannot finish school because she has no money for school fees. In response to a question concerning her ability to provide for her family in the future, Sarah responded, "I don't think I can manage to provide for my family because I am working at an unpaid job which is difficult... unemployment is a big problem, maybe the government can supply us with some jobs" (Individual Interview, Malonga, July 24, 2001).

Although the work involved in these community groups is very labor-intensive and earnings are low and irregular, there are advantages to participating in these grassroots livelihood activities. These groups provide women with opportunities to develop skills and establish networks and businesses with other women that were not allowed under apartheid and certain customary laws that, for example, enforced their socioeconomic status as minors. Thus, involvement in many of these community projects has expanded women's access to training programs, markets, and financial resources that improves their abilities to generate income and acquire skills. For example, members of the Mukondeni Pottery Project received marketing and financial management training from the Northern Province Training Trust and members of the Mvuleleni Sewing Project participated in a training and business development program funded by the United Nations Development Program. Sharon, as a member of Mvuleleni Sewing

\footnotetext{
${ }^{67}$ The pension grant provides the majority of the monthly income at R570. They usually only get paid by the garden project after harvest when they may get R200 each. Some of the individuals, like Nancy, grow their own crops to sell and can make a few Rand a month on these crops.
} 
Project, embraced the opportunity to acquire training in business management, marketing, and accounting:

Sharon is supporting a household of nine on what she makes with the Mvuleleni Sewing Project (Photo 12), her mother-in-law's pension, and her husband's delivery business. The only reliable and stable source of income for her family is the pension grant which makes their monthly household income between R601 and R800. Her husband was retrenched from the railroad in Johannesburg and used his pension to purchase a delivery truck. Because of their training in business management, marketing, and accounting, Sharon's group is working hard to become a co-operative and grow their business. Sharon stated, "women are coming together to form their own projects...they are owning their own businesses” (Individual Interview, Shayandima, July 16, 2001).

In addition to training opportunities and skill development, several of the women participating in these groups noted the social dimensions of working together and sharing experiences that extended beyond the economic realm. As one woman stated, "community projects are important for women...they can get skills, add to family income, and learn to be independent" (Individual Interview, Tshianda, July 16, 2001). Given women's responsibility for most of the reproductive and subsistence activities that sustain households in these rural areas, the flexibility of this work and the location of the groups within their own communities also allows women to simultaneously care for children, farm, and complete other household chores while earning money. Groups often provide shorter work weeks or seasonal days off so that group participants can tend to subsistence farming activities. Other groups allow children to come to work with their mothers (Photo 13).

Many of these community groups and their activities are dependent on the natural environment and access to water, land, and other natural resources. In turn, access to natural resources is largely dependent on the support of local structures, such as the chieftancy. The groups are also vulnerable to fluctuations in weather and droughts and flooding are common natural occurrences in this area that can severely affect earnings and products. For example, a 
bridge on the main road leading to the Rambuda Stone Crushing Project was washed away by heavy rains which made accessing the project very difficult for the dump trucks that transported the gravel.

Finally, support from husbands and other family members as well as local authorities, the state government, and international organizations in the form of land, equipment, or financial resources are instrumental to the start-up and operation of these community groups. Many women obtain membership fees and start-up money from their husbands or other family members in order to join one of the producer groups. In terms of local authorities, the Tshandama Jam Project was organized in 1998 when twelve women in the community approached the village chief with a request to produce jam (Focus Group, Tshandama, July 12, 2001). They were given land and a place to work by the chief and after paying R20 each to purchase basic supplies, the group began to produce and market their jam locally. Members of the Matangari Piggery Project also approached local authorities in their initial efforts to develop income-generating activities. As noted by one respondent:

We went to the extension agents to ask for menial jobs which they did not have and they advised us to create our own jobs... We initially wanted to make wire-mesh and shoe polish. They discouraged us from doing so and advised us to try a piggery. They applied for funds from the Department of Agriculture. We were given money for infrastructure. The government assisted us with two builders (Individual Interview, Matangari, July 13, 2001).

The resources and advice given by these extension agents is similar to other support provided for the community garden, Rambuda Stone Crushing Project, and the bakery. This situation reflects how these community projects are dependent on and operate within the social and economic relations of the local authorities and national institutions. In many instances, groups are granted access to financial and physical capital, but within the confines of existing power structures and 
hierarchical practices. These issues and how they relate to women's livelihoods are discussed further in the next chapter.

\section{Sewing, Knitting and Craft Businesses}

The establishment of sewing, knitting, and craft businesses represent the second livelihood strategy of women in Limpopo discussed here. These types of businesses are generally located in the more urbanized parts of the research area, particularly around Thohoyandou. In this area, there are markets for the clothing and other textile and craft goods produced and needed materials and equipment for production are readily available. Interestingly, the community groups who focused their efforts on sewing and the production of knitted goods and crafts, including Pfananani and Mvuleleni, are also located in more urbanized areas. Three of the women interviewed have businesses at a location called Baobob Kiosk. Joann and Beth have sewing businesses and Carol is in clothing sales. Eve works at the piggery and is also engaged in traditional mat making (Photo 7) (Table 2).

Baobob Kiosk is located in Shayandima just outside of Thohoyandou (Photo 15). The Kiosk is divided into cubicles that women rent as both work and retail space from the Northern Province Development Corporation (NPDC). The building that houses the Kiosk is located in a former industrial area and was previously used to park buses for public transportation to and from Thohoyandou and Johannesburg. Rent for each cubicle is R250 per month plus the cost of electricity and women working at the Kiosk primarily do sewing, knitting, and hairstyling or have clothing businesses (Photo 16). There were over fifty women and only one man working in this facility (Focus Group, Shayandima, July 17, 2001) during the time of the research. Carol was one of the many women operating businesses out of Baobob Kiosk: 
Carol has a clothing business at Baobob Kiosk. She lives in a household of six including herself, her mother, her brother, her brother's wife, and her brother's two children. Her brother is unemployed so Carol and her mother support the household on what she makes with her clothing business and her mother's pension grant. Carol had never been married and had no children of her own. She completed some secondary school and had had some technical/vocational training. They have access to land and grow some of their own food for subsistence purposes. Before she started the clothing business she was a domestic worker for two years, making $R 300$ per month. She had been operating her clothing business for two years at the time of the interview and she was making between R50-R400 per month. Concerning her role in heading the household, Carol stated: “...I help the family with money to buy food...my mother has been heading the household since my father died in 1970...I help now and I have learned from her, she is a strong woman I respect" (Individual Interview, Shayandima, July 17, 2001).

Many of the women working at this facility received training at the local vocational/technical school in sewing and knitting. None of the women reported having any training in business management or marketing (Focus Group, Shayadima, July 17, 2001). When asked where they had obtained financing for their businesses in a focus group, they reported getting money from husbands, relatives, and parents for materials (such as fabric), equipment (such as sewing and knitting machines), and the rental of the cubicle (Focus Group, Shayandima, July 17, 2001). They stated that it was very difficult for them to obtain credit for the purchase of expensive items, such as sewing and knitting machines, because they do not have salary statements and credit account histories. They also reported that they do not have bank accounts that would enable them to acquire a small business loan.

The women purchase needed supplies from retail shops in Thohoyandou, which are expensive. These materials, including fabric, yarn, thread, and other sewing and knitting supplies, are much cheaper in Johannesburg and Pretoria but transportation is costly. Once during the year some of the women travel by train to East London, South Africa to purchase traditional fabric. The transportation cost for this trip is R500 (Focus Group, July 17, 2001). 
The women at Baobob Kiosk primarily sell their goods at pension payout points however, they also market their products at local schools, government offices, and hospitals; house to house; and through special orders. They had not advertised and are the busiest during the winter months when people need jackets and jerseys for the cooler weather. Producing school uniforms, track suits, and jerseys have been the most profitable products for these small businesses. Beth had been operating her sewing business since 1995:

Beth operates a sewing business at Baobob Kiosk. She and her husband support a household of seven including themselves and five children. They also help support a niece who does not live with them. Her work at the Kiosk and his job as a teacher provides them with a comfortable living. She makes around R1500 per month and he around R2000 per month. She is the household manager, taking care of the finances, household chores, and children. They have a small plot of land where they grow food for their own consumption and engage in church and community activities, including a savings club (Individual Interview, Shayandima, July 17, 2001).

When asked about the future of their businesses and the problems they face, women at Baobob Kiosk articulated that they need, first and foremost, financial resources: including credit opportunities to expand their businesses and purchase equipment and supplies and funds to purchase their own retail and work space and employ more women; second, safe, secure, and stable market venues to sell their goods; and finally, security from theft (Focus Group Interview, Shayandima, July 17, 2001). The Kiosk had been robbed numerous times and the women had lost materials, machines, and products. Joanne was outspoken concerning the problems women at Baobob Kiosk face in the operation of their businesses:

Joanne, who has a sewing business, supports a household of 11 on what she earns at the Kiosk and with contributions from an in-law's pension grant. Her husband was unemployed and they do not have land to grow their own food because they live in Shayandima, a suburban area outside of Thohoyandou. When asked about the particular problems she faces in operating her business, she stated: “...we need a free market where we can sell our clothes and sponsors in order to assist us in buying materials so that we can sell our goods at a lower price” (Individual Interview, July 17, 2001). 
Concerning women's economic opportunities in Limpopo, women at the Kiosk stated that under the new government women have more opportunities, but that many of their husbands did not want them to work (Focus Group, Shayandima, July 17, 2001). One respondent discussed how some husbands resent them working outside the home despite the need for income. "My husband cannot allow me to be a migrant worker. It is also not easy to be here [at the Kiosk]. Our husbands say it is better to work at home" (Focus Group, Shayandima, July 17, 2001). This research underscores the oftentimes conflictual positions of women as they attempt to support households and negotiate their multiple responsibilities and gender identities (see also Francis, 2000). These issues will be discussed further in the following chapter.

\section{Informal Trade Activities}

Informal trade activities have long been utilized by women in South Africa, and in other African countries for that matter, as a livelihood strategy and are the third set of strategies utilized by women in this study. Women in this study, including Ruth and Joy, sell fruits, vegetables, sugar cane, and nuts informally at a roadside market in Tshakuma, which is on the main transportation route to Thohoyandou and the northern part of the Kruger National Park (Photo 17) (Table 2).

Joy sells fruits and vegetables at Tshakuma Market and had been doing so since 1971. She has been a widow for three years, however, her husband never really provided for her and their children. He had a second wife and when he married her he moved to Vuwani. He had been a migrant worker in a factory in Johannesburg but was retrenched several years ago. When he died, he had no money and it was very costly for Joy to bury him, taking all of the savings she had. Joy supports three of her six children, her brother, and her mother on the money she makes at the market. Her mother and brother both receive pensions but Joy does not control that money. Her brother moved into Joy's three-room home, which she owns, when he lost his eyesight and his family left him. He had previously worked selling construction materials. She said that her brother was irresponsible and that he wasted all his money. She didn't trust him and said that he was a burden. She said that providing for the family "(was) very difficult for her" and that 
"they (were) heading for the worst, there (were) no job opportunities...it was much easier before 1994 (at the market)...there are so many here (selling produce) because there are no other jobs" (Individual Interview, Tshakuma, July 16, 2001).

Tshakuma Market had been operating for approximately 30 years and in order to sell produce at this market, one must first apply to the headmen, pay an initial fee of R40, and then pay a monthly fee of R4. The land for the market area was initially given by the local chief and in 1996, the Premier's Office provided funds for the construction of the storage building (see Photo 17). There are approximately four hundred women registered to sell produce and nuts at this market and again, we see, local, traditional and patriarchal institutions playing a role in women's livelihood strategies.

The women get the produce and nuts from local, white-owned commercial farms who deliver to the market. They sell their products to local community people who walk or drive to the market, as well as tourists. In a focus group, women selling at this market reported that earnings were low, at around R5 per day, and that they were living "hand to mouth" (Focus Group, Tshakuma, July 16, 2001) (Table 2). At this interview there was also disagreement between the women concerning their marketing strategies. Older women who had been selling at this market for years were dissatisfied with the selling tactics of the younger women who immediately approached cars and buses who pulled into the market. When we, as researchers, stopped at this market in our university van, women with all sorts of fruits, vegetables, and nuts immediately crowded around the van. The older women felt that people should be allowed to browse and choose the produce that they wanted without 'harassment' (Focus Group, Tshakuma, July 16, 2001). They had taken this issue to the headmen and chief and women were being fined for engaging in this aggressive behavior. Some of those women who had been selling produce at this market for many years stated that it was easier to make money under the Venda government 
because you had to have a license in order to sell your goods. They indicated that eased restrictions under the new government had resulted in too much competition (Focus Group, Tshakuma, July 16, 2001).

Women at the fruit market focus group stated that they needed land to grow their own fruits and that "people were dying due to hunger and unemployment" (Focus Group, Tshakuma, July 16, 2001). These women are dependent on the success of local farmers who are susceptible to environmental factors, such droughts and intense rains. They also have to purchase the produce at the local price because they did not have the means to travel to other farming areas and negotiate lower prices. The farmers in the local area are organized into a co-operative and they set the prices and determine the supply. The rainy season, when farm output was low, is also very difficult for them. Ruth, as the head of the household, supports her family on the income she earns from selling fruits and vegetables at the fruit market:

Ruth, a widow, is supporting a household that includes herself and her three children on the money she makes selling produce at Tshakuma Market. Her income is between R200400 per month and she is responsible for all of the productive and reproductive activities that need to be done to support her household. She has a small plot of land to grow maize but says that "it is very difficult to stand on your own and handle the situation (of being the head of the household)" (Individual Interview, Tshakuma, July 16, 2001).

\section{Subsistence Agriculture}

Subsistence agriculture, referring to production for use as opposed to production for exchange (Johnston, Gregory, and Smith, 1994), has long been used as a livelihood strategy to secure food for household consumption in Limpopo and other parts of South Africa (see Francis, 2000; Nel and Binns, 2000). Twelve of the twenty-one women interviewed engage in subsistence food production for their own consumption, representing the fourth livelihood strategy discussed in this analysis (Table 2). 
Subsistence agriculture in this context does not make the women self-sufficient in food, but merely substitutes their low incomes and what they have to purchase from local markets. Women are mainly growing maize but other crops including root vegetables, green leafy vegetables, and fruits are also common. The plots of land that these women have access to are small, the farming required few inputs, and subsistence activities are, of course, vulnerable to local environmental conditions. Subsistence activities are tended to by the women and children and there is little evidence of a peasant agricultural economy ${ }^{68}$, despite people's access to land beyond a homesite in this former bantustan. Consistent with Francis' (2000) findings, this is primarily due to that fact that people in rural areas, particularly the former bantustans, lack the means, including equipment, fertilizer, and credit, to work the land. Commercial agriculture is abundant in this area of Limpopo, however, it remains in the hands of white farmers and established agri-businesses.

\section{Social Assistance}

Social assistance, the fifth livelihood strategy identified in this study, refers to noncontributory and income-tested benefits provided by the state to vulnerable groups unable to provide for their own minimum needs such as the disabled, the elderly and young children in poor households (Woolard, 2003). As of February 2003, 4.8 million South Africans were receiving social assistance benefits, totalling 2.2 billion Rand (Woolard, 2003). The numbers have jumped to over nine million recipients and R3 billion as of July 2005 (SouthAfricaInfo, 2005).

\footnotetext{
${ }^{68}$ Meaning household subsistence producers with some form of production for sale and some degree of surplus production over needs (Johnston, Gregory, and Smith, 1994).
} 
Government-sponsored social programs, including Old Age Pension and Child Support Grants (CSG), are the most regular and consistent source of income for the women in this study unless they have access to income generated in the formal economy from salaries and wages ${ }^{69}$ (see also Francis, 2000). During the time of the research, Old Age Pension grants were provided to men at age 65 and women at age 60 in the amount of R510 per month ${ }^{70}$ and now, in 2005, total R740 per month (South Africa Social Security Agency, 2005). The Old Age Pension is means-tested $^{71}$ and single persons with income above R1410 per month and married persons with a combined income above R2610 per month are not eligible for the grant (Woolard, 2003). Woolard's 2003 study on social assistance grants in South Africa illustrates the impact of pension grants on poverty. In the absence of any grants, Woolard concluded that 55.9 percent of the elderly in South Africa would be in poverty and 38.2 percent would be in ultra-poverty. According to her model ${ }^{72}, 75$ percent of the elderly receiving pension grants in Limpopo were in poverty before receipt. This number drops to 30 percent after receipt (Woolard, 2003).

Strikingly as well, 50 percent were in ultra poverty before receipt, dropping to just 2.8 percent after receipt.

On the basis of extensive fieldwork and consistent with the findings of this research project, Ardington and Lund (1994) concluded that pensions are "a significant source, with definite redistributive effects; they are a reliable source of income, which leads to greater household security; they are the basis of credit facilities in local markets, further contributing to

\footnotetext{
${ }^{69}$ Review Table 2 to see respondents, Hope, Janet, and Beth, whose households have access to income from salaries and wages in the formal economy.

${ }^{70}$ As of 2004, the Old Age Pension Grant had risen to R740.

${ }^{71}$ A means test is the most important factor when a person applies for social assistance and it assesses his/her financial position. The reason for this is that grants are only awarded if the applicant's financial resources are below a certain level. In determining whether an applicant qualifies for a grant, and if so, to what amount he/she would be entitled, the income and assets of the applicant and spouse or the concerned foster child are assessed (South African Social Security Agency, 2005).

${ }^{72}$ See Woolard's (2003) complete article for an explanation of her detailed model on assessing the impact of social assistance programs in South Africa.
} 
food security; they deliver cash into remote areas where no other institutions do; they are gender sensitive to women ${ }^{73}$; and they reach rural areas as few other services do." Nine out of the 21 households in this study have access to Old Age Pension funds and all have a household size of three or greater with children present (Table 2). All but one had a monthly income of over R400, with three having incomes over R1,000 per month.

While access to these pension funds does not bring people out of poverty, it does increase their security, particularly with respect to food, utility payments, and school fees. This regular source of income also makes participating in community groups or starting a business, where earnings are initially low and a small investment must be made, possible. Pension points, where payments are made to grant recipients, were also local markets for many of the community groups, business owners, and informal traders. The Tshandama Jam Project had been selling at pension points since their inception and it was one of the most stable and reliable markets for their products (Focus Group, Tshandama, July 12, 2001). Diane combines her work with Mukondeni Pottery with a pension grant to support her household:

Diane supports a household of six, including herself, two of her own children, a daughter-in-law, and two grandchildren, through her involvement in Mukondeni Pottery Project and an Old Age Pension. She has been a widow for four years but was supporting the household prior to her husband's death because he was ill. Her pension is R510 per month and earnings from the pottery group varies from R50 to R200 per month. She has her own house and she grows maize and peanuts for her household's own consumption. She counts on her pension to pay school fees for her children and one of her grandchildren and to buy food and other needed household items. She stated that she has been supporting the whole household "for a long time... many, many women do this... it is difficult..." (Individual Interview, Mukondeni, July 26, 2001).

Child Support Grants (CSGs) were introduced in South Africa in 1997. This grant is also means-tested on the basis of the income of the primary care-giver and his/her spouse. Initially, only children under the age of 7 qualified for the grant, but in 2003 coverage was extended to

\footnotetext{
${ }^{73}$ More than twice as many women as men qualify for the Old Age Pension because women qualify at an earlier age and have a longer life expectancy.
} 
children under the age of 9 and by 2005 all children in need under the age of 14 will be included. At the time of the research, the amount provided was R110 per month per child; it is now, in 2005, R170 per month (South Africa Social Security Agency, 2005). Only two households in this study reported receiving the CSG (Table 2).

Some of the women interviewed simply did not know about the CSG while others were unsure about the application process. Woolard's 2003 study reported that only 31 percent of those eligible for the CSG in Limpopo had registered for the grant. Barriers such as illiteracy, transportation, and lack of knowledge about existing programs prevent many people from accessing social assistance benefits in South Africa. As researchers with knowledge of some of these programs, we communicated with our respondents about these social programs and the application process. Diane stated that her daughter-in- law knew about the CSG but had not applied for the funds (Individual Interview, Mukondeni, July 26, 2001). Helen made use of the CSG to help her support her children and household:

Helen works with the Pfananani Community Center and produces beautiful tapestries and other woven goods as well as clothing and knitwear (Photo 14). Helen and her mother-in-law, who sells vegetables and meat informally, are supporting a household of six. This household includes Helen, her husband and child; her mother-in-law; and two sister's-in-law. Helen brings home approximately 50 percent of the household income from her work at Pfananani and she is able to receive a child grant of R110 per month for her young child. According to Helen, "my work here (at Pfananani) and the child grant allow me to care for my child... it is important because if you spoil yourself by relying on your husband you will one day die of hunger with your children or have to go back to your parents home with your children" (Individual Interview, Tsianda, July 16, 2001).

Other grants, including the disability grant, care dependency grant, and foster child grant, to which some of the households may have qualified for were not being utilized by any of the respondents interviewed. Tina has a son who is handicapped and she did not receive the care dependency grant which is specifically designed to help parents with special needs children who 
require full-time care. May's husband, who has walked with a very severe limp since birth, did not receive and had not applied for a disability grant which is designed for adults with mental and physical handicaps. Mary, who was caring for two of her deceased brother's children, did not receive the foster child grant, which now, in 2005, totals R530 per month (South Africa Social Security Agency, 2005).

Mary has been supporting two of her deceased brother's children on her income from Pfananani Community Center, where she does sewing and knitting, and part of her inlaw's pension grant. Mary's brother had seven children and it is impossible for her sister-in-law to support all of them on what little she makes as a farm laborer. Mary's monthly income is less than R200, which is not enough to purchase food and clothing for the children as well as pay utilities and school fees. When asked about the problems that she faces Mary responded, “... another problem is that I am taking care of my brother's orphaned children and I don't have enough money to support them" (Individual Interview, July 16, 2001).

The process for applying for these grants takes time, money, and transportation to complete medical assessments, acquire documentation, and obtain court orders. It also requires visits to the Welfare Office and literacy and knowledge of the social assistance program to which one is seeking. These issues make it difficult for many South Africans, especially those in rural areas, to access social assistance programs. The implications of social assistance programs on the livelihoods of women in South Africa are discussed further in the following chapter.

\section{Family and Community Assistance}

Family and community assistance is the final livelihood strategy identified in this study (Table 2). Supporting family members through the provision of both financial and personal care resources, such as housing, food, and child and elder care, is part of South African culture, as it is in many other African societies. Children are often responsible for their parents as they age; aunts, uncles, and grandparents take in nieces, nephews, and grandchildren if necessary; 
wealthier family members oftentimes assist relatives with expenses such as school fees, medical costs, and funeral arrangements in times of need; and extended family members will also oftentimes 'double-up' to ensure everyone has shelter as well as care. Every household interviewed reported a different, yet blended, household membership of parents, parents and brother and sister in-laws, children, grandchildren, nieces, and nephews. Louise and Diane both reported on how important it was to have their daughter-in-laws around to help with household chores (Individual Interviews, Tshandama, July 12, 2001 and Mukondeni, July 26, 2001) while Joy stated that her brother was a burden (Individual Interview, Tshakuma, July 16, 2001). Community structures, such as local churches, also often assist those in need through financial, spiritual, and emotional support. Agnes reported that her church had helped her in the payment of school fees for her children (Individual Interview, Matangari, July 13, 2001).

Community producer groups; sewing, knitting, clothing, and craft businesses; the informal trading and selling of goods; subsistence agriculture; social assistance programs; and family and community assistance represent some of the activities that women heading households in Limpopo are utilizing to construct a livelihood for themselves and their families. This section of the chapter has defined these livelihood activities and outlined how they are organized; their location and contributions to household incomes; women's training, educational, and credit issues; and the particular conditions that have led to women heading households in the region. The following chapter will further discuss these issues as they relate to the benefits and drawbacks of these activities for women and how they are affected by local, regional, and global socioeconomic processes and institutions. The following section of this chapter turns to the livelihood activities of women heading households in West Virginia in Appalachia. 


\section{Livelihoods in West Virginia—“On our own...," Women Heading Households in Rural Appalachia}

\section{West Virginia}

West Virginia, with a population of 1.8 million and land area of 24, 078 square miles, is one of the most rural states in the United States with approximately 54 percent of its population living in settlements with less than 2500 people, compared to just 21 percent nationally (U. S. Census Bureau 2000a and c). It has a total of fifty-five counties and is the only state that lies totally within the boundaries of the ARC (Maps 1 and 6). Like many other rural states, it has a low population density with no large city within its borders (Dilger and Witt, 1994). According to the 2000 Census, there are 114 people per square mile in the Appalachian region, but only 75 people per square mile in West Virginia. In addition, between 1980 and 1990 West Virginia's population declined 8 percent (Hawley, 1994). While the nation experienced 13.1 percent population growth between 1990 and 2000, West Virginia's population grew only 0.8 percent (U.S. Census Bureau, 2005).

West Virginia, like other Appalachian states, has a large elderly population. In 2000, 15.3 percent of West Virginia's population was 65 years or older compared to 12.4 percent nationally (U.S. Census Bureau, 2000c). West Virginia's median age increased from 35.4 in 1990 to 38.9 in 2000 and is the highest in the nation. West Virginia's lagging economy has been cited as the cause for the unusually large out-migration of 20-30 year olds during the 1990s and limited in-migration of workers from other states (Latimer, 2004; Hawley, 1994). On the subject of out-migration and the need to find employment, DeeDee, a respondent in this study, stated:

I moved to Pittsburgh on my own because I could not find a job here (in Morgantown, West Virginia) that paid anything...I went with my girlfriend who lived up there to drop off resumes and I dropped off seven and had three job offers. I took one and it lasted for four years...then I needed to come back here (to Morgantown). My mom is in a nursing home and my son and the girl he was dating had a baby...Bob (her ex-husband who she 
helps care for) was sick, I needed to be here and as soon as I found something that paid and I could keep my head above water, I moved back...I took over a $\$ 4,000$ pay cut to come down here, so here we go again...(Individual Interview, October 16, 2001).

In 2000, 95 percent of West Virginians were white, compared to 75 percent nationally, and African-Americans constituted the largest ethnic minority in the state at 3.2 percent (U.S. Census Bureau, 2000c). A larger percent of West Virginia families are married than the rest of the nation with married couples constituting 54 percent of West Virginia households in 2000, compared to 51 percent nationally (U.S. Census Bureau, 2000c). Female householders, which are defined by the United States Census Bureau as women with no husband present and children under 18 years, constituted 5.7 percent of households in West Virginia in 2000 compared to 7.2 percent nationally (U.S. Census Bureau, 2000c).

West Virginia is one of the poorest states in the United States and the Appalachian region. In 2000, per capita income in West Virginia was only $\$ 16,477$, five thousand less than the national rate of $\$ 21,587$ and the second lowest in the Appalachian region. ${ }^{74}$ As indicated by Table 4, per capita income in West Virginia rose to $\$ 22,862$ in 2001 but still lagged considerably behind the national average of $\$ 30,413$, a $\$ 7,551$ difference (ARC, 2005). In 2000, significant gaps also existed between West Virginia and the rest of the nation in terms of median income for households, $\$ 29,696$ for the state compared to $\$ 41,994$ for the country, and median family income, at just \$36,484 for West Virginia and \$50,046 for the United States as a whole.

\footnotetext{
${ }^{74}$ Mississippi had the lowest per capita income in the Appalachian region at $\$ 15,853$ (U.S. Census Bureau, 2000b).
} 
Table 4: Comparative National, Regional, State, and County Level Data for Research Areas in West Virginia

\begin{tabular}{|c|c|c|c|c|c|c|c|c|}
\hline & $\begin{array}{c}\text { Harrison } \\
\text { County }\end{array}$ & $\begin{array}{l}\text { Marion } \\
\text { County }\end{array}$ & $\begin{array}{c}\text { Monongalia } \\
\text { County }\end{array}$ & $\begin{array}{l}\text { Preston } \\
\text { County }\end{array}$ & $\begin{array}{l}\text { Taylor } \\
\text { County }\end{array}$ & $\begin{array}{c}\text { West } \\
\text { Virginia }\end{array}$ & $\begin{array}{c}\text { Appalachian } \\
\text { Region }\end{array}$ & United States \\
\hline \begin{tabular}{|l|} 
Population, 2000 \\
\end{tabular} & 68,652 & 56,598 & 81,866 & 29,334 & 16,089 & $1,808,344$ & $22,894,017$ & $281,421,906$ \\
\hline Per Capita Income, 2001 & $\$ 26,254$ & $\$ 22,230$ & $\$ 25,878$ & $\$ 17,898$ & $\$ 15,837$ & $\$ 22,862$ & $\$ 24,912$ & $\$ 30,413$ \\
\hline Poverty Rate, 2000 & 17.2 & 16.3 & 22.8 & 18.3 & 20.3 & 17.9 & 13.6 & 12.4 \\
\hline $\begin{array}{l}\text { Percent of Adults with High } \\
\text { School Diplomas, } 2000\end{array}$ & 78.4 & 79.5 & 83.6 & 74 & 74.7 & 75.2 & 76.8 & 80.4 \\
\hline
\end{tabular}

Source: Appalachian Regional Commission, Regional Data Results_Socioeconomic Data: Harrison, Marion, Monongalia, Preston, and Taylor Counties, 2005. Online Documents: www.arc.gov. 
In 2000, full-time, year-round women workers in West Virginia earned 68 cents for every dollar earned by comparable men workers $(\$ 21,154$ versus $\$ 27,194)$ while the national rate was 73 cents per dollar (U.S. Census Bureau, 2000b). In addition, more than one-third of West Virginia women and one-fifth of West Virginia men sixteen years or older with earnings in 1999 had incomes of less than $\$ 10,000$ (U.S. Census Bureau, 2000b). ${ }^{75}$

Income for West Virginia residents comes from a variety of sources, of course, including wages and salaries, profits from businesses, interest and dividends, and transfer payments. What is interesting in the state is the amount of income that is coming from Social Security retirement benefits, Social Security Disability Insurance $(\mathrm{SSDI})^{76}$, and Supplemental Security Income (SSI) ${ }^{77}$ Because of the state's large elderly population, 33.9 percent of West Virginia residents receive income from Social Security and 22 percent have retirement income. The national figures for these incomes are only 25.7 percent and 16.7 percent respectively (U.S. Census Bureau, 2000d). In terms of SSDI, all fifty-five counties in West Virginia have a county work disability percent that is above the mean for the United States (Latimer, 2004). Eighteen of West Virginia's counties are part of the national 20 percent of counties with the highest rates of worker disability (Burkett, 1994). In 2000, 22.8 percent of West Virginia's population five years and older had a disability and the national rate was just 17.5 percent. Approximately 7 percent of West Virginian's, compared to 4.4 percent nationally, received SSI benefits in 2000. Latimer

\footnotetext{
75 The poverty level for a single person household in 1999 was $\$ 8,240$ per year (U.S. Department of Health and Human Services, 2005).

${ }^{76}$ SSDI is financed with Social Security taxes paid by workers, employers, and self-employed persons. To be eligible for SSDI, the worker must earn sufficient credits based on taxable work to be "insured" for Social Security purposes. Disability benefits are payable to blind and disabled workers, widow(er)s, or adults disabled since childhood, who are otherwise eligible. The amount of the monthly disability benefit is based on the Social Security earnings record of the insured worker (Social Security Online: www.ssa.gov).

${ }^{77} \mathrm{SSI}$ is a program financed through general tax revenues. SSI disability benefits are payable to adults or children who are disabled or blind, have limited income and resources, meet the living arrangement requirements, and are otherwise eligible. The monthly payment varies up to the maximum federal benefit rate, which is $\$ 579$ per month for an individual and $\$ 869$ for a couple, and may be supplemented by the State or decreased by countable income and resources. West Virginia does not supplement SSI benefits (Social Security Online: www.ssa.gov). Many of those individuals who qualify for SSI also qualify for Medicaid and Food Stamps.
} 
and Mencken (2003) highlight the possibility that disability benefits have become a de facto income maintenance strategy in depressed regions of Appalachia, as unemployed workers are placed on disability. This may also be true for Social Security and other retirement benefits where elderly family members become the most reliable income source for their households, which often include extended family members.

In 1980, 1990, and 2000 West Virginia's labor force participation rates for both women and men were among the lowest in the United States (Latimer, 2004; U.S. Census Bureau, 2000d; Hannah, 1995). In 2000, nationwide, 59.7 percent of individuals age sixteen years or older were in the labor force, compared to 50.4 percent in West Virginia (U.S. Census Bureau 2000d). Nationally, 54 percent of women age sixteen and older were in the labor force, compared to just 44.4 percent in West Virginia (U.S. Census Bureau, 2000d). In addition, a much larger percentage of female workers than male workers in West Virginia were employed part-time (approximately $29.6 \%$ versus $13.4 \%$ in 2000) or for only part of the year (36.5\% of women worked for fewer than 48 weeks a year compared to $28.6 \%$ of men in 2000) (Latimer, 2004; U.S. Census Bureau, 2000d).

Historically, West Virginia has also had one of the highest unemployment rates in the nation and in1990; it had the highest at 12 percent compared to a national average of $6.3 \%$ (Hannah, 1995). West Virginia's unemployment rate has improved in recent years, partly because of economic growth in the Eastern Panhandle and the Kanawha Valley, and also due to the out-migration of people looking for work (Latimer, 2004). In 2001, the state's unemployment rate stood at 6.1 percent compared to the national rate of 5.8 percent (ARC, 2005). 
Rural communities in West Virginia have been particularly hard hit by deindustrialization and economic restructuring and their associated shifts from higher-paid, benefit-providing jobs in goods-producing industries to lower-paid, oftentimes part-time employment in the rising service sector. Between 1979 and 1983, West Virginia lost 73,000 jobs in the goods-producing industries. The decline in these industries continued through the 1980s with mining jobs reduced by half, manufacturing jobs reduced by one-quarter, and construction jobs by one-third (Hawley, 1994: 59). By 1990, the total employment in these industries bottomed out at its lowest level in fifty years (Cushing, 1994: 20). In contrast, employment in the service industry in the state grew by 38.2 percent between 1980 and 1990 (Hawley, 1994).

The 2003 Bureau of Employment Programs data for West Virginia indicates that employment in goods-producing industries continued to decline while employment in serviceproducing industries grew. Approximately 47 percent of the jobs lost were in manufacturing; 22.1 percent were in trade, transportation, and utilities; 15.6 percent were in natural resources and mining; 9.1 percent were in construction; and 6.5 percent were in information. Forty-four percent of the job growth in the service industries occurred in professional and business services; 21.8 percent was in leisure and hospitality; 16.7 percent was in educational and health services; and 17.9 percent was in government, financial activity and other services (Latimer, 2004). As highlighted in Chapter IV, employment in the service producing industries constituted an overwhelming 84 percent of the total non-farm payroll in January of 2005. The majority of the service sector growth in rural West Virginia has been in the service industry's low-wage sector. The 1990 average annual salaries for jobs in the rapidly expanding wholesale/retail trade and services industries were between $\$ 10,000$ and $\$ 15,000$ less than the average salary for manufacturing jobs and between $\$ 22,000$ and $\$ 26,000$ less than the average salary for mining 
jobs (Latimer, 2004; Hawley, 1994). The 2001 average annual wages for workers still employed in mining and manufacturing were $\$ 50,081$ and $\$ 38,215$ respectively. The average annual wages for whole trade and retail trade services were between $\$ 3,500$ and $\$ 13,000$ less than the average wages for manufacturing jobs and between $\$ 15,000$ and $\$ 35,000$ less than the average wages for mining jobs for this same time period (Latimer, 2004). Probably the most telling statistic is that Wal-Mart Associates, Inc. is now the largest private employer (http://www.state.wv.us/bep/). Employment in West Virginia remains highly segregated in terms of sex. Women have been highly concentrated in retail trade and services; finance, insurance, and real estate; and government industries and underrepresented in all other sectors, most particularly mining and construction (Latimer, 2004; Hannah, 1995). In 1990, the top five occupations for women in West Virginia were secretaries, elementary school teachers, cashiers, nursing aides and attendants, and registered nurses. Women interviewed in this study correspond to these findings with five involved in secretarial work, three in retail and food service, one is a certified nursing assistant (CNA) and another is in medical assistant training, and two are involved in home health care, one as an aid and another as a supervisor. Although the percentage of West Virginia women in sales and service occupations has declined to 60 percent (in 2000), most women are still concentrated in these occupations (Latimer, 2004). This percentage contrasts sharply with the 27.6 percent of West Virginia men in these occupations. Forty-seven percent of men work in the higher-paid construction, extraction, maintenance, production, transportation, and moving occupations, compared to just 6.6 percent of women in the state (U.S. Census Bureau, 2000d).

In the post-industrial, restructuring economy, workers must have higher levels of education and training than were previously required for middle-income jobs (Latimer, 2004; Tickamyer and Duncan, 1990). These new employment qualifications are particularly 
problematic in rural areas where there are twice as many unskilled workers as in urban areas and where workers have low educational levels (Deavers and Hoppe, 1992). Adults in the Appalachian coal regions lag far behind the nation in educational attainment. Some counties have non-high school completion rates at least twice the national rate of 24 percent, and all Appalachian coal counties in 1990 had percentages of adults not graduating from high school higher than the national rate (Latimer, 2004; Latimer and Mencken, 2003). Educational deficits are one of the legacies of the region's dependence on natural resource industries who employed large proportions of non-high school graduates. When the mines close and the jobs leave, the more educated move away and those with the least skills and education are often those left behind.

In 1990, only 66 percent of West Virginians twenty-five years or older had at least a high school degree and the state had the lowest percentage, 12.3 percent, of college graduates over the age of twenty-five in the nation (ARC, 2005). In 2000, the state's overall high school completion rate reached 75 percent, and the college completion rate improved slightly to 14.8 percent (ARC, 2005).

Overall, women in the United States currently have higher average educational attainment than men, however; women in West Virginia do not have this educational advantage over their male counterparts. In 1990, 14 percent of males and 11 percent of females in West Virginia had at least a bachelor's degree. In 2000, the situation had only marginally improved with 16 percent of males and 14 percent of females having at least a bachelor's degree (U.S. Census Bureau, 2000d).

Income and educational deficits, low labor force participation and high unemployment rates, and a poorly diversified and low-paid labor market translate into unprecedented poverty 
rates in West Virginia. According to Hannah (1995: 45), "West Virginia historically has had a higher rate of poverty than the United States as a whole; however, this gap widened considerably during the 1980s." In fact, the percentage of West Virginia families living in poverty increased from 12 percent in 1979, to 16 percent in 1989, and to 17.9 percent in 2000 (compared to $12.4 \%$ nationally in 2000) (Latimer, 2004; U. S. Census Bureau, 2000d; Hannah, 1995). Additionally, 25.5 percent of households in West Virginia, compared to just 15.8 nationally, had incomes below $\$ 14,999$, which was well below the poverty rate of $\$ 17,050$ for a four-person family in 2000 (U.S. Census Bureau, 2000b). Eleven of the households interviewed in this study, which is over half of the sample, had annual incomes below $\$ 15,000$ (Table 5). In fact, female-headed households had the highest poverty levels of any family type in West Virginia. Sixty-three percent of female-headed households with children under the age of five in the state were poor compared to the national rate of 46.4 percent. According to Snyder and McLaughlin (2004: 138), between 1980 and 2000 poverty decreased for female-headed households in metro central city and suburban areas of the United States and increased for those in non-metro areas. In addition, America's Second Harvest (ASH) (2002) reports that 9 percent of all households in West Virginia are food insecure and 3.1 percent are food insecure with hunger (Latimer, 2004). Approximately 24 percent of the state's children receive Food Stamps, ${ }^{78}$ and nearly 30 percent

\footnotetext{
78 The Food Stamp Program (FSP) is administered by the WV DHHR and governed by federal law and regulations of the U. S. Department of Agriculture, Food Nutrition Services. The Program started in 1961 with issuance of the first food coupon in McDowell County, West Virginia. The FSP provides monthly benefits to help eligible households buy food. Eligibility to receive benefits is based on household size, income, assets and some household expenses. The income and asset limits are determined by the federal government. The asset limit is $\$ 2,000$ for most households, but if at least one person is at least age 60 or disabled, the asset limit is $\$ 3,000$. Most people must pass a gross income test and then a net income test. Before total income is compared to the federal net income limits, certain deductions are applied to the income, such as: $20 \%$ earned income disregard, child care costs, excess shelter/utility costs, court-ordered child support paid out, medical expenses over $\$ 35 /$ mo., etc. Most adults must meet a work requirement to remain eligible to receive benefits, although there are some exceptions. However, all able-bodied adults who do not live with dependent children may only receive Food Stamp benefits for 3 months out of every 36 months unless they work or participate in a work activity. Food Stamp benefits may only be used to purchase food for human consumption and seeds/plants to grow food at home. Food Stamp benefits cannot be used for: household items, grooming products, tobacco, alcohol products, pet food, etc (http: www.wvdhhr.org).
} 
receive reduced price or free lunches through the National School Lunch Program (ASH, 2002: Child Welfare League of America, 2001).

West Virginia's limited employment and income bases affect communities across the state by lowering the local tax base. This lower tax base affects the development, quality, cost, effectiveness, and availability of public services. The lower average median household incomes found in rural areas also limits the money spent on educational, transportation, and other infrastructure resources (Latimer, 2004; Zimmerman et al. 1999). In fact, West Virginia's local public expenditures and taxes per capita are lower than the national average, and lower than surrounding states such as Maryland, Ohio, Pennsylvania, and Virginia (Reece, 1994). Reece (1994: 311) argues that, "Businesses and labor looking for high levels of police and fire protection, extensive public libraries, high levels of public water, sewer, sanitation, and other local public services will not find these in many West Virginia localities."

West Virginia has no county highway system and only half the state's highways are paved. According to Martinelli and Eck (1994), 60 percent of the highways that are paved have a fair to very poor sufficiency rating in terms of curves, grades, land and shoulder widths, and number of lanes. In terms of health care, the National Association of Community Health Centers (NACHC) recently reported that in West Virginia, 58.2 percent of the state's population is medically underserved, and 28.2 percent do not have a regular source of primary care. In addition, 17 percent of West Virginians currently do not have any kind of health insurance, and 
16 percent receive Medicaid ${ }^{79}$ or some other form of public assistance healthcare (NACHC, 2001).

Income, poverty status, unemployment, and educational levels can vary considerably at the local level throughout Appalachia. By illustrating county level data for the five counties where this research takes place on Table 4 one can see this diversity within West Virginia. Preston and Taylor counties (Map 6), the two most rural and marginalized areas of the research, have lower per capita incomes and higher poverty rates ${ }^{80}$ than the other three counties as well as lower rates for adults with high school diplomas and college degrees. These counties have no major road system going through them and their largest cities, Grafton in Taylor County and Kingwood in Preston County, have populations of only 5,489 and 2,944 respectively. Monongalia and Marion counties both house state universities and Harrison County is an evergrowing business center for central West Virginia and home to the large Federal Bureau of Investigation (FBI) site. One of the major highways, Interstate 79, which runs north to south, also passes through all three of these counties. These counties have a more educated population and higher per capita incomes. Marion, Preston, and Taylor counties all have per capita incomes that are lower that the state average and Monongalia, Preston, and Taylor counties have higher poverty rates that the state as a whole and much higher that the Appalachian region and United States' poverty rates.

\footnotetext{
${ }^{79}$ Medicaid provides medical care in the community or in an institutional setting, such as a nursing home, to individuals who otherwise might not be able to afford the care. A variety of services are provided, according to state and federal guidelines, depending of the individual or family circumstances. Recipients of SSI automatically qualify for Medicaid. In addition, other individuals and families may qualify for and receive Medicaid, if eligible and it is provided under a number of coverage groups. Medicaid is administered at the federal level by the Centers for Medicaid and Medicare Services (CMS) under the Department of Health and Human Services. There are many ways to qualify for Medicaid and most are based on income, poverty, unemployment, disability, and health issues. Some of these coverage groups are mandatory, that is required by CMS to be covered by each state, and some are optional (West Virginia Department of Health and Human Resources (WVDHHR) online: www.wvdhhr.org).

${ }^{80}$ The poverty rate in Monongalia County is likely high due to the high number of students who attend university in the county and have very low incomes.
} 
Like South Africa, issues around poverty, rural location, a lagging state economy, and poor educational levels affect women's abilities to acquire and sustain a livelihood for themselves and their families in West Virginia. The struggles and triumphs of women heading households in West Virginia are discussed in the following pages.

\section{Description of Sample}

This section of the chapter presents the data gathered through a socioeconomic survey conducted with each respondent interviewed in West Virginia and highlights income, age, educational, household status, and health data concerning the sample. Table 5 provides a summary of pertinent information concerning the respondents and can be used as a reference guide throughout this and the following section of the chapter.

All eighteen respondents reside in five counties that are located in the north-central part of West Virginia and northern region of Appalachia (Maps 1 and 8). All of the counties are nonmetropolitan counties, as defined by the United States Census Bureau. Six of the respondents reported that they have lived in their present community for ten to twenty years; seven for five to ten years; two for two to five years, and two for less than two years. One of the respondents had lived in her community all of her life. The respondents vary by age with 44 percent between thirty and thirty- nine years old. One respondent is nineteen; two are between twenty and twentynine; three are between forty and forty-nine; three are between fifty and fifty-nine; and one is over the age of sixty. Seventeen of the women are white/Caucasian and one is AfricanAmerican. 
Table 5: Summary Data for Respondents in West Virginia, Appalachia

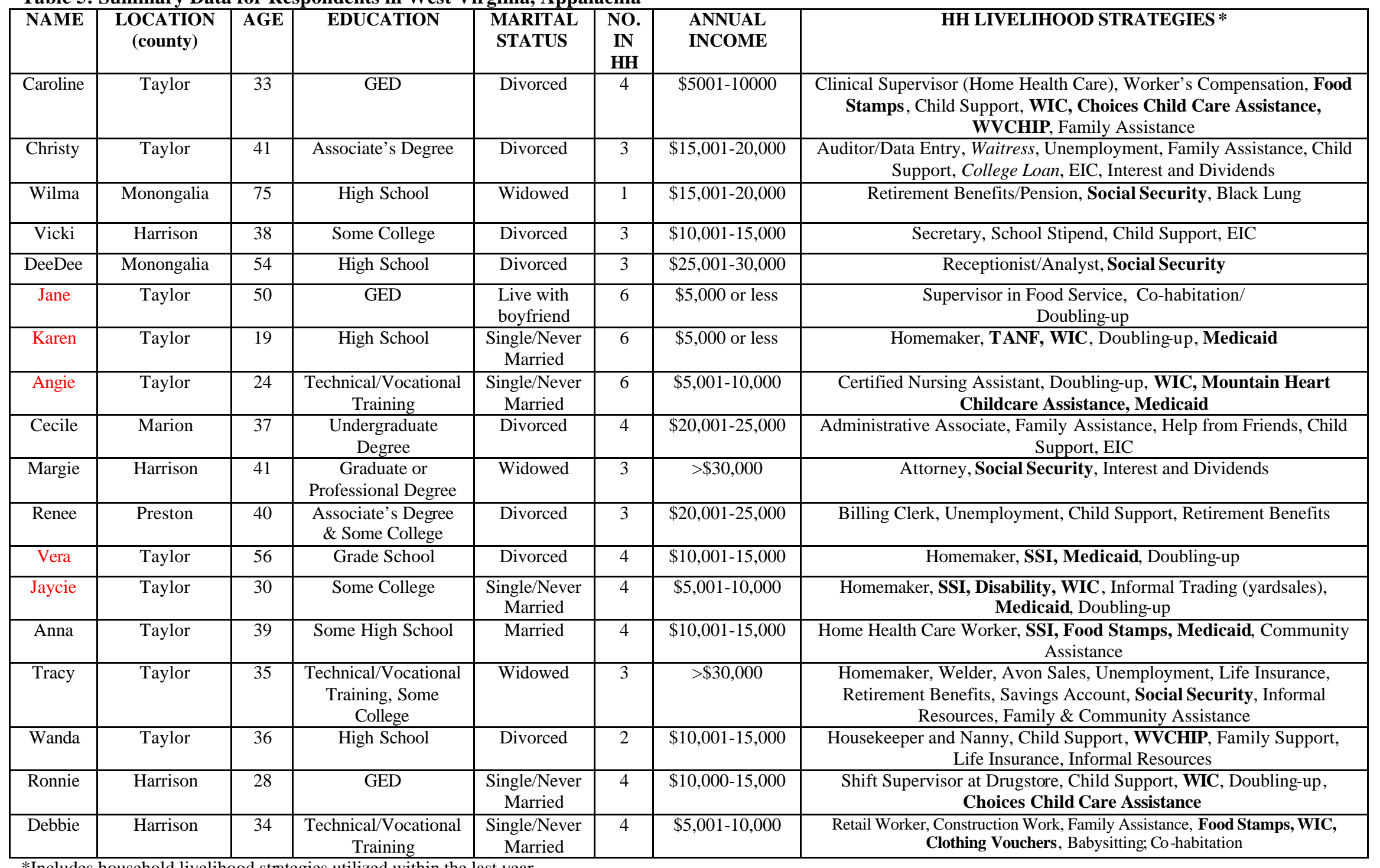

*Includes household livelihood strategies utilized within the last year.

Under Name, the respondents highlighted in red are those that double-up together.

Under Household Livelihood Strategies, italicized text shows strategies of household members other than respondent. Bold text shows government programs. 


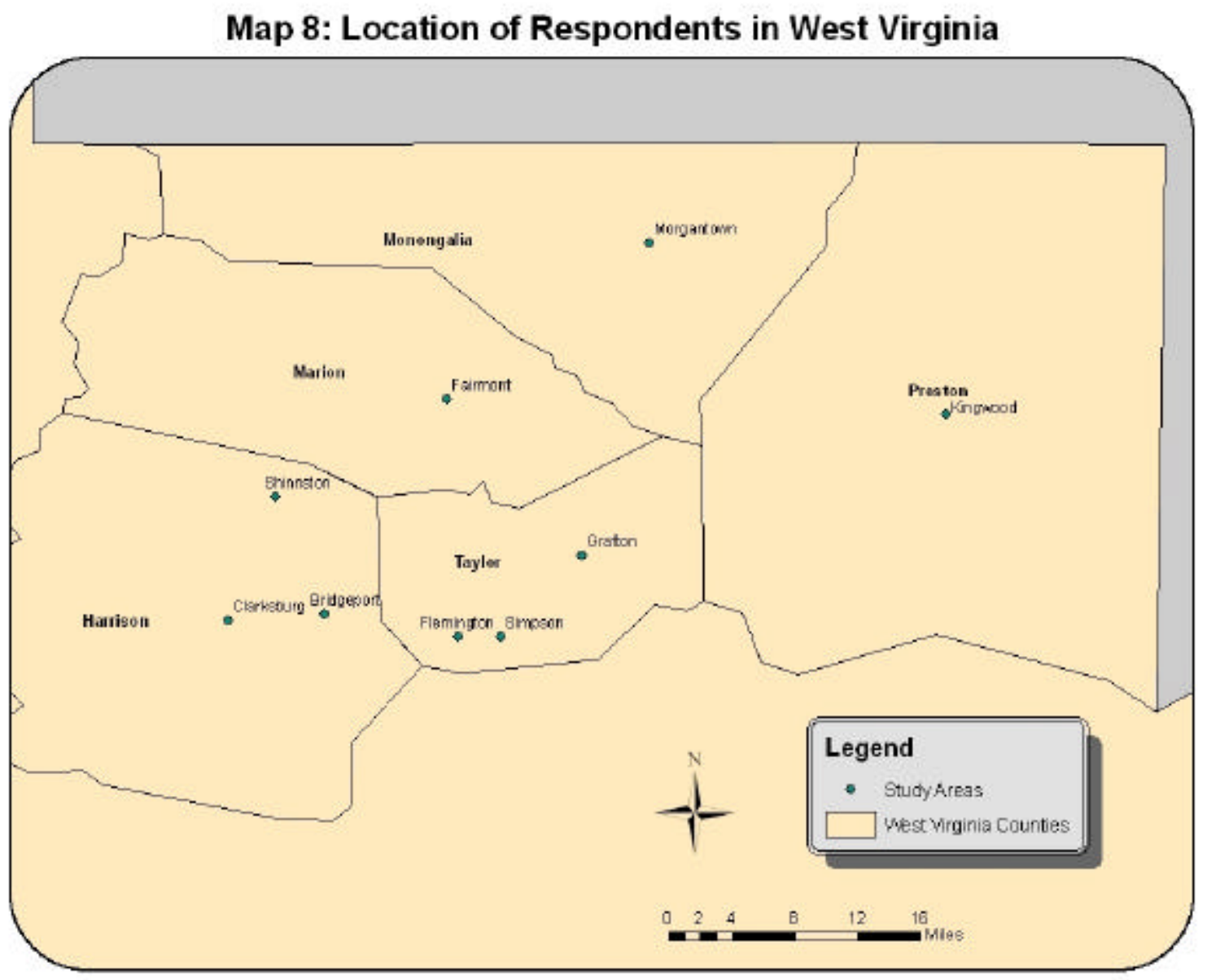

The educational attainment of the respondents varied considerably. One reported only attending grade-school and another has some high school education. Three have high school diplomas and three have General Education Diploma's (GED). Four of the respondents have some technical or vocational training and two have Associate's Degrees. Four had attended college but not received degrees; one has an undergraduate degree; and one has a graduate or professional degree. Throughout the interviews, women commented on the issues of education and their desire to either go to school or finish a degree.

Jane, in Simpson: "I wish I would have gone back and got my education." Karen, in Simpson: "I wish I would have finished high school before I had him...he was born May $21^{\text {st }}$ and I graduated June $1^{\text {st }}$, my graduation present."

Ronnie, in Clarksburg: "I have thought about going back to school but I don't know if I could do it." 
Renee, in Kingwood: "I wish I had my degree and had that behind me..."

Vicki, in Clarksburg: "... you have to have an education to get a good job, when you look at my income compared to a professional person and I wish I made half that much...it blows my mind, there is a huge gap."

In terms of household status, 44 percent are divorced; 28 percent are single/never

married; 17 percent are widowed; and one is married and one is living with a boyfriend. Eight of the women have two dependent children; six have three dependent children; three have three dependent children; and one has none (Table 5). Three of the households have six members; seven of the households have four members; five households have three members; two households have two members; and one household has one member. The average household size for West Virginia is 2.40 (U.S. Bureau of the Census, 2000c). Household members include husbands, boyfriends, parents, children, and grandchildren. Four of the households include disabled family members. Two of those disabled family members are respondents for this study.

Sixty-one percent of the respondents reported annual incomes below the poverty level for a family of four in 2000 , which was $\$ 17,050$. Specifically, five have annual household incomes of between $\$ 10,001-15,000$; two have annual incomes between $\$ 5,000-10,000$; and two have annual incomes of less than $\$ 5,000$. Two have incomes between $\$ 15,001-20,000$; two have annual incomes between $\$ 20,000-25,000$; and only three have incomes above $\$ 25,001$ (Table 5). Eight of the respondents reported that they have three members of the household contributing to the household income; four have two members contributing; six have only one member contributing; and only one has four members contributing. Many of the women in this sample 'double-up', that is live with parents, extended kin or other family, or other non-relatives, including other women heading households, to save on rent and other household costs, such as utilities and groceries. Only two of the women in this sample co-habitate with a partner to whom they were not married. On the subject of doubling-up, Ronnie stated: 
I help out but I don't have to pay rent, I buy my stuff and (my daughter's) stuff, groceries, I buy more groceries than they do, they are never home...it is working out but I don't really like living here...financially it is good. If I could afford it, I would move out, I could probably get HUD, ${ }^{81}$ but I am not going to do that, because of where they put you, in an apartment, I am not moving (my daughter) into an apartment, I have never signed up...I don't like living with mom and (my step-dad). I am almost 28, you know (Individual Interview August 3, 2004).

Income sources and livelihood strategies for these households include wages, salaries, and unemployment benefits; help from family and friends; school stipends, scholarships, and loans; the Earned Income Tax Credit (EIC); child support; retirement benefits, pensions, and Social Security; informal trading and homework; interest and dividends; and government assistance such as TANF, Food Stamps, Women, Infants, and Children (WIC) ${ }^{82}$ and SSDI and SSI. Of the eighteen respondents, seven have been heading the household for more than ten years; three for five to ten years; four for two to five years; one for one to two years; and three for less than one year. On the subject of being the head of the household, Christy stated: "you have to put your kids first, no matter what, over jobs, men...as long as they have been first; it has worked out for me" (Individual Interview, April 20, 2002). When asked about her own and other women's abilities to head households Margie stated: “women are more pragmatic...this is it, my

\footnotetext{
${ }^{81}$ HUD is the Department of Housing and Urban Development. It was created by President Lyndon B. Johnson in 1965 and during the War on Poverty. HUD is responsible for national policy and programs that address America's housing needs, that improve and develop the nation's communities, and enforce fair housing laws. HUD's primary programs include: mortgage and loan insurance through the Federal Housing Administration (FHA); community development block grants (CDBGs) to help communities with economic development, job opportunities, and housing rehabilitation; HOME Investment Partnership Act block grants to develop and support affordable housing for low-income residents; rental certificates in the form of Section 8 certificates or vouchers for low-income households; public or subsidized housing for low-income individuals or families; homelessness assistance provided through local communities and faith-based and non-profit organizations; and fair housing public education and enforcement (HUD online at: www.hud.gov).

${ }^{82}$ WIC is a federal grant program that provides nutritious foods, nutrition counseling, and referrals to health and other social services to participants at no charge. WIC serves low-income pregnant, postpartum, and breastfeeding women and infants and children up the age of five who are at nutrition risk. To be eligible, applicants must fall at or below 185 percent of the U.S. Poverty Income Guidelines (currently $\$ 37,873$ for a family of four). A person who participates or has family members who participate in other benefit programs, such as the Food Stamp Program, Medicaid, or TANF, automatically meets the income eligibility requirement. WIC is administered by State agencies, such as health departments. Of the 7.63 million people who received WIC benefits in fiscal year 2003, approximately 3.82 were children, 1.95 million were infants, and 1.86 million were women (USDA, 2004).
} 
lot in life. Whether you make $\$ 10,000$ or $\$ 100,000$, the choice is you got to get up and run the house and do it. Women are amazing...we are the stronger sex" (Individual Interview, August 9, 2004).

In terms of healthcare, nine of the women have private health insurance; three have public employee health insurance; five have Medicaid; one uses a rural health care clinic with a sliding fee; and two have no health coverage at all. With respect to children and other household members, seven of them have private health insurance; two have public employee insurance; seven have Medicaid; two have the West Virginia Child Health Insurance Program (WVCHIP), ${ }^{83}$ a low cost health insurance program for children of working families; and one has none. On the subject of living with no health insurance:

Anna is heading a household that includes her disabled husband, who has epilepsy, and her two sons. Anna works as a home health care worker and her husband and son receive SSI benefits. They have an annual household income of between $\$ 10,001$ and 15,000. Anna has no health insurance but her sons have a Medical Card and her husband has Medicaid. Medicaid, however, does not pay for her husband's medications and they cost over $\$ 800$ per month. Anna states: “as far as (my family's) health goes...my kids have a medical card. As long as they have it, that's all that matters... and my husband has red, white, and blue, Medicaid. I take my kids to the doctor if they need to go, I don't go myself, I have high cholesterol, but I can't afford to go, I need to go, look at these spots on my face, if you go, then you have to buy the prescription, it is more expensive, I don't have that kind of money... We are trying to rebuild our house, it burned down a couple of years ago...” (Photo 18) (Individual Interview, August 6, 2004).

Concerning childcare, seven of the women reported that they care for their children; nine utilize other family members; one relies on a friend or neighbor; four use a daycare center; and one has a nanny. Three of the respondents reported getting state-funded childcare assistance

\footnotetext{
${ }^{83}$ WVCHIP is comprehensive health insurance including doctor and hospital visits; immunizations and prescriptions; tests and x-rays; vision and dental care; emergency and urgent care; and mental health, case management for special needs, and diabetic supplies. Children are eligible if they live in West Virginia; are 18 and younger; don't currently have insurance and haven't had it in the last six months; are not eligible for West Virginia Public Employee Health Insurance (PEIA); are not eligible for Medicaid; live in families that meet the WVCHIP income guidelines; and are United States citizens or qualified aliens (WVCHIP online: www.wvchip.org). WVCHIP income guidelines are based on family size and only the income of the child's natural or adoptive parent is counted to qualify. As of August 2005, forty-five percent of the children in West Virginia were either covered by Medicaid or WVCHIPS (WVCHIP online: www.wvchip.org).
} 
from Mountain Heart in Taylor County and Choices in Harrison County. ${ }^{84}$ Regarding Mountain Heart in Taylor County, Angie stated:

(My daughter) goes to a babysitter while I work and when I went to school...I go through Mountain Heart, they pay for her childcare...fifteen dollars a day...they go by income and with being a single parent, I don't have to pay anything. It is state money but they have a separate office from the DHHR (Individual Interview, October 13, 2001).

\section{Livelihood Strategies of Female-Headed Households in West Virginia}

Understanding women's livelihoods in West Virginia involves looking at women's roles within households and local economies and linking them to historical factors as well as contemporary socioeconomic processes at the regional and global scales. These factors, along with state, market, and cultural institutions, work together to determine the livelihood strategies women in West Virginia have access to and engage in today.

The livelihood strategies of women heading households in West Virginia are embedded in persistent barriers that have excluded women from equal participation in the Appalachian economy. Historically, the West Virginia economy has been dependent on extractive industries, such as coal mining and timbering. These industries primarily excluded women, creating an occupationally-segregated labor market where wo men, if they worked, were located primarily in lower-paid, service-sector jobs. It is true that during early industrial development in West Virginia, women were oftentimes confined to households and associated reproductive duties,

\footnotetext{
${ }^{84}$ Mountain Heart and Choices are West Virginia Child Care Resource and Referral Agencies that are managed by the Division of Early Care and Education under the WVDHHR. These agencies operate with money from the federal Child Care and Development Block Grant, developed in the early 1990s. Under this grant, states were legally required to expend part of their federal dollars on initiatives designed to improve the supply and quality of its child care programs. West Virginia used some of its money to establish resource and referral agencies around the state. These agencies manage the child-care subsidy program; link parents with childcare options; provide consumer information; offer technical assistance and training to providers; and inform parents of other resources in communities. These agencies are located all over the state, with a total of twenty-one offices. Financial assistance to families for childcare covers the majority of the costs of direct care and protection of children while parents work, attend training, or are otherwise unable to provide care. Families are eligible for financial assistance if their monthly gross income falls below 150 percent of the fiscal year 2000 federal poverty level and can receive assistance until their income exceeds 185 percent of the fiscal year 2000 federal poverty level (WVDHHR online: www.wvdhhr.org).
} 
such as child-rearing and subsistence farm activities. Their labor, although essential to household survival and the reproduction of the labor force, was undervalued.

Extractive industry did not produce highly trained workers or contribute to the educational development of the workforce in West Virginia. Therefore, when the economy began to 'restructure' in the 1970s and capital, corporations, and jobs began to flee the Appalachian region and West Virginia in particular many men who were the breadwinners of the family lost the ir jobs and were without the skills to access higher-paying jobs in the new economy. During this time, the economy also began to demand workers for low-paid, oftentimes part-time service sector work in retail, office work, and healthcare, for example. Women in West Virginia and other parts of Appalachia were brought into the labor force by their need to supplement jobs lost in extractive industries and manufacturing and provide families with sufficient income to maintain basic needs such as health, housing, food, transportation, and so forth (Couto, 1994). Couto (1994), in his work on Appalachia and the welfare state, has particularly highlighted how changes within the family reflect changes that occur in the labor force. The male wage earner has declined in labor force participation and he has fewer high wage employment opportunities. When this economic change is combined with social changes in marriage and lifestyle, one can account for the rising numbers of women heading households in the United States.

According to Couto (1994), these economic and social changes have caused many women to enter the labor force at time of decline in the real and social wage, due to economic restructuring, and a corresponding decline in social investment, due to welfare reform. Thus, the restructuring economy has further marginalized women and their labor. Women have become the new Appalachian workforce in a global economy and their labor has been reconstituted as a 
cheap, yet readily available resource that is expendable and not worthy of health or retirement benefits. Jobs in this economy offer few work supports, such as childcare, flexible hours, or training opportunities, that can accommodate or improve women's needs to sustain households and balance their responsibilities at both work and home. Welfare reform has taken away 'safety net' resources, such as public assistance, from many households in West Virginia. Work requirements and time limits on benefits are extremely difficult for men and women to meet in a state with high employment like West Virginia. Welfare provides only minimal support to women in West Virginia who are heading households and is not enough for families to 'live off'. In regard to current research on women heading households in rural areas, Snyder and McLaughlin (2004) particularly point to the paucity of information that we have in the United States concerning the economic and family circumstances of rural, female-headed households. Brown and Lichter (2004) and Lichter and Jensen (2001) specifically state that the economic circumstances of non-metro single mothers are typically ignored or forgotten in public policy debates. This lack of attention prevents the establishment of job training or work support programs and creation of employment opportunities for women heading households in places such as West Virginia. This research contributes to developing better understandings of women heading households in rural areas and their economic circumstances by investigating their livelihoods and all of the interconnected strategies that compose them. The stories of eighteen women in West Virginia and the diverse and innovative strategies they develop and utilize to support households "on their own" are told below.

The livelihood strategies that women in this study utilize are immediately affected by the local economy, rurality issues, women's individual household situations, and women's access to human, physical, financial, and social capital. They are also affected by various structures 
including familial, cultural and social institutions, such as the church and community

organizations, as well as collective and policy/government institutions including local, state, and national government and their associated processes, such as economic development and social policies, laws, and legislation.

The fieldwork in West Virginia was conducted between 2001 and 2004 and women's livelihood strategies identified through this study and discussed below include: work in the formal sector; public assistance and child support; doubling-up and co-habitation; savings and retirement and life insurance benefits; informal activities; co-strategizing between women; and family and community assistance. Women in this study do not make use of only one or two of these strategies but combine multiple ones to create a livelihood that can take care of their families (Table 5).

Caroline combines multiple strategies to sustain a household that includes herself and her three children. She has worked a variety of jobs over the years: in food service, as a waitress; in hospitality work, as a housekeeper at a local motel; in sales, for a Kirby vacuum dealer; and, most recently, in home health care work, as a caregiver for the disabled and mentally impaired. Caroline was injured while working in home health care work and at the time of the interview was receiving $\$ 803.52$ per month from Worker's Compensation. It was unlikely that she would be able to return to that type of work because of her back injury and she was planning to start college in the fall of 2004. Caroline receives child support for two of her children, however, it is irregular. The father of her oldest daughter was ordered to pay $\$ 400$ per month in child support and she usually receives that money. However, the father of her second daughter, who is supposed to pay $\$ 50$ per week, is not reliable, sometimes only paying $\$ 20$ per week or nothing at all. Caroline had been in an abusive relationship with this man and is afraid to push him on the child support issue. He had held her at gunpoint and threatened to kill her numerous times. She receives no child support from the father of her third child, whose identity she will not reveal to the WVDHHR because of safety concerns for herself and her son. On the subject of child support, Caroline stated: "I feel if a man doesn't want to pay for a child, he doesn't have respect or love for his kids, but if he does it willingly, then he does."

Prior to her back injury at work, Caroline had never received public assistance. Due to the reduction in her income and need for assistance to care for and feed her children while going to school, she recently applied for and was receiving food stamps, totaling $\$ 90$ per month, and Choices child care assistance. She was also planning to apply for CHIP in order to have health insurance for the children and also HUD to help 
out with her housing expenses. She was receiving WIC for her youngest child to help with his nutritional needs. She had received a Pell Grant that would pay her tuition at Fairmont State College and was getting a small student loan to help out with commuting expenses and school supplies. "...when I called (about her financial aid package) and they said the (Pell Grant) would pay my tuition, I just started crying...I thank God." Concerning her decision to go to college Caroline stated: "If I want to better my life and do better for my kids I am going to have to have a better education and I have always wanted a higher education."

Caroline also receives both financial and emotional support from her family and friends. Her parents often provide groceries, money for gas, and items for the children. Her father performs maintenance work and repairs on her car and her mother helps her with childcare. According to Caroline her parents, "are the rock in my life...my mom and dad have been there financially and spiritually, any way you could imagine." At the time of the interview, she was working on what she called "the Master Plan" for when she started college in the fall. This plan is designed to help Caroline manage her household duties, school work, and the care of her children and includes the assistance of her mother, father, aunt, and friends.

Times have been tough for Caroline. "I have worked hard... and never have received government benefits, a welfare check...my kids will tell ya, we lived pretty much on rice and kidney beans and oodles and noodles for a lot of years. My kids were fed but it wasn't what they wanted or needed... it is a struggle...I have been like, "do I pay the electric bill or the water bill, which one do I need more? I will have to pay the water bill cause the kids need to eat and have clothes" and then pray they don't turn the electric off. But you have to make those decisions and it gets frustrating. I have sat down and cried my heart out, and then the crying is over, (and I say) now get up off your butt, and do something about it... This is my reality...I ain't no June Cleaver and this ain't the Brady Bunch...” (Individual Interview, August 11, 2004).

Work in the Formal Sector

Recent studies by Brown and Lichter (2004) and Lerman et al. (2001) highlight the limited understanding scholars and practitioners have of the economic benefits of formal employment among single mothers in nonmetro areas. Little information also exists concerning the differences between metro and non-metro single mothers in employment opportunities and constraints. Overall, annual earnings and wage rates remain lower in nonmetro than metro areas and nonmetro workers face higher rates of unemployment and underemployment (Brown and Lichter, 2004; Slack and Jensen, 2002; Conger and Elder, Jr. 1994). As well, jobs that pay a living wage are less available and the average dollar of government cash assistance is lower in 
nonmetro areas (Weber, Duncan, and Whitener, 2002; Lichter and Jensen, 2001; Jensen and Chitose, 1997). Brown and Lichter (2004) specifically found that nonmetro single mothers are less likely to benefit financially from full-time employment than women in metro areas.

There is no doubt that work provides an important route to economic self-sufficiency however, the "working poor" have replaced the "welfare poor" as the largest share of America's poor female-headed families (Brown and Lichter, 2004; Lichter and Jensen, 2001). As will become evident below, the jobs available to most of the women interviewed in this study, are often unstable, offer few benefits, and pay low wages. In addition, many of the women have had limited educational and job training opportunities. The employment structure of this part of West Virginia is directly related to its rurality and associated issues such as poor infrastructure and low tax base; history of extractive industry; the effects of economic restructuring such as a rising service sector, cyclical unemployment, and capital and corporate flight; and historical lack of social investment in the human population.

Women in this study who are engaged in formal sector work have various jobs. Five of the women are employed in secretarial work including auditing and data entry work, billing, and secretarial and administrative work; two are in retail work and one in food service; one is a CNA; two are home health-care workers; one is a housekeeper and nanny; one is an attorney; four are homemakers and two of these homemakers are disabled and one is seeking training to be a medical assistant; and one is retired from being a cafeteria worker at a local school (Table 5).

With respect to the women employed in secretarial work, one is employed at a local university and another at a local elementary school; one is employed by a government contract site; one works for a temp agency; and another is in local government administration(Table 5). The pay for these jobs varies with DeeDee, who is employed by the government contractor in 
Morgantown, reporting the most income at between $\$ 25,001-30,000$. Also employed in Morgantown, Cecile, who works at West Virginia University, and Renee, who works for the city of Westover, report incomes of between $\$ 20,001-25,000$. Christy and Vicki's incomes are the lowest for secretarial work, at between $\$ 15,001-20,000$ and $\$ 10,001-15,000$ respectively (Table 5). Christy is currently working for a local utility company in Fairmont but is technically employed by ManPower, which is an agency that places temporary workers. Vicki is employed by the Taylor County School System and works in the town of Grafton. Despite the varying salaries, all of these jobs include health and retirement benefits for the women and their families. One of the women has a college degree, two have associate's degrees, and two have high school degrees. Renee is currently enrolled at Fairmont State and working toward a Bachelor's degree in business (Table 5). Vicki had attended Fairmont State but was forced to drop-out for both financial and personal reasons after her husband left.

Christy, DeeDee, Renee, and Vicki have always worked in an office setting and have many years of experience in office work. Vicki had actually helped her husband build a successful business by "taking care of the office, and all of the books" (Individual Interview, April 18, 2002). Cecile was a homemaker before getting her first job at West Virginia University. She has worked in numerous departments all over the campus and is currently working on a graduate degree.

These jobs fit the needs of these women at the time of the interviews. All of the women highlighted here under formal employment have either schoolaged or grown children and only after-school childcare is an issue for them. All of them, except DeeDee whose son was over 18, are receiving child support although it is oftentimes irregular. There are very particular aspects 
of these jobs that accommodate the multiple financial and family responsibilities of these

women.

Christy supports herself and her two children through a diverse array of livelihood strategies. She works as an auditor/data entry person at a local utility company and her daughter works as a waitress while going to college. She was laid off before acquiring her current job and had received unemployment benefits. She gets child support for her younger son, some help from family, and the Earned Income Tax Credit (EIC). Her daughter has a student loan for college and Christy has some savings from which she draws some interest. When asked about her current job situation Christy stated: "(My job) is good, it's not permanent, just contract work, but I pick my own hours and days, it is flexible. When asked about the most important aspects of a job to her, Christy replied: "anymore, it is the hours, although I like getting a good salary. Right now, I get nine dollars an hour and I will get a raise in June...but I think the flexibility because I like to go in when I want and have the three day weekend with my family... this summer when (my son) was home, it was nice” (Individual Interview, April 20, 2002).

When asked about the particular benefits and drawbacks of her current employment

situation at West Virginia University, Cecile made these interesting points:

...one advantage I feel I have, in (her department), is when I first started there, the first thing I did with them, which I hadn't done before, I just told them the truth, I just point blank told them at a staff meeting, I had recently divorced, this is what I have been going through and this is what might come up... They understood that I lived in Fairmont. Eventually I brought my kids to the office, they met my children, upfront they knew my situation...so I had more flexibility... If I get a call and one of my kids is sick they say "Bye, Cecile". I have had them get my coat for me and push me out the door...My environment is extremely sensitive and understanding, its secure enough that they know I am not making up a story or trying to get out of there and they know for me not to come or leave early, it has to be serious... My kids feel comfortable calling me, they know everyone's voice, they call and say, "Will you please tell my mom that we are home from school?" I always get the message and it is great...My kids have even come to work with me... and to functions...Things I don't like, well...it bothers me that I have to get my family up so early... because of the commute (from Fairmont), and it is an hour and a half before I can get home...sometimes I have functions that I have to work at and last night I missed my daughter's basketball game, I miss their stuff sometimes because I have to work (Individual Interview, October 10, 2001).

Vicki made these points when asked about searching for her current job as a secretary at 
a local elementary school. She had previously been employed at her church as a secretary, a job that had afforded her great flexibility. Part of her motivation for seeking new employment, however, was the need for health benefits for her children ${ }^{85}$ and retirement benefits for herself.

I wasn't too concerned about finding a job but I was concerned about the quality of the job I would have...If it would be a job that I could do, have a good income, and work for my family. I could stay home and babysit for a minimum wage job, some women think they have to be out working so they will go out and get a job at a restaurant and I am not degrading that, but its just that they are working at a job where they work for 5 or 6 dollars an hour and they are away from their families...It had to be a job that would be worth my while to leave my kids. The insurance is a big thing...At the church, it was so flexible, it was only a few minutes away from the school if they (her children) needed anything. I had bosses that understood family and I could do what I needed to do with (my children). (My daughter) had her appendix rupture a couple of years ago and we didn't know what was wrong and they paid me for all that time I missed...in order to leave (my children and that job), it had to be something that would make me feel like I was compensating for leaving that flexibility, even though you can't put a price on that....but there are things you have to have, the income and the insurance too...It's hard to get them all, the job I have now (at the school), I have lost the flexibility, I get personal and sick days but it is not as flexible...there are those moms who stay home, the perfect mom, who goes everywhere with their kids, you don't get to do those things...it just gets you, you feel guilty (Individual Interview, April 18, 2002).

Two of the women interviewed in this study work in the retail business, one as a shift supervisor for a Rite-Aid and one as a cashier at a local grocery store, and another interviewee works as a supervisor for a fast food chain. All of their incomes are below $\$ 10,000$ per year. Ronnie and Jane both work about a forty hour week and have health benefits through their employers (Table 5). Debbie works part-time, around 15-20 hours per week, and also does babysitting in her home. She has no health benefits for herself but her children are covered through their father's employer. Ronnie and Debbie both have small children and childcare is an important issue to them. ${ }^{86}$ Jane's children are grown but her two daughters and their two

\footnotetext{
${ }^{85}$ Vicki's divorce settlement mandated that her ex-husband carry health benefits on her two children. He had recently dropped these benefits stating that as a self-employed individual, it was too costly.

${ }^{86}$ Childcare strategies will be discussed further later in the chapter.
} 
children live with her. ${ }^{87}$ Ronnie has a four-year old daughter and she currently lives with her mother and step-father. She receives child support from her daughter's father, WIC, and childcare assistance from Choices, which will be discussed further below. When asked about her employment history, current job, and job satisfaction, Ronnie stated:

(I have been at Rite Aid) for eight years...I am a shift supervisor. I worked at (K-Mart) for two years. I have medical benefits for me and (my daughter). I only get $\$ 7$ per hour. I get a raise once a year, I started out at a minimum wage, $\$ 4.75$ an hour, I get $\$ 246$ a month from (her daughter's) dad. If a manager is out, I will get a few more hours (than 40 hours). The past few months I have only been getting 36-37 hours, our hours are based on our sales, and how much we make.... I have thought about going back to school... I would still have to work, how could I do it and go to school? I would have to work part-time and I can't afford it with a car payment...(On the subject of getting a different job)...I like it there (at Rite Aid), the only bad thing is the pay, the benefits are great. I have to stay full-time, work 35 hours per week, if go down so many consecutive weeks, they take it (the benefits) away. They (Rite Aid) work with me as far as the schedule goes. I know it (her job) so well, it's what I know how to do, I have been there longer than the manager...I have never called off. But I would love to get an 8-2 job, cause she (her daughter) goes to pre-school and I feel bad cause I am going to miss so much, I work three nights a week too...I need an office job (Individual Interview, August, 3, 2004).

Ronnie and Jane both have GEDs and Debbie did have some vocational training in cosmetology. On the subject of her current job and education and training issues, Jane stated: "I have been there (at Hardee's) for seven years. I am a supervisor now and I didn't go to college but I went back six years ago and got my diploma...that was the only way I could move up at Hardee's, at just about any place now" (Individual Interview, October 13, 2001).

Three of the women in this study are involved in healthcare work (Table 5). Angie is a certified nursing assistant (CNA). She received training and her certification at Salem College and at the time of the interview was thinking about going back to school to become a licensed practical nurse (LPN). ${ }^{88}$ Caroline and Anna are both involved in home health-care work. Until she was hurt on the job, Caroline was employed as a clinical supervisor by ResCare, a human

\footnotetext{
${ }^{87}$ Co-habitation strategies will be discussed later in the Chapter.

${ }^{88}$ Communications with Angie revealed that she did go back to school and is now an LPN.
} 
service company that delivers services to people with disabilities, youth with special needs, and adults with barriers to employment. Anna is a home health aid who cares for the elderly in their homes.

Caroline started working for ResCare as a quality employment advisor making \$7 per hour. She eventually worked her way up to the position of quality employment supervisor where she managed thirty-two employees who provided personal, direct, twenty-four-hour care to ResCare consumers. For this job, Caroline was paid \$16 per hour and she also received health benefits for herself and her children. She oftentimes worked sixteen to eighteen hour days and was on-call twenty-four hours per day. "This was a very difficult job...physically and mentally...I stayed for six years and the only reason I stayed was because of my consumers..." stated Caroline (Individual Interview, August 11, 2004). Caroline had however been injured on the job while lifting a client out of a wheelchair and was currently receiving Worker's Compensation from the state of West Virginia. At the time of the interview, her income from compensation was 66 percent of her previous income at ResCare, totaling \$401.76 every two weeks. Her total monthly income, including Worker's Compensation, child support, and the food stamps is around $\$ 1500$ per month although the child support is very irregular. Due to her back injury, it was unlikely that she would be unable to return to ResCare, therefore she had applied and been accepted to Fairmont State College. She was starting classes in the fall of $2004^{89}$ and was interested in a career in criminal justice.

Anna is a home health aid and at the time of the interview she was working for a private company out of Bridgeport and also for the Marion County Senior Citizens. When asked to describe her job, Anna explained:

\footnotetext{
${ }^{89}$ Communications with Caroline indicate that she is still taking classes at Fairmont State and doing well.
} 
I clean their (the elderly) home, do the dishes, laundry, sweep and mop, bath them, I have a gentleman that I have to use a suction on to clear his throat, the one I care for on the weekends has a urine bag, I clean that, you name it, I have done it. The grocery shopping...take them to the beauty shop...make sure they take their medicines, put drops in their eyes, and last week, I even shampooed carpets (Individual Interview, August 6, 2004).

Anna had on-the-job training and is certified in CPR and First Aid and also has a Food Handler's Card, all of which are required for her job. She works very long hours: daily, including weekdays and weekends, from nine to one and then three to seven, translating to a fifty-six hour work week. On Wednesdays, she stays with a client from seven at night until seven in the morning. Anna makes \$5.50 per hour working for Marion County Senior Citizens and a little more per hour working for the private home healthcare agency in Bridgeport. ${ }^{90}$ Her reported annual household income is between \$10,001-15,000 (Table 5). As indicated previously, Anna does not take advantage of the medical benefits offered by her employer.

Anna had been doing private home health care for almost twenty years and had just joined the agency in Bridgeport and the Senior Citizens in Marion County about eight months prior to the interview. This is not easy work and when asked about how she managed her job with heading the household, Anna stated:

no, (it is not easy), I have been married nine years now and before, I didn't have a husband. I was on my own. I would go to work, go home, I had the kids on my own and raised them on my own. I mean it is not easy. At the time, I would work from 9-3 and my kids would get home at 4 and I would get dinner done, clean the house, and do their clothes, and go out again in the evening. I detailed cars in the evening and took care of the elderly during the day. It was hard work...I would get home at two or three in the morning (Individual Interview, August 6, 2004).

At the time of the interview, Anna was heading a household that included her husband, who is disabled, and her two sons. Their household livelihood strategies include her income, disability payments, Food Stamps, Medicare, and Medicaid. This family had also received some

\footnotetext{
${ }^{90}$ Anna did not feel comfortable revealing either the name of or specific wage she received from the private company.
} 
community assistance, which will be discussed further below, concerning the construction of their house.

Wanda, a single mother with one son, is employed as a housekeeper and nanny (Photo 19) (Table 5). Wanda had been cleaning houses for nearly eighteen years. Initially, she was in business with her mother, who had since passed away, but at the time of the interview she was doing residential cleaning on her own. She currently cleans for three clients in the Bridgeport area and is also a part-time nanny for one of these clients. This job affords Wanda great flexibility and in the summer months and during school holidays she can take her son to work with her. She is usually paid in cash; however, she reports all of her earned income.

Wanda works Monday through Thursday and is off Fridays, Saturdays, and Sundays. On Wednesdays and Thursdays, Wanda cleans for two different clients. Her duties include dusting, sweeping, and mopping; changing beds and cleaning bathrooms; vacuuming and laundry. She works on these days from around 8:30am until between 1 and 1:30 and receives sixty dollars a week per client. Both clients give her a Christmas and spring bonus and an annual raise and she charges extra for additional duties such as spring cleaning. One of these clients also pays her federal and state income taxes. She has been cleaning for these two clients for over ten years.

Wanda has an interesting relationship with her third client, Margie. Margie, who was also interviewed for this study, is the head of the household and a patent attorney. She is a widow, having lost her husband to cancer in 2001, and has two children. Wanda had been cleaning for Margie for four years and then in 2002, became a nanny to Margie's children. During the summer months, Wanda works at Margie's all day on both Mondays and Tuesdays doing cleaning and watching the children. During the school year, she has Monday and Friday mornings off, does cleaning for Margie on Tuesdays, and watches the children, including her 
son, everyday after school. Throughout the year she maintains the same Wednesday and Thursday schedule. At Margie's, Wanda performs the same cleaning duties highlighted above, including the laundry and ironing. She also cooks and provides transportation for the children if needed.

The salary arrangement between Margie and Wanda is creative and part of the costrategizing ${ }^{91}$ that oftentimes takes place between women heading households. When Margie realized that she needed a new childcare situation when her son went to elementary school, she devised a plan that she thought would work for both her and Wanda. Margie offered Wanda $\$ 250$ per week as well as paid school tuition and books, which is around $\$ 2,000$ per year, for Wanda's son at the private school that her son attends. When asked about how this arrange developed, Margie responded:

The housekeeper and nanny is part of the new arrangement. She (Wanda) cleans every week, does all of the laundry and ironing... serves dinner if I need her to, and helps transport the kids around...It works out great...(My son) goes to a Christian school, (my daughter) is now at the public middle school .... and part of Wanda's salary is that I pay the tuition for her son. When I did this last (childcare) switch, I was looking for options, Wanda was only cleaning, every two weeks...I thought, Wanda is such a sweetheart and I made an estimate of what she was making from cleaning houses and I thought, I can match that...Basically she picks up the kids from school and brings them here, this is three to six, and to sweeten the pot, she is in another county and wasn't thrilled with the school, so I thought I could get her (with the tuition)....I thought she was best for the job, her circumstances fit, and I thought I could offer her something she would otherwise not be able to do. Religion and environment mean a lot to her, the boys would be on the same school calendar, I took her situation into account and I realize some things might be easier for me because of my income, and I would rather help people that I know and like. I would rather help (Wanda's son) and the school and give him a good start...I always ask her if she is happy, she has some flexibility (Individual Interview, August 9, 2004).

When asked about the benefits and drawbacks of her current employment situation,

Wanda responded:

The advantages, I can go to work when I want, if I want, and if I have a problem they are considerate, they understand. If it is snowing, I don't go if I can't, I don't put up with no

${ }^{91}$ Co-strategizing between women heading households is discussed further below. 
one at work, no bickering. A great advantage is that it is flexible, I can take (my son), I love that. A disadvantage is no benefits, no paid vacations. I have taken weeks off but with no pay, no health insurance, that scares me, I don't carry that on myself and I pray that nothing happens to me, now (my son) has CHIP... with Margie, it is you scratch my back, I will yours...if I help myself, she will help me, she does not like a deadbeat. She is real considerate of me, wants to know if there is anything going on, she has had trouble with sitters before, and she said to me, "If there is a problem, let me know" so it has been good (Individual Interview, August 7, 2004).

Wanda's monthly income, including her child support, is around $\$ 1,500$, translating to a yearly income of between $\$ 10,001-15,000$. Before her son turned five years old, she had WIC and a Medicaid.

As stated above, Margie is a patent attorney (Table 5). She moved to Bridgeport, West Virginia in 1996 from the greater Washington, D.C. area to start an intellectual property practice for a local, general practice firm. Her husband, an aerospace engineer, was diagnosed with cancer in the Fall of 1999 and died in February of 2001. Margie has undergraduate and Master's degrees in computer science and finished her law degree by attending an evening program at the University of Maryland in 1995. Margie had her first child while attending law school and her second after starting the intellectual property practice in Bridgeport.

Margie works fairly regular hours and travels only a few times a year. Because her work is mostly transactional and not litigation, she oftentimes brings work home to do at night when the children are in bed. Concerning her financial and personal situation since her husband died, Margie made these points:

I did lose some income, but he had life insurance. In the long run, his income would have been more than the insurance, but there was an initial gain... With the insurance, I paid off everything but the mortgage. All we had were two car payments, I paid those off, and that still left a chunk of change... On top of the insurance, the kids get social security and since then I have become an equity partner in the firm, so my salary has doubled...plus I teach at the law school... it is very easy to raise the kids here (in Bridgeport) and be a single parent here...my commute is only five minutes, now I have my routine with Wanda, schools, my job, the kids' activities. I have my own network of help with the 
house and carpool, that makes it an easy life...I am very blessed (Individual Interview, August 9, 2004).

Because she is a professional, Margie's income is quite high and as stated previously, she is now a partner in the law firm where she works. Her livelihood strategies include her income, life insurance, social security, interest and dividends from investments, and of course, Wanda and her services.

Four of the women were homemakers at the time of the interviews (Table 5). Karen is a single mother with a five-month old baby. She had just graduated from high school and was preparing to attend Webster College and become a registered medical assistant. She lives with her mother, Jane, who raised her and her three siblings as the head of the household; her sister, Angie, who is also a single mother of a thirteen month old; and her mother's boyfriend in a small trailer (Photo 20) in Simpson, West Virginia. Karen, Jane, and Angie were all interviewed for this study (Table 5).

Karen had received some grants and student loans for her education. While in school, she can also qualify for child-care assistance through Mountainheart Childcare Resource and Referral Agency. At the time of the interview, Karen was receiving \$301 per month from TANF and Medicaid. She could not receive Food Stamps because Program counted her income as well as everyone else's in the home, including Jane and Angie's, when assessing eligibility. This combined income, however, is still less than $\$ 20,000$ per year for a household of six. ${ }^{92}$ Karen $^{2}$ did not receive child support from the father and according to her, "he has never helped me...he has no responsibility, he is twenty-one years old and still lives with his dad" (Individual

\footnotetext{
${ }^{92}$ The poverty rate for a six member household at the time of the interview (2001) was $\$ 22,850$ (U.S. Department of Health and Human Services, 2005).
} 
Interview, October 13, 2001). On the subject of her income and ability to take care of her son, Karen and her mother, Jane, responded:

Jane: "most people have the idea that anyone that is on (public assistance) just does it for the ride. And there are those people, we have seen it around...I told Karen when (her son) was born, I will help where I can but when it comes to the diapers and all that, formula, I will supply the house and utilities, you have to take care of him. That check is nothing..."

Kim: "(the check from TANF) is not enough...not really...(Individual Interview, October 13, 2001)."

When asked about her abilities to continue to care for son, Karen responded: "it's really hard, but I'll do it" (Individual Interview, October 13, 2001). The key role that Karen, Jane, and Angie's doubling-up strategy plays in their livelihoods is discussed below.

Tracy, who was recently widowed, was recovering from her husband's death and beginning to sort out the future when she was interviewed (Table 5). Prior to her husband's death, Tracy was a stay-at-home mom who sold Avon and worked at a local greenhouse parttime. Tracy earned between $\$ 200$ and $\$ 300$ per month with her Avon business and $\$ 6.25$ per hour at the local greenhouse during the late spring and early summer months. Her husband was a welder and had had a history of heart problems. While doing farm work, he suffered a massive heart attack and died, leaving Tracy with two sons and a horse farm to care for (Photos 21 and 22). He was only 43 years old.

Prior to starting a family, Tracy had worked in retail and food service; as a maid at a local hotel; and as a CNA. She had also attended Fairmont State College as an accounting major and was planning to return and finish the degree in the spring of 2005. She is currently receiving social security benefits for herself as well as her two children, totaling \$1600 per month. Tracy’s husband also had a life insurance policy and with it she was able to pay for the funeral expenses, pay off a personal loan of around $\$ 12,000$, and put a couple thousand dollars in a savings 
account. She does not have a water bill because they have a natural spring and she heats with wood and coal. Her current household expenses include a mortgage payment; utilities, such as electricity, cable, and a phone bill; groceries, gas, and clothing; car and homeowner's insurance; and farm expenses, including horse feed and hay and the upkeep on equipment.

When asked about the problems and difficulties she was facing as the head of the household, Tracy responded: "probably (the most difficult) jobs around here are the ones that require human strength...there might be something that has to be moved or lifted, I am used to doing heavy work, but there are some things a woman just can't do" (Individual Interview, August 9, 2004). At the time of the interview, Tracy was preparing for winter on the farm by getting truckloads of hay to feed her animals and keep them warm and assessing how much grain she would need to buy as a supplemental food source for the horses. By her estimation, she would need fifty pounds of grain per week and a total of 800 bails of hay to last the winter. The cost of the grain was $\$ 100$ per month and the hay, at $\$ 1.25$ per bail, would be around $\$ 1,000$ for the winter. When her husband was alive, he put up their own hay at his parents' farm and it was not a farm expense.

Financially, Tracy reported that things were quite well due to the social security she and her children were receiving and the life insurance money had allowed her to pay off the personal loan. She is determined to finish her education and on the subject of available employment opportunities in the area without some training or advanced education, Tracy stated: “...there might be (jobs around) but it would be jobs at like Wal-Mart, or fast food places...yeah, I could bring in a paycheck and get by, but mentally, it wouldn't be good" (Individual Interview, August 9, 2004). Since she lost her medical benefits for herself and her children when her husband died, she is also seeking a job that can provide health insurance to her and her boys. She is currently 
looking into the WVCHIP program for her two sons but could not afford to carry a personal policy on herself.

Jaycie and Vera are both disabled (Table 5 and Photo 2). Jaycie, who suffers from cerebral palsy, has a nineteen month old daughter, Mandy, and is living with Vera and her son, Brian, who is also disabled. Vera has been heading the household for over twenty years. She left her husband, who was extremely abusive, when Brian was seven years old. She has supported the two of them by receiving SSI; she and Brian both have a congenital eye condition that causes the loss of their eyesight, and AFDC, Food Stamps, and Medicaid and doing informal work, such as collecting aluminum cans. She has never received child support from Brian's father but she inherited the house that she, Brian, Jaycie, and Mandy now live in from her exhusband's father. Vera has never been able to work in formal sector employment. At the time of the interview, Vera and Brian were receiving $\$ 563$ per month each from SSI and they also had Medicaid for their health-related expenses. Their combined annual income is $\$ 13,512$. On the subject of her disability and her ability to raise her son, Vera stated:

I have a birth defect; they said if my mom and dad would have taken me for surgery when I was younger, they maybe could have corrected it. But they didn't and it was too long, so now I am 97 percent blind...distance and everything. Like they told me at the social security office, "well it sounds to me like you kept your own home, raised your child, you know, you have done a pretty good job"...I took care of my kid, just like a mother should...it was my responsibility to raise him (Group Interview, August 2, 2004).

Jaycie was thrilled with her current situation despite the financial difficulties she is facing as a new mother. Prior to moving in with Vera and Brian, Jaycie lived with her mother who was very protective, placing limitations on her abilities and aspirations due to her disability. On the subject of being the head of the household and dealing with her disability, Jaycie stated:

My story is a little different. I lived at home with my mother until the age of 24. I did not become independent until then. I did not even boil water in the kitchen without my mom standing right there... if I was in the bathroom for more than five minutes, she 
would come knocking on the door....I have learned a lot since then, that was four years ago, and in that four years, I have become a mother of a nineteen month old, and I was told that would be impossible because I have cerebral palsy. And I was always told I could not do anything, everyone would shoot down my dreams before they would let me try or even start... whatever she (her mother) could do to keep me at home is what she did. I moved out in 2000, and from 2000 till now, I can do everything, there are a few things I cannot do, I have some limitations, but I try everything...I didn't want to be labeled as somebody that has cerebral palsy...the only time you can tell that I have cerebral palsy is when I have my crutches...I don't use them much anymore, in the house not at all, that is my next personal goal. I am starting to meet the personal goals I have set for myself...not only for myself, but for Mandy, I have to keep up with her. She has been such a blessing, I thank God for her everyday and the life that I have right now... The things that I have asked for in my life, I have now, and I am just thrilled to death...to remain healthy, to find people that love me, to have a child of my own, and to be able to be an independent person...(Group Interview, August 2, 2004).

At the time of the interview, Jaycie was supporting herself and Mandy on a monthly SSDI check, totaling \$888, and she received WIC to help with Mandy's nutritional needs.

Mandy, because she was pre-mature and low birth weight, had previously received SSI and Medicaid however; since she is healthy and shows no signs of developmental delay or disability, she had recently been cut-off from those benefits. This loss of benefits is placing financial strain on Jaycie and her ability to provide for Mandy and she is very concerned about the loss of Mandy's Medicaid. Jaycie stated: “my main concern is Mandy's health care...if I just had the security of the healthcare, or that little extra to make sure that if something did happen to her, she would be taken care of. The healthcare is a big issue..." (Group Interview, August 2, 2004). The doubling-up strategy between Jaycie and Vera is again a key livelihood strategy for their household.

Offering more of a historical perspective on heading the household, Wilma, who raised two children on her own throughout the 1970s and early 80s and was now retired, provided this research with an autobiographical account of raising children and taking care of the household on her own (Table 5). 
Wilma's husband died of a heart attack when he was 37 years old, leaving Wilma with two children to raise in Tunnelton, a small, rural community in Preston County, West Virginia. He left her with a house that was paid for and she and the children were able to receive Social Security and Veteran's benefits. Wilma stated:

I got social security for me and the kids, and from the veterans. From the veteran's, the kids each got $\$ 11$ per month, well what can you do with that, and I got $\$ 42$. My husband didn't make much money (as a coal miner) and he only lived 15 years of our married life. I think we got about $\$ 200$ in social security, we lived on that. At least my house was paid for, it was never finished. We had three bedrooms, some land, a bathroom, a car, it was paid for (Individual Interview, April 18, 2002).

Prior to her marriage, Wilma had worked in a war factory in Akron Ohio, "I was what you call Rosie the Riveter," stated Wilma, "that's when women found out they could be independent and support themselves if they had to...that helped me (when her husband died) and when I went to work in my forties" (Individual Interview, April 18, 2002). She had also worked as a soda jerk in a drugstore and as a supervisor at Pepsi-cola. All of these jobs were located in Ohio, where she had relatives.

Because she would have lost her social security benefits if she had worked outside the home after her husband's death, Wilma did not seek employment until her son had turned 18 and her daughter was in high school. At that time, she went to work at the local high school as a cafeteria worker. She worked there for 21 years and then retired. On the subject of her job and finding employment, Wilma stated:

I enjoyed my work and I could build myself up, and I had good (health) insurance. My insurance meant more to me than anything (she had never had health insurance for herself or the children) and we got raises and I kept making more, I never made a lot...I would have lost my social security when the kids turned 18 and if I was not able to find work, I don't know what I would have done...I was lucky I was healthy and could find work. (Individual Interview, April 18, 2002). 
After her children left home, Wilma cared for her mother for eleven years. During the summer months, when the public schools were closed, she would also help to care for her grandchildren. After her retirement, Wilma moved to Morgantown to be closer to her children and grandchildren and she concluded the interview with these words:

When my husband died I said that God put his arms around me and said it would be ok...he showed me the way and I took advantage of it, we had to work for it but he showed us the way. When we left the cemetery (after her husband's funeral), I had my children on each side and an arm around my shoulders, and he said I will take care of you (she is emotional). I stayed home, I sold Avon and Sarah Coventry Jewelry, I registered voters and then I went to work at the school (in the school cafeteria), the kids got Social Security...I have been blessed and God is still letting me live for my kids (Individual Interview, April 18, 2002).

Throughout the various discussions with the women involved in this study concerning work and employment issues, they constantly commented on both the material and non-material aspects of their job situations and how important not only pay and health benefits were to them, but also flexibility. Many women reported that despite the low earnings, their current job situation afforded them a great deal of flexibility when it came to their work schedules and time off and that was why they did not seek other employment. Many of their current situations also suited the jobs of other members in the household, allowing them to 'work around' each other's schedules concerning childcare and other household duties. Employment that allowed these women to manage both their productive, the need to acquire financial resources, and reproductive, their household and childrearing duties, responsibilities was essential to their overall livelihoods. 


\section{Public Assistance and Child Support}

Public assistance and child support represent the second set of livelihood strategies discussed in this analysis. As a livelihood strategy, the receipt of government cash assistance represents an alternative to work and economic support from family and friends, including child support. Although families in nonmetro areas, including female heads of households, have higher rates of poverty than metro families, studies have shown that they are less likely to receive cash assistance (Lichter and Jensen, 2001). Jensen and Eggbeen (1994) show that single mothers in nonmetro areas are less likely to receive public assistance than single mothers in metro areas and that the dollar value of assistance is often too low to lift them and their children out of poverty. Poor people in nonmetro areas often face greater stigma, misinformation about welfare eligibility, and significant obstacles to receipt, such as limited transportation (Weber $e t$ al. 2002; Rank and Hirschl, 1988).

Cash assistance levels in rural areas are often insufficient to meet even the most basic needs for food, shelter, and clothing (Parisi et al. 2003). Lack of jobs, unreliable transportation, and inadequate childcare also place nonmetro single mothers at greater risk of being sanctioned off welfare rolls for failing to comply with mandated work requirements (Swenson, White, and Murdock, 2001). In their article titled "Poverty, Welfare, and the Livelihood Strategies of Nonmetropolitan Single Mothers," Brown and Lichter (2004) question whether the receipt of welfare is an adaptive strategy or a manifestation of economic hardship and single parenthood in the new welfare policy environment. Through quantitative analysis, they compare how livelihood strategies, such as co-habitation, doubling-up, and employment, are associated with government assistance among similarly disadvantaged single mothers in both metro and nonmetro areas. They found that nonmetro poor single mothers are less likely than their metro 
counterparts to receive food stamps and cash assistance. Thus, welfare is less likely to provide an economic safety net for nonmetro single mothers (Brown and Lichter, 2004).

Women heading households in the rural communities included in this study utilize various forms of public assistance to supplement their household incomes and need for basic items such as food, clothing, and housing. Government programs utilized by women in this sample included the Food Stamp Program, TANF, and WIC for food and cash assistance; Medicaid and WVCHIP for health care; HUD for housing; Choices and Mountain Heart for assistance with child-care; and clothing vouchers, ${ }^{93}$ as well as SSI and SSDI. At the time of the interviews, three of the households were receiving food stamps; six were receiving WIC; three had child-care assistance; two had access to WVCHIP and five to Medicaid; two were receiving SSI and/or SSDI; and only one was receiving TANF (Tables 5 and 6). The women in this study utilize government assistance as a temporary livelihood strategy and none of them, except Jaycie and Vera who are disabled, are or had been 'living off' the system. Concerning her use of HUD after her divorce, Cecile stated:

I ended up moving into public housing cause that was the only place I could find to stay. I promised my kids that we would only live there for a year, it ended up being a year and a half... I told them it was temporary, public assistance is temporary until you can do it yourself. And once I got control of my finances, and how to pay bills I quickly got out and I am doing it on my own (Individual Interview, October 10, 2001).

\footnotetext{
${ }^{93}$ Clothing vouchers are available to low-income families, who meet income and asset eligibility requirements, and have school-aged children. A family can receive $\$ 150$ per child in clothing vouchers and the vouchers can be used for clothing and shoes. There is no sales tax on items that are purchased with clothing vouchers and the clothing vouchers program is administered by the WVDHHR (WVDHHR online: www.wvdhh.org).
} 
Table 6: Current Use and History of Government Benefits* Received by Respondents in West Virginia, Appalachia.

\begin{tabular}{|c|c|c|}
\hline Name & Current Benefits Received $* *$ & Previous Benefits Received \\
\hline Caroline & $\begin{array}{c}\text { Food Stamps, WIC, Choices Child Care Assistance, } \\
\text { WVCHIP }\end{array}$ & None \\
\hline Christy & None & AFDC, Food Stamps \\
\hline Karen & TANF, WIC, Medicaid & None \\
\hline Angie & WIC, Mountain Heart Child Care Assistance, Medicaid & TANF \\
\hline Cecile & None & HUD, Food Stamps \\
\hline Renee & None & WIC \\
\hline Vera & SSI, Medicaid & SSI, Medicaid, AFDC, Food Stamps \\
\hline Jaycie & SSDI, SSI, WIC, Medicaid & SSDI, SSI, WIC, Medicaid \\
\hline Anna & Food Stamps, SSI, Medicaid & Food Stamps, SSI, Medicaid \\
\hline Tracy & None & Food Stamps \\
\hline Wanda & WVCHIP & WIC, Medicaid \\
\hline Ronnie & WIC, Choices Child Care Assistance & Food Stamps \\
\hline Debbie & WIC, Food Stamps, Clothing Vouchers & Medicaid \\
\hline
\end{tabular}

*Governments Benefits here include Food Stamps, WIC, TANF or AFDC, Clothing Vouchers, WVCHIP, Medicaid, Child Care Assistance, and SSI and SSDI. It does not include retirement or death benefits paid by Social Security or Medicare.

**Indicates benefits received within the last year.

The women in this study reported on their diverse experiences with the West Virginia Department of Health and Human Resources (WVDHHR) and varying reasons for accessing government benefits. For example, Vera and Jaycie are both disabled and unable to maintain employment outside the home. They need SSI and SSDI for cash assistance and Medicaid for their medical care. Christy, Cecile, and Vera had utilized welfare benefits, in the form of AFDC, food stamps, and HUD, to escape emotionally and physically abusive situations. Christy, who had never received government assistance prior to leaving her husband, told this story about accessing public assistance in order to "get back on her feet" after she left her abusive husband in Florida. 
We had guns pulled on us, (my daughter) was dragged by her hair across the living room one time, he locked me and (my son) in the closet and told me if I didn't shut the little SOB up he was going to blow both our M-F heads off... he would always say, "call the cops, I'll shoot you, I'll shoot the kids, I'll shoot the cops when they get here, and I'll shoot myself." That was his favorite line, all the time, and it got to the point that I didn't have to call 911, my neighbors did... I just had to get out, leave Florida...so when I first came up here (to West Virginia) before I had a job, I (applied for public assistance) because I was living with my aunt and I didn't have an income... and when I first signed up with them in May, I got $\$ 264$ per month... and when I got the job at the bank, they cut me down to $\$ 18$ per month. But they still gave me food stamps and they gave me WIC for (my son). I got that cause I wasn't receiving child support at the time either. I got \$200-300 in food stamps at that time...it was hard to miss work and go there and sit for three hours every three months to get them (the food stamps) but it was worth it (Individual Interview, April 20, 2002).

Vera had to get away from her husband because, "plain and simple, he was going to kill (her)":

...when I first left, I got some assistance because I didn't have enough to keep us (her and her son, Brian) going. But, you know, with the food stamps that helped me buy groceries....if he (her ex-husband) would have paid child support, we wouldn't have needed it. They give me $\$ 145$ (in AFDC) a month...they tried to get back child support, the welfare did...I said I don't want his money, I don't want his vehicle, I don't want nothing, I said this is my child and that is it....I was (afraid of him)...he tried to kill me, beat me, stomp me, you name it, I had it...I was down to 87 pounds when I left him...he just constantly beat me...he beat me right there in the head [pointing to the side of her head], with a gun, it bled for a month, and I was pregnant then...(Individual Interview, August 2, 2004).

Angie utilized TANF, WIC, and child care assistance benefits in conjunction with doubling-up to seek training as a CNA and her sister, Karen, would soon do the same to become a registered medical assistant. Child-care assistance from both Choices and Mountain Heart enable Angie, Ronnie, and Caroline to maintain employment and seek training and educational opportunities that would otherwise be difficult due to the high costs of childcare.

Caroline, who had been heading the household for over sixteen years and had never received government assistance, recently signed up for food stamps, child care assistance, and 
WVCHIP, in order to seek a college education. On the availability and her current use of welfare benefits (Table 5), Caroline stated:

I have applied for Choices and it's a program that is absolutely wonderful. It gives people the incentive to work or go to school without having to pay it all in daycare. They will pay all of (her son's and daughter's) expenses for daycare. For after-school care too...I get $\$ 90$ a month in food stamps... Dad wants me to apply for (HUD) and I probably will, but self-pride is keeping me from it...my rent is $\$ 390$ a month plus electric. I use child support to pay the rent, and my worker's comp to buy groceries and pay for the electric and other living expenses, car insurance, there is not much left...this (meaning her apartment) (Photo 23) would qualify for HUD and I wouldn't have to move. 75 percent here are HUD. I am going to check on it...I am going to apply for everything I can get. I have worked and paid taxes all these years, I don't drink or do drugs, so I will try to get the help I need to get my education (Individual Interview, August 11, 2004).

Food stamps and SSI supplement Anna's household income and Medicaid offers health

care assistance to her sons and disabled husband. Tracy's family had received food stamps when her husband had his first heart attack and was unable to work for a period of time. Wanda had received WIC and Medicaid for her son to help with his nutritional and medical needs and Medicaid for herself when she was pregnant. On the subject of needing to apply for government assistance for medical care, Wanda stated:

After I found out I was pregnant...I continued to live here (with her parents)...but I thought, how am I going to pay for this? Well, needless to say, I had to go to the state and ask for (medical) help. They did, there was no ifs, ands, or buts...they helped until (my son) was five years old, and I felt bad but I felt, I pay in and my mom and dad pays in...(Individual Interview, August 7, 2004).

WIC, food stamps, and clothing vouchers supplement Debbie's household income and assist her in buying food and clothing for her two sons. Debbie stated:

I couldn't do it without the food stamps and WIC especially. We wouldn't have much to eat if it wasn't for those programs...I just got the clothing vouchers cause my son will start school and it is a big help...mom bought him some stuff but now I can get him a nice pair of shoes to start school with (Individual Interview, August 8, 2004). 
The WVDHHR is a mix of case workers, paperwork, eligibility requirements, and program jargon that requires time, transportation, and a certain level of knowledge and understanding about benefits offered that many women in this study and beyond do not have accessible to them. Many of the women in this study reported that they did not sign up for food stamps because they had to continually reapply and verify their financial situation. On this subject, Ronnie stated: "one time I signed up (for food stamps) and it was like $\$ 40$ and it is not worth going there every three months for that..." (Individual Interview, August 3, 2004). In an interview with DHHR worker, Diane, in Taylor County, it was confirmed that clients do have to reapply but it is only every six months. After this interview, the researcher called those women who expressed concern around the reapplication process to be sure they had the correct information. It is still true; however, that getting time off from work to apply for benefits can be a challenge for these women.

Some of the women did have a lack of knowledge and understanding about some programs that might be accessible to them. The researcher continually told women in this study about WVCHIP and encouraged those who might be eligible for food stamps, HUD, or TANF to apply. Personal pride, privacy issues, and social stigma also prevented some of these women from applying for benefits. When asked about the main barriers to people accessing benefits, Diane, the DHHR worker interviewed commented: "pride..., many people feel that the (application process) is an intrusion into their family,...(and) some people say they are looked down on if they use food stamps or get a Medical Card" (Individual Interview, August 12, 2004). In a discussion concerning public assistance, the researcher asked Vicki if the stigma associated with welfare prevented her from accessing benefits and she said: "well, yeah, most people would not have known I was doing it...but, it was more the fact that was it the right thing to do?" 
(Individual Interview, April 18, 2002). Diane did report however, that if a client comes to the DHHR office to apply for one program, such as Medicaid, they are evaluated for other programs as well, such as WVCHIP, to maximize the time and effort a client puts forth to complete the application for benefits.

Interestingly, HUD had only been utilized by one respondent in this study (Table 6). Several of the women commented on the quality of life in HUD housing and did not like the idea of apartment living (Photo 23). They liked the 'home life' and extended family support they had with a co-habitation or doubling- up strategy where they could be in a house with a yard, surrounded by people they can depend on. The researcher expects that the lack of use of HUD as a livelihood strategy is one dimension of the rural nature of many of the communities where these women reside and general lack of available HUD housing as well as the close kin relationships that most of these women depend on.

There are many 'catch 22s' associated with public assistance and various other livelihood strategies utilized by women in this study. For example, co-habitation and doubling-up strategies that save women heading households from the high costs of rent and utility bills oftentimes prevent them from receiving food stamps. On the application for food stamps, all household members' incomes must be reported and this frequently results in the household exceeding the income requirements to receive benefits. Employment, which provides many women with much needed financial resources and is the aim of "work first" welfare reform programs that seek to move poor single mothers into the labor force and off benefits, oftentimes pushes women over the income limit to receive certain types of government assistance. However, in rural West Virginia the jobs women often engage in do not provide them with enough income to feed, clothe and provide housing for their families as well as pay for child care 
and transportation costs associated with employment outside the home. Women are, according to both Caroline and Jane, "damned if they do and damned if they don't."

Despite the receipt of needed financial resources, including cash assistance to pay bills, buy food, and obtain childcare, welfare was not lifting women in this study out of poverty or significantly improving their econo mic well-being. Contrary to popular belief and stereotypical characterizations of female-headed households and poor families in general, these resources only minimally supplement other livelihood strategies, including employment, doubling-up and cohabitation, and family and community resources and are not enough to 'live off'. Women in this study are not and could not survive on the few programs they have access to without combining them with other livelihood strategies.

Seven of the women in this study receive child support, despite the fact that it is oftentimes irregular and not a reliable source of cash income for them and their children (Table 5). This support is distributed to the women either monthly or weekly through the Child Advocate Office or directly from the father and the amount is usually determined through the family court system. These women spend an incredible amount of time and money in the court system and with the Child Advocate Office to get child support from the father's of their children. Detailing the fight she has went through to receive child support for her two daughters, Vicki told this story:

...we have been back (to court) probably three to four times... he has tried to lower it (the child support)...I have been trying to get the back child support when he wasn't paying...the Child Advocate would give him court dates for him to appear and give tax return information and things like that and one time he didn't even show up. It's been one fiasco after another...I couldn't get any help when he was in arrears. When I go to the Child Advocate's Office they will ask if I owe the state and I say no. A lot of people tell me that I would get more response from Child Advocate if I was receiving welfare, cause they want to get their money and get people off assistance...It's been hard, I mean for three years I have lived without the child support. He was supposed to be paying $\$ 200$ per week and I was getting \$400 a month, it is too long to go without the child 
support... that was my house payment, I had to come up with everything else. It didn't even come close to paying for everything. But finally, I don't know how they (Child Advocate) did it, and they don't want your help, its funny, you want to help and give information you have, a new address, they don't return calls, they didn't seem too concerned about helping me out...it's been a struggle...(Individual Interview, April 18, 2002).

There were numerous accounts from the women about how the fathers of their children work to reduce or totally eliminate their financial responsibilities to their children. On this subject, Ronnie, Christy, and Wanda stated:

Ronnie: "he (her daughter's father) wanted to give up his rights, he even checked into it but he would have to pay all this money for court costs, so he didn't...(he wanted to give up his rights) cause he don't want to pay child support...but it is court ordered, they take it right out of his paycheck" (Individual Interview, August 3, 2004).

Christy: "when he (her son's father) works, I get it (child support), if not, I don't. When he gets laid off, I get a portion from his unemployment. Right now, I get a portion from worker's comp, but he had been cut off three times...I never know. I was getting a check for about a year and then he got hurt and laid off...(now it is unstable)...he doesn't want the responsibility, he told me to get married so he would not have to pay (child support)" (Individual Interview, April 20, 2002).

Wanda: “he (her son's father) sends me a small check a month, he says he doesn't make that much but I know he does...it is only $\$ 100$ (per month), he got off cheap cause he lied, he says he only works for (a local construction company), but he is also selfemployed...they only go by his paycheck...” (Individual Interview, August 7, 2004).

Jane, who raised four children with no child support, stated:

...they (the authorities) brought him (the father of her children) in and he said he did not have a job and that was the end of that. But at the same time, he would come to our house, he hauls junk and has his own business, and he would show the kids a check for $\$ 600$ for one day's work. But as far as paying child support, he said it was my choice to be rid of him and it was my choice to take care of the kids. I said, ok, fine, I will (Ind ividual Interview, October 12, 2001).

In sum, child support payments, which should be a stable source of income for these women to help with the expenses associated with raising their children, was almost never a consistent and reliable livelihood source for their families or received without struggle on the women's part. The lies and manipulations, court battles, and general disregard for supporting 
children among many of these men are most disturbing. Most of these women lack both

financial support and a parenting partner when it comes to raising their children. Emotions

among the women and their children run very high on this subject and while none of the women

feel that they should be totally dependent on child support or the financial support of a man in

general, they are generally frustrated with the fact that many of these fathers can just walk away

from their financial and emotional responsibilities to their children. On the subject of fathers and

their lack of responsibility to their children these women commented:

Vicki, on the subject of how her two girls feel about their father, who they have not seen in years: "they recognize him for what he is. They realize that there are people who have problems...that require more help than they are willing to admit, and they understand, that maybe he needs help and its not to say that they would receive him with open arms, you know, if he came through the door right now, they would have a few things to say to him. But they will never have that trust, you can never get that back, I don't think they hate him, they pray for him every night, he is still in their hearts and they would like to see him change... they don't really know him, they were so little (when he left)..."

(Individual Interview, April 18, 2002).

Ronnie, concerning the lack of a relationship between her daughter and the father and her daughter's feelings about the father: "she (Ronnie's daughter, who was four years old at the time of the interview) won't say anything...he was supposed to come a month and a half ago, he said he would come and I told her. Well, he didn't show up and she cried and cried. It was awful. What do you tell her? I don't know what to say...I am always going to have to deal with it...it is so sad. How can he not come and see her? He doesn't know anything about her...(I want him to have a relationship with her) if he is going to be there and come when he says and make an effort. But I would rather him give up his rights if he is not going to do anything... she will be hurt by him all her life...he works close by and goes right by the house on his way home and never stops...I don't care for how long, just stop and see her" (Individual Interview, August 3, 2004).

Jane, Angie, and Karen, on the subject of men supporting their children: Jane: "I think they (Angie and Karen) both have found too that most women have their babies and the man can or can't or simply doesn't want to (support or be involved with his children). If they have someone that is going to be there, that's great. But, if not, they have found out that men don't have the same kind offeelings..."

Angie: "That's the truth. Hailey's (her thirteen month old daughter) father...we went to court and he does not see her. He has visitation... he did (pay child support) until it was raised...it was $\$ 50$ dollars a month, now it is $\$ 188$...He hasn't seen her since

January...she has seen him a total of maybe seven times in her entire life...he hasn't been here for so long, she would be afraid of him...he would probably be in and out (of her 
life) and I would rather him either be here or not, completely...it bothers me that her dad doesn't want anything to do with her but I can't make him be a dad to her. I can't force him to do something he doesn't want to do..."

Karen: "I think Zane is better off (without his father around)... they (the father and his family) have never come ... they have never seen him...He (the father) has no responsibility..."

Joyce: "you finally get to a place where you are not angry or hurt anymore, it's just I have my kids and I will take care of them..." (Group Interview, October 13, 2001).

\section{Co-habitation and Doubling-up}

Co-habitation and doubling strategies represent the third set of livelihood strategies utilized by women in this study. For a growing share of young adults, co-habitation is an increasingly important stage in the transition to marriage (Bumpass, Raley, and Sweet, 1995) and it has become a common family context for both childbearing and childrearing. Roughly 40 percent of nonmarital births in the United States are born to co-habitating couples (Bumpass and $\mathrm{Lu}, 2000)$. Co-habitation is especially common among low-income mothers and moving in with a boyfriend or partner may be a way to adapt to economic hardship. Indeed, Acs and Nelson (2002) found that children living with a single mother and her co-habitating partner are less likely to be poor than are children living with only a single mother. Co-habitation can offer financial and nonfinancial benefits for a single mother. Clearly, one financial incentive for a single mother to cohabitate is the sharing of housing and utility costs. Co-habitating partners may also share childcare responsibilities and augment women's networks of family and friends and, indirectly, their access to financial assistance or social support. Co-habitating single mothers also may be better able than other single mothers to pursue employment, work more hours, or obtain training necessary for securing a good job (Brown and Lichter, 2004).

According to Brown and Lichter (2004) and Snyder, Brown, and Condo (2004), we know surprisingly little about patterns of co-habitation in rural areas. However, these researchers 
claim that there are good reasons to believe that co-habitation, as a livelihood strategy, may be less prevalent among non- metro single mothers. Traditional family values, gender roles, and other normative constraints may make unmarried co-habitation a less acceptable option for single mothers (Brown and Lichter, 2004). Single mothers in non- metro areas may also be less able than metro single mothers to partner with "economically-attractive" men who provide economic support and who subsidize single mothers' job search activities (McLaughlin, Gardner, and Lichter, 1999). Although co-habitation may be positively associated with economic well-being among single mothers, this association may be weaker in rural areas.

In this sample of women heading households, only two women utilize co-habitation as a livelihood strategy (Table 5). Debbie lives with her boyfriend, who is also the father of her two children, and Jane, who is also doubling-up with her two daughters who are also single mothers, is living with her boyfriend. Both women discussed the financial benefits of co-habitating in regard to housing and utility costs. Debbie's partner also provides childcare for her children while she works in the evenings and on weekends. According to Debbie:

Joe works regular hours so he can be home in the evenings and on the weekends to watch the boys while I work at the store and I do the babysitting during the day...It would be hard on my own, I have my mom but she also helps my sister with (her daughter). My sister helps me sometimes with my boys, we have a good relationship, cause I watch her daughter... I don't know if I could pay the bills on just what I make and have extra for my kids...I suppose I would do it, I do bring in most of the money, but it would be tough...(Individual Interview, August 8, 2004).

For many of the women in this study, however, doubling-up is a more common strategy. As indicated by the discussion on child support, the unwillingness of many fathers to financially and emotionally care for their children coincides with the point made above concerning the lack of "economically-attractive" and responsible men in the lives of these women. For others in this study, religion and family values are also a major barrier to co-habitation. Due to her religious 
beliefs, Wanda would not even consider re-marrying, let alone co-habitation, because she was divorced and felt it was "not right in God's eyes" (Individual Interview, August 7, 2004). Others commented that they did not feel that 'living with' a man was a good example to set for their children.

As an adaptation to economic hardship, single mothers may 'double-up' by moving in with parents, extended kin or other family, and other non-relatives or some may have never left the parental home. Six women in this study sample utilize doubling-up as one of their livelihood strategies and live with family and/or other female heads of the household (Table 5). Previous studies have clearly shown that welfare benefit levels are associated with the independent living arrangements of single mothers: single mothers are more likely to form separate households in high- rather than in low-welfare benefit states (Moffitt, Reville, and Winkler, 1998; Bane and Ellwood, 1986). Welfare reform in the 1990s has made cash assistance no longer available to single mothers under age 18 who did not reside with other adults. ${ }^{94}$ This restriction may anchor teen unwed mothers to the parental home, but may also have created new economic hardships that cause some teen mothers to give up their children rather than rear their children alone without government cash assistance (Brandon, 2000). Indeed, the number of children living with at least one grandparent (with or without a biological parent) increased over the past decade (Bryson and Casper, 1999).

While doubling-up can mediate housing costs and is required in order for teen mothers to receive TANF, it can also preve nt many women heading households from receiving other cash assistance, particularly food stamps. When making an application for food stamps, the applicant must list all members of the household and their incomes. For the households in this study who

\footnotetext{
${ }^{94}$ The goal was to eliminate any real or perceived incentive to "use" out-of-wedlock childbearing as a mechanism or pathway to leaving the parental home.
} 
utilize doubling-up as a livelihood strategy, their combined incomes put them over the income limit to receive food stamps. ${ }^{95}$ Thus, either a woman can set up house on her own by relying on whatever she can earn in the formal economy and struggle to pay the rent and utilities; buy groceries and clothe the children; and acquire and pay for childcare and medical costs maybe with some government assistance through HUD, TANF, the Food Stamp Program, and Medicaid or stay with family and avoid having to get HUD and struggles with childcare and oftentimes have a better quality of life for herself and her children but not be able to receive food stamps and sometimes TANF. This is one of the many 'catch 22s' and cases of 'you are damned if you do, damned if you don't" involved in women's livelihood strategies and how they negotiate the many structures and processes, such as family and government institutions and social relations and welfare policies, to financially and emotionally support themselves and their families.

On the subject of doubling-up, Jane, Angie, and Karen highlighted how they "depend on each other" (Group Interview, October 13, 2001). Their doubling-up strategy allows them to share household duties and expenses as well as childcare responsibilities. This strategy permitted Angie to seek training as a CNA and at the time of the interview they were sorting out work, home, and childcare schedules to accommodate Karen's upcoming medical assistant training. Karen, because she got pregnant as a teenager and is still living at home, is able to receive TANF and Medicaid. Angie had also received TANF while going to school, as well as Medicaid. However, because of the total household income, none of them are able to receive food stamps. When asked about their doubling-up strategy and government assistance, Jane and Angie made these comments:

\footnotetext{
${ }^{95}$ For a household size of four, as in Ronnie and Vera and Jaycie's households the monthly gross income limit was $\$ 2,097$ in 2004, which is 130 percent of the poverty level. For a household of six, as in the case of Jane, Karen, and Angie, the monthly gross income limit in 2004 was $\$ 2,803$, which is also 130 percent of the poverty level (United States Department of Agriculture online: www.fns.usda.gov).
} 
Amy (researcher): "now, Angie, were you ever able to qualify for some assistance?" Angie: "for seven months, I had it (TANF), until I finished school."

Jane: "but they penalize both of them (Angie and Karen) when it comes to food stamps because of my income."

Angie: "if we would move out and find a place to live it (TANF) would be raised about $\$ 100$. It is $\$ 401$ if you live outside, but if you live with someone else, it is \$301. \$401 is the maximum you can get...no matter how many kids you have."

Amy: "that would not even help if you did want to get your own place, how would you pay rent?"

Jane: "they have both checked, you are talking utilities, rent, food, security deposit, sometimes first and last month's rent, they basically put you in a situation where you can't leave or move out...they are trying to get people off assistance, which I agree with, but they need to help people, because it is hard to get out. The system punishes you, even if you make a little money, although not enough to support a household, they take your benefits..."

Amy to Karen: "what would you do without these guys?"

Karen: "I don't know, I don't want to think about it."

Amy: "what would you all do without each other?"

Jane: that's what I tell them, if they have family, they will be ok...they (Karen and Angie) have had to grow up in a hurry. I help them as much as I can and as long as they need to be here, I am going to have a house anyway...it is fine with me. But, they have to do for their babies..." (Group Interview, October 13, 2001).

Ronnie has been living with her parents since before her daughter was born. Doublingup relives her of a great deal of financial stress concerning household costs, such as rent and utilities, and provides her with childcare assistance from her mother and step-father. On her doubling-up strategy, Ronnie stated:

...I won't ever be able to live on my own unless I get married, not on one income, (you can't do it) unless you have a good job, and there aren't any around here...if it wasn't for them (her parents), I would have had a nervous breakdown...if I wasn't living here, I would be in trouble. Living here, I'm ok...I couldn't do it, just me and (my daughter), having my own house...I would have to get food stamps and all that stuff (Individual Interview, August 3, 2004).

For Vera and Jaycie, doubling-up is an essential livelihood strategy for both financial and health-related reasons. Since Vera and Jaycie, as well as Vera's son who also lives in the house, are disabled, doubling-up allows them to care for each other, as well as Jaycie's daughter. They divide the household tasks according to their limitations and abilities. Jaycie enjoys cooking and 
can do some light cleaning, laundry, and the shopping, with Brian's help; Vera does the heavier cleaning, scrubbing, and vacuuming; and Brian does the yard work, driving, and maintenance duties on the house and car. They all assist in the care of Jaycie's young daughter. They pull together the financial resources they receive in SSDI and SSI to pay their utilities, buy food, and maintain a vehicle for transportation. Jaycie primarily takes care of her daughter's financial needs however, since Brian is the father, he also helps out. Jaycie and Brian would like to get married; however, they will lose some of their social security benefits if they do so. This is yet another 'catch 22' involved in piecing together a livelihood for one's family and negotiating the various institutions that women's livelihoods depend on, such as the Social Security Administration in this case. According to Jaycie:

...when we get married I will lose my disability and go to SSI and there is only an $\$ 888$ pay for a couple who is married with disabilities. That is all you can get per month for the two of us. He (Brian), right now, has a SSI check and I have a disability check. When we get married and plus raising a child, it will only be $\$ 888$. That is the max you can receive (as a couple). I would lose $\$ 600$ and that is a lot for us (Group Interview, August 2, 2004).

Co-habitation and doubling-up represent forms of social and physical capital that oftentimes allow women heading households to access financial and human capital resources. In regard to co-habitation and doubling-up as livelihood strategies, social capital includes the working together and sharing of household duties; trust, reciprocity, and exchange when it comes to childrearing and childcare; the emotional care and security that comes from a family environment; and the sharing of knowledge when it comes to accessing social assistance programs. Physical capital, in regard to co-habitation and doubling-up, reflects one's ability to acquire and sustain housing and basic needs such as water, food, electricity, and transportation. Thus, having access to both social and physical capital allows the women in this study to 
maintain employment in the formal economy and not subsist on government assistance; avoid both logistical and financial issues in regard to childcare; seek training or further their education; and enhance their cash resources. Encompassing both material and non-material benefits, cohabitation and doubling-up represent key livelihood strategies for women heading households in rural West Virginia.

\section{Savings and Retirement and Life Insurance Benefits}

Despite their low-incomes, four of the women in this study have savings, retirement, and life insurance benefits that provide them with additional financial resources above and beyond their wages, child support payments, and/or government benefits (Table 5). Christy receives a small amount of interest and dividend income from some of her savings and Wilma, because she is retired, has a pension. Tracy and Margie, who are both widowed, have access to life insurance policies in addition to their savings accounts and the Social Security their children receive as death benefits. The life insurance money they both received after their husbands' deaths was utilized to pay off debts and ease the financial burden of losing a spouse. Wanda, whose mother had recently passed away, also inherited a life insurance policy which she was saving for her son's education. On the subject of her inheritance, Wanda stated: “...I am not spending my inheritance. I am saving that for Hunter's education. I put enough back for him for college, I want him to go..." (Individual Interview, August 7, 2004).

It should be mentioned, however, that cash savings are not the norm among these women and several of the women reported that there is little money left at the end of each month. As one woman said: "my savings is gone, by the time you pay bills, there is nothing left" (Individual Interview, August 2, 2004). Several of the women also reported having a large amount of debt 
on credit cards and in the form of personal and student loans and two of the women had previously filed bankruptcy.

\section{Informal Activities}

Informal activities represent the fifth set of livelihood strategies. While these activities were not significant strategies among the women interviewed in this study, they deserve to be mentioned and always considered in livelihood analyses. They are often difficult to measure and are certainly not quantifiable, however, as in the case of South Africa, can be important activities that provide women heading households with both material and non-material benefits. In the case of the women interviewed in West Virginia, informal trading includes the use of yard sales to earn extra income. This strategy is utilized by Jaycie and is an economic activity that she, as a disabled person, can do. She conducts these sales at home, in her front yard, on Friday and Saturdays during the spring, summer, and fall months. The money earned is extra spending money and Jaycie enjoys the contact with the public during these sales.

Other informal resources identified in this study include the use and sale of natural resources. Tracy, who has a horse farm, depends on the free water she has on her property. When her husband was alive, they also put up their own hay to feed their horses and cut their own fence posts on his parents' farm. They rely on wood and coal to heat their house and a garden for vegetables to eat in the summer and can for the winter. Wanda, who had inherited a large farm with over two hundred acres of land and a house (Photo 24) from her parents, ${ }^{96}$ also depends on the free water and gas she has on her property. This saves her thousands of dollars throughout the year in utility costs. At the time of the interview, Wanda had however decided to

\footnotetext{
${ }^{96}$ Wanda's parents had both died recently at very young ages. Her father, who had his own timber business and was a farmer, was killed in a logging accident and her mother died of cancer.
} 
sell the farm because the up-keep on the land and large house was "too much to take care of" (Individual Interview, August 7, 2004). The sale of the farm would provide her with enough money to build and pay cash for land and a new house that would be much closer to her extended family, which were a great source of emotional support to her and her son.

\section{Co-strategizing}

The sixth livelihood strategy identified in this study is what this research calls costrategizing among women he ading households. Co-strategizing is a new, innovative strategy identified by this research project. It is related to other strategies, such as co-habitation and doubling-up, family and community support, work in the formal sector, and public assistance and women's need to continually negotiate and balance their productive and reproductive responsibilities, such as employment and childcare.

As previously discussed, Wanda is employed by Margie as a nanny and housekeeper and both are heading the household. As highlighted in the discussion on work and employment issues, when Margie's husband died and her household situation changed she devised a plan that would work for both herself and Wanda in terms of their own productive and reproductive duties as heads of the household. Margie was in need of more help around the house in terms of household maintenance and childcare for her two children. Wanda needed a job that was flexible, that she could bring her son to, and that offered more financial benefits. Because Wanda had been employed by Margie as a housekeeper for a number of years, Margie knew her personally as well as her current household and employment situation. She therefore offered Wanda a new job that would offer her more pay, a flexible schedule, and a private-school education for her son. This co-strategizing between these women fits their productive duties: 
Margie needs to maintain her job and work schedule at the law firm and Wanda needs to keep her job as a housekeeper to earn a living for their families. This situation also fits their reproductive duties: Margie needs assistance with household reproductive duties and childcare and Wanda needs a job that is flexible and one she can bring her son to and avoid childcare costs. The added benefit for Wanda is the paid tuition to the private Christian school for her son, which she would otherwise not be able to afford. At the time of the interviews, both women were satisfied with their co-strategizing solution to their particular household situations and being part of each other's overall livelihood.

Ronnie has a co-strategizing relationship with her sister, Denise, who is also heading a household that includes her two sons and boyfriend. Ronnie, who works at a local drug store, relies on Denise for childcare for her daughter. Ronnie does qualify for childcare assistance through Choices, making it possible for her sister to not only earn a reliable and constant source of income, but also qualify for a food program offered through the State to assist with the cost of feeding Ronnie's daughter as well as her two sons. Ronnie is pleased that her sister is caring for her daughter stating: "I'd rather leave her with Denise than in a daycare. It will be perfect when she goes to school because (Denise's son) goes the same time as (my daughter) and Denise will get them after school" (Individual Interview, August 3, 2004). Ronnie provides childcare for Denise's children while Denise works part-time in retail.

Ronnie's sister Denise is also in an abusive situation with her live-in boyfriend who is the father of her children. Because he oftentimes refuses to help Denise financially, Ronnie holds money owed to Denise until she absolutely needs it in order to keep the boyfriend from taking it for his own spending. On the co-strategzing she engages in with her sister, Ronnie stated:

...I don't pay her every month, I keep track everyday of when she (Denise) watches (my daughter), so when she don't have money for her water bill or something, then I pay her. 
She just bought a car and I paid for that, more or less. I gave her $\$ 350$ and I take that off and now she owes me $\$ 50$, but she will work it out, it is an arrangement we have (Individual Interview, August 3, 2004).

As indicated by Ronnie in the quote above, she oftentimes pays household bills directly for her sister to ensure that utilities are not turned off, the rent is paid, and that the children have food to eat. Ronnie and Denise exchange money as well as labor to be able to maintain their jobs in the formal economy and care for their children. They also work together to ensure that Denise has the household resources she needs for herself and her boys. This co-strategizing between the two of them fits both their reproductive and productive responsibilities and mediates the financial and emotional difficulties of Denise's abusive situation and Ronnie's lack of parental support from her daughter's father.

Jane, Karen, and Angie and Jaycie and Vera also have co-strategizing strategies that comple ment their doubling-up strategies and allow them to meet their productive and reproductive duties. Jane, Karen, and Angie arrange their work schedules around their childcare needs and Angie's previous schooling and Karen's anticipated medical assistant training, for example. Renee co-strategizes with a co-worker who is also heading the household to arrange after-school care for their middle-school aged children. Jaycie and Vera co-strategize in the care of each other, Jaycie's daughter, and Vera's ailing mother, who is in an assisted living facility.

Co-strategizing between women heading households represents an important livelihood strategy that allows women to capitalize on social capital resources available to them such as networks of connectedness ${ }^{97}$ and the trust, reciprocity, and exchanges between women heading households that facilitate co-operation and reduce costs for things such as childcare. These resources make it possible for women to access financial, human, and physical capital resources

\footnotetext{
${ }^{97}$ As defined in Chapter II, networks of connectedness, which may be vertical, such as patron-client, or horizontal, as with individuals, are social capital resources that are developed by those with shared interests. They facilitate working together and access to institutions.
} 
by allowing them to maintain jobs in the formal economy, seek an education or job training, or access certain forms of public assistance. They are connected to family and community resources and women's common roles as heads of households and allow women to access resources that may, in other forms, be inaccessible to them for financial and logistical reasons. For example, Ronnie would not be able to maintain her job at Rite Aid without the childcare her sister provides. She would also find it difficult, both financially and logistically because of her work schedule and hours, to place her daughter in a daycare. Denise, Ronnie's sister, would not be able to manage financially or have access to the food program without providing care for Ronnie's daughter. Margie eliminated the need for both a housekeeper and nanny when she devised her co-strategy with Wanda and now has dependable, flexible, and affordable care for her children and household. She can maintain her job and work schedule with the security and peace of mind that her children and household duties are taken care of. Wanda also has the flexibility she needs, the ability to bring her son to work, and a private-school education for her son. She can also maintain her other cleaning jobs.

\section{Family and Community Assistance}

Family support and community assistance are the last of the livelihood strategies discussed in this section and again, these strategies are connected to other strategies such as public assis tance and doubling-up, as well as co-strategizing and informal strategies. Couto (1994), in his analysis of the declining welfare state and its role Appalachia, has particularly recognized the increasing roles that family and community resources play in sustaining households in rural Appalachia today. According to Couto (1994), the family and community, including non-profit, activist, and church, organizations have become economic reactors in the 
new political economy of the region. These diverse sources of support are subsidizing jobs lost, reductions in wages and public assistance benefits, and changes in family structure by providing everything from basic necessities, such as food, housing, and clothing and cash assistance; to job placement, education and training, and health care; to environmental and social advocacy work. Reliance on family and community resources is necessitated by both the lack of social investment in the region, historically, as well as broader, contemporary economic and social change. Family and community sources of support depend on and are sustained by the efforts of local citizens as well as regional, national, and even global non-governmental, charitable, religious, and advocacy organizations and groups through various combinations of financial, physical, human and social capital resources. They have benefits, as well as limitations, in the delivery of social and economic resources with respect to obtaining and sustaining financial resources and the coordination of comprehensive social services, for example, which are too complex to detail in this analysis. However, the need for these family and community resources and their operation in the region is consistent with major trends in local economies across the globe.

Diane, the social worker interviewed at the Taylor County Department of Health and Human Resources, reported on the integral role of community organizations in the meeting of people's socioeconomic needs. In her office, Diane has a "resource board" (Photo 25) that showcases the many community organizations and resources that can provide assistance when the DHHR is unable to offer help. This resource board is accessible to workers in all departments at the Taylor County office and utilized regularly. Local community organizations oftentimes deliver presentations or provide correspondence and literature to DHHR workers in Taylor County concerning the services provided and assistance offered to community members 
in need. The Salvation Army, Community Action, Family Resource Network, rural Health Clinics, and the Food Pantry are all organizations in local communities in the case study area that offer help in the form of food, utility payment assistance, clothing, medical care, and other social services. The DHHR office in Taylor County regularly refers clients, through a referral process that conforms to confidentiality requirements, to these organizations and is well-informed about their services.

The partnership between the DHHR and local community non-profits, charitable organizations, and churches is an interesting relationship and vital in the provision of basic needs in rural communities in the case study area. These local organizations can oftentimes relieve economic and social stress on families and meet immediate needs when DHHR resources are maximized or not accessible to a person due to income and/or eligibility requirements. These organizations are increasingly 'picking up' where the welfare state is 'dropping off'.

Family resources in this study include cash assistance as well as labor exchanges and emotional support. Community resources come in the form of financial, physical, and human capital from neighbors, non-profit and community groups, and church organizations. Many of the women reported getting everything from money to pay utility bills; to groceries; to automobiles; to houses, from family members (Table 5). Caroline stated that her parents oftentimes bring her groceries to feed her children when they don't have food themselves. Christy's parents had given her a house, oftentimes fill her heating oil drum, and provide clothing and other items for her children. On the subject of family support, Christy stated: "I would have never gotten through having (my daughter) without mom and dad. They have been a big help with (my son) too. It's hard when they go to Florida in the winter (because they are retired), January through April is the hardest without them" (Individual Interview, April 20, 
2002). Debbie's father had given her a car and Ronnie's mother buys many of her daughter's clothes and shoes. Vera's ex father-in-law willed her a house and some cash savings and after her husband's death, Tracy's aunt and uncle loaned her money until she received the life insurance settlement. As mentioned previously, Wanda inherited a farm and house from her deceased parents.

In terms of community resources, women in this study have received everything from cash assistance; to labor and farm supplies; to construction materials and food from neighbors, local churches, and non-profit and cha ritable organizations (Table 5). When her husband died, Tracy received money and food from friends, neighbors, and local churches. Some neighbors also got together to purchase the supplies and provide the labor for the completion of her horse and hay barn for the upcoming winter months. Others had donated hay for her horses and provided transportation for her boys to their activities. She was also awaiting a work crew from World Servants, a group that is affiliated with international faith-based organization, World Vision, ${ }^{98}$ and local community organization, Vision Appalachia (Photos 26 and 27), which would repair her roof and do some plumbing work on her bathroom. Anna's house had actually burned down twice and she had also received assistance from World Servants and Vision Appalachia in the form of building supplies, such as windows and lumber, and labor, concerning the construction of a front porch (Photo 18). Anna stated: “...I can't take all the credit and neither can he (concerning the construction of their home), we had a lot of money and stuff

\footnotetext{
${ }^{98}$ Vision Appalachia partners with World Servants and World Vision, which are international, faith-based organizations focusing on improving conditions in communities around the world. Both are 501(c)3 non-profits. Vision Appalachia provides children and youth services; special activities and community events; training and housing for work groups from World Vision, World Servants, Appalachian Community Care and local churches concerning mission work; and a storehouse that distributes donated materials and products to needy families. Vision Appalachia has a community center and storehouse in the town of Philippi in Barbour County, West Virginia (Photos 28 and 29) (Vision Appalachia Literature, 2005).
} 
donated to us...(from) people around here and elsewhere, we had a lot of help. This foundation is built on love, that's what I call it" (Individual Interview, August 6, 2004).

Defining and assessing the use and workings of family and community resources can only be done through qualitative studies, such as this, on the livelihoods of women. They are difficult to measure and quantify and oftentimes ignored in analyses of women's livelihoods and studies on the economic well-being of rural households in general. How they work with and subsidize other livelihood strategies is a question that deserves the attention of scholars and development practitioners, those in the social service fields, and government and policy-makers. Questions concerning their roles in local communities, operation, and services provided must be interrogated and their connections to other social agencies, such as the DHHR, and local, regional, and global economic change must also be addressed and analyzed. Although these livelihood strategies operate at very local levels, they are directly connected to regional and global processes, such as welfare reform and economic restructuring, as well as organizations and groups, including regional, national, and international non-profit, charitable, and faith-based associations.

In conclusion, death, divorce, emotional and physical abuse, teenage pregnancy, and dead-beat dads are all circumstances that have led women in this study to become heads of the household. In their roles as heads of the household, these women are innovative and resourceful when it comes to supporting their households. Throughout the interviews with the women in West Virginia, it was repeated over and over that they felt someone was always "worse off" than themselves.

Ronnie: "I am sure some people have it worse than me, I am not that bad off..." Caroline: "There is always somebody in a worse situation that I am." Margie: "Someone is always in a worse situation. I have nothing to complain about..." 
Women in this study are also eager to give insightful and thought-provoking advice to other women heading households, particularly around education training, and self-esteem issues. For example, Vicki stated: “take advantage of any resources available, don't feel guilty about not being there all the time. Get an education so that you can provide...get a good job...it seems like a long time to do it, but it really isn't. You are not a bad mom for doing that" (Individual Interview, April 18, 2002). DeeDee stated: “....always hold yourself in higher esteem and don't let anyone sell you short..." (Individual Interview, October 16, 2001). Many of these women also have interesting ideas for programs that could help women in similar situations concerning everything from subsidized and cooperative childcare; to household maintenance services for low-income families; to financial planning and budgeting services for newly divorced or widowed women; to referral services, support groups, and divorce counseling through the family court system. These women show great sensitivity to the situations of other women heading households, both in their communities and beyond. Caroline was eager to help and very political in her statements concerning women heading households. She made these comments when asked about her ideas on how women heading households could be assisted:

Women are going to have to get a backbone and stand up for what they believe in and need. Take a stand, get out there and tell people, I am a woman and I am going to make it...we can rally around...we are punished (as single mothers) and it's all political. We have got to get these women together to get politicians, senators, governors, and advocates, we need to get these women together to fight, just like when we fought to have independence and vote....show them that we are trying but we just keep getting knocked down...I am very political, I am a Democrat. Everyone must vote... we have got to get women together to make a stand....until then, women will be pushed aside, we have to fight for ourselves (Individual Interview, August 11, 2004).

\section{Summary}

This chapter has presented a detailed analysis of the diverse livelihood strategies of women heading households in South Africa and Appalachia. Through geographic and 
socioeconomic data gathered through various statistical sources and a survey conducted with the respondents, it presents demographic information on the case study areas and sample populations. Through qualitative methods, including individual interviews, focus groups, and participant observation, the analysis also describes women's livelihood strategies, such as employment, participation in community groups, public assistance, informal sector activities, cohabitation and doubling-up, and family and community support. It analyzes how women's livelihoods depend on the adoption, negotiation, and piecing together of many of these strategies to support households in rural parts of the case study areas. The analysis describes each livelihood strategy; how it is accessed and utilized by women in the study; how it fits with their household situation; and how it is oftentimes related to other livelihood strategies. This chapter also describes women's encounters with state structures, such as government welfare agencies, and local structures, such as the chieftaincies and community and non-profit organizations and highlights how their livelihood strategies are intimately connected to socioeconomic, cultural, and political processes, such as economic restructuring, welfare reform, democratic transformation, community economic development efforts, and changes in family structure, occurring at local, regional, and global scales. These issues are discussed further and compared across the two case study areas in the following chapter. Through respondent profiles and direct quotes, every attempt is made to describe the livelihood experiences of women in this study in their own words.

The livelihood strategies identified in this study are dependent upon many different types of resources, including financial capital; access to training and educational opportunities and job skills; basic needs such as food, shelter, energy sources, clean water, and transportation; land and natural resources; and social networks that provide relationships of trust, reciprocity and 
exchange that develop into informal safety nets. These resources depend on familial and cultural, communal, social, and collective and government institutions, the ideologies that these institutions are built upon and therefore, women's positions within these institutions. These socioeconomic, cultural, and political institutions empower or constrain women's abilities to access, engage in, and further develop certain livelihood strategies and negotiate both their productive and reproductive responsibilities.

Despite differences in their household situations and needs, women's livelihood strategies in Limpopo and West Virginia are remarkably similar. In addition, most of the women in both of the case study areas were not in economically secure situations despite the many livelihood strategies they were piecing together. The long-term sustainability of their livelihood strategies was in question and they were mostly just 'getting by'. 


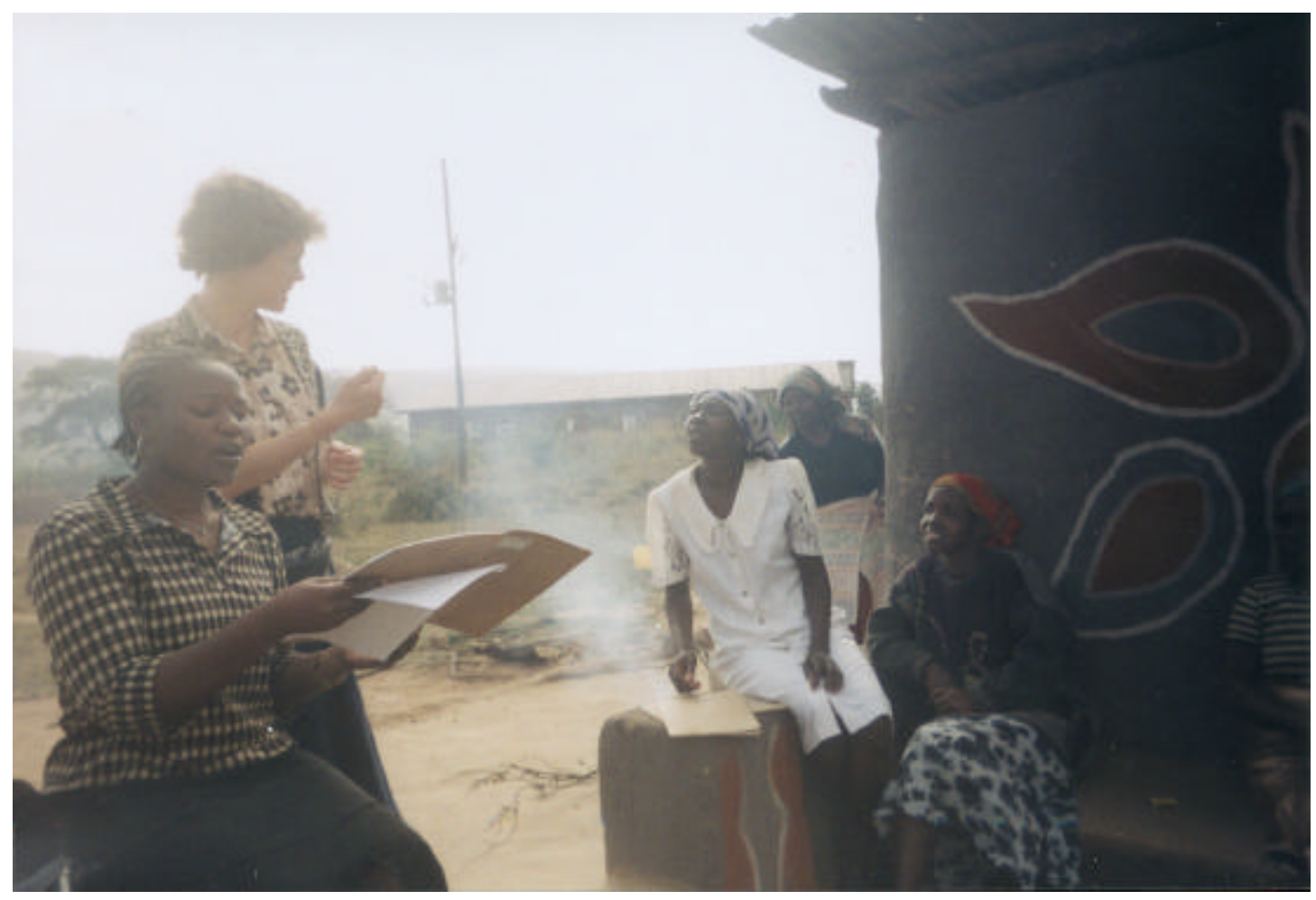

Photo 1: Focus Group Discussion with Jam Project, Tshandama, Limpopo.

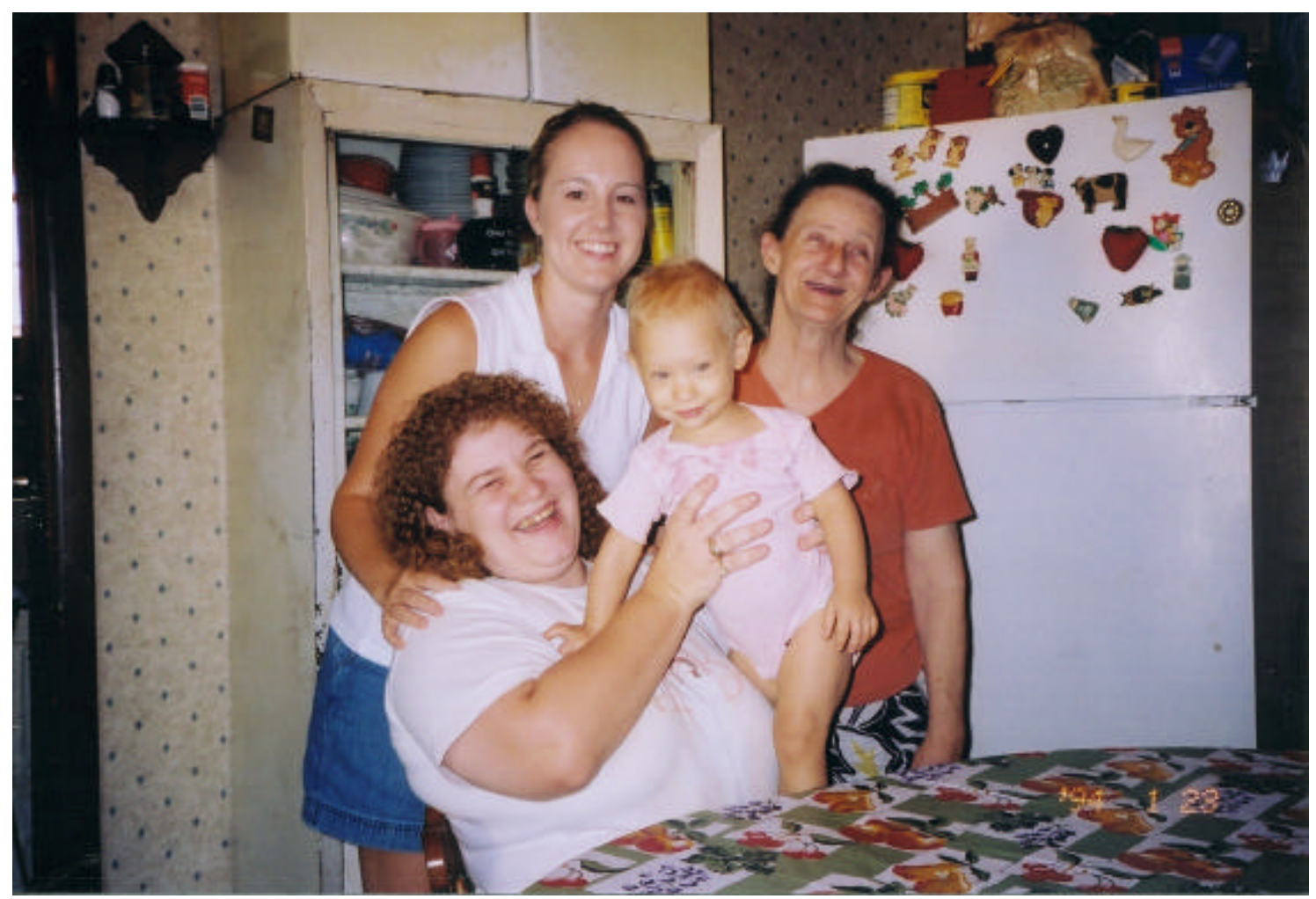

Photo 2: Researcher with Respondents, Jaycie and Vera, in Simpson, West Virginia. 


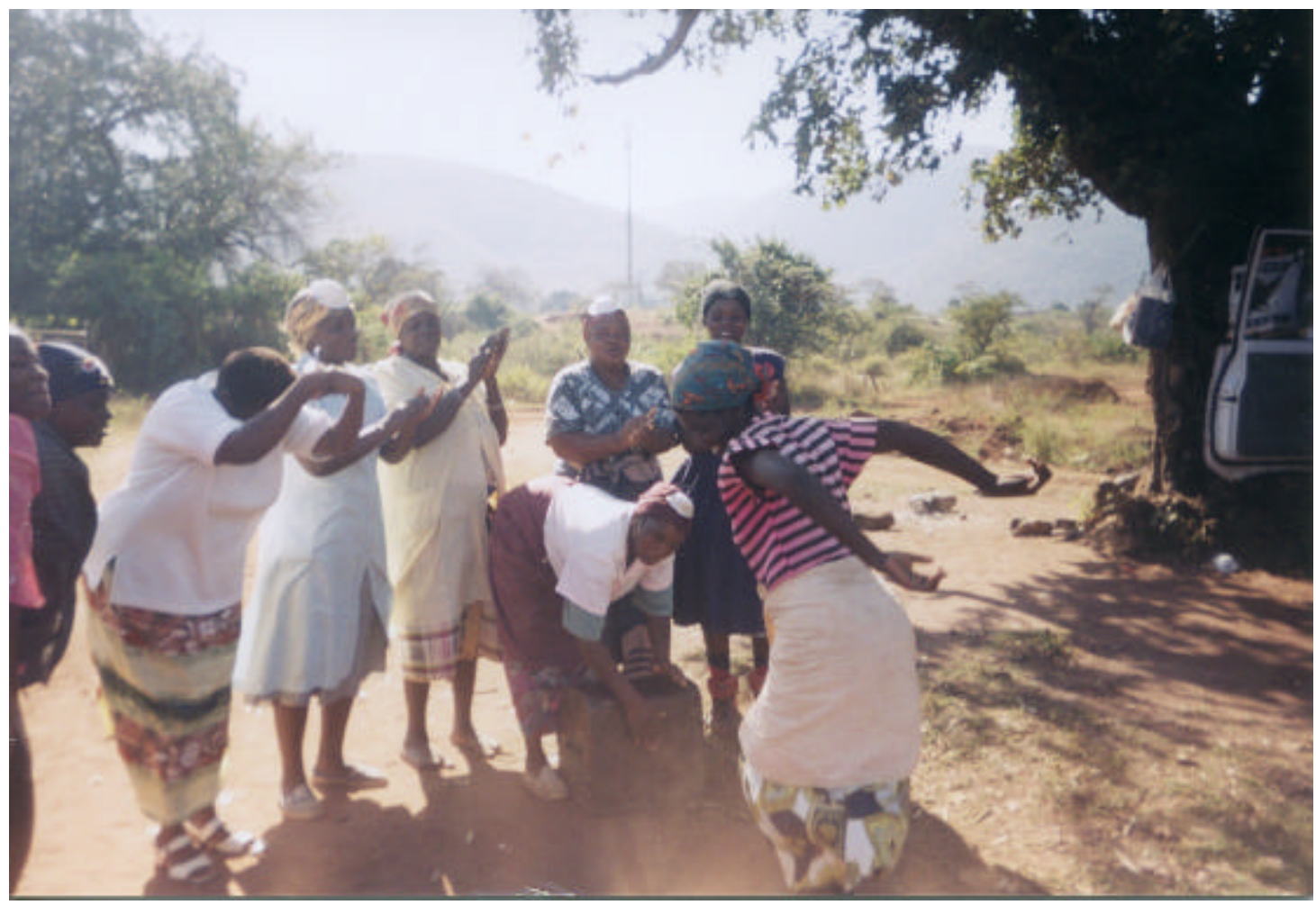

Photo 3: Dancing at Rambuda Stone Crushing Project, Rambuda, Limpopo.

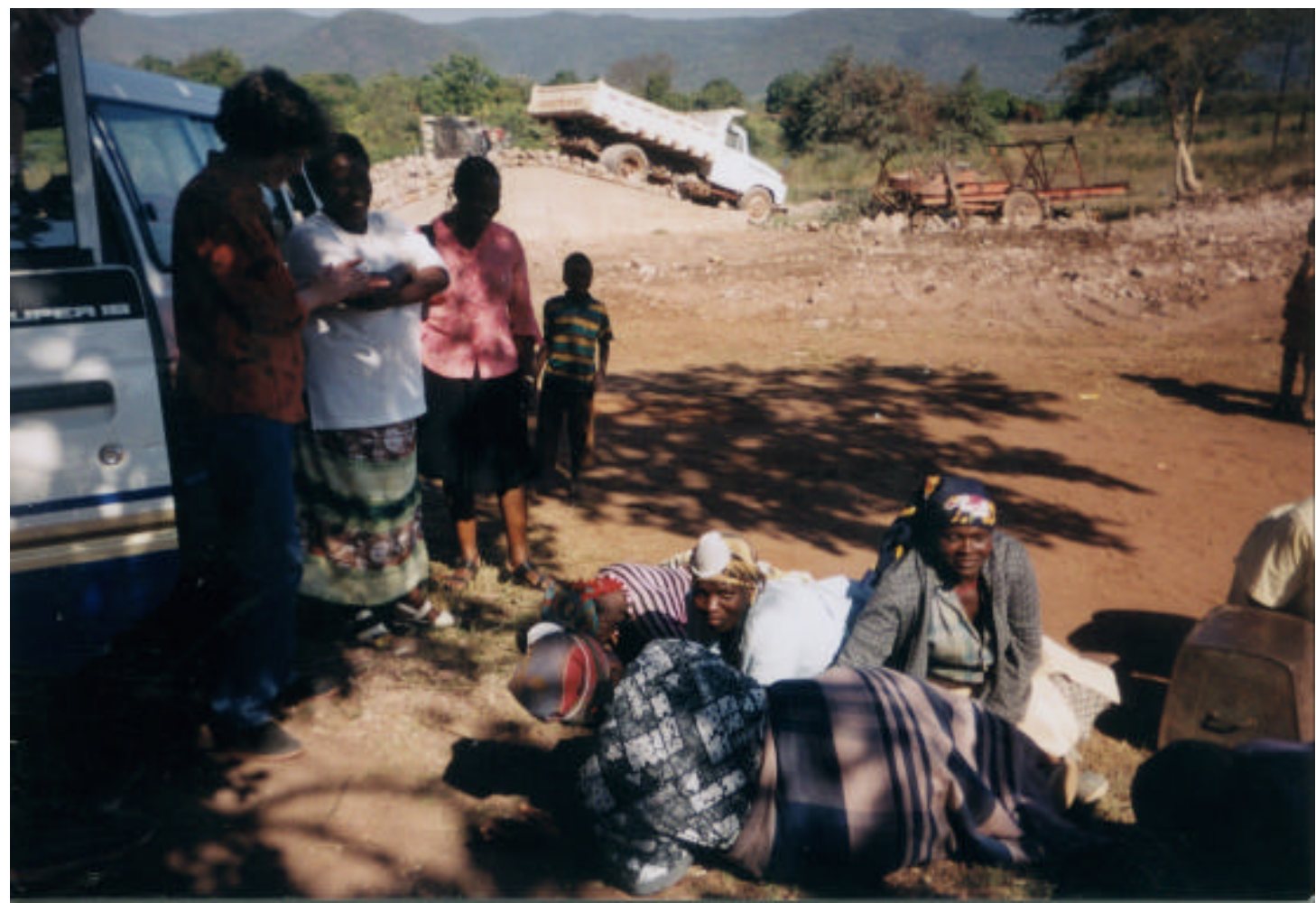

Photo 4: Venda Women Expressing Gratitude at Rambuda Stone Crushing Project. 


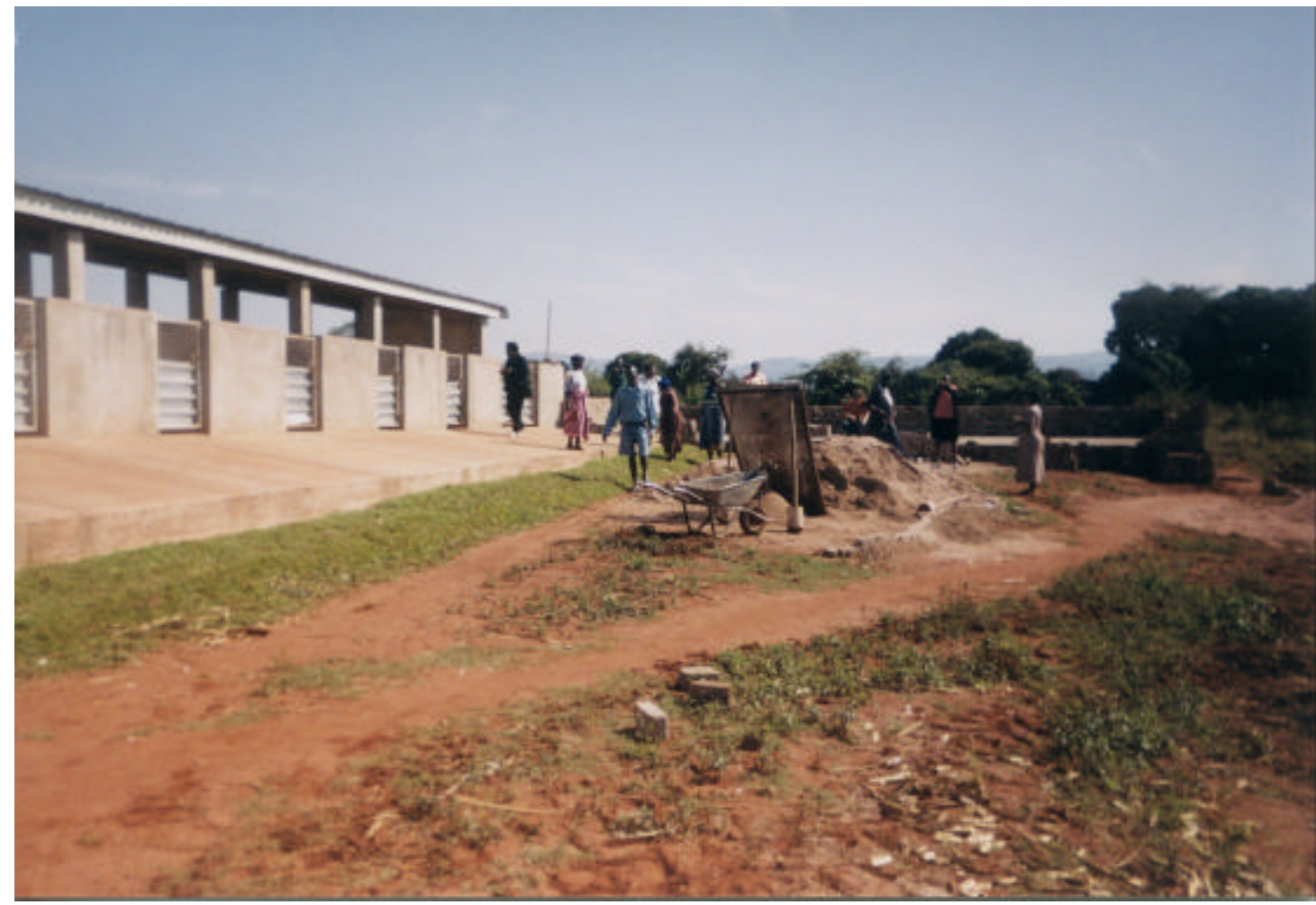

Photo 5: Piggery

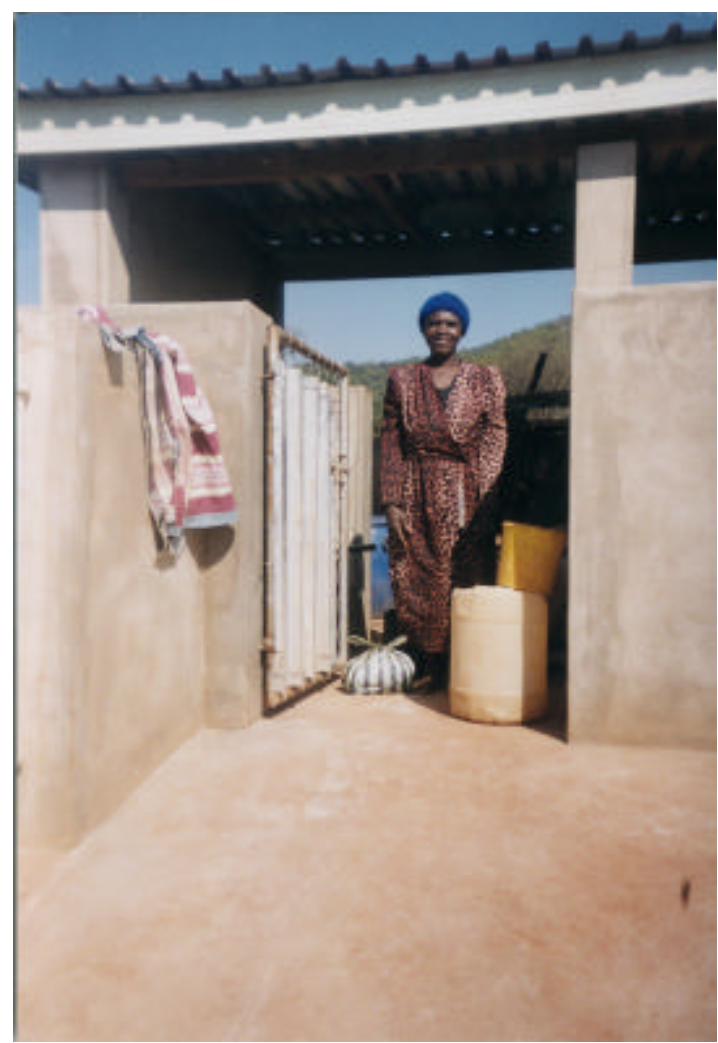

Photo 6: Eve working at the Piggery. 


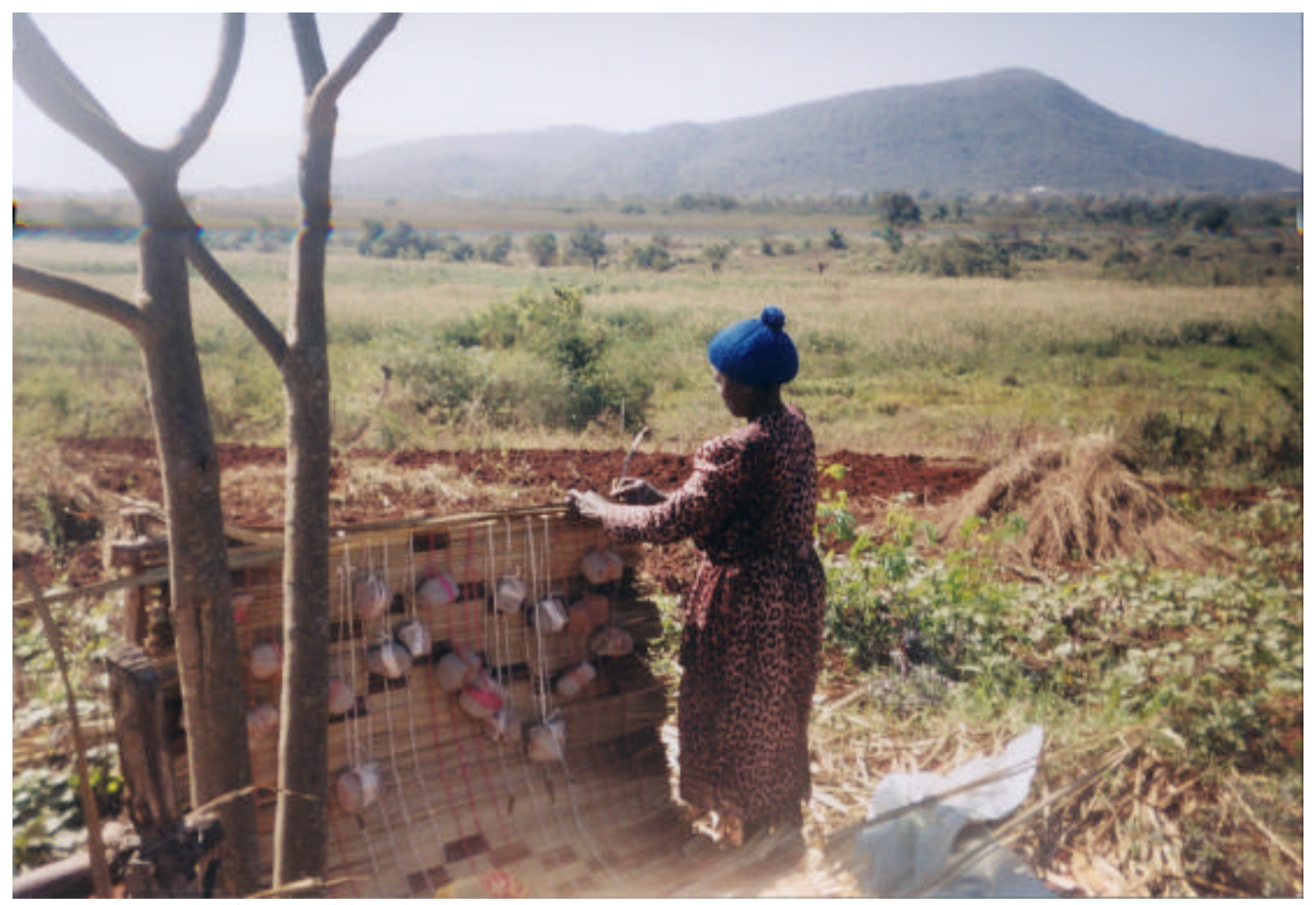

Photo 7: Eve making traditional mats.

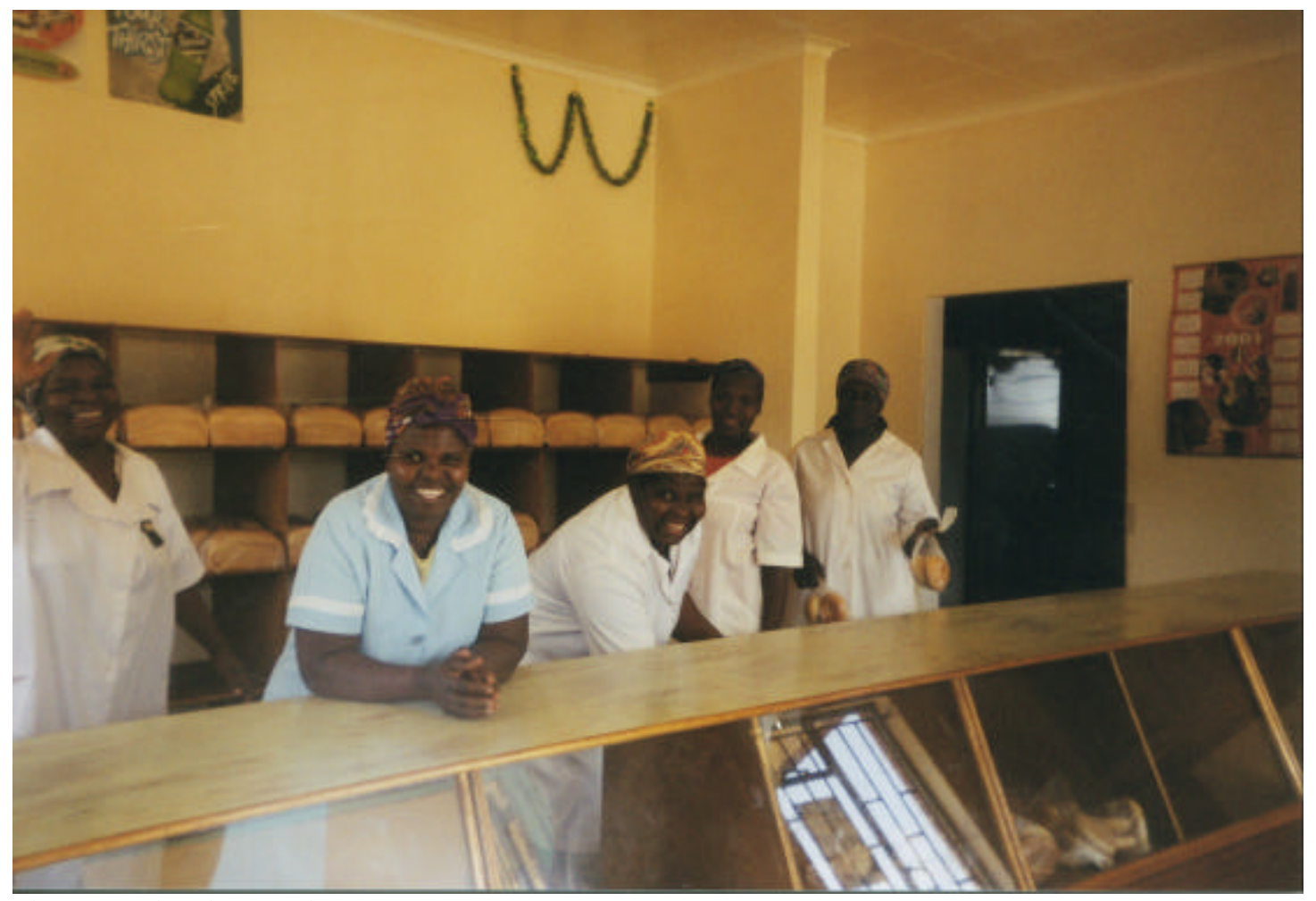

Photo 8: Tshandama Bakery 


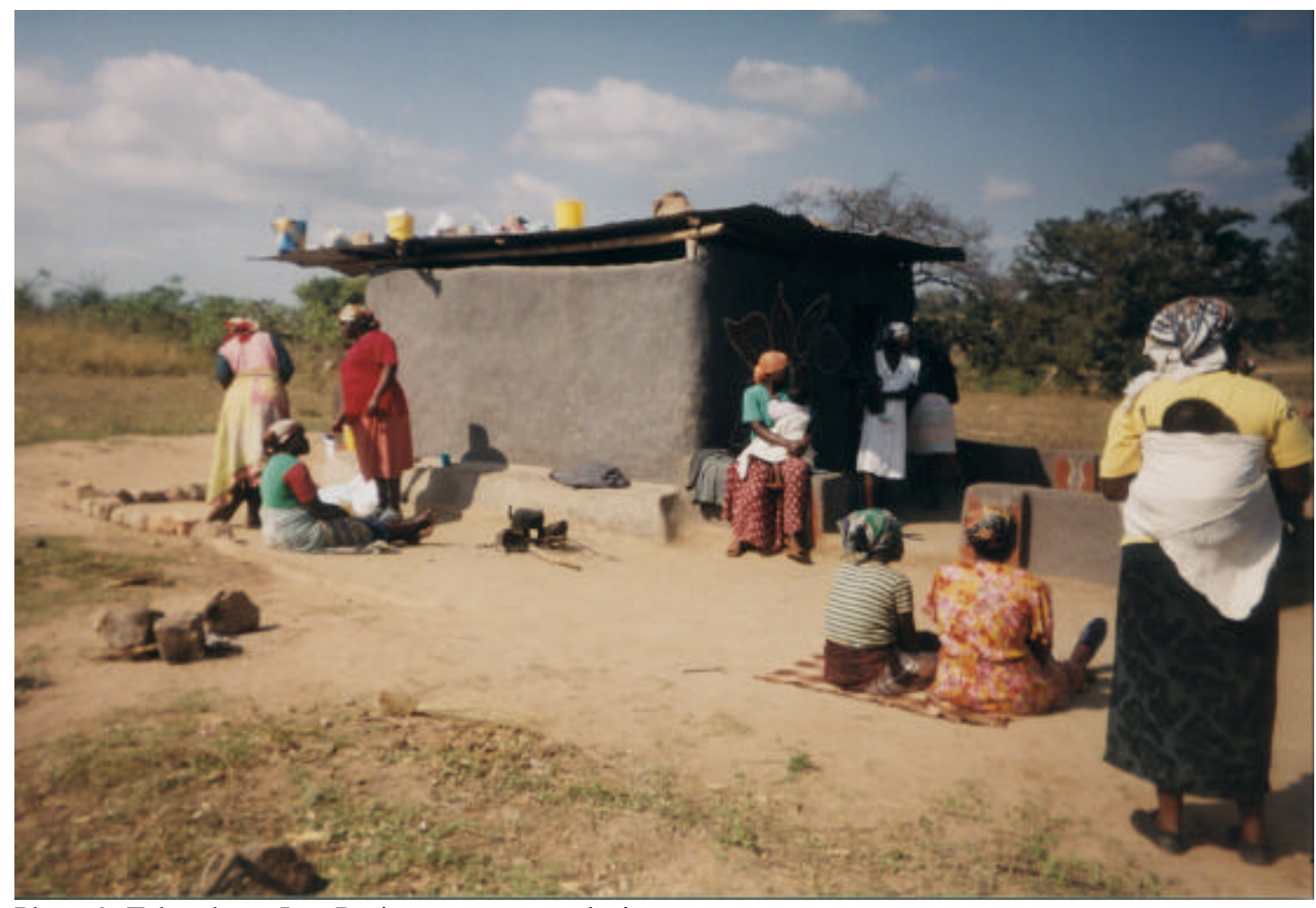

Photo 9: Tshandama Jam Project: current work site.

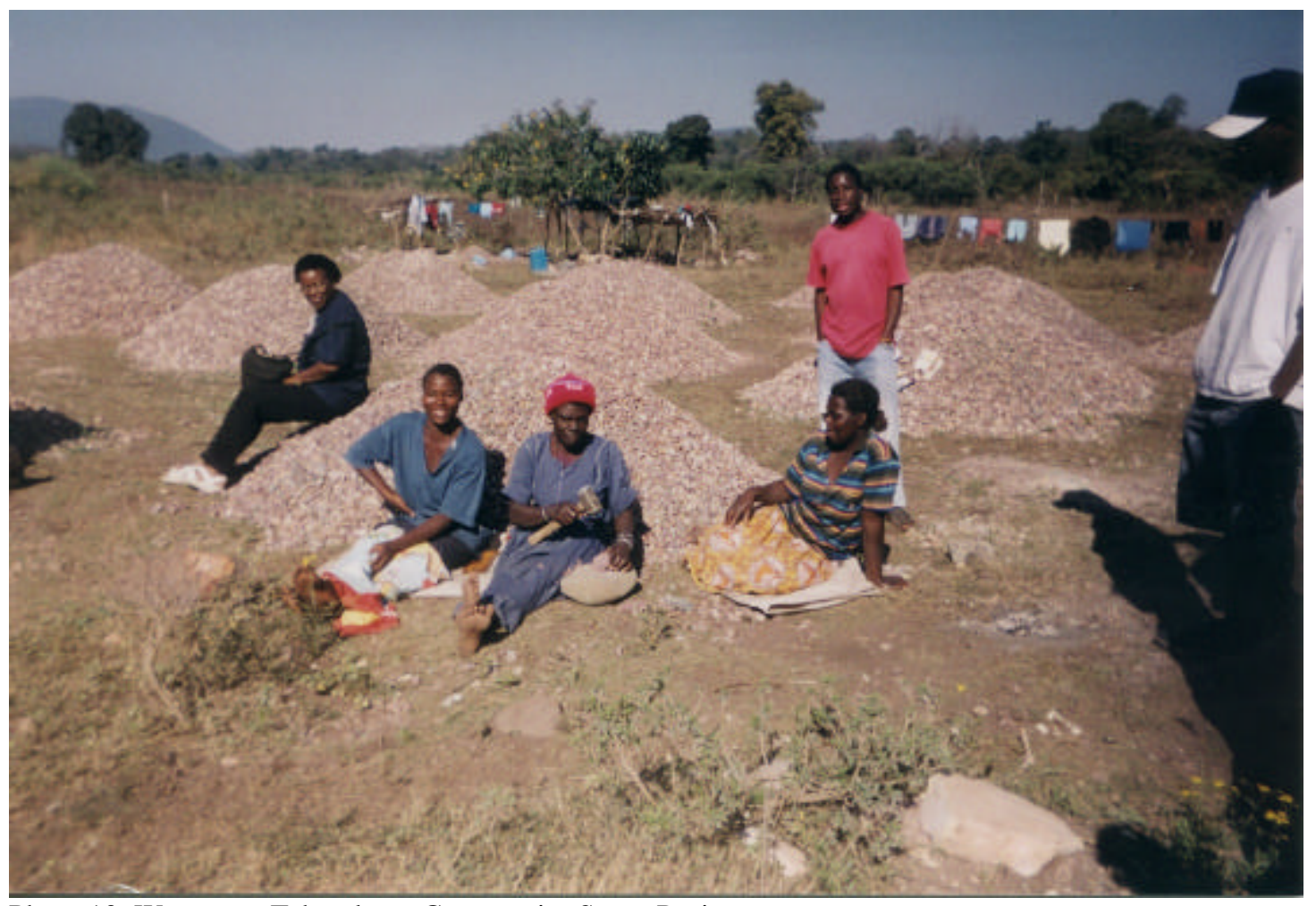

Photo 10: Women at Tshandama Community Stone Project. 


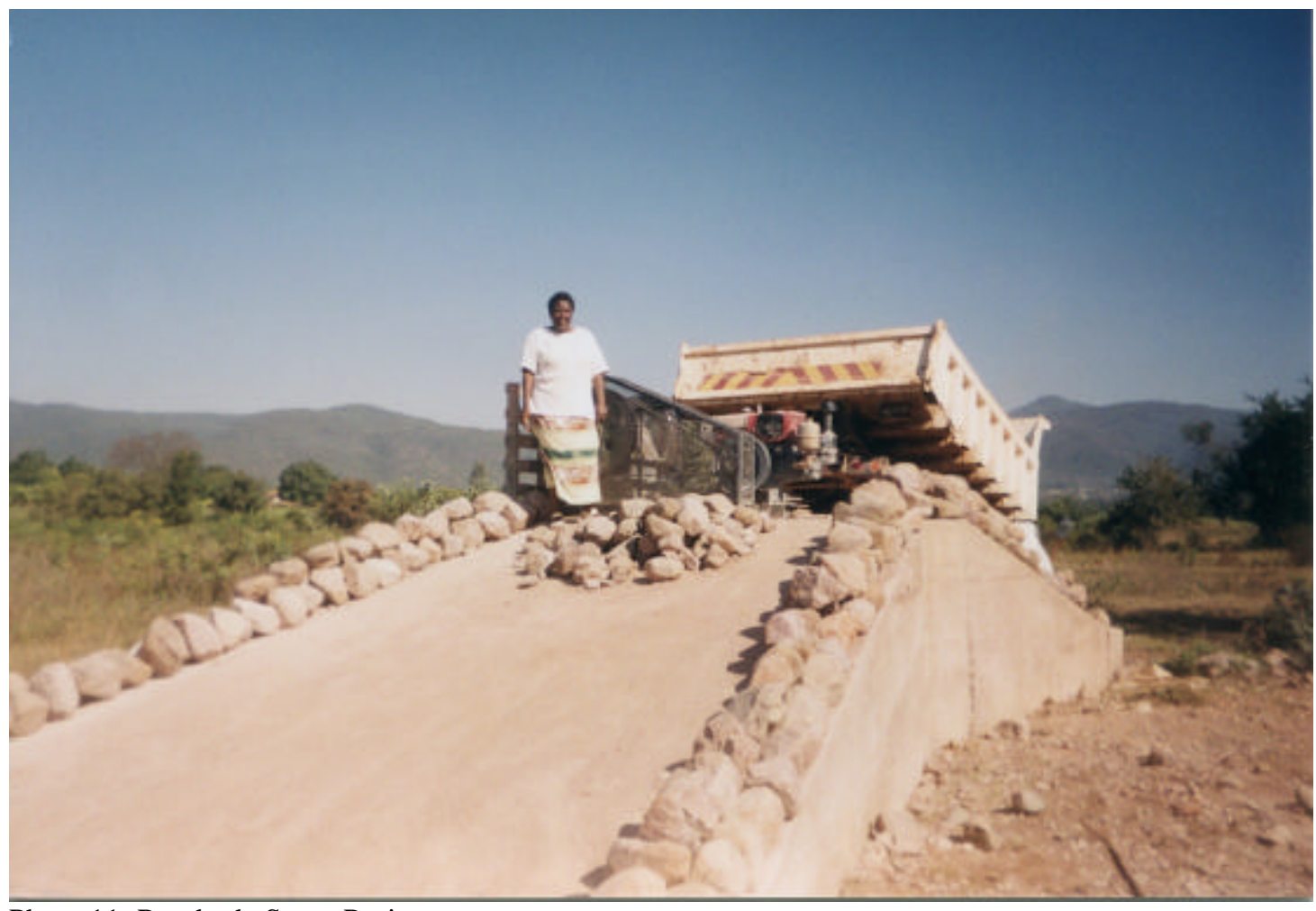

Photo 11: Rambuda Stone Project.

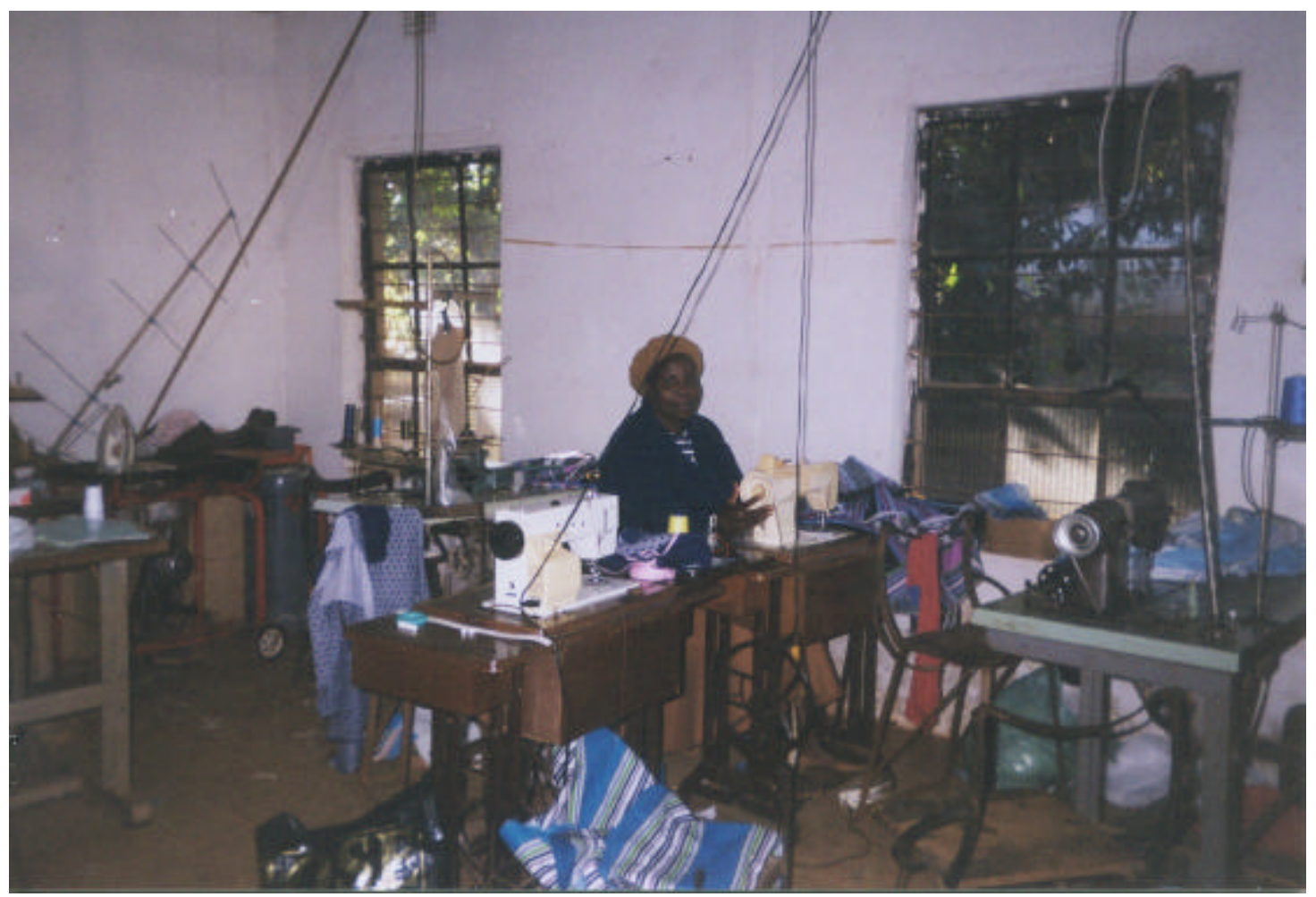

Photo 12: Sharon at sewing machine at Mvuleleni Sewing Project. 


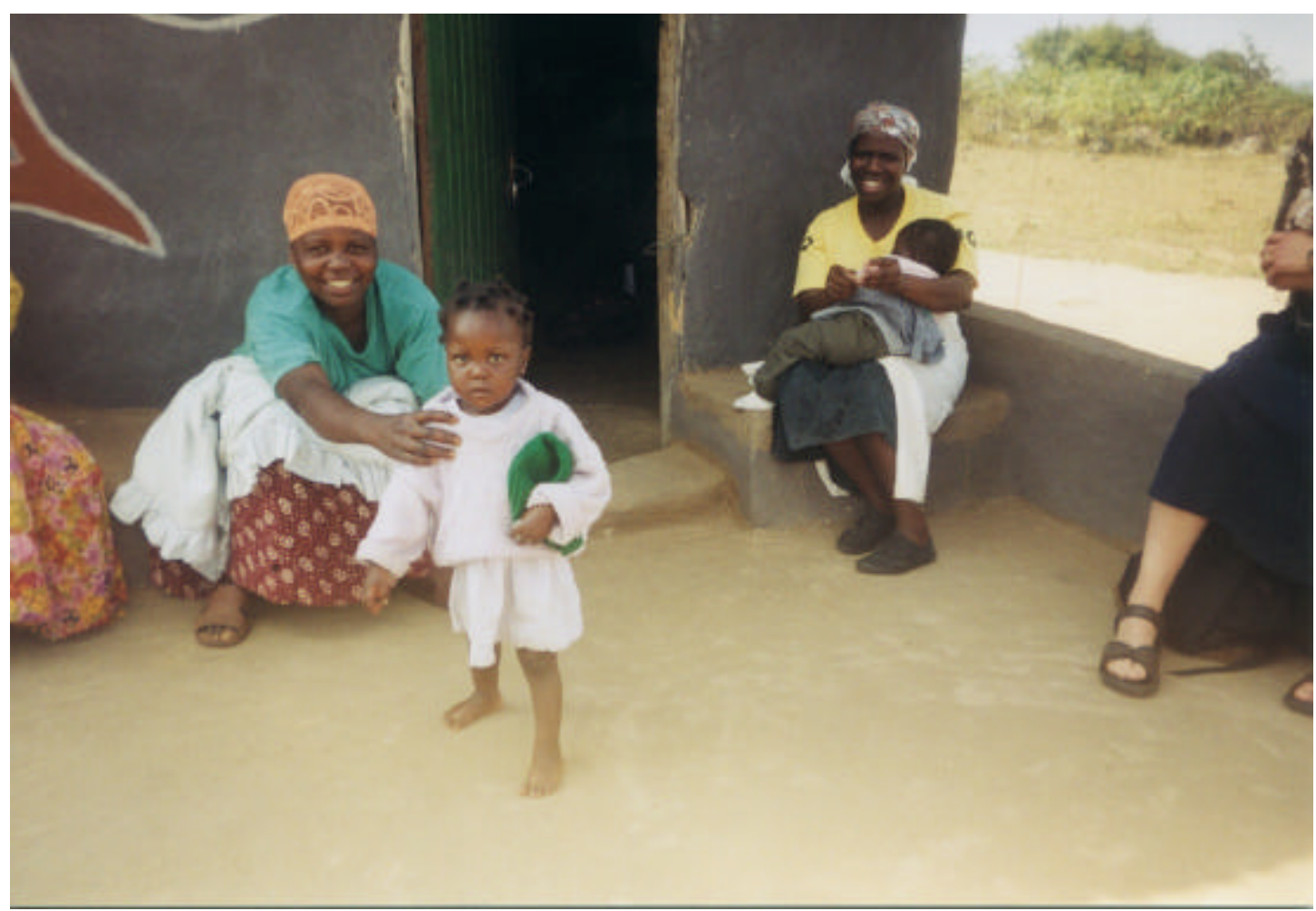

Photo 13: Women with children at Tshandama Jam Project.

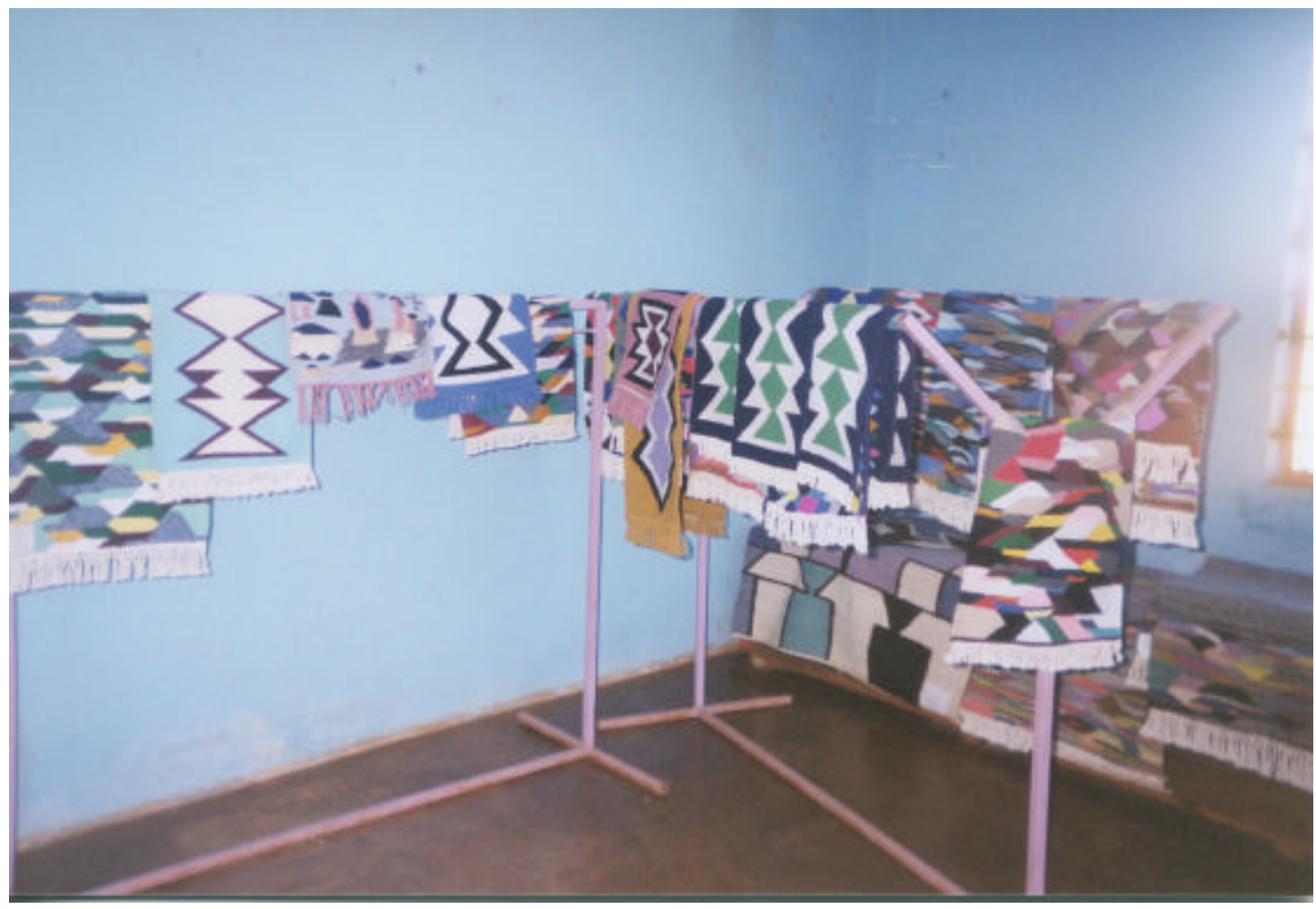

Photo 14: Woven goods at Pfananani Community Center. 


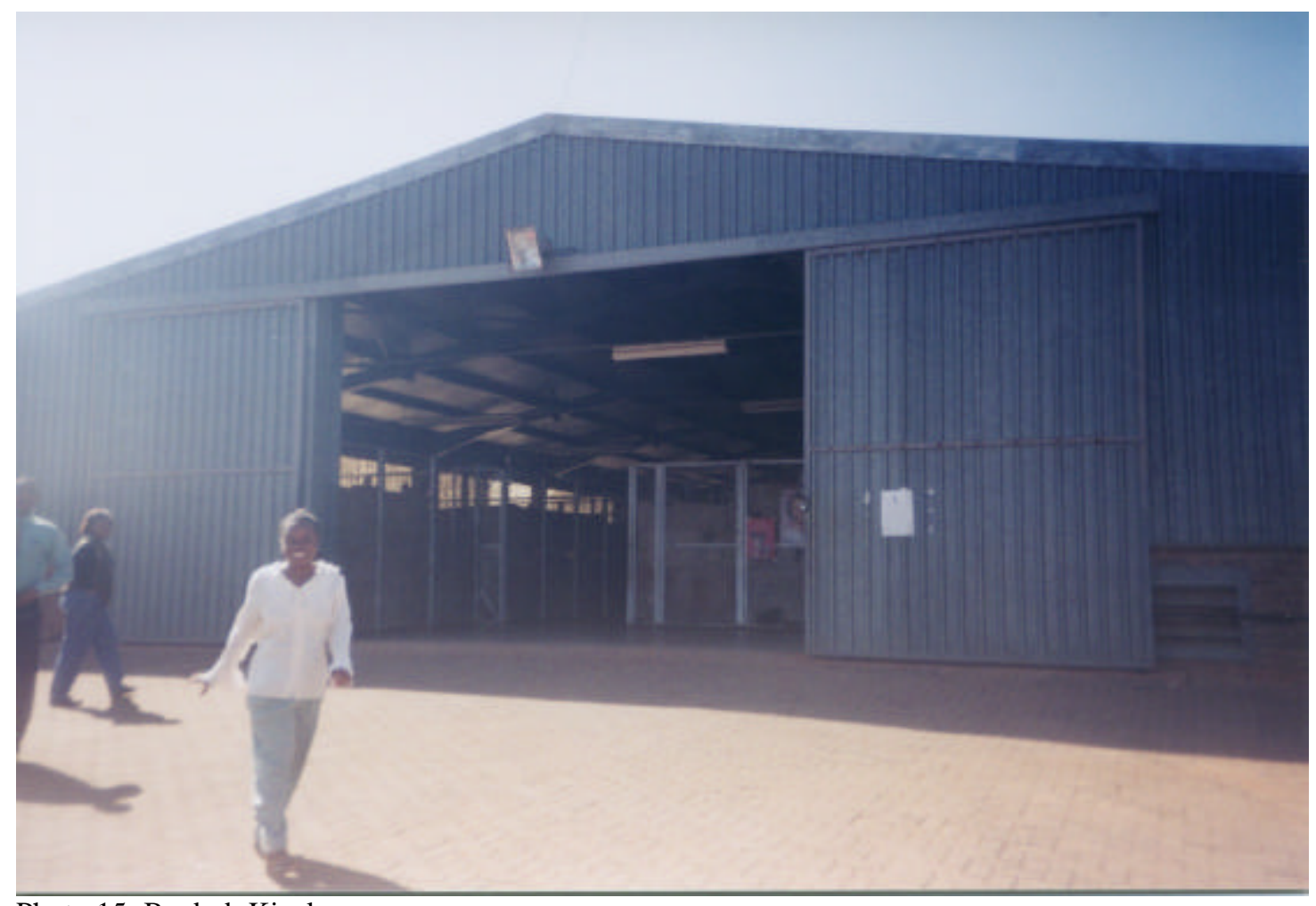

Photo 15: Baobob Kiosk

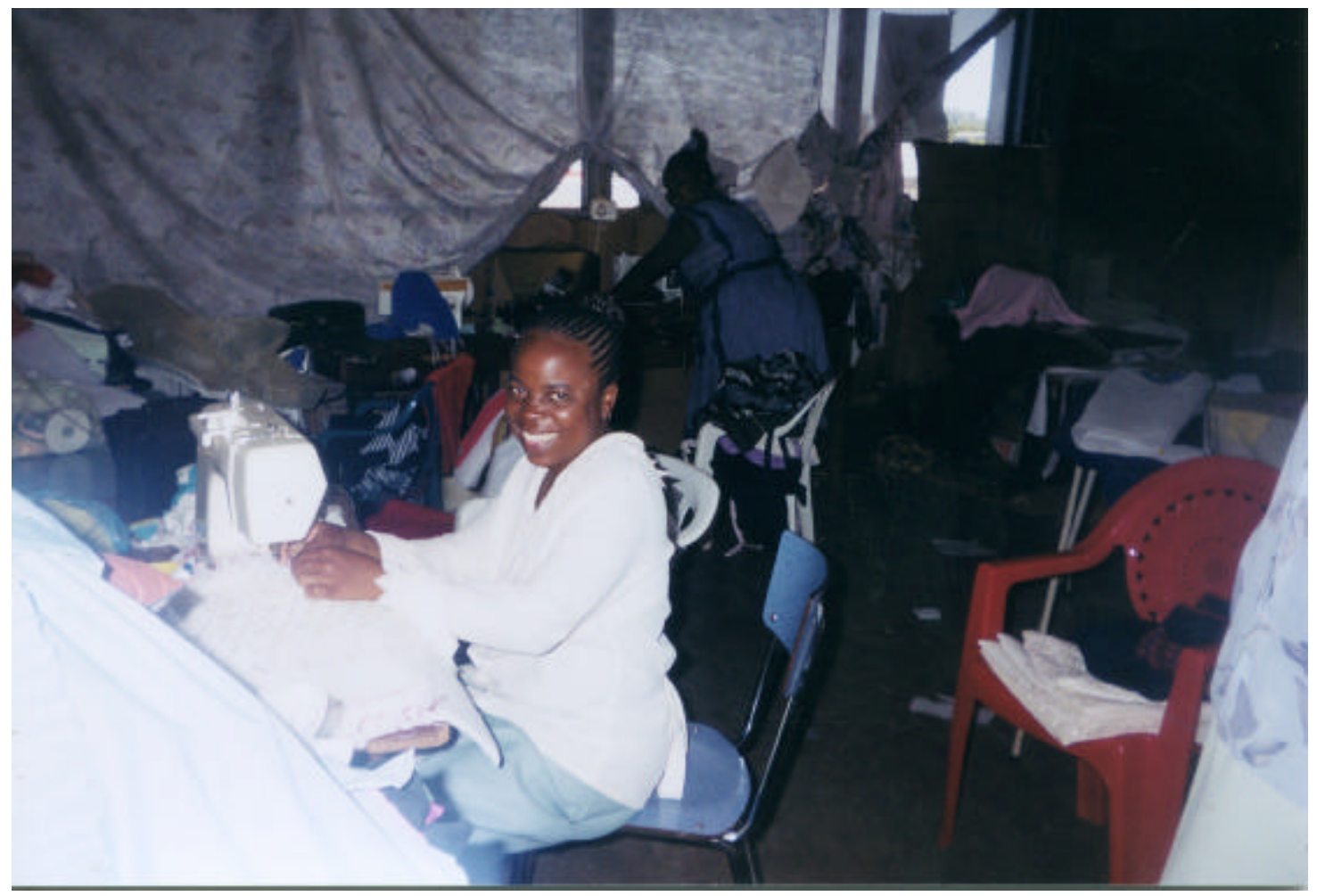

Photo 16: Women working at Baobob Kiosk. 


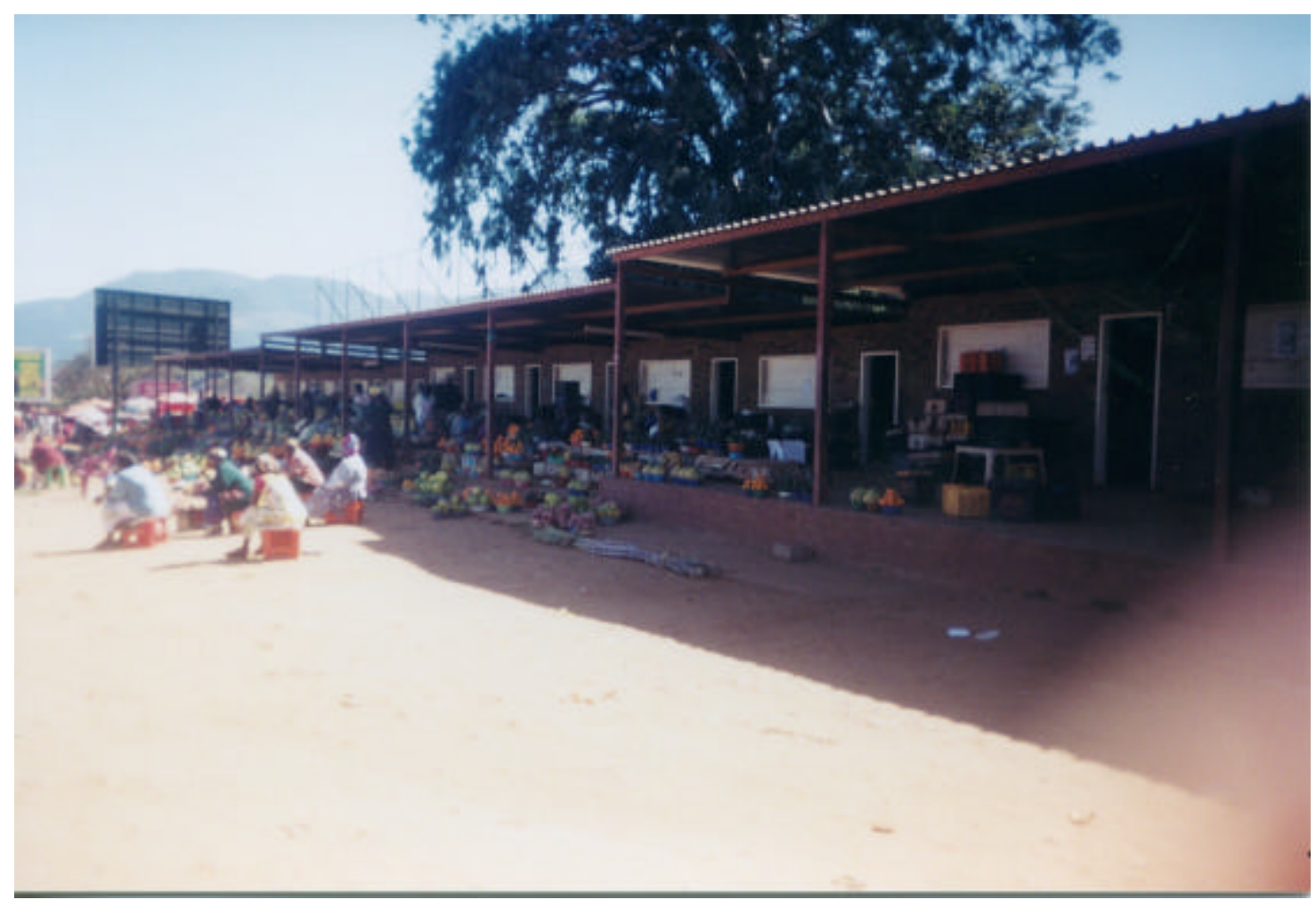

Photo 17: Tshakuma market

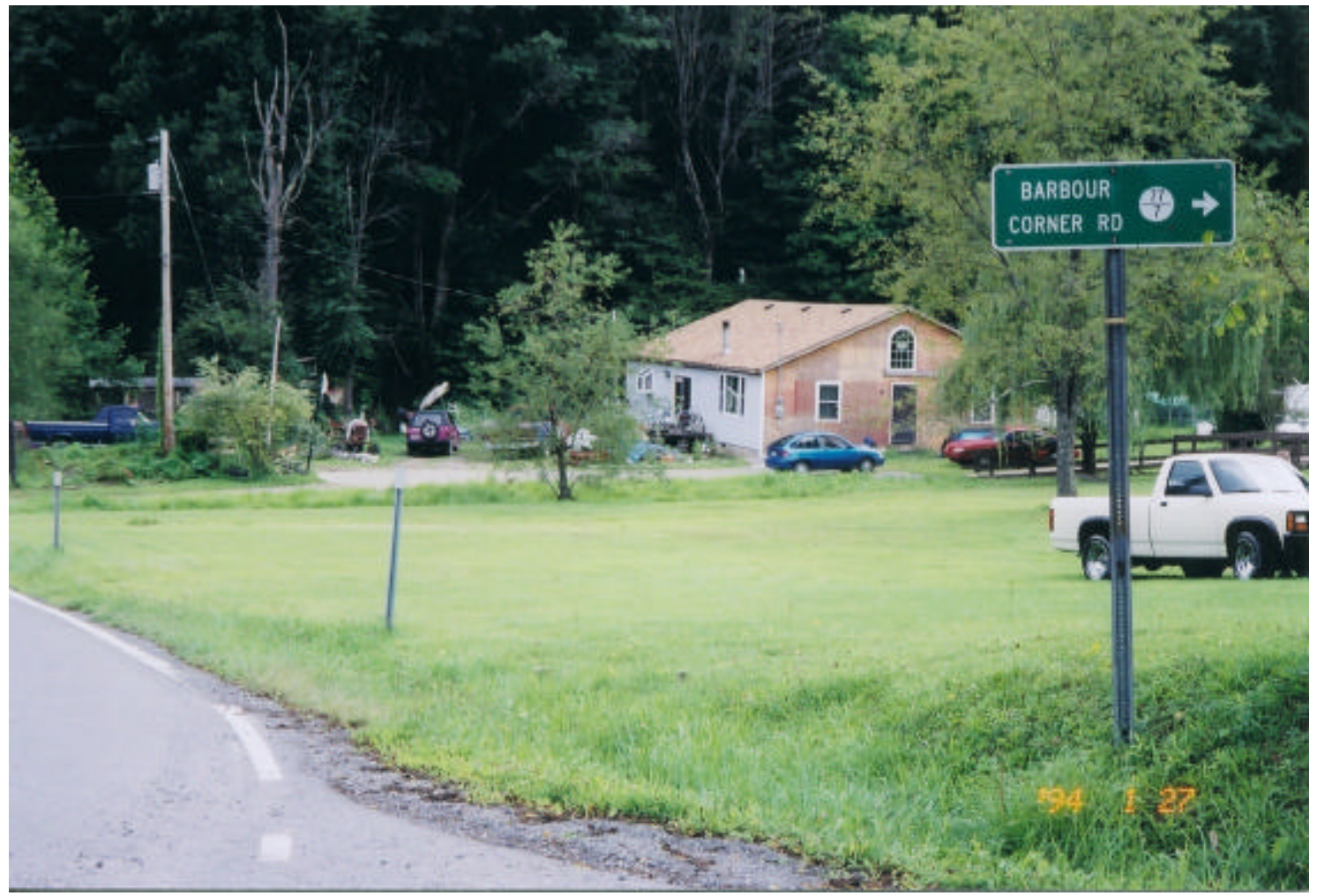

Photo 18: Anna's home in Flemington, West Virginia. 


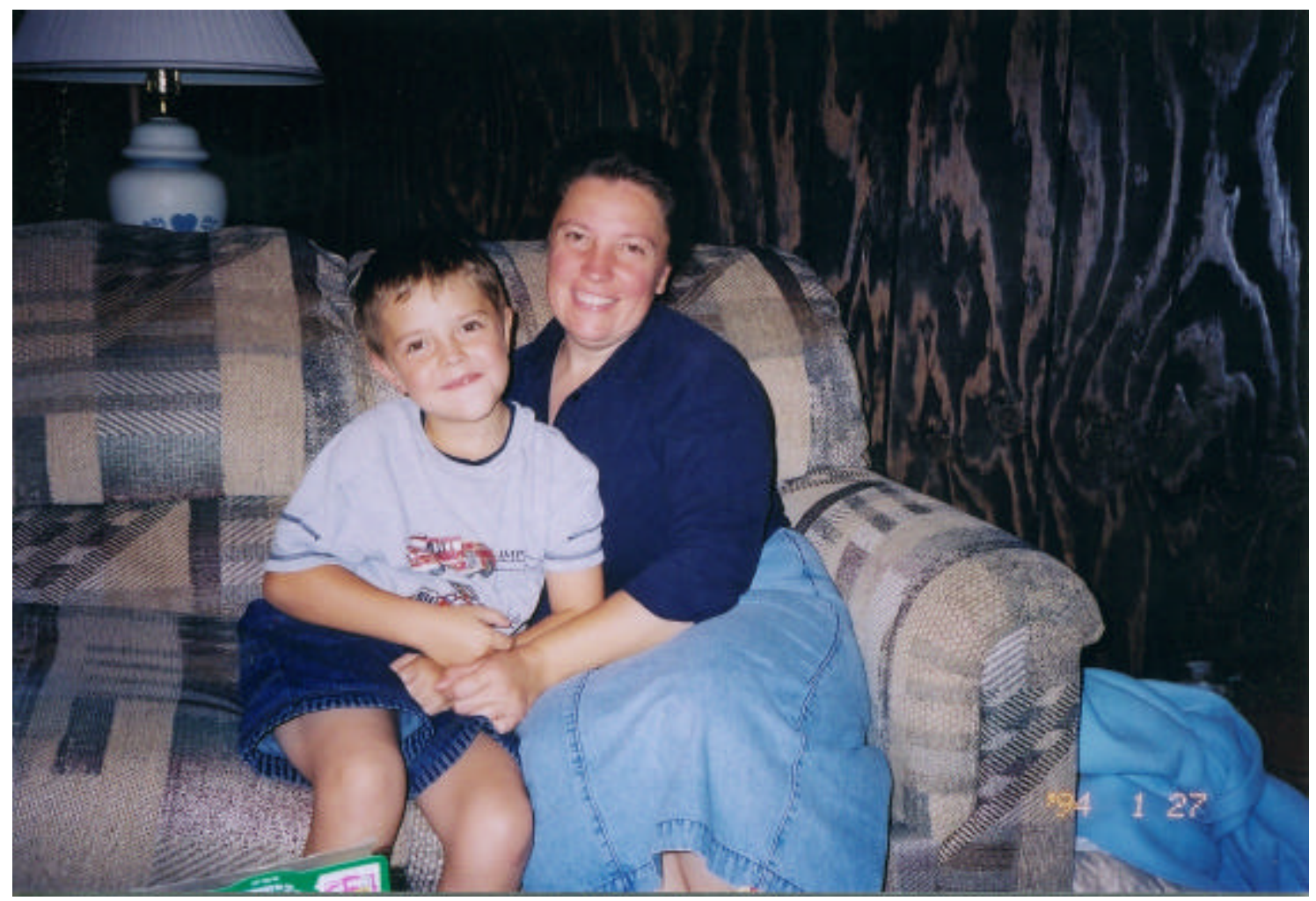

Photo 19: Wanda and her son.

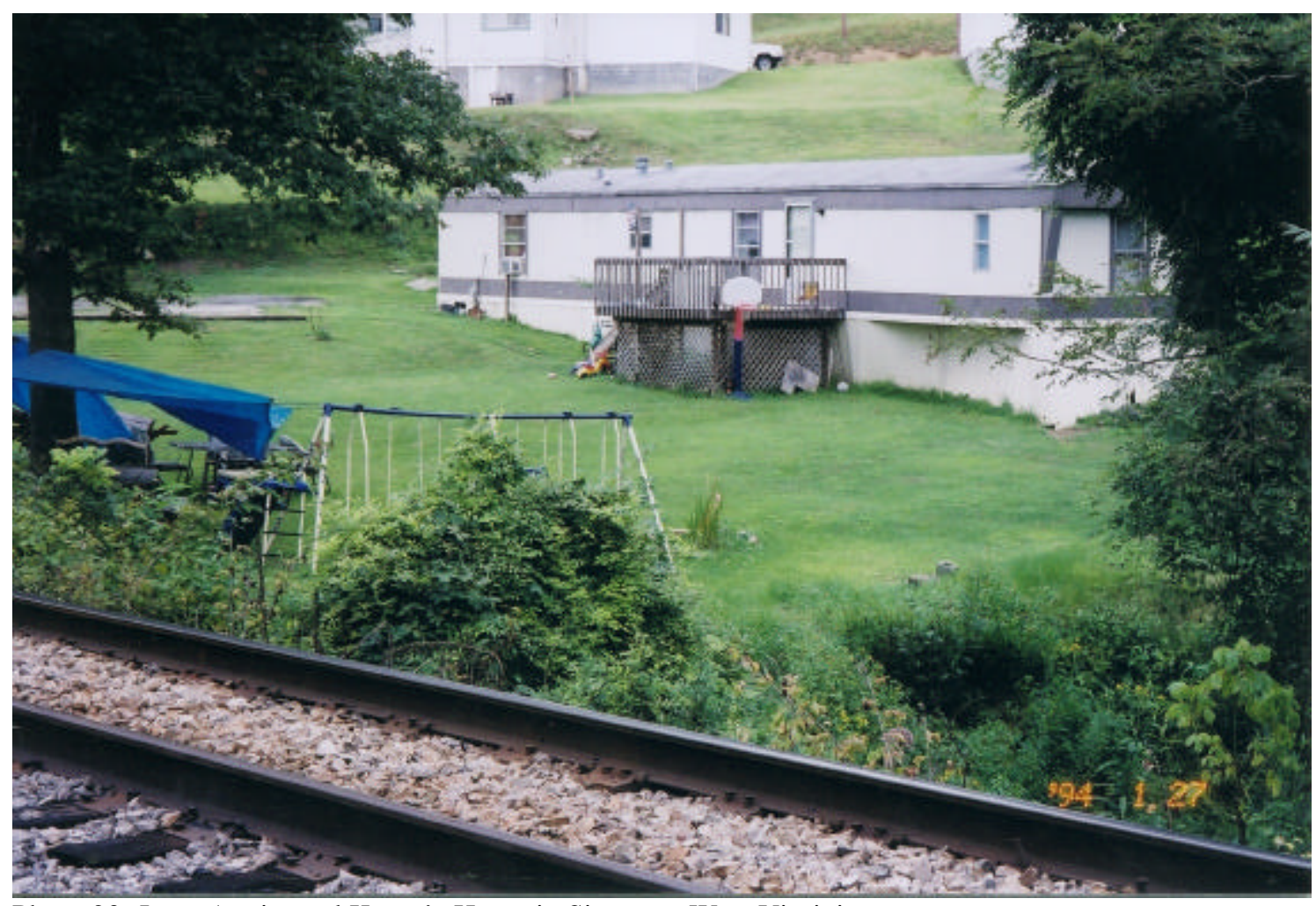

Photo 20: Jane, Angie, and Karen's Home in Simpson, West Virginia 


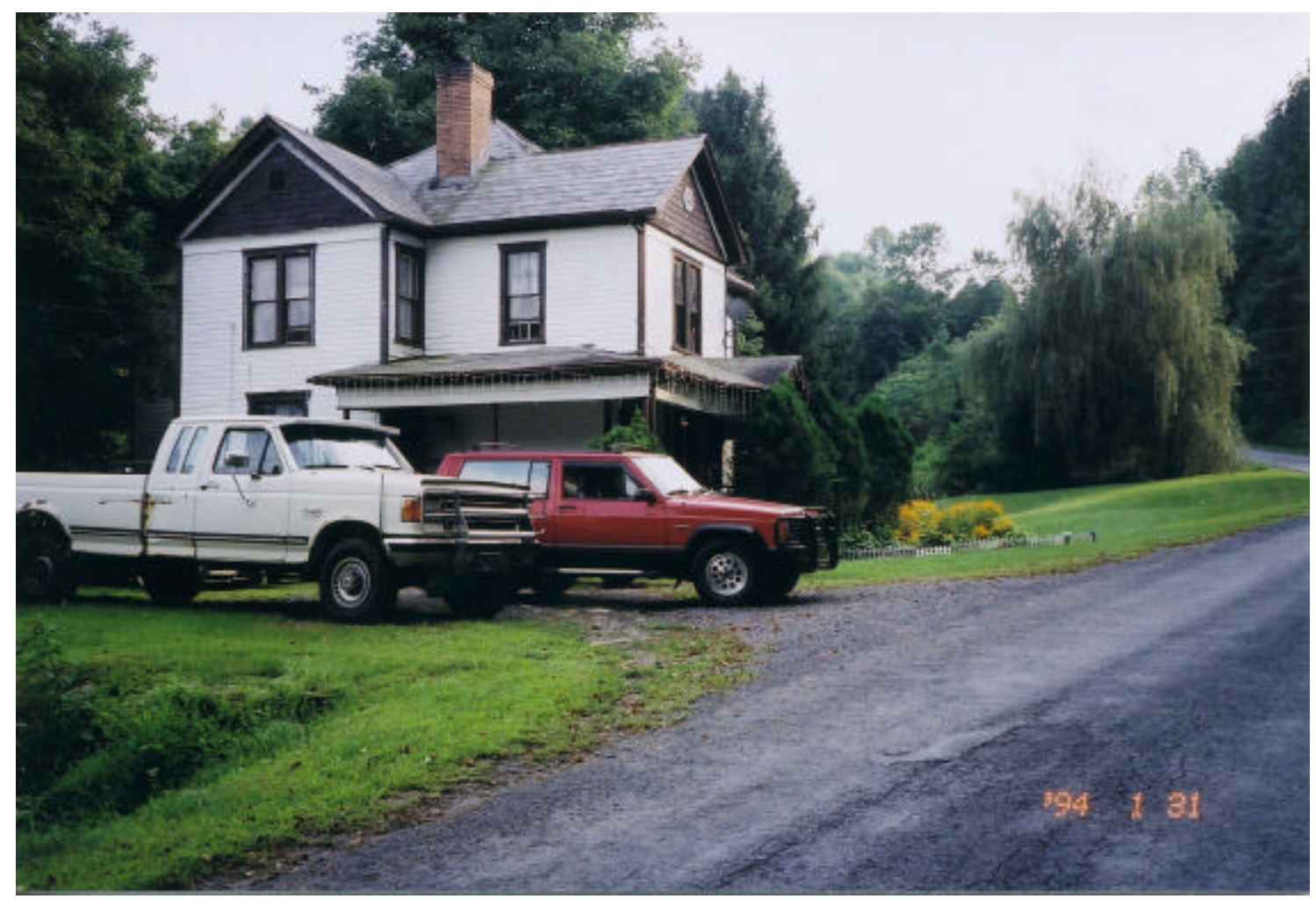

Photo 21: Tracy's home in Simpson, West Virginia.

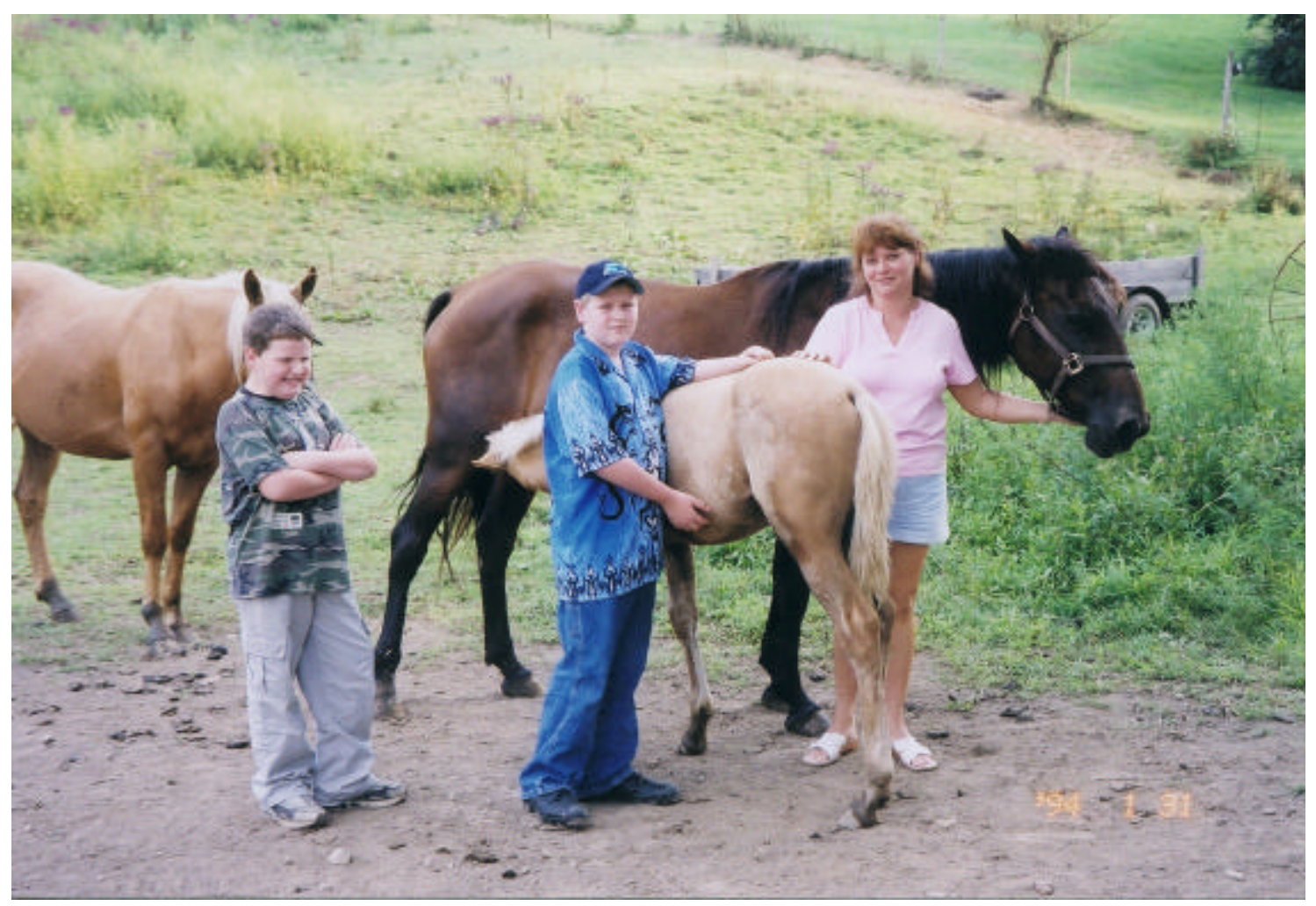

Photo 22: Tracy and her two sons with their horses. 


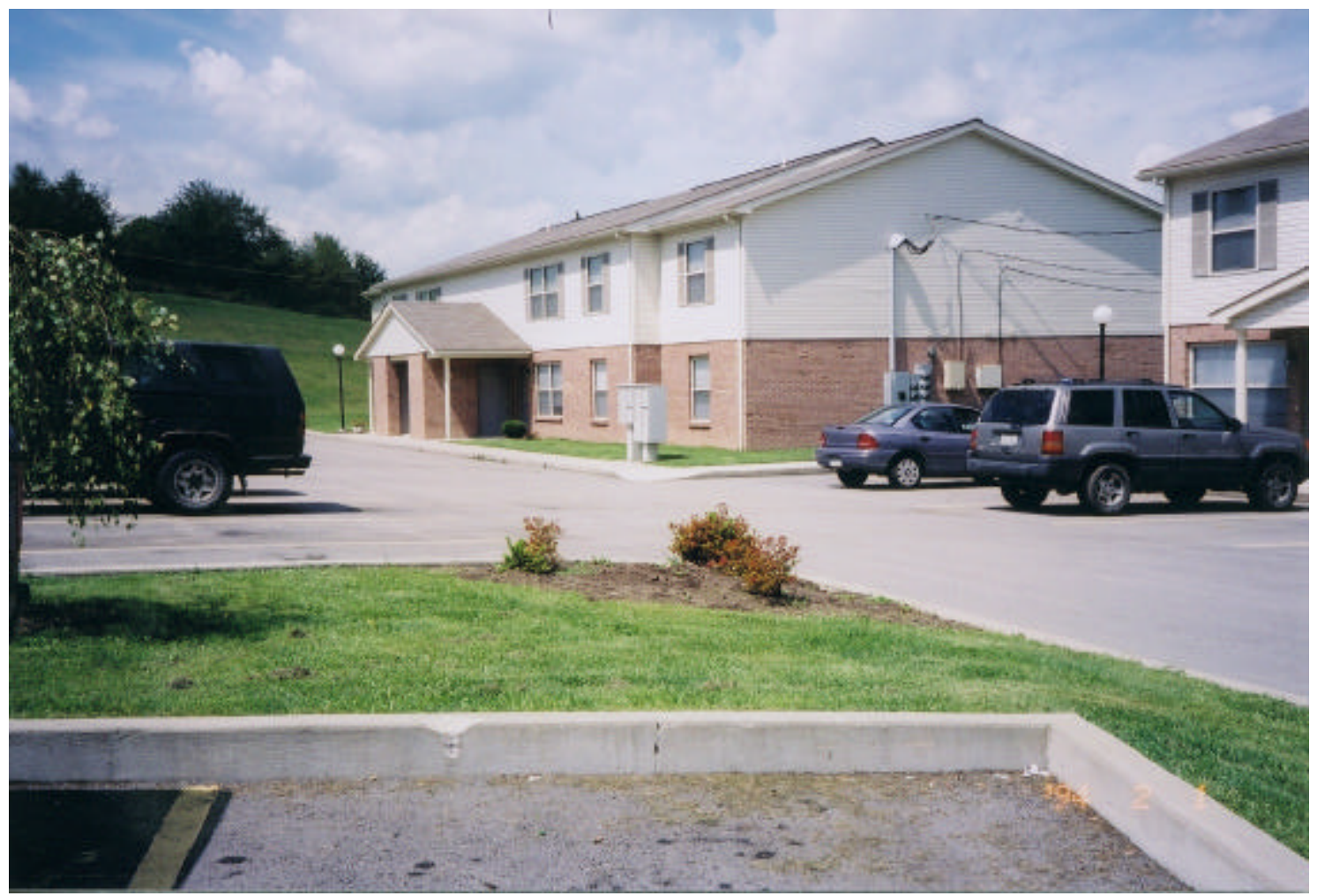

Photo 23: Caroline's apartment in Bridgeport, West Virginia which qualifies as HUD housing.

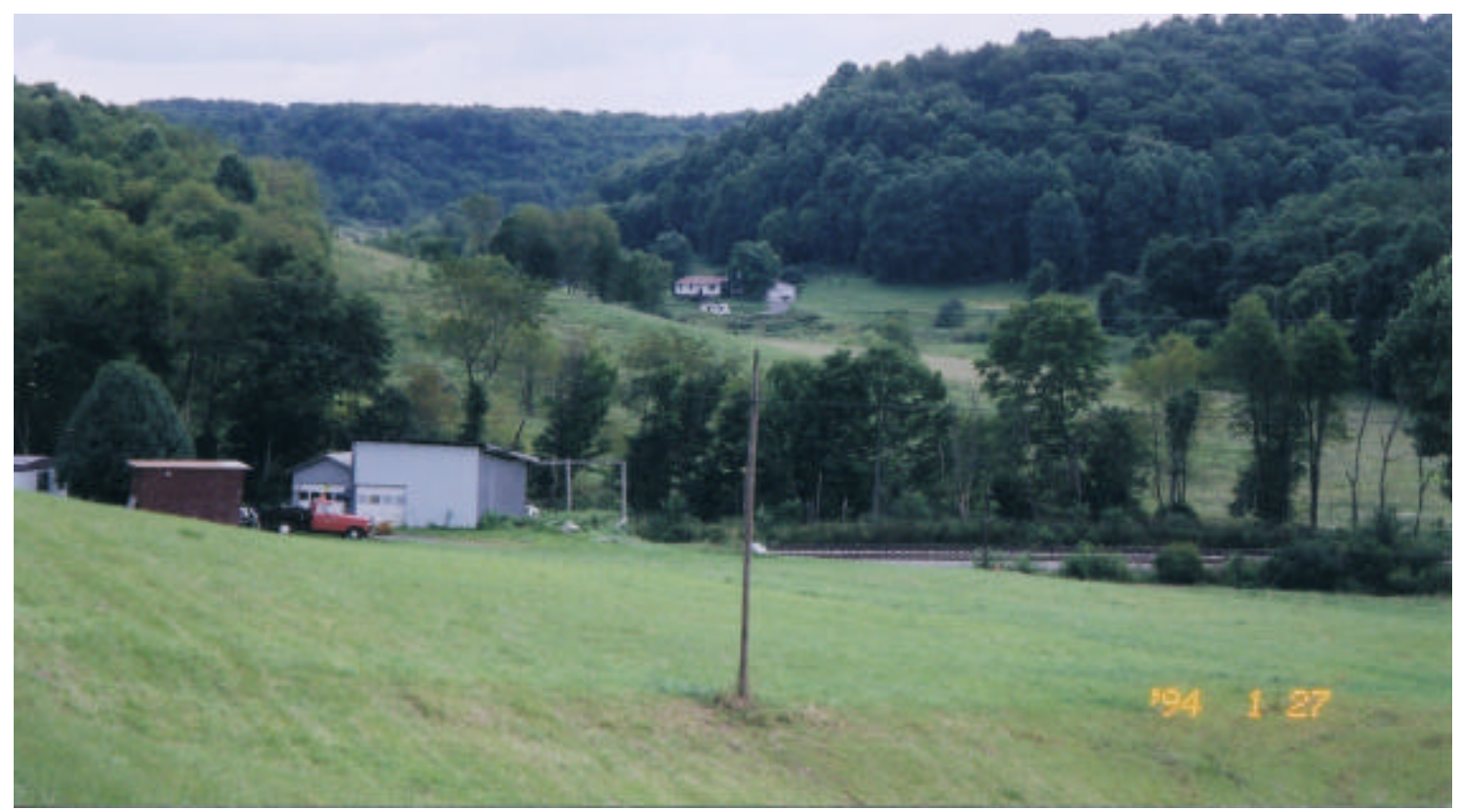

Photo 24: Wanda's farm that she inherited from her parents. 


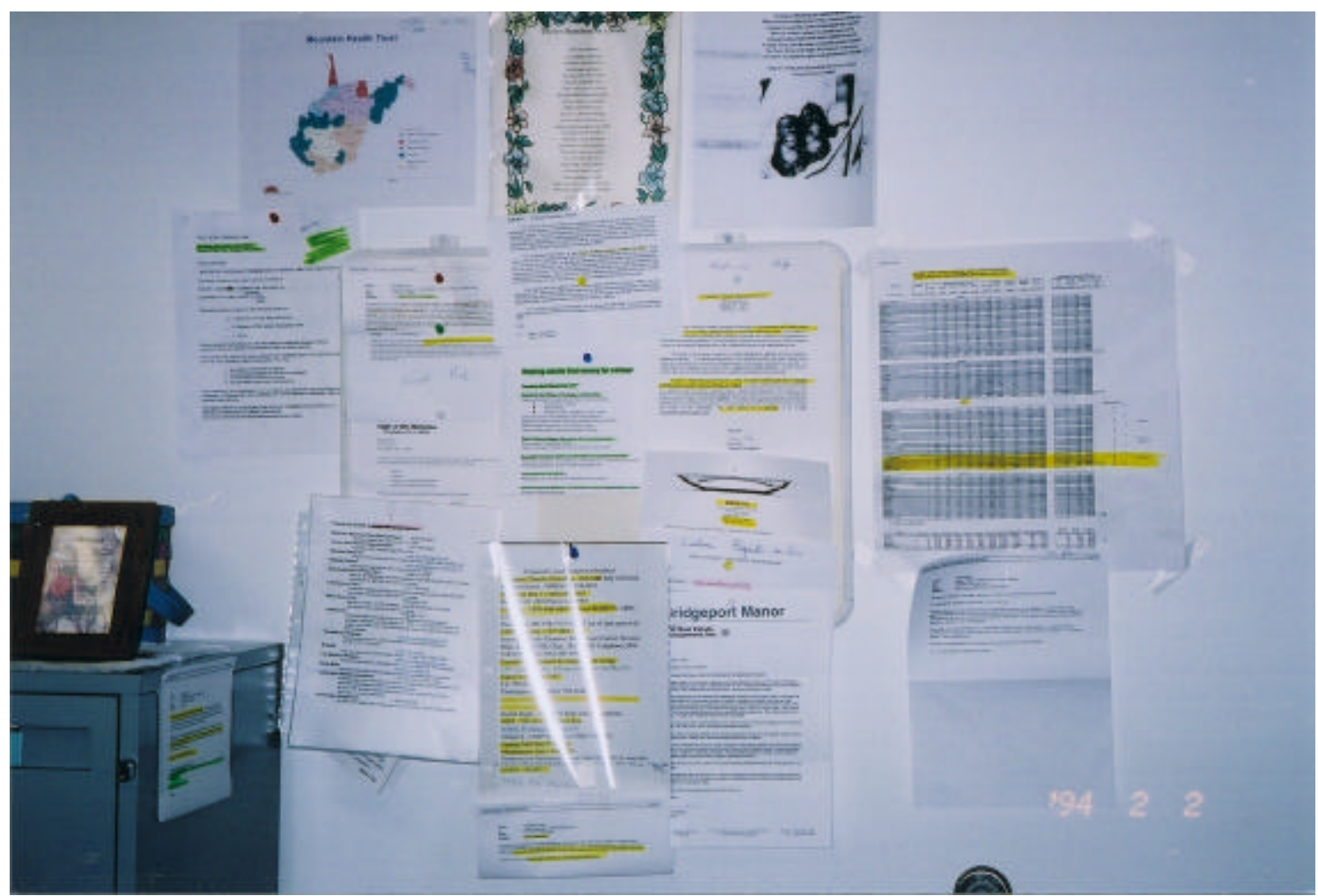

Photo 25: Diane's "resource board"

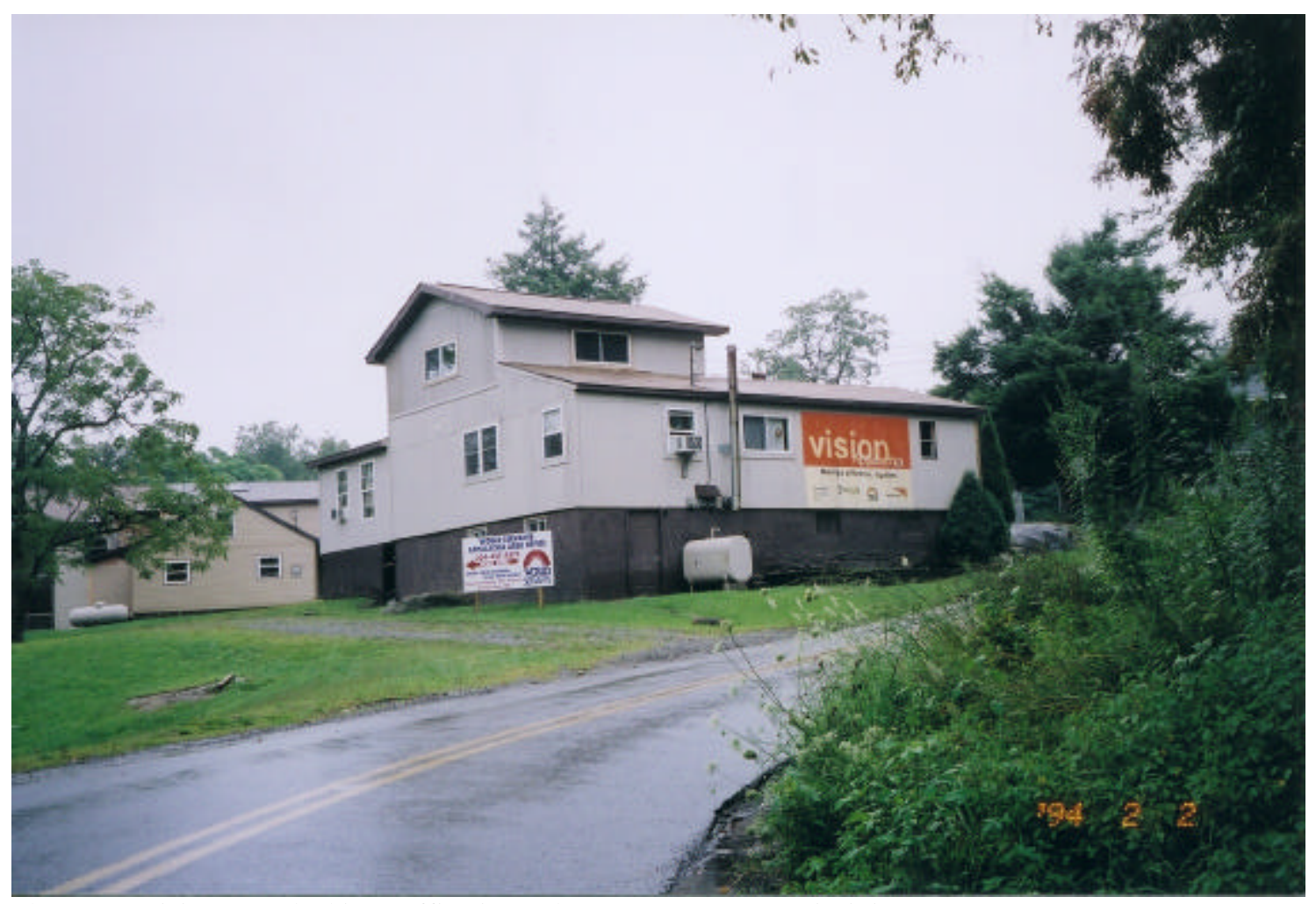

Photo 26: Vision Appalachia's Office in Barbour County, West Virginia. 


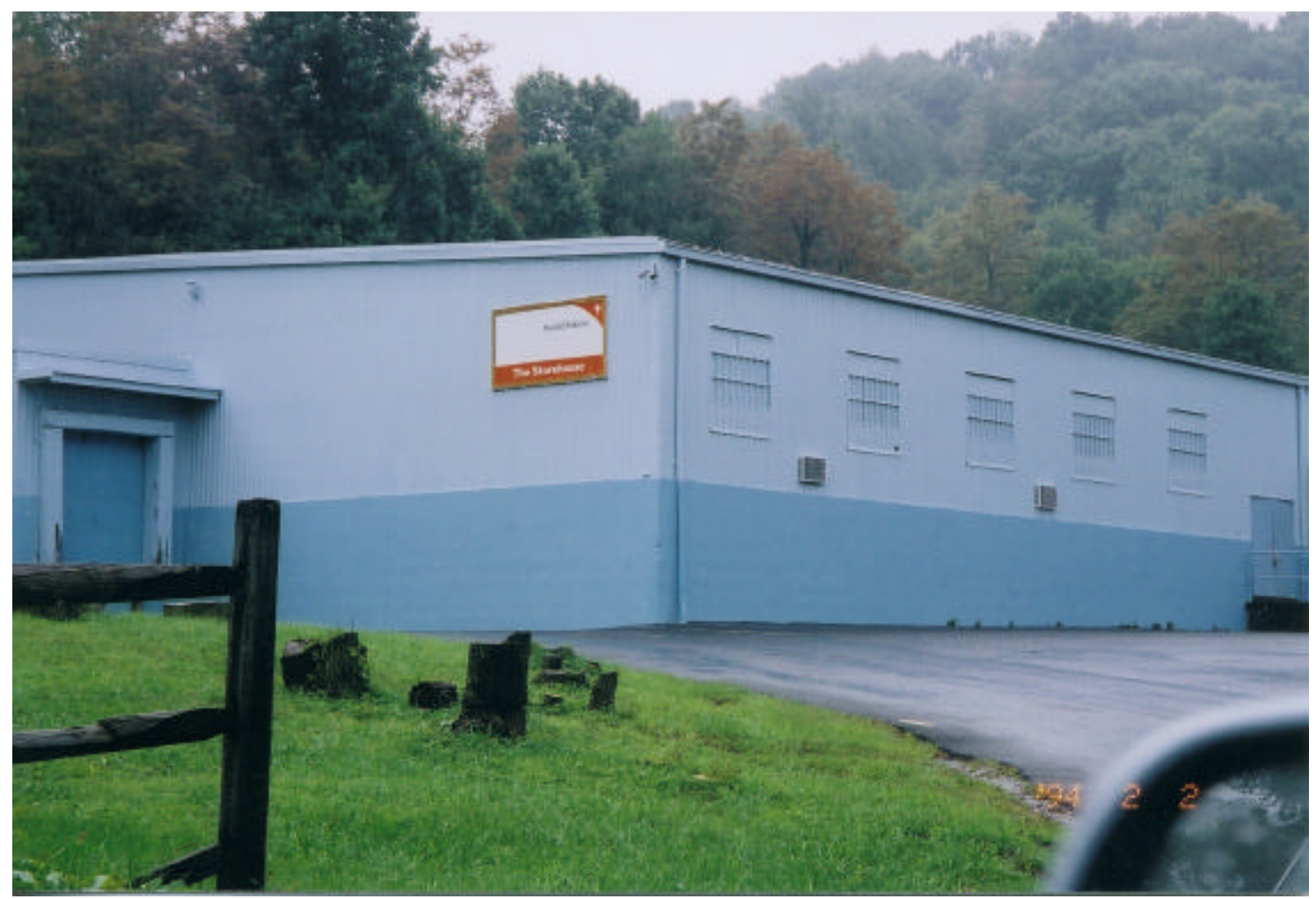

Photo 27: The WorldVision Storehouse in Barbour County, West Virginia. 


\section{Typologies and Topographies-Comparing the Livelihoods of Female-Headed Households}

\section{Introduction}

As indicated in the previous chapter, livelihoods among women heading households in the two case study areas include both capitalist and non-capitalist activities. The need to piece together a variety of income, subsistence, welfare, and family- and community-based strategies to sustain a household has evolved out of contradictions within capitalism at the macro-level, as well as local historical and contemporary socioeconomic, cultural, and political factors in Limpopo and West Virginia. It has always been difficult for women to meet the needs of a household through reliance on a single activity or income source, however, the new forms this is taking in rural parts of the world today is revealed through this research. This research engages women in their particular places and captures the dynamic and relational processes that inform the intricate array of livelihood activities that comprise women's ways of 'making due'. It emphasizes women's agency and how they develop their own unique strategies to deal with social and economic change in their daily lives.

Until recently, livelihood analyses have ignored the role of gender when investigating rural economies and the economic strategies that people utilize in rural parts of the world (see, for exception, Oberhauser and Pratt, 2004; Hapke and Ayyankeril, 2004; Mandel, 2004; Trauger, 2004; de Haan et al., 2002; Whitehead and Kabeer, 2001; Francis, 2000). This research develops a feminist livelihood framework that involves defining and analyzing women's particular strategies and how they are affected by access to various types of capital and resources. A feminist livelihood framework also seeks to understand how access to productive and reproductive resources is shaped by the gendering of socioeconomic, cultural, and political 
structures and processes. This framework is analytically strengthened by feminist geographical theories and methodologies, such as topographical analysis, that can account for the micro, mezzo, and macro scales in which these structures and processes occur and inter-relate.

Feminist topographic al analysis, in particular, facilitates comparative work that investigates women's livelihoods in and across place by illustrating how women in seemingly different locales are affected by common factors and thus adopt similar livelihood strategies. Topographical analysis acknowledges that every woman is situated within a household, community, and region that have distinct livelihood options and constraints. These livelihood options and constraints are shaped by socioeconomic, cultural, political, and geographical forces that operate in both different and similar ways across place and at various scales of analysis. Analyzing the operation of these various forces and comparing them across place provides feminists with the means to link macro-level processes, such as economic restructuring, to microlevel outcomes and responses, including women's livelihood strategies. This research argues that establishing and understanding these links facilitates an understanding of how women, all over the globe, both differently and similarly cope with, adapt to, or challenge the various forces that either enable or impede their efforts to support households. It therefore also presents opportunities for women's organization, transnationally, around their shared needs and concerns and the exchange of information concerning economic and political strategizing. Lastly, comparative feminist work provides feminists with a better understanding of women's economic geographies in a contemporary world and a path toward the construction of a transnational feminist movement that can articulate women's issues at a global level. Despite diverse socioeconomic and geographical 'locations', women face gendered oppression and 
marginalization that result in inequality and power differentials which impede their abilities to acquire a sustainable livelihood for themselves and their families.

This chapter continues the analysis of women's livelihoods in Limpopo and West Virginia. It presents the comparative aspects of the research by building a typology of women's livelihood strategies across the two case study areas and analyzing the benefits of and challenges to women's livelihood strategies and overall livelihoods. This typology facilitates comparing and contrasting the pertinent issues around women's livelihoods in and between Limpopo and West Virginia and is devised to encourage comparative analyses of women's strategies in other regions.

With respect to feminist topographical analysis, the chapter then constructs a topographical model that illustrates the multiple and binding local, regional, and global forces that affect women's socioeconomic conditions and positions in Limpopo and West Virginia and ultimately, their livelihoods. This is part of topographical analysis that seeks to uncover and dissect the various historical and contemporary forces that affect women's livelihoods in the two case study areas. It then moves on to begin to construct the analytical contour lines that connect women heading households in the two regions that can facilitate the formation of countertopographies. Counter-topographies can engage women heading households transnationally and work to develop strategies that enable them to construct sustainable livelihoods for themselves, their families, and their communities.

\section{A Typology of Livelihood Strategies}

Typology refers to "the study of types, as in systems of classification" or "set or listing of types" (Funk and Wagnalls Standard Desk Dictionary, 1994). Thus, typologies are useful for 
categorizing and organizing data with common themes and/or characteristics into a format that is easily understood, accessible, and possibly applicable to other related work. They also facilitate the comparison and synthesis of information.

This section of the chapter establishes a classification of livelihood strategies utilized by women in both Limpopo, South Africa and West Virginia, Appalachia. This typology is useful in comparing and contrasting women's livelihood strategies in the two case study areas as well as for future research on women's strategies in other regions. The categories developed here should never be taken as absolute and any adoption of this typology in future research should adapt it or add to it as needed. This research realizes and will illustrate how these strategies are interconnected and oftentimes dependent upon one another. They do not exist in isolation or independent of other livelihood strategies utilized by women. Fundamentally, this typology is developed to facilitate understandings of the livelihood strategies of women heading households in Limpopo and West Virginia; the main issues affecting these strategies; and the comparison of women's livelihood strategies across the two case study areas.

The typology developed here is two-fold: it groups the various livelihood strategies identified through the research into five types and then distinguishes these types as either growth strategies: including strategies that are not only sustainable but have the potential to expand women's access to both productive and reproductive resources, or needs-based strategies: including strategies that meet basic living requirements. The distinction between growth strategies and needs-based strategies is done for practical reasons: it can facilitate the identification and development of programs and policies that could assist women in meeting their day-to-day, basic living requirements; the further growth and expansion of their current strategies; and possible identification of new livelihood options. 
This research has identified five types of livelihood strategies utilized by women in Limpopo and West Virginia: formal strategies, including work in the formal economy and business ownership; informal strategies, including participation in community groups, the informal selling and trading of goods, and the use of and dependence on natural resources; government assistance, including all types of welfare and transfer payments; family and community-based strategies, including family support and assistance from community, nonprofit, and charitable organizations; and co-strategizing, including the ways women who head households work together to meet their productive and reproductive needs.

\section{Formal Strategies}

With respect to this research, formal strategies include employment in the formal sector and business ownership. Work and access to cash income in the formal economy provides women heading households with an important route to economic self-sufficiency. The health and retirement benefits afforded through employment are also essential resources for women heading households with respect to caring for themselves and their children and preparing for the future on their own. The ability to engage in formal employment requires access to an economy that has available jobs; certain skills, training, or education; able-bodiness; transportation; and for many of the women in this study, social and childcare support. In Limpopo and West Virginia, access to these resources is shaped by the history and contemporary nature of rural economies and women's positions and conditions within these economies, as highlighted by Chapters III, IV, and VI. Various structures, such as the state, community organizations, and the family, and their associated ideologies about women and work influence these local economies 
and women's economic roles and abilities to adopt, engage in, and further develop certain livelihood strategies.

Both of the case study areas have faced histories of labor and resource extraction, underdevelopment, and the socioeconomic marginalization of their rural populations that contribute to both the availability and types of jobs that women have access to today. The case study area in Limpopo includes the former bantustan of Venda. As articulated in Chapters III and VI, under apartheid the country of South Africa was separately 'developed' and 'underdeveloped' through a geographical exercise that specifically linked race and place. The former bantustans were places from which Black labor, which was largely male, was extracted to support the mining and manufacturing industries of the 'white' economy. Resources, such as land, were strictly controlled by the apartheid government and other government and traditional institutions, including the chieftaincies, and oftentimes not accessible to local people, especially women. Infrastructure in the former bantustans was poorly developed and few educational and training opportunities for women existed or were not accessible due to economic, as well as cultural reasons. Local bantustan economies lacked diversification and Black women were usually employed as domestic or agricultural workers or as low-paid industrial workers in border industries: industries set up on the borders between the bantustans and white areas that were designed to exploit the cheap labor, which was largely female, available in the bantustans.

Labor and resource extraction, processes of development and underdevelopment, and the socioeconomic marginalization of women was sustained by the apartheid state, bantustan authorities, and traditional institutions. Current economic and social development policies, including GEAR, target macroeconomic, market-driven economic development and are urbanbiased. They have invested little in the development of human capital and the provision of basic 
needs, especially in the rural periphery, and the process of land reform is slow. Thus, Black women's abilities to access sustainable employment, training and educational opportunities, and natural resources were, and still are, limited. Add to this mix of historical economic, cultural, and political factors that have marginalized and oppressed Black women in South Africa, as well as transformed household structure and community life, the contemporary issue of HIV/AIDS and one can see the tremendous challenges to progressive and diversified economic development in the country. ${ }^{99}$

UNAIDS estimated that at the end of 2003, there were 5.3 million people in South Africa living with HIV, which was 23 percent of the population at that time. 13 percent of all the people in the world living with HIV can be found in South Africa (avert.org online:

www.avert.org). This epidemic, which has devastating effects on the most productive portion of the population, is one of the major factors affecting the future of South Africa. Excess mortality due to HIV and AIDS can result in lower life expectancy, higher infant mortality and death rates, lower population and economic growth rates, and changes in the distribution of population by age and sex than would otherwise be expected.

In South Africa, women are more likely to be infected than men and the social stigma attached to the disease can affect employment, housing opportunities, and social relationships and prevent people from accessing health care. There is correlation in South Africa between extreme poverty and high levels of HIV prevalence and the lack of healthcare infrastructure, particularly in rural areas, means that many people do not have access to medical services for testing and treatment. There is a great shortage of drugs, including Nevirapine, an antiretroviral drug that prevents HIV transmission from mother to her unborn child. Because of the historical

\footnotetext{
${ }^{99}$ There was an explosion in HIV prevalence between 1993 and 2000 in South Africa, jumping from just 4.3 percent to 24.5 percent respectively (avert.org online at: $\underline{w w w}$.avert.org).
} 
marginalization of so many from education and training opportunities, there is also a lack of trained medical professionals all over the country that have the skills to ensure safe, ethical, and effective treatment and use of medications, as well as provide counseling and other social support services to those people and their families affected by the disease. HIV/AIDS threatens the political and social stability and economic development and growth of the country. The issue of HIV/AIDS therefore impacts all of the livelihood strategies identified in this study.

Only seven of the women interviewed in Limpopo for this study reported utilizing formal strategies to support their households. Three of the women, Hope, Janet, and Beth, have access to formal strategies only through their husbands who were teachers and a welder (Table 2). Their household incomes were significantly higher than other households in the study (Table 2) and they were more confident about their future and abilities to support their households. The income earned by their husbands in the formal economy also made it possible for Hope and Janet to join Tshandama Jam Project and for Beth to start her sewing business. The further growth and development of these women's strategies may be dependent on the fact that they have access to reliable wages in the formal economy.

Formal strategies in rural Limpopo do not, however, always translate into higher incomes for households. For example, Sharon and her husband both engage in formal strategies: she runs her own sewing and beadwork business and he has a delivery business yet their household income is only between R601-800 per month, including an old age pension (Table 2). Joanne, Helen, and Mary also have access to formal strategies in the form of sewing businesses however, as livelihood strategies, only Joanne reported an income of over R1,000 per month. Helen and Mary earn less than R200 per month (Table 2). In fact, the insecure nature and marginal benefits of formal strategies and wages revealed through this research are consistent with Francis' (2000) 
study on rural livelihoods in South Africa. She also points to the fact that access to a waged income oftentimes only marginally improves economic well-being and it is usually the case that people are just barely getting by month to month in rural parts of the country. Household structure and access to land, remittances, or a pension, of course, affect the benefits of and one's ability to engage in formal employment and must also be considered in analyses of individuals or particular households.

While bringing in some cash income, these strategies are therefore not providing enough to meet even the basic needs of these households. In order for these strategies to grow and develop into sustainable sources of income that provide a living wage, they will need investment and access to markets, credit opportunities, and further training in marketing and business ownership. They are also dependent on a growing and prospering local economy, which is currently stagnant. Women in the study constantly commented on the issues of unemployment and joblessness, even for people with skills and advanced education, in their area as well as the rest of the country (see also Francis, 2000).

Questions concerning formal employment, as a livelihood strategy for women in rural South Africa, thus loom: Will Black women become a reconstituted source of cheap labor in South Africa's quest to become a more active and profitable player in the global economy? In the context of rising numbers of female-headed households, how will women effectively balance formal employment and their household reproductive duties? How will Black women gain access to educational and training opportunities to become employable and where will jobs in rural economies come from? How will work supports, such as child-care programs and subsidies, and demand-side solutions, such as rural economic development, be developed to accommodate women heading households in the former bantustan areas? In the 'new' South 
Africa, it is well known that the ills of colonialism and apartheid are not easy to undo, however, the questions concerning the female labor force and its future must continually be reflected upon at all levels of society.

In sum, current development policies, the lack of investment into human capital and the provision of infrastructure and basic needs in the rural periphery, the slow process of land reform, and the spread of HIV/AIDS all inform the questions highlighted above and the future of women in formal economic strategies in Limpopo. Some local economic development efforts are taking place, such as those led by the cheiftancies, non-profit and non-governmental organizations, and other civic groups, and if supported, show promise in stimulating local economies in the former bantustans and creating job opportunities. Concerning the need to invest in human capital and increase employment opportunities, a local chief in the greater Thohoyandou area of Limpopo stated: “you can't just give people housing. People here do not need housing. They have it. It is not a township area. People here need jobs and employment...” (Individual Interview, July 24, 2001). The chief questioned the increasing centralization of the national government and emphasized the need for strong local government supported by district councils, to deliver local needs. In his area, this chief has started closed corporations, which are participant-owned, for people with skills in electrical work, plumbing, carpentry, and sewing, for example. He is also starting a development trust with compensation money that his community is receiving for land that will be flooded for the construction of a dam. He will use the development trust to develop infrastructure, schools and clinics, and to fund educational bursaries for all students in his area and establish their own community technical school. He also intends to establish micro-financing programs and a village bank. He says, "chiefs must protect people and get investment for communities...my goal is permanent 
employment for skilled people, serious economic development" (Individual Interview, July 24, 2001).

Similar to South Africa, West Virginia, which lies at the heart of Appalachia, has faced a long history of resource extraction, exploitation and marginalization concerning the rural population and land, and underdevelopment in the rural periphery. Being an economy that was built on resource extraction in the form of coal and timber businesses, much of West Virginia and its people have been subject to the control of outside landowners, corporations, and big government concerning their economic opportunities, labor, and land and other natural resources. As indicated in Chapter IV, employment in coal and timber and their associated industries was male-dominated, leaving women to reproductive work in the home or low-wage, oftentimes parttime work in the service sector. Work in extractive industry required few skills from the labor force in the early years and only basic infrastructure.

Consequently, in the late 1970s and 1980s when the industry began to decline while also increasingly mechanize, the labor force that was displaced lacked the necessary skills, training, and education to be competitive in the job market. Women, who had experienced relative exclusion from viable, formal employment, were entering the labor force in large numbers but lacked the skills and work experience to acquire a job that provided wages and benefits that could make up for a spouse's job lost in the higher-paid mining or manufacturing industries. This was also a time of economic restructuring; the manufacturing industries that were located in West Virginia began to seek cheaper labor, raw materials, and tax and environmental costs by 'fleeing' to the global south. The job market that could provide employment with a living wage and benefits remains constricted in West Virginia yet the low-paid, oftentimes insecure service 
sector continues to rise. Women increasingly fill these service-sector jobs that do not provided a living wage or much needed health and retirement benefits.

Related to its socioeconomic history and rurality, rural localities in much of West Virginia also lack economic diversification as well as infrastructure in the form of roads and other transportation services; water, sanitation, and sewerage; and electrical, phone, cable, and Internet service and other resources. In addition, solvent tax bases, high levels of education among the population, and available municipal services and public amenities that could attract businesses that provide sustainable employment are not found in many rural localities.

In sum, many rural communities and people have been 'underdeveloped' and are not prepared to attract global businesses or for employment that provides a living wage in the increasingly global economy. Similar to South Africa, it is difficult to undo what it has taken decades to create and requires investments into the provision of people's basic needs, infrastructure, and the development of human capital. This type of social and economic development is comprehensive and has not been the direction taken by both regional and local development policies in the region or state over the last twenty-five years.

As indicated in Chapter IV, ARC regional development policy, despite its initial intent to be comprehensive in its approach, historically focused on big highway development and a growth center strategy rather than significant investment into the development of local infrastructure, business development, and human capital. In many parts of the Appalachian region, the ARC has improved transportation networks; increased the provision of public utilities and rural health services; reduced poverty levels; and improved people's access to vocational and technical educational programs. However, it has neglected and further marginalized many of the 
most disadvantaged and economically distressed communities in the region, many of which are in West Virginia.

Because of its lack of attention to increasing the economic diversification and infrastructure capacity of rural communities and development of human capital resources in its early years, the ARC has also been unable to effectively deal with the more contemporary effects of economic restructuring in the region, including high levels of job loss and consequent unemployment; the rise of unstable and non-sustainable service sector work; and the need to be globally competitive in the development of investment opportunities. Combine these issues with federal reductions in social welfare programs that could temporarily supplement lost jobs and low wages, and you have many people in rural parts of West Virginia struggling to 'make due'. And worse still, participation in social movements for civil, welfare, and women's rights and labor activism and unionization has declined leaving many people in the region with no mechanism for voicing their concerns (see the work of Couto, 1994; Obermiller and Philliber, 1994; Gaventa, Smith, and Willingham, 1990).

Increasingly, there are some local economic development efforts coming from the ARC as well as local government and non-profit and community organizations. Contemporary ARC programming includes a focus on highway development as well as the Area Development Program. The Area Development Program is a comprehensive economic development initiative with three goals: to promote diversified economies and create and retain businesses and jobs; to help communities develop skilled, educated workforces and create access to affordable, quality health care; and to support the development and improvement of infrastructure, including water and sewerage services and Internet access (ARC online: www.arc.gov). The Asset-Based Development, Telecommunications, and Entrepreneurship Initiatives, Grants for Distressed 
Counties, Business Development Revolving Loan Grants, and Export Trade Promotion are programs designed to help the ARC meet these goals. In addition, local governments and nonprofit, religious-based, and other community organizations are developing innovative ways to train and educate people, provide work supports such as child care, and build on local resources to economically develop their communities. Despite both regional and locale efforts however, West Virginia still currently lags behind the nation and the region in terms of jobs, income, and economic diversification, as well as poverty and education. There is much work to do, especially concerning women in formal employment.

In terms of formal employment as a livelihood strategy, West Virginia women in this study are primarily located within the service sector (Table 5). With the exception of Margie, who is an attorney, their jobs are low-paid (Table 5), require little or no advanced training or education, and offer no work supports, such as childcare. While some of the jobs offer health benefits, few have pension or retirement plans.

Women in this study are employed as secretaries and administrative workers; nurses and home health care workers; housekeepers and nannies; and food service and retail workers (Table 5). While pay is an important issue to women in this study concerning employment, key issues also included: flexibility, childcare, and benefits, especially health insurance. Several of the women stated that while they could always use more money and that they were struggling financially, there main motivation for seeking their current jobs was either flexibility and/or access to benefits. Because their wages were so low in many circumstances, women in this study had to rely on other livelihood strategies, such as co-habitation or doubling-up for their household needs and public assistance for food, clothing, and childcare, for example. Offering only minimal material benefits, formal strategies alone cannot sustain the households of the 
women in this study and this finding is consistent with the findings of Brown and Lichter (2004) in their analysis of the livelihood strategies of non-metropolitan single mothers. Through quantitative analyses that measured the benefits of certain livelihood strategies, including employment, welfare receipt, and co-habitation and doubling-up, between metro and non- metro single mothers they found that single mothers in non-metro areas are less likely to benefit from full-time employment than their metro counterparts and have lower incomes and higher rates of poverty (Brown and Lichter, 2004).

Like the women interviewed in Limpopo, women interviewed in West Virginia also constantly commented on the lack of available jobs in their areas and their interest in training and educational opportunities. Many of the women wanted or were attempting to access more education and training to improve their employment situation but they faced tremendous barriers in terms of childcare; the balancing of work, home, and school; financial resources; and time and transportation. Concerning their interest in accessing educational opportunities and the difficulties they face, Ronnie and Wanda respectively stated:

...I have thought about going back to school but I don't know if I could do it....I would still have to work, how could I do it and go to school? I would have to work part-time and I can't afford it.... with a car payment...I have to stay full-time, work 35 hours per week, if you go down so many consecutive weeks, they take (health benefits) away...I have thought about (going back to school) for a long time...(Individual Interview, August 3, 2004).

...I do want to go back to school...I wanted to get into the radiology program at United Hospital Center but I found out I would have to work a night shift and afternoons cause you have to have hands-on training...I had the money but I said no. I could have started Alderson-Broaddus College (in Phillippi, West Virginia)... but it would be too much traveling, with (my son) in school in Bridgeport...maybe someday this will work out...I don't know if I could do school, it's scary...but it is always in the back of my mind...(Individual Interview, August 7, 2004). 
Questions concerning the future of women in formal employment in West Virginia also loom and relate to employment issues for women in South Africa. How can women overcome their continued occupational segregation and marginalization from viable income-generating activities in West Virginia? Will West Virginia women continue to be a source of cheap labor for the service sector in the state? Where will higher paid, more sustainable forms of employment for women come from? How will West Virginia women heading households access and fulfill educational and training programs to access these jobs? How will rising numbers of women heading households balance work and home life in a rural economy without sustainable job opportunities, work supports, and government assistance? How will work supports, such as childcare programs and family leave policies, that could facilitate the balancing of home and work become a goal of employers, local communities, and the state?

Women in Limpopo and West Virginia have a lot to say to each other about their needs to access formal strategies in the construction of their livelihoods. Women in both areas are embedded in constraints created by local economic and social histories that have marginalized them from viable income-generating activities and exploited their productive and reproductive labor. Women in West Virginia have been 'adjusting' to economic restructuring for some time now and working out their 'places' and strategies within the global capitalist economy. Thus, women in rural South Africa, especially the former bantustans, who have recently begun to experience local and global economic change as a result of both socioeconomic and political transformation within the country can learn from women's experiences in West Virginia and other rural parts of Appalachia. For example, what could women's unionization and labor activism around wages, benefits, and work supports, which was not embraced by women in 
Appalachia, do for women in South Africa as they become further integrated in the South African economy?

Despite the profound challenges women face concerning formal employment in both Limpopo and West Virginia, formal strategies here are considered growth strategies because they have the most potential for expanding women's access to cash resources and much needed retirement and health benefits which will ensure the future and sustainability of their households. As indicated above, their growth and development is dependent on many social, economic, and political factors, however, women in the two regions are resourceful and innovative and will be constantly working against the forces that marginalize them and for the necessary resources that can improve their access to sustainable employment.

\section{Informal Strategies}

Informal strategies, the second type of livelihood strategy identified in this study, include women's participation in community economic groups, the informal selling and/or trading of goods, subsistence activities, and the use and sale of natural resources. While not significant in West Virginia, informal strategies in South Africa represent important components of women's livelihoods. The Central Statistical Service (1995) concluded that $75 \%$ of Africans employed in the informal sector are women. Community groups, in which many women in this study participate in, are considered informal because of the lack of regulation involved in their start-up and operation.

The types of community economic groups highlighted in this study (Table 3) involve collective activities that help to support households and communities in the context of high unemployment and lack of resources stemming from the legacy of colonialism, apartheid, and 
contemporary neo-liberal policies. Community-based groups challenge these barriers through the sharing resources, exchanging skills, and selling or bartering goods to other local people. This research shows how these groups contribute to household livelihood strategies by not only providing economic opportunities, but also by allowing women to balance other demands in their lives through flexible work schedules and the sharing and exchange of duties among members. Despite low earnings, these groups are also building local capital and resources for reinvestment while seeking to create links with other regional businesses and communities. In addition, these activities represent important forms of grassroots economic activities that are being developed by and for women. Through these collective, community activities, women are therefore developing a sense of ownership with respect to their own communities and playing a role in local economic development by stimulating employment and economic opportunities for themselves and other women (see also Oberhauser and Pratt, 2004). Thus, while defined as informal strategies in this typology, community economic groups in Limpopo can also be considered a form of co-strategizing among women designed to help them cope with poverty and confront multiple forms of social and economic oppression.

In this research, several of the community economic groups reported on the role of local structures, such as the chieftaincy and local civic organizations, in developing their projects. Members indicated that many chiefs and other local community leaders and groups encouraged the development of their economic projects through community meetings, the provision of land and access to needed natural resources, funding assistance, and partnerships with extension and provincial government. However, these local, patriarchal structures are embedded in hierarchical institutions and power relations that have historically marginalized and oppressed rural, Black women. One cannot ignore the gendered nature of the work women engage in, including 
agricultural work and food production and artisan, sewing, and craft activities, and the fact that this work operates within the confines of their own communities and homes. As indicated in the previous chapter, the flexibility of this work and the location of the groups within women's own communities allow them to maintain their reproductive duties while earning some cash income, however, it also sustains the gendered nature of women's work in the country. In South Africa, the Central Statistical Service (1995) found that eight in every ten females (82 percent) in the informal sector were in low-paid, elementary occupations. In contrast, males are found in diverse, higher paid, and more skilled types of informal occupations such as construction, housepainting, and woodworking.

Overall, the community groups investigated here are not providing women with access to educational and training opportunities of financial benefits that will grow their current businesses or allow to them acquire a sustainable job elsewhere. The local chief who was interviewed offered very limited ideas on integrating women into his development efforts, simply stating that “women lack skills" (Individual Interview, July 24, 2001). He said he will develop closed corporations for women to do cleaning and laundry services.

Despite the importance of women working together, learning skills, and establishing their own economic activities, the sustainability and long-term benefits of these types of activities is consequently in question. Both the material and non-material benefits of these types of groups concerning the social, economic, and political development of rural communities and empowerment of rural, Black women must be considered at all levels of society and the economy. As also indicated by the work of Oberhauser and Pratt (2004), the success of these groups is mediated by shifting axes of power and social relations in this region which determine access to much needed resources, such as land and other natural resources, credit and educational 
and training opportunities, and certain types of jobs as well as the provision and improvement of infrastructure and people's basic needs. As indicated by this discussion, there are as many challenges as benefits to women participating in these types of community strategies. Targeted development strategies that recognize and meet the needs of women-owned and operated businesses could shift the balance and reduce the obstacles of these groups and transform them into growth strategies for women and local, rural development. Supportive programs and policies that are sensitive to women's goals and productive and reproductive roles and duties within rural economies in the former bantustans could transform some of these community groups into profitable businesses that provide women with stable incomes and business ownership opportunities.

Concerning other informal strategies, such as the informal selling and/or trading or goods, subsistence activities, and the use and sale of natural resources, it can be said that while not easily measured or quantified, they provide women heading households in both Limpopo and West Virginia with basic living requirements that are necessary to sustain a household. These informal strategies are needs-based and provide women with land to grow food for their own consumption or sale, gather firewood, and/or graze and keep animals; other resources such as water, natural gas for heat and sale, and hay or timber for barter or sale; and access to some cash income. Access to these informal strategies is oftentimes determined by very local kin, tribal, or community relations and transactions. They are essential to the reproduction of households in rural communities throughout Limpopo and West Virginia and represent important components of women's livelihoods in this study (see also Francis, 2000 and Halperin, 1990; Pudup 1990a and b; Oberhauser 1995a and b). 
With respect to informal strategies, what could women in West Virginia, for example, learn about collective community ventures as alternative rural economic development strategies from women in Limpopo? What are the differences and similarities in the local economies and social relations of these two areas that could either facilitate or impede the adoption of these types of strategies in West Virginia? Collective ventures, in the form of co-operatives and marketing and training networks, are utilized in parts of Appalachia (see the work by Oberhauser, Pratt, and Turnage, 2001; Oberhauser and Turnage, 1999; Oberhauser, 1995a and b; 1993). What are the differences between these types of strategies in West Virginia and community economic groups in Limpopo concerning their development, operation, and contributions to rural households and economies? How could women in West Virginia and Limpopo in this study, who have access to and are benefiting from the use and bartering and selling of natural resources communicate with each other both within and between the two case study areas? The possibilities for exchange abound and could be informative discussions concerning the improvement of women's access to informal, yet essential, livelihood strategies and resources.

\section{Government Assistance}

Government assistance represents the third category in this typology of women's livelihood strategies in Limpopo and West Virginia. The ability to access transfer payments and other government-sponsored programs is intimately linked to all of the other livelihood strategies identified in this analysis as well as household structure, literacy and knowledge of available programs, and time and the availability of transportation. Eligibility for benefits is needs-based and dependent on income and assets owned, including land, automobiles, and savings. Some of 
the "catch 22s" of eligibility, such as female heads of households in West Virginia not qualifying for food stamps when doubling-up with family because of the total household income, was highlighted in the previous chapter. Recipients of government assistance include vulnerable groups who are unable to provide for their own minimum needs such as the disabled, the elderly, and young children in poor households.

Social assistance, in the form of Old-Age Pension and Child Support grants, is the most regular and consistent source of cash income for most of the women interviewed in South Africa. Consistent with the findings of Francis (2000) concerning rural livelihoods and the impact of particularly pension grants in South Africa, combining grants with work in the formal and/or informal economy, subsistence activities, and family and community assistance increases the security of many households by providing them with much-needed cash resources that may otherwise be unavailable (Table 2). Income from these grants allows households to purchase food items, make utility payments, and pays school fees and oftentimes facilitates the development of or participation in community economic groups, where earnings are oftentimes low and unstable and a small investment must be made. Pension points, where payments are made to recipients, are also local markets for the community groups, business owners, and informal traders in rural areas.

Without access to both Old-Age Pension and Child Support Grants, the female-headed households in this study, as well as the rural population of South Africa in the former bantustans in general, could not survive. The Social Development Minister, Zola Skweyiya says, "the provision of social grants is the government's most effective programme to address the income poverty of our people (SouthAfrica.inforeporter, July 19, 2005: www.safrica.info). Annual expenditure on social grants increased 3.5 times in the 10 years between 1994 and 2004, from 
R10-billion to R34.8-billion. During the same period, the number of South Africans receiving social grants increased from 2.6 million to over seven million (SouthAfrica.inforeporter, July 19, 2005: www.safrica.info). This number is now over nine million, with a budget of over R55million for the 2005-06 financial year with the child support, care dependency, and foster care grants contributing to this increase. In fact, the South African government is progressively extending the child support grant to cover children up to the age of 14 by 2005-06. Benefit amounts for all grants are also increasing and the government is working on the implementation of a comprehensive social security system.

Poverty in rural parts of the country is profound and related to the failure and absence of rural economic development and process of land reform in the rural periphery; high rates of unemployment; and death, the issue of orphans, and the increasingly changing household structure of the country due to HIV/AIDS. Currently, social assistance grants are providing the cash resources that people need to meet their basic requirements for survival and are one of the main poverty alleviation programs in the country. The sustainability of social programs as a poverty alleviation tool is questionable and in his 2004 State of the Nation address, President Thabo Mbeki stated that while the government would continue to build a social security net to alleviate poverty, a society that is dependent on social welfare cannot sustain itself. Mbeki said:

Our comprehensive programme to grow the economy, including interventions in both the first and second economies, improving sustainable livelihoods, and creating work, is meant to ensure that, over time, a smaller proportion of society, in particular the most vulnerable, subsists solely on social grants (SouthAfrica.inforeporter, July 19, 2005: www.safrica.info).

While access to various forms of government assistance is increasing in South Africa, it is and has been on the decline in West Virginia and the United States in general due to welfare 
reform at both the national and state levels. Designed to "end welfare as we know it"100, the sixyear, $\$ 110$ billion Personal Responsibility and Work Opportunity Act of 1996 began the process of welfare reform in the United States. This federal law emphasized the work attachment strategy and contained numerous provisions, including a new 60 -month maximum limit on the receipt of benefits and the imposition of mandatory state work participation rates and fiscal sanctions for noncompliance that, collectively, were designed to force recipients and state welfare bureaucracies to "change their ways" (Dilger, 2004). Importantly, the law also "delinked" cash assistance from Medicaid. The result was a dramatic decline in welfare caseloads nationwide and in West Virginia.

Nationally, TANF enrollment fell from 11.4 million in January 1997 to 9.1 million in January 1998. Enrollment continued to decline, falling to 7.4 million in January 1999 and 6.2 million in January 2000 (Dilger, 2004). The reductions were even more dramatic in West Virginia. In January 1997, there were 98,690 West Virginians on welfare. By January 1998, that number had been cut almost in half, to 51,348. A year later, the figure was 32,161 , and by January 2000, there were 28,850 West Virginians receiving cash assistance (DHHS, 2000). It should be mentioned that government programs, such as HUD, WIC, SSI, and SSDI, have not been affected by welfare reform legislation.

Since the welfare reform law's enactment, West Virginia's caseload has dropped 64 percent (Blakely, Dilger, and Locke, 2004; WVDHHR, 2002 and 2001) however the efficacy of associated programs in addressing poverty and reducing welfare dependency is debatable. It is true that the percentage of WV WORKS ${ }^{101}$ recipients engaged in a work related activity has increased. In addition, cash payments to recipients and funding for childcare and other support

\footnotetext{
${ }^{100}$ Quote from President Bill Clinton's 1992 presidential campaign.

${ }^{101}$ WV WORKS is West Virginia's TANF program.
} 
services, such as job training and educational programs and other resources that enable participation in approved work-related activities ${ }^{102}$, have also increased. Nonetheless, studies have shown that nearly half of those who have left WV WORKS are not working and nearly all of those who left are still living in poverty (Dilger et al. 2004 and 2000). Also, although the percentage of WV WORKS recipients engaged in a work-related activity increased to record levels, West Virginia's work participation rate of 17 percent in fiscal year 2000 was the lowest in the nation (DHHS, 2002). These findings relate to the findings of this research and the work of Brown and Lichter (2004) that point to the marginal financial benefits of employment for women heading households in rural areas of West Virginia and the United States and has important implications for "work first" welfare programs that aim to move poor single mothers into the labor force.

Women heading households in West Virginia who were interviewed for this study utilize various forms of government assistance to supplement their household incomes and need for basic household items such as food, clothing, and housing. Programs utilized by women in this sample include the Food Stamp Program, TANF, and WIC for food and cash assistance; Medicaid and WVCHIP for health care; HUD for housing; Choices and Mountain Heart for assistance with childcare; and clothing vouchers, as well as SSI and SSDI. These programs supplement the low wages and lack of benefits provided by women's work in the formal sector. They also provide women with work supports, such as childcare, and assist them while they obtain job training or attend college. In fact, many of the women in this study would find it difficult to engage in paid employment if they did not have access to childcare support through the state or to health benefits for their children. Government programs also aid those women

\footnotetext{
${ }^{102}$ Resources such a these may include assistance with incidental expenses such as clothing, tools, driver's licenses, relocation expenses, transportation, and vehicle repair and/or insurance that assist clients with accessing work.
} 
who are disabled and those who receive no child support from the father's of their children. The women in this study utilize government assistance as a temporary strategy and none of them, except those who are disabled, are or had been 'living off' the system. Brown and Lichter (2004) interestingly found that non-metro single mothers are, in fact, less likely to receive cash assistance that their metro counterparts in the United States and that welfare is less likely to provide an economic safety net for non-metro single mothers.

Unlike the women interviewed in South Africa, the women who participated in this study in West Virginia were quite knowledgeable about government assistance programs available to them. They often exchanged information with other women heading households about available programs, eligibility requirements, and benefits and had access to county DHHR offices, the West Virginia DHHR website, and program literature. Many women also reported getting information about certain programs, such as WVCHIPS, through the public schools. Informal exchange networks that are used by women in West Virginia could benefit the spread of knowledge about available programs among women in rural parts of South Africa, especially since many of them face transportation and literacy issues. The use of social service field workers who hold community meetings and provide application assistance in rural parts of South Africa could also help spread the word about social assistance programs in the country. Local schools in rural parts of the country could also be utilized to disseminate information about social assistance programs to rural populations.

It should be mentioned that a number of women in West Virginia had utilized government assistance to escape abusive situations. In fact, six out of the eighteen women interviewed, which is third of the sample, had been or were currently in emotionally and/or physically abusive situations. Various forms of domestic abuse are also prevalent in South 
Africa and access to social assistance could help many women in desperate situations. For example, when the women in the focus group at Baobob Kiosk were asked about the issue of HIV/AIDS and how they protect themselves from husbands who have other sexual partners and may have or be susceptible to the disease, one women stated: “...if I refuse my husband or ask him to wear a condom, he will assume I am cheating on him and beat me and give me no money to buy food for my children. What am I to do? I cannot refuse...(Focus Group Interview, July 17, 2001). This quote illustrates the complexity of gender relations and how they determine women's social and economic status, mental and physical health, self-esteem and self-efficacy both within households and society.

Gender relations are material, social, ideological, and moral. They knit together divisions of labor, sexuality and affection, ideas about rights and responsibilities, and ideologies about what men and women are and how they should treat one another. Gender relations in Limpopo and West Virginia are shaped by local culture and religion as well as state and market institutions and they determine men's and women's access to and control over resources and decisionmaking at all levels of society. Gender relations thus contribute to the construction of women's livelihoods and their abilities to protect themselves and their children in the two case study areas.

As indicated throughout Chapters III, IV, and VI, women in both case study areas have been marginalized and oppressed socioeconomically and politically by the gendered nature of capitalist, colonial, and patriarchal processes. Women in both places also oftentimes lack control over their own bodies and are forced to compromise the ir own emotional and physical well-being to provide for their children. Gender relations are powerful and patriarchy is deeply entrenched in both areas and few supportive services that offer women alternative living situations and the means to become financially independent in order to escape the control of an abusive partner 
exist. Social assistance programs and the financial support they provide is one important avenue out for women who are in abusive situations and important components of the livelihoods of women heading households.

Government assistance programs, including those that provide cash assistance, food, housing, clothing, and healthcare, are needs-based strategies that meet basic living requirements. However, programs, in the form of childcare and educational and training assistance and work support that have been developed through welfare reform in the United States, are considered growth strategies because they assist people in accessing formal strategies. Adopting growthoriented, social service programs by South Africa's newly developed social service department in conjunction with those needs-based strategies that provide cash assistance and healthcare could facilitate more comprehensive human and economic development in the rural periphery.

\section{Family and Community-based Strategies}

Family and community-based strategies are the fourth category of livelihood strategies identified in this analysis. Strong kin ties bind extended families in both case study areas and family members oftentimes socially and economically support one another through the provision of basic needs, financial resources, housing, and emotional and physical care. Historically, extended families in South Africa have been important components in sustaining rural households, communities, and economies. For example, the wife of a son will oftentimes come to live with the son's family to help care for the household and elders; children are responsible for their parents as they age; the labor of women and children sustains agriculture in rural areas that feeds families and communities; extended family members double-up or take in orphaned children and elders to prevent homelessness and provide needed care; and pension grant funds from elder family members often sustain households financially. 
Extended families are also important societal and economic components of rural communities in West Virginia. Historically, the household was the central productive unit in the mountain state and the labor of men, women, and children, and oftentimes extended kin and community members, sustained families and communities. As discussed in Chapter IV, industrialization and modernization disrupted the social and economic structure of mountain life but kin ties remain strong in the region

Women in this study reported on the financial and emotional support they get from their families. Women heading households in the two case study areas reported on utilizing family resources for childcare provision, housing through doubling-up strategies, cash assistance for food and utility bills, access to transportation, and other needed resources. In the absence of a partner to assist them with their childrearing responsibilities, many of them also commented on the importance of the emotional support they receive from their parents, siblings, and other extended family members. These less tangible aspects of women's livelihoods in rural communities are oftentimes overlooked in analyses that investigate women's social and economic well-being and abilities to 'make due'. However, these elements are essential in women's abilities to engage in paid employment, access training and educational opportunities, and maintain an adequate and nurturing home environment for their children. While family assistance strategies are characterized as needs-based in this analysis, they do lay a foundation for growth, particularly when women are accessing training and educational opportunities with the help of these resources.

While households and family units can be a source of great support, both financially and emotionally, for women heading households, they can also be a site of contention and struggle. As highlighted previously, many of the women interviewed have been subject to various forms 
of abuse and control within their households. In the context of investigating livelihoods and women's social and economic roles, power relations within households should always be carefully considered. Gender relations may vary greatly between households within a single locality and households with different bases of livelihood strategies oftentimes show different kinds of relations between men and women.

Changing opportunities for constructing a livelihood that come from socioeconomic and political change, including both economic and political restructuring, may alter the terms on which men and women attempt to get access to land, labor, and cash income, shifting household relations between interdependence and dependence. This is clearly the case in many rural communities in both Limpopo and West Virginia where you have many women heading households as a result of declining employment opportunities for men in the local economies. Importantly, it should also be mentioned that access to cash resources does not always translate into bargaining power within households. Women may generate most of the income within a household but have little control or power over those resources. Socioeconomic and political changes may also result in profound social changes by, for example, encouraging households to fragment or reconfigure around relationships other than marriage. As indicated in Chapter VI, we have seen a rise in co-habitating in West Virginia and the United States in general as a context for both childbearing and childrearing and an adaptation to economic hardship (see the work of Acs and Nelson, 2002 and Bumpass and Lu, 2000).

Community assistance, in the form of charitable and religious organizations, non-profits and non-government agencies, and other civic groups, is also important to the livelihoods of women heading households in the two regions. The resources community assistance strategies provide are diverse in the two regions and include: the provision of basic needs such as food, 
clothing, and shelter; infrastructure development and assistance with utility payments; and job training, educational assistance, and business development funds. Some of this assistance is means-tested while other forms require no information concerning income, property, or household status.

Because of the local histories of the two case study areas concerning the oppression and marginalization of rural people, benevolent organizations have a long history in attempting to address poverty and underdevelopment issues within rural communities. New, more comprehensive forms of community assistance are emerging and their connections to government assistance programs, rural livelihoods, and broader economic change deserve greater attention. Community assistance programs and organizations in the two regions are providing people with access to not only needs-based strategies, but also growth strategies. For example, in South Africa we see the chieftancies and local civic organizations working with women to develop community economic groups through the provision of land and access to community natural resources; by establishing connections between women's groups and extension agents who have knowledge about rural development; and by facilitating access to funding and training opportunities. In West Virginia, we see community non-profit, charitable, and religious-based organizations picking up where government assistance programs are dropping off in the provision of basic needs as well as more comprehensive services and human development efforts. Community organizations are playing a key role in the development of growth strategies in rural communities by assisting people with housing issues, work supports, and literacy, job training, and educational programs. People who cannot receive help through the WVDHHR are oftentimes directly referred to local organizations that might be of assistance. 
Questions concerning the current and future role community assistance strategies are important in the context of women's livelihoods as well as rural development in general in the two regions. Are local community and civic organizations playing a major role in rural economic development in the former bantustans because of the failures of development policy in the country or are we seeing more activity because they are finally empowered enough by the new government to become active and have a role in the economic future of their communities? What are the benefits and drawbacks between government assistance and various forms of community assistance in working for poverty alleviation and community development? How can women more actively engage with and benefit from community assistance strategies? Are these community assistance strategies too entrenched with local, patriarchal power relations and thus not transformative enough to provide women with sustainable livelihood options and strategies? Is local social and economic development that comes from community organizations sustainable in the two regions?

\section{Co-strategizing}

The fifth and final category of livelihood strategies identified in this typology is costrategizing. This strategy is the planning and coordination between female heads of households that enable them to meet both productive and reproductive responsibilities. This livelihood activity was not an anticipated finding of the research but one that was identified through detailed discussions with the respondents, particularly in West Virginia. Co-strategizing is an intricate part of the other livelihood strategies identified in this analysis and represents important practical and strategic elements of the livelihoods of women heading households in the two case study areas. 
For example, many of the community economic groups in Limpopo began by women getting together to 'co-strategize' about their need to access cash resources. This co-strategizing led to the development of community groups that allow women to earn money while maintaining their household duties, thus contributing to grassroots forms of economic development in rural communities. In West Virginia, the research illustrated how women, such as Margie and Wanda, 'co-strategized' to meet both their formal employment and childcare needs. When Margie's husband passed away she needed help with the household duties and childcare. Wanda, needed a flexible job where she could earn money and avoid childcare costs. Through co-strategizing, Margie and Wanda have become intricate parts of each other's livelihoods.

Other elements of co-strategizing between women heading households in the two regions can be seen in the sharing of household duties and subsistence activities, such as gardening and collecting firewood and water, particularly in Limpopo, and the sharing of childcare duties. These exchanges are often between female heads of households that are 'doubling-up' or living near to one another. As mentioned in the previous chapter, Ronnie and her sister, Denise, costrategize around their childcare needs. This strategy, in turn, enables Denise to have control over her cash resources and circumvent conflict over money with her abusive partner. Renee costrategizes with a co-worker, who is also heading the household, to arrange after-school care for their middle-school aged children.

Co-strategizing, as a livelihood strategy, thus allows women heading households to access various financial, human, and physical capital resources and can be considered both a needs-based and growth strategy because it enables women to meet basic household living requirements and their responsibilities within the formal economy. This strategy also often facilitates the exchange of information, empowerment, and independence of many women 
heading households. Co-strategizing represents a very local, grassroots form of organizing around women's multiple roles and responsibilities and illustrates the possibilities for cooperation and exchange, at a broader level, around women's common needs.

This very interesting finding of this research therefore raises numerous questions about how to further investigate and build upon this livelihood strategy among women. For example, how can comparative feminist research on women's livelihoods better understand and enhance co-strategizing among women? How can the forms that co-strategizing is taking in other parts of the world and around other women's issues and needs be researched further? How can the benefits of co-strategizing to women and their livelihoods be measured? How can costrategizing at very local levels be translated into women's organizing strategies at the regional and global scales?

While facilitating the synthesis and comparison of the data gathered through this research on women's livelihood strategies, this typology consequently raises many questions and illustrates the need for further research on the diverse and innovative strategies women in rural parts of Limpopo and West Virginia adopt to construct a livelihood. The typology highlights specific characteristics of women's livelihoods in the two regions and the various factors that affect their adoption, operation, and material and non-material benefits and drawbacks. It also illustrates the complex negotiation of the formal and informal economies, state programs, and community and family resources, involved in the construction of women's livelihoods in rural areas. It also demonstrates the importance of a livelihoods approach in conceptualizing the multiple economic strategies that support rural households and the various factors that either enable or restrict women's access to various forms of employment and productive and reproductive resources. Finally, it also disturbingly reveals that while women are creative in the 
construction of their livelihood strategies, these strategies, even in combination, are not enough to adequately support rural households. Women, despite their best efforts, are struggling to 'make due' in the two case study areas.

\section{Topographical Models, Contour Lines, and Countertopographies}

Chapters III and IV provided the background information on the gendered, socioeconomic histories and geographies of the two case study areas and Chapter VI presented the detailed research on the development, organization, and types of livelihood strategies utilized by women heading households in Limpopo, South Africa and West Virginia, Appalachia. This information thus constructed typographies of women's livelihoods in the two regions that communicate the historical and contemporary forces and players that affect how women gain access to and engage in certain economic spaces and scales, social, economic, and political resources, and ultimately, certain livelihood strategies. Because of the conceptual and methodological frameworks developed for this work, which include both feminist and geographical perspectives, it is understood that the forces and players that either impede or empower women and their abilities to acquire sustainable livelihoods exist at all levels of society. Thus, constructing feminist topographies allows us to develop a topographical model (Figure 1) for illustrating the complex system of interrelated forces that affect the livelihoods of women in Limpopo and West Virginia.

The topographical model (Figure 1) developed here is a conceptual framing of the multiple and binding socioeconomic structures and relations that occur at various scales of analysis and affect women's livelihood strategies in the two regions. In Limpopo, South Africa, it can been seen that broad socioeconomic structures, such as colonialism, in the form or apartheid, and capitalism and patriarchy, have contributed to Black women's economic marginalization by maintaining 'traditional' and conventional understandings of gender through 
racist and sexist policies and exploiting women's productive and reproductive labor. Global political and economic arrangements that are associated with the spread of global capitalism and South Africa's desire to be more fully integrated into world politics and the global economy, are also transforming the economy and society in the country under the new democratic government. All of these global and national structures and processes thus affect women's livelihoods.

In West Virginia, Appalachia, imperialist practices such as the historical outside ownership and control of land and resources in the state, little reinvestment, and the marginalization and oppression of the rural population created underdevelopment in many parts of the state leaving women, in particular, without access to sustainable forms of employment. Combine these marginalizing forces with a patriarchal ordering of society and the result is the marginalization and undervaluing of women's labor both within and outside the home. More contemporary processes, including economic restructuring and the globalization of capital, have resulted in a large service sector economy that takes advantage of the labor history of women and their marginal socioeconomic status in the state. This 'new' economy in West Virginia provides economic opportunity for women however; many of the jobs women have access to do not provide adequate financial support or benefits to support their households. All of these socioeconomic processes affect women and their abilities to construct a livelihood in West Virginia.

These broad structures also relate to, strengthe n, and often depend upon other elements, including gender, race, and class processes, divisions of labor, state ideologies and institutions, and the structure of local economies. These more localized forces are operationalized by particular gendered and racialized socioeconomic and political policies, such as the migrant labor system in South Africa or welfare reform in West Virginia and local, regional, and state 
development policies, for example. They are reinforced by, for example, capitalist relations of production and reproduction and dichotomous notions of women and men and home and work embedded within these policies as well as broader capitalist, colonial, and patriarchal structures. Also included in this complex system, are household and community relations and culture and religion that affect gender relations at very local levels. These relations are affected by local institutions such as the chieftaincies, the family, churches, and civic groups that dictate control over local resources. These structures and processes are mutually constitutive of one another and also in tension. There is no balance to this system and the global, regional, and local are in a constant state of working with and against each other.

The topographical model presented here acknowledges that the power to exclude or empower women socially, economically, and politically is constituted through various institutions, people, and policies that function at various scales of analysis. As facilitated by the construction of topographical analysis, this "interrelational" framework emphasizes the complexity of socioeconomic relations by utilizing a multi-scale approach. This multi-scale approach facilitates an understanding of how broad socioeconomic and political structures work with very local spatial and place-based factors to impact women's material realities, such as their livelihoods, in both different and similar ways in diverse local contexts. This model builds upon the geographical work on scale and topographical analysis outlined in Chapter II that maintains that scale should be seen as a relational element in a complex mix that also includes space, place, and environment and culture, history, economy, and geopolitics in the making of the geographies within which we live (Katz, 2001a and b; Howitt, 1998). 


\section{Figure 1: A Topographical Model}

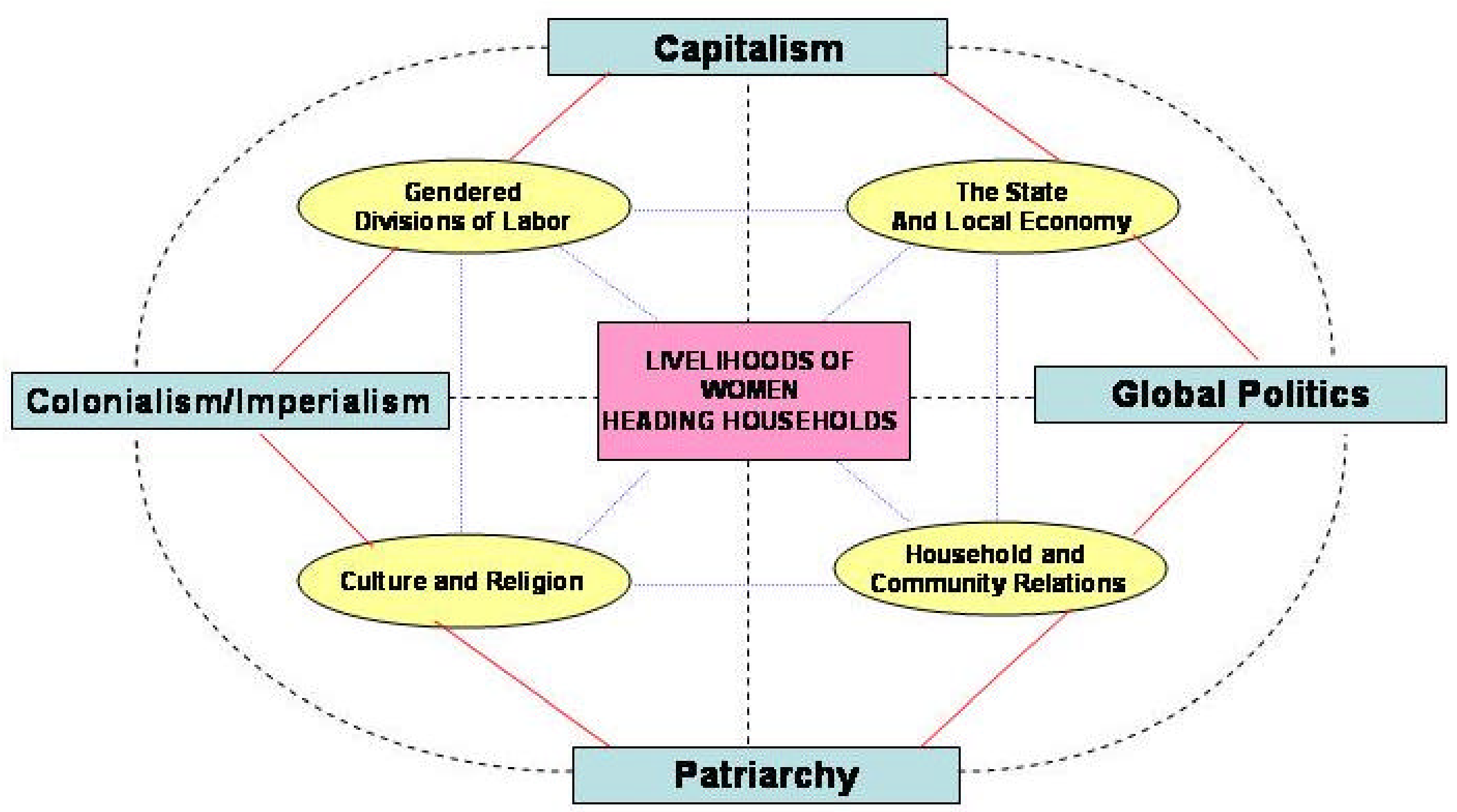

Represent socioeconomic structures that operate at the global and national scales.

Represent associated processes that operate at national, regional, community and individual scales. 
Topographical analysis and modeling, because they investigate social and spatial relationships and the workings of scale, facilitate the drawing of contour lines and construction of countertopographies between Limpopo and West Virginia. As defined in Chapter II, contour lines and countertopographies analytically connect places, typically thought of as discrete, in relation to a particular process and are designed to enhance both local and global struggles in the name of common interests. Thus, the contour line can link underdeveloped places, such as the former bantustan area of Limpopo and rural parts of West Virginia that have been made by similar histories and policies of exclusion and marginalization. They can connect women within these areas based on the material effects of underdevelopment that contribute to their abilities to acquire sustainable livelihoods including occupational segregation, low wages, and lack of education and skills, for example.

Other contour lines can be drawn between women in Limpopo and South Africa around the contemporary issue of economic restructuring and how it is changing relations of production in the two case study areas. West Virginia women have been subject to the disarticulations of global capitalism and a 'restructuring' economy for quite some time with the decline of maledominated mining and manufacturing industries in the state and rise of the service sector. Women live within a constrained rural economy that is struggling to fit into the global economy and with their history of marginalized and undervalued labor, have become the workers that are sustaining this new economy and households in the area. Their employment opportunities within this economy offer low wages and few benefits and work supports and social development policy, which has been reformed and cut back, does not make up for the poor incomes and few benefits these jobs provide. 
As South Africa further restructures, both politically and economically, women in rural places such as Limpopo can connect to women in West Virginia the contour line and learn from their experiences within economic restructuring. With different priorities and policies at all levels of society, women in South Africa could avoid becoming a reconstituted source of cheap labor as the country seeks further integration into the global economy and political environment. They can lobby for progressive social development policies that invest into human development as well as economic deve lopment to address the history of underdevelopment concerning not only place, but also people in the former bantustans.

Contour lines could also be drawn between the two case study areas on the issue of social reproduction. Social reproduction is in a constant state of flux within these two places and has been transformed by social and economic histories of resource extraction and industrialization and more recently, economic restructuring and changing community and family structures in rural West Virginia and colonialism and apartheid, democratic transition, and the effects of HIV/AIDS in the former bantustans of South Africa. It relates to underdevelopment and economic restructuring issues and women's roles in production. Rural women are and always have been working with and against these forces to support their families but the new common and differing forms these are taking, such as the livelihoods strategies discussed in this work, can be illustrated through the drawing of contour lines around issues of social reproduction.

In relation to women heading households and their common issues within processes of underdevelopment, economic restructuring, and social reproduction, this work imagines the development of countertopographies around how women's livelihood strategies at very local levels in two different locales are affected by a common set of processes. Through countertopographies on women's livelihoods, alternative representations of the economy, 
including community economic groups, informal activities, co-habitation and doubling-up, costrategizing, and family and community support, are revealed. These very local strategies challenge the hegemony of global capitalism, patriarchal relations, and economic marginalization at all scales. Countertopographies therefore have powerful implications for strengthening the viability of non-capitalist strategies in the construction of livelihoods among women heading households in rural parts of the world.

\section{Summary}

This chapter has further developed this project's analysis of the livelihoods of women heading households in Limpopo, South Africa and West Virginia, Appalachia by building a typology of women's livelihood strategies and comparing them across the two case study regions. This typology illustrates some of the common issues and concerns faced by women heading households in the two places and highlights areas where information and strategies could be exchanged. Constructing topographies of women's livelihoods in the two places through both historical and contemporary analyses and fieldwork and then building a typology of these strategies facilitates the development of a topographical model that illustrates the various socioeconomic, political, and cultural factors that affect the construction of wo men's livelihoods. These analytical exercises also contribute to the drawing of contour lines between the two places and the development of countertopographies. This work contributes to both the conceptual and methodological advancement of comparative feminist research both within feminist geography, specifically, and feminist research, more broadly. It also provides various paths for feminist strategizing and action, at a global level, around women's livelihood issues. 
In conclusion, women in the two regions face many barriers in the construction of a livelihood that can adequately support themselves and their families and these barriers are related to the socioeconomic histories of the two regions, local gender relations and women's social and economic status and roles, rurality issues, and contemporary global economic change. As demonstrated over and over again by the very personal stories and innovative combinations and utilization of the livelihood strategies identified through the fieldwork however, women are resourceful and working hard everyday to 'make due'. They are empowering themselves, establishing their independence, and working against those forces that attempt to "keep them down”. In their words, Helen, in Limpopo, and Debbie, in West Virginia respectively state:

The community project we have developed is important for women here. We can get skills, add to the family income, and support our families. We also learn to be independent and not depend on a husband anymore. We won't starve...(Individual Interview, July 16, 2001).

...its tough sometimes, but we get by...you might rob Peter to pay Paul sometimes, but you figure it out, I always do, I am very independent in that way. I say to myself all the time, "I can take care of these kids and this house, on my own" (Individual Interview, August 8, 2004). 


\section{Conclusion}

Women in rural parts of Appalachia and South Africa have always contributed to the well-being of households; however, women have been consistently marginalized in varying degrees from viable income-generating activities and productive and reproductive resources in both places. This work explores the marginalization women have confronted in West Virginia and Limpopo and the various global and local forces that have excluded them through a detailed examination of their contemporary livelihood strategies. Thus, the innovative ways Appalachian and South African women access resources they need and learn skills; find employment and create income-generating activities; and work together to construct a livelihood to support their families are revealed through this research

This research argues that the concept of a livelihood is a more adequate and holistic understanding of the diverse economic strategies women in rural Appalachia and South Africa piece together to 'make due' in a global economy and as heads of households. A livelihoods framework, as utilized in this research, includes an analysis of women's particular livelihood strategies as well as the socioeconomic, cultural, and political factors and institutions at various levels of analysis that impact upon them. Livelihoods include both capitalist and non-capitalist activities and the need to piece together a variety of income, subsistence, social welfare, and family- and community-based strategies to sustain a household has evolved out of contradictions within capitalism. These contradictions exist at the macro-level, including the spread of global capitalism and its associated processes, such as economic restructuring. They also exist at the local level and include both historical and contemporary factors, such as welfare reform, apartheid and underdevelopment, democratic transition, and changes in family structure, for example. As feminists, we know that it has always been difficult for women to meet the needs of 
a household through reliance on a single activity or income source; however, the new forms this is taking in rural parts of the world, such as Appalachia and South Africa, are revealed through studies such as this.

This research illustrates that the livelihood strategies of women heading households identified in this study are intimately connected to the development of Appalachia and the former bantustans in South Africa as distinct places; the socioeconomic histories of the regions, gender relations, and local culture; contemporary global and local social, economic, and political processes; and household structure and family and community relations. As identified through this research, women in the two areas utilize a number of livelihood strategies including formal employment, community economic groups, informal activities, government assistance, family and community support, and co-strategizing, for example. Multiple livelihood strategies are needed by female-headed households in these diverse, rural contexts due to lack of education and training, control over productive resources, and access to credit, land, and other employment opportunities, as well as geographic isolation and rurality issues, lack of infrastructure, strong patriarchal and class structures, and household reproductive activities.

This research conducts a comprehensive, in-depth analysis of the various livelihood strategies identified concerning their organization and location; material and non-material benefits and drawbacks; access to training and educational opportunities; and 'fit' with individual household situations. The data on women's livelihoods was collected through qualitative fieldwork including individual interviews, focus groups, and participant observation conducted in both Limpopo and West Virginia. Upon this analysis, a livelihood's typology is developed to assist in the comparison of women's livelihood strategies across the two case study area. This typology illustrates the similarities of and differences in women's strategies across 
place and is designed to encourage and facilitate further comparative research on women's livelihoods transnationally.

The comparative approach taken by this research is an interesting one and it has conceptual and methodological as well as practical goals for feminist research and women's organizing transnationally. Conceptually and methodologically this work was designed to build upon feminist topographical analysis, as developed by geographer Cindi Katz, and mobilize it as a framework for comparative research. It was also designed to build a feminist livelihoods framework that focused on gender in analyses of rural women's economic strategies. Finally, it was developed to forward on-going discussions (see Mohanty, 2004 and Gender, Place, and Culture, 2002) within feminism concerning the possibilities for women coming together across the divisions of place, identity, class, and race and illustrate the common set of processes women in diverse contexts are embedded in and their common and differing needs and strategies.

Findings from this research project thus contribute to the fields of feminist geography and women's studies with respect to feminist materialism, scale theory, and feminist politics and organizing both locally and transnationally. It forwards new theoretical ground and methodological tools, including feminist topographical analysis, to theorize and analyze the ‘connectedness' of places, processes, and women. Specifically, topographical analyses recognize that while the material ground of women's marginalization is local, the multiple processes that affect them are translocal and working at all scales. This project therefore emphasizes the interconnections between informal and formal livelihood strategies, household and community gender relations, and broader processes of restructuring and capitalist economic development in and between rural places concerning female-headed households and their livelihoods. Importantly, approaches such as this recognize contextual differences between 
places and women but also encourage connections based on a common set of processes, needs, and issues. This project demonstrates that strategizing for women and their economic empowerment must be locally sensitive but not abandon the possibilities for transnational organizing and action.

This project also contributes to livelihoods literature, especially with respect to women who are heading households in rural parts of the world. A feminist livelihood framework, as utilized in this project, illustrates how what women do to support households is affected by their access to various types of resources and how this access is shaped by the gendering of socioeconomic and political structures and processes. This framework accounts for the micro, mezzo, and macro scales in which these structures and processes occur and inter-relate. Along with feminist materialism and topographical analysis, this framework reveals the multiple and interrelated structures and processes, occurring at various scales of analysis, that affect women's abilities to engage in particular livelihood strategies and devise a sustainable livelihood that can support their households.

By utilizing a feminist livelihoods framework to examine the economic activities of women heading households, work such as this is able to illustrate women's multiple roles and duties in society and articulate the constraints, as well as opportunities, in all the spheres of women's lives that determine their livelihood options. It also reveals that for women heading households, constructing a livelihood is not simply about monetary support but also social reproduction Finally, and of much concern, it also reveals that despite their adoption of many diverse livelihood strategies, women heading households in Limpopo and West Virginia are barely 'getting by'. 
Livelihoods are complex and a livelihoods framework is vital to feminist work because it can capture the dynamic, historical, and relational processes that inform the intricate array of activities and social, economic, and natural resources that comprise women's ways of 'making due' in a contemporary world. A livelihoods framework demonstrates that women are active agents that develop their own unique strategies to deal with social and economic change and support their families on a day to day basis. In addition, this framework seeks to both analyze and overcome power differentials that exist within households and communities and between individuals, communities, non-governmental organizations, funding agencies, and the state that affect access to resources and authority. It also acknowledges that every woman is situated within a household, community, and region that have distinct livelihood options and constraints shaped by social, political, cultural, economic, and geographical forces that operate in both different and similar ways across places. Finally, a feminist livelihoods framework that is informed by geographical work also provides the means for linking macro-level processes to micro-level outcomes and responses which provides this research with a view into how women are coping with or adapting to both local and global socioeconomic processes. The strengths of this framework and its comprehensive approach to analyzing women's ways of supporting households can and should inform economic, social, and development policy and subsequently forward women's socioeconomic empowerment.

In terms of the prospects for a transnational feminist politics, this work contributes to ongoing feminist discussions about women's organizing globally. By constructing detailed topographies of women's livelihoods in Limpopo and West Virginia, comparing them, and then connecting common processes that affect them with contour lines, one can see how solidarity, as defined by Mohanty (2004), in terms of mutuality, accountability, and the recognition of 
common interests, could be developed among these diverse communities of women. Embedded in a common set of processes, they face common issues and utilize similar strategies and could come together on those issues and overcome the crisis within feminist organizing around identity-and place-based politics.

Given the important contributions this work makes with respect to feminist geographical work, gender and livelihoods, and transnational feminism, it also raises many questions and gives direction for future research. First, more research that involves a larger study sample than was possible here must be conducted on women's livelihood strategies in the two case study areas. More information on the types of livelihood strategies women heading households are adopting and how they are connected to household and community gender dynamics and broader socioeconomic and political factors must be a subject of research within geography, women's studies, and development studies. More research will shed light on the viability and long-term sustainability of women's contemporary livelihood strategies in West Virginia and Limpopo and the various forces that impact upon them.

Secondly, and considered a limitation of the study, more work must be done to understand the diverse meanings of 'head of household' in the two regions. This is a question about power and control as well as women's identities and roles within households and communities. Assessing the various definitions and conceptualizations of the term 'head of household' in Appalachia and South Africa involves talking to men as well as women and interrogating local gender relations as well as socioeconomic and political factors. It is a contentious term that will continue to be debated in gender work on the two regions.

Thirdly, a study that assesses the differences between rural and urban female-heads of households in the two regions would be an informative research project. Comparing female 
heads of households in rural and urban areas would shed light on how socio-spatial and demographic characteristics affect women's access to, adoption of, and success with certain livelihood strategies within the two regions. Do women in rural and urban areas of the two regions adopt different or similar livelihood strategies? Do they receive the same material and non- material benefits from the strategies they adopt? Do urban biases in social welfare and development policies privilege urban female-heads of households over rural female-heads of households? All of these questions could be addressed in a rural urban comparative study and the theoretical and methodological framework developed here could be utilized for the research project.

Fourth, from an economic and social policy perspective, what can be done to improve and further develop women's current livelihood strategies and create new, more sustainable ones? And, what, in a more comprehensive analysis, is the role of regional and national government as well as civil society in providing needed resources to rural families in the two case study areas? What types of economic and social development programs that could assist in the provision of women's basic household needs, such as housing, food, clothing, health care, and transportation, as well as educational, training, and credit opportunities and work supports, be developed? What institutions, government, family and community, or elements of civil society, should take the lead in the provision of these needs and how can better connections and links between these 'players' be developed to make assisting women heading households easier and more productive?

Fifth and in a broader sense, what are the livelihood strategies of women in other rural parts of the world and can the comparative approach utilized in this research, both theoretically and methodologically, be used to research and compare their livelihoods? How can a 
transnational research project on women's livelihoods, which is led by feminist researchers in geography, sociology, and development studies, be encouraged and facilitated? Could global, feminist research projects that partner academics with non-profit and grassroots research, activist, and development organizations offer new possibilities for and insight into a transnational feminist movement? What are the possibilities for a transnational feminist movement around issues such as women's employment, women's basic needs, and government assistance, for example? Is a transnational feminist movement even necessary?

These are all issues, questions, and debates for future feminist research projects that build upon the information gathered through this dissertation research. No matter what issue or question is embraced, feminists must be continually working to put women and their issues at the forefront of both global and local discussions concerning the economy, development, and social change. As feminist researchers, it is our responsibility to not only develop critical theorizations and methodological perspectives within feminist research but formulate ways for our research to reach out to women and inform and improve the realities of the ir everyday lives and ultimately, work for their socioeconomic and political empowerment. 


\section{Bibliography}

Acker, J., Barry, K., and Esseveld, J. 1991. "Objectivity and Truth: Problems in Doing Feminist Research." In M. M. Fonow and J. A. Cook, eds. Beyond Methodology-Feminist Scholarship as Lived Research. Bloomington and Indianapolis: Indiana University Press.

Acs, G. and Nelson, S. 2002. "What if Welfare Reform Led to a Rise in Co-habitation?" Presented at the Annual Meetings of the Association of Public Policy Analysis and Management, Dallas, TX, November 7-9.

Adepoju, A. and Oppong, C. eds. 1994. Gender, Work and Population in Sub-Saharan Africa. London: James Currey.

Ahrentzen, S. 1997. “The Meaning of Home Workplaces for Women.” In H. J. Nast, J. P. Jones, and S. M. Roberts, eds. Thresholds in Feminist Geography. Lanham: Rowman and Littlefield Publishers.

America’s Second Harvest. 2002. www.secondharvest.org.

American Federation of State, County, and Municipal Employees (AFSCME). 1984. The States, the People, and the Reagan Cuts: An Analysis of Social Spending Cuts. Washington, D. C.: AFSCME.

Amott, T. and Matthaei, J. 1984. "Comparable Worth, Incomparable Pay." Radical America 18(5): 25 .

Anderson, B. 1983. Imagined Communities: Reflections on the Origin and Spread of Nationalism. London: Verso.

Anglin, M. K. 1995. "Lives on the Margin: rediscovering the women of Antebellum Western North Carolina." In D. B. Billlings, M. B. Pudup, and A. Waller, eds. Appalachia in the Making: The Mountain South in the Nineteenth Century. Chapel Hill: University of North Carolina Press.

Anthias, F. and Yuval-Davis, N. 1983. "Contextualizing Feminism—Gender, Ethnic and Class Divisions." Feminist Review 15: 62.

Appalachian Land Ownership Task Study. 1980. An Examination of the Extent and Impact of Large-Scale Land Ownership in West Virginia, Vol. VII.

Appalachian Regional Commission (ARC). 2005. Economic Overview. Online Document: www.arc.gov

2005. Regional Data Results for Harrison, Marion,

Monongalia, Preston, and Taylor Counties. Online Documents: www.arc.gov. 
. 2005. Regional Data Results for Forsyth and

Lumpkin Counties. Online Documents: www.arc.gov.

2005. Strategic Plan, 2005-2010. Online

Document: www.arc.gov.

. 2004. Distressed Counties in the Appalachian

Region. Online Document: www.arc.gov.

. 2001. Regional Data Results Personal Income

Rates In Appalachia. Online Document: www.arc.gov.

. 2000. Regional Data Results for Barbour, Calhoun,

Webster, Mingo, and McDowell Counties. Online Documents: www.arc.gov.

. 2000. Regional Data Results Education-High

School and College Completion Rates in Appalachia. Online Document: www.arc.gov.

2000. Regional Data Results Poverty Rates In

Appalachia. Online Document: www.arc.gov.

2000. Unemployment Rates in Appalachia. Online

Document: www.arc.gov.

. 1985. Appalachia: Twenty Years of Progress.

Appalachia 18(3) (Special Issue).

Appiah, K. A. 1996. "Is the Post in Postmodernism the Post in Postcolonialism?" In P. Mongia, ed. Contemporary Postcolonial Theory: A Reader. London: Arnold.

Ardington, E. and Lund, F. 1994. "Pensions and development: the social security system as a complementary track to programmes of reconstruction and development." Mimeograph. Centre for social Development Studies: Durban.

Armstrong, A. W. 1935. "The Southern Mountaineers." Yale Review 24: 539-554.

Aspaas, H. R. 1998. "Heading Households and Heading Businesses: Rural Kenyan Women in the Informal Sector." Professional Geographer 50(2): 192-204.

Bailey, K. R. 1973. "A Judicious Mixture: Negroes and Immigrants in the West Virginia Mines, 1880-1917.” West Virginia History 34: 141-161.

Ball, R. 1968. "Poverty Case: the analgesic subculture of the southern Appalachians." American Sociological Review 33: 885-895. 
Bane, M. J. and Ellwood, D. T. 1986. "Slipping into and out of Poverty: The Dynamics of Spells." Journal of Human Resources 21: 1-23.

Barnett, C. 1999. "Deconstructing context: exposing Derrida." Transitions of the Institute of British Geographers 24: 277-293.

. 1997. "Sing along with the common people: Politics, postcolonialism, and other figures." Environment and Planning D: Society and Space 15 (2): 137.

Barney, S. 1995. Accepting the Findings of Medical Science: Gender, Class, and the Political Economy of Health Care in Central Appalachia, 1880-1935. Ph D Dissertation. West Virginia University.

Barrett, J. 1985. Vukhani Makhosikazi: South African Women Speak. London: Catholic Institute for International Relief.

Barrett. M. 1992. "Words and Things: Materialism and Method in Contemporary Feminist Analysis." In M. Barrett, M. and A. Phillips, eds. Destabilizing Theory Contemporary Feminist Debates. Stanford, California: Stanford University Press.

. 1980. Women's Oppression Today. London: Verso.

Barrett, M. and McIntosh, M. 1979. "Christine Delphy: towards a materialist feminism." Feminist Review 1: 66-82.

Beall, J. 2002. "Living in the present, investing in the future: household security among the urban poor." In C. Rakodi and T. Lloyd-Jones eds. Urban Livelihoods: a people-centered approach to reducing poverty. London: Earthscan Publications.

Beall, J. and Kanji, N. 1999. "Households, livelihoods and urban poverty." Presented at the Conference on Urban Governance, Partnership and Poverty, University of Birmingham, August (accessed at: www.livelihoods.org).

Beaver, P. 1986. Rural Community in the Appalachian South. Lexington: University Press of Kentucky.

Bebbington, A. 1999. "Capitals and capabilities: a framework for analyzing peasant viability, rural livelihoods and poverty." World Development 27: 2021-2044.

Beechy, V. 1979. “On patriarchy.” Feminist Review 3: 66-82.

Beinart, W. and Bundy, C. 1987. Hidden Struggles in Rural South Africa. Berkeley: University of California Press.

Beinart, W. 1994. Twentieth Century South Africa. New York and Oxford: Oxford University Press. 
Bell, D. and Valentine, G. eds. 1995. Mapping Desire: Geographies of Sexualities. London: Routledge.

Benston, M. 1969. “The political economy of women's liberation.” Monthly Review 4.

Benton, L. 1990. Invisible Factories: The Informal Economy and Industrial Development in Spain. Albany, NY: State University of New York Press.

Berger, J. 1974. The Look of Things. New York: Viking.

Bernstein, H. 1985. For Their Triumphs and For Their Tears: Women in Apartheid South Africa. London: International Defense and Aid Fund for Southern Africa.

Billings, D. B. 1974. "Culture and Poverty in Appalachia: a theoretical discussion and empirical analysis." Social Forces 53: 315-323.

Billings, D. B. and Blee, K. 2000. The Road to Poverty: The Making of Wealth and Hardship in Appalachia. Cambridge: Cambridge University Press.

Billings, D. B., Blee, K., and Swanson, L. 1986. "Culture, Family, and Community in Preindustrial Appalachia." Appalachian Journal 13: 154-170.

Billings, D. B., Pudup, M. B., and Waller, A. 1995. "Taking Exception with Exceptionalism: New Approaches to the Social History of Early Appalachia." In D. B. Billlings, M. B. Pudup, and A. Waller, eds. Appalachia in the Making: The Mountain South in the Nineteenth Century. Chapel Hill: University of North Carolina Press.

Bingen, J. 2000. Institutions and Sustainable Livelihoods. DFID Working Paper.

Blunt, A. and G. Rose. eds. 1994. Writing Women and Space Colonial and Postcolonial Geographies. New York: Guilford Press.

Bob, U. 2001. "The Intersection of Gender, Race, and Class: the Socio-Economic and Spatial Implications of Differentiation in the Former Homelands of South Africa." The South Africa Geographical Journal 83(3): 190-197.

1999. African Rural Women and Land Reform in South Africa: Case Studies from the Midlands Region of KwaZulu-Natal Province. PhD Dissertation. West Virginia University.

1997. "Gender Struggles and Social Differentiation." In R. Levin and D. Weiner, eds. No More Tears...Struggles for Land in Mpumalanga, South Africa. New Jersey: Africa World Press.

Bob. U., and Musyoki, A., 2002. "Gender Geography in South Africa: Facing Challenges and Exploring Opportunities." The South African Geographical Journal 84(1): 98-106.

Bondi, L. 1992. "Gender and Dichotomy." Progress in Human Geography 16: 98-104. 
22(2): 156-167.

1990. “Feminism, Postmodernism, and Geography: Space for women?" Antipode

Bordo, S. 1990. "Feminism, Postmodernism, and Gender Sceptism." In L. Nicholson, ed. Feminism/Postmodernism. New York and London: Routledge.

Bowlby, S. ed. 1984. "Women and the built environment". Built Environment, Special Issue.

Bowlby, S., Lewis, J., McDowell, L. and Foord, J. 1989. “The geography of gender." In R. Peet and N. Thrift, eds. New Models in Geography (Volume II). London: Unwin and Hyman.

Bozzoli, B. 1991. Women of Phokeng: Consciousness, Life Strategy, and Migrancy in South Africa, 1900-1980. New York: Heinemann.

Bradshaw, M. 1992. The Appalachian Regional Commission: Twenty-Five Years of Government Policy. Lexington: The University Press of Kentucky.

Brah, A. 1992. "Questions of difference and international feminism." In J. Aaron and S. Walby, eds. Out of the Margins: Women's Studies in the Nineties. London: Falmer.

Brandon, P. D. 2000. "Did the AFDC Program Succeed in Keeping Mothers and Young Children Living Together?" Social Science Review 74: 214-230.

Branscome, J. 1977. The Federal Government in Appalachia. New York: Feld Foundation.

Bray, H. 1975. “Appalachia: the View from Washington” Progressive 39: 31-34.

Brenner, N. 1997. "State territorial restructuring and the production of spatial scale: urban and regional planning in the Federal Republic of Germany, 1960-1990. Political Geography 16: 273.

Britt, R. D. 1971. “The Appalachian Regional Development Program.” Growth and Change 2(3): 3-13.

Brown, J. B., and Lichter, D. T. 2004. "Poverty, Welfare, and the Livelihood Strategies of Nonmetropolitan Single Mothers." Rural Sociology 69(2): 282-301.

Bryson, K. R. and Casper, L. M. 1999. Coresident Grandparents and Grandchildren. P23-198, U. S. Bureau of the Census. Washington, DC: Current Population Reports, Special Studies.

Bullock, S. 1994. Women and Work (United Nations Non-governmental Liaison Service). London: Zed Books.

Bumpass, L. L., Raley, K. R., and Sweet, J. A. 1995. “The Changing Character of Stepfamilies: Implications of Co-habitation and Nonmarital Childbearing." Demography 32: 425-436. 
Bumpass, L. L. and Lu, H. 2000. “Trends in Co-habitation and Implications for Children's Family Contexts in the United States." Population Studies 54: 29-41.

Burkett, G. L. 1994. "Status of Health in Appalachia." In R. Couto, N. K. Simpson, and G. Harris, eds. Sowing Seeds in the Mountians: Community-Based Coalitions For Cancer Prevention and Control. Washington, DC: The National Cancer Institute.

Cancian, F. 1995. "Participatory Research and Alternative Strategies for Activist Sociology." In H. Gottfried, ed. Feminism and Social Change: Bridging Theory and Practice. Urbana: University of Illinois Press.

Carney, D. ed. 1998. Sustainable Livelihoods: what contributions can we make? London: Department for International Development.

Central Statistical Service, South Africa. 1995. 1995 October Household Survey. Central Statistical Service Publication.

Chambers, R. 1983. Rural Development: putting the last first. London: Longman.

Chambers, R. and Conway, G. 1992. Sustainable Rural Livelihoods: Practical concepts for the $21^{\text {st }}$ century, Discussion Paper 296, Institute for Development Studies.

Children's Policy Institute of West Virginia (CPI). 1995. Welfare to Work: Breaking the Cycle of Poverty, Part I. Charleston, West Virginia: The Children's Policy Institute of West Virginia.

Child Welfare League of America. 2001.

www.cwla.org/advocacy/statefactsheets/2001/westvirginia.htm.

Chouinard, V. and Grant, A. 1996. "On Being Not Even Anywhere Near "The Project."” In C. Duncan, ed. BodySpace. London: Routledge.

Cloke, P. and Little, J. 1997. Contested Countryside Cultures: Otherness, Marginalization, and Rurality. London: Routledge.

Cobb, J. C. 1986. “The Southern Business Climate: A Historical Perspective." Forum for Applied Research and Public Policy 2(1): 98.

Cock, J. et al. 1983. "Women and Changing Relations of Control." In South African Research Service, ed. South Africa Review I-Same Foundations, Same Facades? Johannesburg: South African Research Service.

Cock, J. 1980. Maids and Madams-A Study in the Politics of Exploitation. Johannesburg: Ravan Press.

Cockburn, C. 1983. Brothers. London: Pluto Press. 
Cohen, A. 1974. Two-dimensional man: an essay on the anthropology of power and symbolism in complex society. Berkeley, CA: University of California Press.

Commission on Gender Equality (CGE). 1999. CGE Annual Report, 1999. Online Document: www.cge.org.za/docs/ann_report1.htm.

Conger, R. D. and Elder, Jr. G. H., 1994. Families in Troubled Times: Adapting to Change in Rural America. New York: Aldine de Gruyter.

Conn, P. 1983. "The Appalachian Regional Commission: an experiment in intergovernmental management." Appalachian Heritage 11 (Fall): 49-58.

Couto, R. A. 1994. "The Future of the Welfare State: The Case of Appalachia." In P. Obermiller and W. Philliber, eds. Appalachia in International Context: Cross-National Comparisons of Developing Regions. Westport, Connecticut and London: Praeger.

. 1988. "TVA, Appalachian underdevelopment, and the post-industrial era." Sociological Spectrum 8: 323-347.

Cox, K. 1998a. "Spaces of dependence, spaces of engagement and the politics of scale, or: looking for local politics." Political Geography 17: 1.

. 1998b. "Representations and power in the politics of scale." Political Geography 17:

41.

1996. "Editorial: the difference that scale makes." Political Geography 15: 667.

. 1995. "Globalization, competition, and the politics of local economic development." Urban Studies 32: 213.

Cressy, P. F. 1949. "Social Disorganization and Reorganization in Harlan County, Kentucky." American Sociological Review 14: 389-394.

Criminal Justice Statistical Analysis Center. 1998. Department of Military Affairs and Public Safety, State of West Virginia, July.

Crow, B., Bernstein, H., and Johnson, H. eds. 1992. Rural Livelihoods: Crises and Responses. Oxford: Oxford University Press.

Crush, J. 1995. "Post-colonialism, de-colonization, and geography." In A. Godlewska and N. Smith, eds. Geography and Empire. Blackwell: Oxford.

Cubby, E. A. 1962. “The Transformation of the Tug and Guyandot Valleys: Economic Development and Social Change in West Virginia, 1888-1921. Ph D Dissertation. Syracuse University. 
Cumberland, J. H. 1971. Regional Development: Experiences and Prospects in the United States of America. Paris: Mouton.

Cushing, B. 1994. "West Virginia's Economy, 1940-2000.” In R. J. Dilger and T. S. Witt eds. West Virginia in the 1990s: Opportunities for Economic Progress. Morgantown, WV: West Virginia University Press.

Dalla Costa, M. and James, S. 1972. The Power of Women and the Subversion of the Community. Bristol: Falling Wall Press.

Deavers, K. and Hoppe, R. 1992. "Overview of the Rural Poor in the 1980s." In C. M. Duncan, ed. Rural Poverty in America. New York: Auburn House.

De Haan, A., Drinkwater, M., Rakodi, C., and Westley, K. 2002. Methods for Understanding Urban Poverty and Livelihoods. Livelihoods Connect, available at www.livelihoods.org.

Delphy, C. 1984. Close to Home: A Materialist Analysis of Women's Oppression. Translated and Edited by Diana Leonard. London: Hutchinson.

. 1977. The Main Enemy. London: Women's Research and Resources Center.

. 1976. "Continuities and discontinuities in marriage and divorce." In D. Leonard

Barker and S. Allen eds. Sexual Divisions and Society. London: Tavistock.

Department of Housing and Urban Development (HUD). 2005. Official Website: www.hud.gov.

Department for International Development (DFID). 1999. Sustainable Livelihoods Guidance Sheets. London.

Development Bank of Southern Africa (DBSA). 2000. Building Developmental Local Government. Halfway House, Development Bank of Southern Africa.

(DBSA). 1998. Northern Province Development

Profile. Halfway House, Development Bank of Southern Africa.

. (DBSA). 1993. Regional Poverty Profile:

Eastern and Northern Transvaal. Policy Working Papers No. 3. Halfway House, Development Bank of Southern Africa.

Department of Labor. Children's Bureau. The Welfare of Children In Bituminous Coal Mining Communities in West Virginia by Nettie P. McGill. Publication No. 117. Washington, D.C.: Government Printing Office.

Department of Land Affairs (DLA). 1999. CGE Annual Report, 1999. Online Document: www.cge.org.za/docs/ann_report1.htm. 
1998. Participation. Pretoria, South Africa.

Dilger, R. J. 2004. "Studying Welfare Reform in West Virginia." In R. J. Dilger et al. Welfare Reform in West Virginia. Morgantown, WV: West Virginia University Press.

Dilger, R. J. and Witt, T. S. 1994. "West Virginia's Economic Future.” In R. J. Dilger and T. S. Witt eds. West Virginia in the 1990s: Opportunities for Economic Progress. Morgantown, WV: West Virginia University Press.

Dirlik, A. 1994. "The Postcolonial Aura: Third World Criticism in the Age of Global Capitalism." Critical Inquiry 20(2): 328-356.

Di Stefano, C. 1990. "Dilemmas of Difference: Feminism, Modernity, and Postmodernism." In L. Nicholson, ed. Feminism/Postmodernism. New York and London: Routledge.

Dorsey, S. 1987. "An analysis of West Virginia labor force participation rates." Center for Economic Research, West Virginia University.

Duncan, N. ed. 1996. BodySpace. London and New York: Routledge.

Dyck, I. 1993. "Ethnography: A Feminist Method?" The Canadian Geographer 37 (1): 52-57.

Ehrenreich, B. 1975. Quoted in Holmstrom, N. ed. 2002. The Socialist Feminist Project: A Contemporary Reader in Theory and Politics. New York: Monthly Review Press.

Eisenstein, Z. 1979. "Some Notes on the Relations of Capitalist Patriarchy." In Z. Eisenstein, ed. Capitalist Patriarchy and the Case for Socialist Feminism. New York and London: Monthly Review Press.

Eller, R. 1982. Miners, Millhands, and Mountaineers: Industrialization of the Appalachian South, 1880-1930. Knoxville: University of Tennessee Press.

Ellis, F. 2000. Rural Livelihoods and Diversity in Developing Countries. Oxford: Oxford University Press.

Engels, F. 1942. The Origin of Family, Private Property, and the State. New York: International Publishers.

England, K. 2000. "An elite doing interviewing elites? Researching women managers in Canada's banking industry." In P. Moss ed. Engaging Autobiography: Geographers Writing Lives. Syracuse, New York: Syracuse University Press. 1994. "Getting Personal: Reflexivity, Positionality, and Feminist Research." Professional Geographer 46(1). 
Epstein Jayaratne, T. and Stewart, A. 1991. "Quantitative and Qualitative Methods in the Social Sciences: Current Feminist Issues and Practical Strategies." In M. M. Fonow and J. A. Cook, eds. Beyond Methodology-Feminist Scholarship as Lived Research. Bloomington and Indianapolis: Indiana University Press.

Falconer-Al Hindi, K. 1997. "Feminist Critical Realism: A Method for Gender and Work Studies in Geography." In H. J. Nast, J. P. Jones, and S. M. Roberts, eds. Thresholds in Feminist Geography. Lanham: Rowman and Littlefield Publishers.

Fannon, F. 1966. The wretched of the Earth. London: Penguin.

Firestone, S. 1972. The Dialectic of Sex. London: Paladin.

Fisher, S. ed. 1979. A Landless People in a Rural Region: A Reader on Land Ownership and Property Taxation in Appalachia. Highlander Center, New Market.

Fitchen, J. 1991. Endangered Spaces, Enduring Places: Change, Identity and Survival in Rural America. Boulder: Westview Press. . 1981. Poverty in Rural America: a case study. Boulder, Colorado: Westview Press.

Flax, J. 1990. "Postmodernism and Gender Relations in Feminist Theory." In L. Nicholson, ed. Feminism/Postmodernism. New York and London: Routledge.

Focus Group, Tshandama Community Bakery, July 12, 2001. Tshandama, Limpopo, South Africa.

Focus Group, Tshandama Jam Project. July 12, 2001. Tshandama, Limpopo, South Africa.

Focus Group, Matangari Piggery, July 13, 2001. Matangari, Limpopo, South Africa.

Focus Group, Rambuda Stone Crushing Community Project, July 13, 2001. Rambuda, Limpopo, South Africa.

Focus Group, Tshandama Stone Crushing Community Project, July 13, 2001. Tshandama, Limpopo, South Africa.

Focus Group, Mvuleleni Sewing Project, July 16, 2001. Shayandima, Limpopo, South Africa.

Focus Group, Pfananani Community Center, July 16, 2001. Tshianda, Limpopo, South Africa.

Focus Group. Tshakuma Community Fruit Market, July 16, 2001. Tshakuma, Limpopo, South Africa.

Focus Group, Baobob Kiosk, July 17, 2001. Shayandima, Limpopo, South Africa. 
Focus Group, Fulufhelo Community Garden, July 24, 2001. Malonga, Limpopo, South Africa. Focus Group, Tshino Confectionary Project, July 24, 2001, Tshino, Limpopo, South Africa. Focus Group, Mukondeni Pottery Project, July 27, 2001. Mashamba, Limpopo, South Africa. Folbre, N. 1994. Who pays for the kids? Gender and the structures of constraint. New York: Routledge.

Fonow, M. M. and J. A. Cook. eds. 1991. Beyond Methodology: Feminist Scholarship as Lived Research. Bloomington: Indiana University Press.

Foord, J. and N. Gregson. 1986. "Patriarchy: towards a reconceptualization." Antipode 18: 186-211.

Foucault, M. 1980. Power/Knowledge. Edited by Colin Gordon. New York: Pantheon.

Francis, E. 2000. Making a Living: Changing Livelihoods in rural Africa. London: Routledge.

Frank, A. G. 1980. Crisis in the World Economy. New York: Holmes and Meier.

Friedman, J. 1966. "Poor Regions and Poor Nations: Perspectives on the Problem of Appalachia." Southern Economic Journal 32(4): 465-473.

Frost, W. G. 1899. "Our Contemporary Ancestors in the Southern Mountains." Atlantic Monthly 83: 311-319. . 1896. “Appalachian America.” Women's Home Companion 23: 3-4.

Fuller, T. 1642. The Holy State. The Profane State. Cambridge: John Williams.

Funk \& Wagnalls, L.P. 1994. Funk and Wagnalls Standard Desk Dictionary, Volume 2, N-Z. Harper and Row Publishers, Inc.

Gauthier, H. L. 1973. “The Appalachian Development Highway System: Development for Whom?” Economic Geography 49(2): 103-108.

Gaventa, J. 1994. "From the Mountains to the Maquiladoras: A Case Study of Rural Appalachia." In and J. Obermiller and W. Philliber, eds. Appalachia in International Context. Westport, Connecticut and London: Praeger.

Gaventa, J. 1980. Power and Powerlessness: Queiscence and Rebellionin an Appalachian Valley. University of Illinois Press.

Gaventa, J., Smith, B. E., and Willingham, A. eds. 1990. Communities in Economic Crisis: Appalachia and the South. Philadelphia: Temple University Press. 
Gender, Place, and Culture-A Journal of Feminist Geography. 2002. Viewpoints Section. Volume 9(2): 167-208.

Gibson-Graham, J. K. 1996. The End of Capitalism (As We Knew It)—A Feminist Critique of Political Economy. Oxford: Blackwell

Gilbert, M. 1994. "The Politics of Location: Doing Feminist Research at 'Home'." Professional Geographer 46(1).

Gilbert, M. and Masucci, M. 2004. "Feminist Praxis in University Community Partnerships: Reflections on Ethical Crises and Turning Points in Temple-North Philadelphia IT Partnerships. In D. Fuller and R. Kitchen eds. Radical Theory/Critical Praxis: Making a Difference Beyond the Academy? Praxis (e) Press.

Gillenwater, M. H. 1972. Cultural and Historical Geography of Mining Settlements in the Pocanhontas Coal Fields of Southern West Virginia, 1880 to 1930. Ph D Dissertation. University of Tennessee.

Gilligan, C. 2002. The Birth of Pleasure. New York: Random House.

Gordon, D. M. 1977. “Class Struggle and Stages of American Urban Development." In D. Perry and A. J. Watkins eds. The Rise of the Sunbelt Cities. Beverly Hills: Sage Publications.

Gray, L. C. 1933. "Economic Conditions and Tendencies in the Southern Appalachians As Indicated by the Cooperative Survey." Mountain Life and Work 9: 7-12.

Gray, W. T. 1936. "Mountain Dilemmas: A Study in Mountain Attitudes." Mountain Life and Work 12(April): 1-2.

Greene, J. 1990. “Strategies for Survival: Women's Work in the Southern West Virginia Coal Camps." West Virginia History 49: 21-36.

Gregory, D. 1995. “Imaginative geographies.” Progress in Human Geography 19: 447-485.

Grinberg, M. and McHenry, D. eds. 1996. Women and the Law: A Legal Rights Handbook. Charleston, West Virginia: West Virginia Women's Commission and the Women Lawyers Committee of the West Virginia State Bar.

Group Interview with Angie, Jane, and Karen, October 13, 2001. Simpson, Taylor County, West Virginia, USA.

Group Interview with Jaycie and Vera, August 2, 2004. Simpson, Taylor County, West Virginia, USA.

Halperin, R. 1990. The Livelihood of Kin: Making Ends Meet the Kentucky Way. Austin: University of Texas Press. 
Handler, J. F. and Hasenfeld, Y. 1997. We the Poor People: Work, Poverty, and Welfare. New Haven: Yale University Press.

Hannah, K. L. ed. 1995. West Virginia Women in Perspective. Charleston, West Virginia: West Virginia Women's Commission.

Hanscombe, G. and Namjoshi, S. 2001. “And there's you and me, my sweet duality." Women's Studies International Forum 24(3/4): 401-407.

Hansen, N. 1970. Rural Poverty and the Urban Crisis. Bloomington: Indiana University Press. . 1969. A Review of the Appalachian Regional Commission Program. Report for the Economic Development Administration, U. S. Department of Commerce. University of Texas, Mimieographed.

. 1966. "Some Neglected Factors in American Regional Development Policy: The Case of Appalachia." Land Economics 62(1): 1-9.

Hapke, H. and Ayyankeril, D. 2004. "Gender, the Work-Life Course, and Livelihood Strategies in a South Indian Fish Market.” Gender, Place, and Culture 11(2): 229-256.

Haraway, D. 1991. "Situated knowledges: the science question in feminism and the privilege of partial perspective." In D. Haraway, ed. Simians, Cyborgs, and Women: the reinvention of nature. London: Free Association Books.

Harding, S. ed. 1987. Feminism and Methodology. Bloomington: Indiana University Press. . 1986. The science question in feminism. Ithaca: Cornell University Press.

Hartmann, H. 1981. "The unhappy marriage of Marxism and feminism: towards a more progressive union." In L. Sargent, ed. Women and Revolution: the Unhappy Marriage of Marxism and Feminism. London: Pluto Press.

1976. “Capitalism, patriarchy, and job segregation by sex.” Signs 1: 137-68.

Hartsock, N. 1996. "Theoretical Bases for Coalition Building: An Assessment of Postmodernism." In A. Gottfried, ed. Feminism and Social Change. Chicago: University of Illinois Press.

. 1990. "Foucault on Power: A Theory for Women?" In L. Nicholson, ed.

Feminism/Postmodernism. New York and London: Routledge.

1979. "Feminist Theory and the Development of Revolutionary Strategy." In Z. Eisenstein, ed. Capitalist Patriarchy and the Case for Socialist Feminism. New York and London: Monthly Review Press. 
Harvey, D. 1984. "On the history and present condition of geography: an historical materialist manifesto." Professional Geographer 36: 1.

Hawley, C. 1994. "Demographic Change and Economic Opportunity." In R. J. Dilger and T. S. Witt eds. West Virginia in the 1990s: Opportunities for Economic Progress. Morgantown, WV: West Virginia University Press.

Hayford, A. 1974. "The geography of women: An historical introduction." Antipode 6: 1-18.

Hays-Mitchell, M. 1993. "The Ties that Bind. Informal and Formal Sector Linkages in Streetvending: The Case of Peru's Ambulantes." Environment and Planning A 25: 1085-1102.

Hendricks, F. and Ntsebeza, L. 1999. "Chiefs and rural local government in post-apartheid South Africa." African Journal of Political Science 4: 99-126.

Hensley, F. S. 1990. "Women in the industrial workforce in West Virginia, 1880-1945." West Virginia History 49: 115-124.

Herod, A. 1997. "Labor as an agent of globalization and as a global agent." In K. Cox, ed. Spaces of globalization: reasserting the power of the local. New York and London: Guilford: 167.

. 1991. "The production of scale in United States labor relations." Area 23(1): 82.

Hindson, D. 1987. Pass Controls and the Urban African Proletariat. Johannesburg: Ravan Press.

Hitchcock, P. 1997. "Postcolonial Africa? Problems of Theory." Women's Studies Quarterly, 3 and 4: 233-244.

Holmstrom, N. ed. 2002. The Socialist Feminist Project: A Contemporary Reader in Theory and Politics. New York: Monthly Review Press.

(1): 208. . 1981. "Women's Work, the Family and Capitalism.” Science and Society 45

Hondagneu-Sotelo, P. 1988. “Gender and fieldwork.” Women's Studies Forum 11: 611-618.

hooks, b. 1984. Feminist Theory from Margin to Center. Boston: South End Press.

Howitt, R. 1998. "Scale as relation: musical metaphors of geographical scale." Area 30(1): 4958.

Individual Interview with Lousie, July 12, 2001. Tshandama, Limpopo, South Africa.

Individual Interview with Hope, July 12, 2001. Tshandama, Limpopo, South Africa. 
Individual Interview with Janet, July 12, 2001. Tshandama, Limpopo, South Africa. Individual Interview with Eve, July 13, 2001. Matangarie, Limpopo, South Africa. Individual Interview with Agnes, July 13, 2001. Matangarie, Limpopo, South Africa. Individual Interview with Joan, July 13, 2001. Rambuda, Limpopo, South Africa. Individual Interview with Margaret, July 13, 2001. Rambuda, Limpopo, South Africa. Individual Interview with Sharon, July 16, 2001. Shayandima, Limpopo, South Africa. Individual Interview with Helen, July 16, 2001. Tshakuma, Limpopo, South Africa. Individual Interview with Mary, July 16, 2001. Tshakuma, Limpopo, South Africa. Individual Interview with Joy, July 16, 2001. Tshakuma, Limpopo, South Africa. Individual Interview with Ruth, July 16, 2001. Tshakuma, Limpopo, South Africa. Individual Interview with Joanne, July 17, 2001. Shayandima, Limpopo, South Africa. Individual Interview with Beth, July 17, 2001. Shayandima, Limpopo, South Africa. Individual Interview with Carol, July 17, 2001. Shayandima, Limpopo, South Africa. Individual Interview with local chief, July 24, 2001. Thohoyandou, Limpopo, South Africa. Individual Interview with May, July 24, 2001. Nesengane, Limpopo, South Africa. Individual Interview with Tina, July 24, 2001. Nesengane, Limpopo, South Africa. Individual Interview with Nancy, July 24, 2001. Malonga, Limpopo, South Africa. Individual Interview with Sarah, July 24, 2001. Malonga, Limpopo, South Africa. Individual Interview with Diane, July 26, 2001. Mukondeni, Limpopo, South Africa. Individual Interview with Frances, July 26, 2001. Mukondeni, Limpopo, South Africa. Individual Interview with DeeDee, October 16, 2001. Granville, Monongalia County, West Virginia, USA.

Individual Interview with Cecile, October 10, 2001. Morgantown, Monongalia County, West Virginia, USA. 
Individual Interview with Christy, April 20, 2002. Grafton, Taylor County, West Virginia, USA. Individual Interview with Vicki, April 18, 2002. Clarksburg, Harrison County, West Virginia, USA.

Individual Interview with Wilma, April 18 2002. Morgantown, Monongalia County, West Virginia, USA.

Individual Interview with Ronnie, August 3, 2004. Quiet Dell, Harrison County, West Virginia, USA.

Individual Interview with Anna, August 6, 2004, Flemington, Taylor County, West Virginia, USA.

Individual Interview with Wanda, August 7, 2004. Simpson, Taylor County, West Virginia, USA.

Individual Interview with Debbie, August 8, 2004. Shinnston, Harrison County, West Virginia, USA.

Individual Interview with Margie, August 9, 2004. Bridgeport, Harrison County, West Virginia, USA.

Individual Interview with Tracy, August 9, 2004. Simpson, Taylor County, West Virginia, USA.

Individual Interview with Caroline, August 11, 2004. Bridgeport, Harrison County, West Virginia, USA.

Individual Interview with Renee, August 11, 2004. Kingwood, Preston County, West Virginia, USA.

Individual Interview with Diane, August 12, 2004. Department of Health and Human Resources, Taylor County Office, Grafton, West Virginia, USA.

Ingstad, B. 1994. "The grandmother and household viability in Botswana." In A. Adepoju and C. Oppong, eds. Gender, Work, and Population in Sub-Saharan Africa. London: James Currey.

International Labor Organization (ILO). 1987. Women's Participation in Cooperatives. International Labor Organization Publication.

Isserman, A. 1997. Excerpts from "A Socioeconomic Review of Appalachia": a report prepared for the Appalachian Regional Commission. Journal of Appalachian Studies 3(1): 4369. 
Isserman, A. and Rephann, T. 1995. "The Economic Effects of the Appalachian Regional Commission: An Empirical Assessment of 26 Years of Regional Development Planning." Journal of American Planning 61(3): 345-364.

1993. "Geographical and Gender Differences in Labor Force Participation: Is There an Appalachian Effect?" Growth and Change 24(4): 539-578.

Jackson, P. and J. M. Jacobs. 1996. "Postcolonialism and the politics of race." Environment and Planning D: Society and Space 14 (1): 1-4.

Jackson, S. 2001. "Why a Materialist Feminism is (Still) Possible—and Necessary." Women's Studies International Forum 24(3/4): 273-281.

. 1998. "Feminist Social Theory." In S. Jackson and J. Jones, eds. Contemporary

Feminist Theories. New York: New York University Press.

Jackson, S. and Jones, J. 1998. Contemporary Feminist Theories. New York: New York University Press.

Jagger, A. 1986. "Prostitution.” In M. Pearsall, ed. Women and Values. Belmont, California: Wadsworth.

$\overline{\text { Allanheld. }}$

1983. Feminist Politics and Human Nature. Totowa, New Jersey: Rowman and

Jefferys, S. 1990. Anticlimax: A Feminist Perspective on the Sexual Revolution. London: The Women's Press.

Jensen, L. and Eggebeen, D. J. 1994. "Nonmetropolitan Poor Children and Reliance on Public Assistance.” Rural Sociology 59: 45-65.

Jensen, L. and Chitose, Y. 1997. "Will Workfare Work? Job Availability for Welfare

Recipients in Rural and Urban America." Population Research and Policy Review 16: 383-395.

Johnston, R. J., Gregory, D. and Smith, D. 1994. The Dictionary of Human Geography. Third Edition. Oxford: Blackwell.

Jones, J. P., H. J. Nast, and S. M. Roberts. eds. 1997. Thresholds in Feminist GeographyDifference, Methodology, and Representation. Lanham: Rowman and Littlefield Publishers, Inc.

Kaluzynska, Eva. 1980. "Wiping the floor with theory: a survey of writings on housework." Feminist Review 6: 27-54.

Kandiyotti, D. 2002. "Bargaining with Patriarchy." In N. Holmstrom, ed. The Socialist Feminist Project: A Contemporary Reader in Theory and Politics. New York: Monthly Review Press. 
Katz, C. 2001a. "On the Grounds of Globalization: A Topography for Feminist Political Engagement." Signs: Journal for Women in Culture and Society 26(4): 1213-1234.

. 2001b. "Vagabond Capitalism and the Necessity of Social Reproduction." Antipode $709-728$.

1994. "Playing the Field: Questions on Fieldwork in Geography." Professional Geographer 46(1).

. 1993. “The Expeditions of Conjurers: Ethnography, Power, and Pretense.” In D. L. Wolf, ed. Feminist Dilemmas in Fieldwork. Boulder: Westview Press.

1992. "All the World is Staged: Intellectuals and the Projects of Ethnography." Environment and Planning D: Society and Space 10 (5): 495-510.

Katz, C. and J. Monk. eds. 1993. Full Circles: geographies of women over the life course. London and New York: Routledge.

Kirsten, J. 1996. "The potential for creating additional rural livelihoods in agriculture and the rural non-farm sector in semi-arid areas: a case study in the Northern Province. In M. Lipton, F. Ellis, and M. Lipton, eds. Land, Labor, and Livelihoods in Rural South Africa: Vol.2, KwaZuluNatal and Northern Province. Durban, South Africa: Indicator Press.

Kobayashi, A. 2003. “GPC ten years on: Is self-reflexivity enough?” Gender, Place, and Culture 10(4): 345-349.

. 1994. "Coloring the Field: Gender, 'Race,' and the Politics of Fieldwork." Professional Geographer 46(1): 73-80.

Laing, J.T. 1936. “The Negro in West Virginia.” Social Forces 14: 416-422.

Land and Agricultural Policy Center (LAPC). 1995. Northern Transvaal Regional Overview. Working Paper. Johannesburg: Development Planning and Research, CC.

Lantz, H. R. 1964. "Resignation, Industrialization, and the Problem of Social Change." In A. B. Shostak and W. Gombert, eds. Blue Collar World: Studies of the American Worker. Englewood Cliffs, N.J.: Prentice-Hall.

Lapchick, R. and Urdang, S. 1980. "The effects of apartheid on the employment of women in South Africa and a history of the role of women in the trade unions." A paper delivered at the World Conference of the United Nations Decade for Women, Copenhagen.

Latimer, M. 2004. "Setting the Socioeconomic Context for Welfare Reform in Appalachia." In R. J. Dilger et al. eds. Welfare Reform in West Virginia. Morgantown, WV: West Virginia University Press. 
Latimer, M. and Mencken, F. C. 2003. "Socioeconomic Trends in Mining Dependent Counties in Appalachia." In W. Falk, M. Schulman, and Ann R. Tickamyer, eds. Communities of Work: Rural Restructuring in Local and Global Contexts. Athens, $\mathrm{OH}$ : Ohio University Press.

Lawson, L. 1986. Working Women in South Africa. London: Pluto Press.

Lawson, V. 1995. "Beyond the firm: Restructuring gender divisions of labor in Quito's Garment Industry under Austerity." Environment and Planning D: Society and Space 13: 415444.

1995. “The Politics of Difference: Examining the Quantitative/Qualitative Dualism in Post-Structuralist Feminist Research." Professional Geographer 47 (4).

Lefebvre, H. 1991. The production of space. Oxford and Cambridge: Blackwell (translated by D. Nicholson-Smith).

d'Editions.

1978. De l'etat: les contradictions de l'etat moderne. Vol. 4. Paris: Union General 1977. De l'etat: le mode de production etatique. Vol. 3. Paris: Union General d'Editions.

d'Editions.

1976a. De l'etat: de Hagel a Marx par Staline. Vol. 2. Paris: Union General d'Editions.

1976b. D l'etat: l'etat dans le monde moderne. Vol. 1. Paris: Union General

Legassick, M. 1975. "South Africa: forced labor, industrialization, and racial differentiation." In R. Harris, ed. The Political Economy of Africa. New York and London: Wiley.

1974. "Legislation, ideology, and economy in post-1948 South Africa." Journal of Southern African Affairs, 1: 5-35.

Lehulere, O. 1997. “The Political Significance of GEAR.” Debate 3: 118-129.

Leonard, M. 1998. Invisible Work, Invisible Workers: The Informal Economy in Europe and the U. S. New York, NY: St. Martin's Press.

Lerman, R. I., McKernan, S., and Pindus, N. 2001. "Welfare Reforms and Employment of Single Mothers: Are Rural Areas Keeping Pace?" Rural America 16(3): 22-28.

Levin, R. 1996. "Politics and land reform in the Northern Province: a case study of the Mojapelo land claim." In M. Lipton, F. Ellis, and M. Lipton, eds. Land, Labor, and Livelihoods in Rural South Africa: Vol.2, KwaZulu-Natal and Northern Province. Durban, South Africa: Indicator Press. 
Levin, R. and D. Weiner. eds. 1997. No More Tears...Struggles for Land in Mpumalanga, South Africa. New Jersey: Africa World Press.

Levin, R., Russan, R., and Weiner, D. 1997. "Class, Gender, and the Politics of Rural Land Reform." In R. Levin and D. Weiner, eds. No More Tears...Struggles for Land in Mpumalanga, South Africa. New Jersey: Africa World Press.

Lewis, H. et al. eds. 1978. Colonialism in Modern America: The Appalachian Case. Boone: The Appalachian Consortium Press.

Lewis, R. 1993. "Appalachian Restructuring in Historical Perspective: Coal, Culture, and Social Change in West Virginia." Urban Studies 30(2): 299-308.

1989. "From peasant to proletarian: the migration of southern blacks to the central Appalachian coalfields." The Journal of Southern History 60(1): 77-102.

Lewis, R. and Billings, D. 1997. "Appalachian culture and economic development: a retrospective view on the theory and literature." Journal of Appalachian Studies 3(1) (Spring): 3-42.

Lichter, D. T. and Jensen, L. 2001. "Poverty and Welfare among Rural Female-headed Families before and after PRWORA." Rural America 16: 28-35.

Liddle, J. and Wright, C. 2001. "Introduction—Understanding Local/Global Identities: Towards a Materialist Discursive Feminism." Women's Studies International Forum 24(3/4): 273-281.

Liddle, J. and Wright, C. et. al. 2001. "Special Issue. Understanding Local/Global Identities: Towards a Materialist Discursive Feminism." Women's Studies International Forum 24(3/4): 273-281.

Lipton, M., Ellis, F., and M. Lipton. eds. 1996. Land, Labor, and Livelihoods in Rural South Africa Vol.2, KwaZulu-Natal and Northern Province. Durban, South Africa: Indicator Press.

Little, J. 1987. "Gender Relations in Rural Areas: the Importance of Women's Domestic Role." Journal of Rural Studies 3(4): 335.

. 1986. "Feminist Perspectives in Rural Geography: an Introduction." Journal of Rural Studies 2(1): 1.

Lucas, R. 1987. “The Emigration to South Africa's Mines.” American Economic Review 77(3): 313-320.

Mabin, A. 1989. "Struggle for the city: urbanization and political strategies of the South Africa State." Social Dynamics 15(1): 1-28. 
Mackenzie, S. and Rose, D. 1983. "Industrial Change, the domestic economy, and home life. In J. Anderson, S. Duncan, and R. Hudson, eds. Redundant spaces and industrial decline in cities and regions. London: Academic Press.

MacKinnon, C. A. 1982. "Feminism, Marxism, Method, and the State: An Agenda for Theory." Signs 7(3): 515-44.

Mager, A. 1999. Gender and the Making of a South African Bantustan. Oxford: James Curry, Ltd.

1989. "Moving the Fence: Gender in the Ciskei and Border Textile Industry, 1945-

1986." Social Dynamics 15(2): 46-62.

Maggard, S. W. 1994. "From the Farm to Coal Camp to Back Office to McDonald's: Living in the Midst of Appalachia's Latest Transformation." Journal of Appalachian Studies Association 6: 14-38.

. 1990. "Gender contested: women's participation in the Brookeside coal strike." In G. West and R. Blumberg, eds. Women and Social Protest. New York: Oxford University Press.

. 1981. "From farmers to miners: the decline of agriculture in eastern Kentucky." In Busch ed. Science and Agricultural Development. Totowa.

Mandel, J. 2004. "Mobility Matters: women's livelihood strategies in Porto Novo, Benin." Gender, Place, and Culture 11(2): 257-287.

Manufacturers' Record. Baltimore, 1882-1930. Periodical.

Marcus, T. 1989. Modernizing Super-exploitation: Restructuring South African Agriculture. London: Zed Press.

Marcus, T., Eales, K., and Wildschut, A. 1996. Down to Earth: Land Demand in the New South Africa. Durban: Indicator Press, University of Natal.

Marston, S. 2000. “The social construction of scale.” Progress in Human Geography 24(2): 219-242.

Martin, V. M. and Rogerson, C. M. 1984. "Women and Industrial Change: The South African Experience." South African Geographical Journal 66(1): 32-46.

Martinelli, D. and Eck, W. R. 1994. "West Virginia's Transportation Infrastructure: Conditions, Trends, and Implications for Economic Growth." In R. J. Dilger and T. S. Witt eds. West Virginia in the 1990s: Opportunities for Economic Progress. Morgantown, WV: West Virginia University Press. 
Marx, K. 1967. Capital vol. 3. New York: International Publishers.

Publishers.

1964. Economic and Philosophical Manuscripts of 1844. New York: International

Marx, K. and Engels, F. 1947. The German Ideology. New York: International Publishers.

Masika, R. and Joekes, S. 1996. Employment and sustainable livelihoods: a gender perspective. BRIDGE Report No. 37 (available at: www.livelihoods.org).

Massey, D. 1994. Space, Place, and Gender. Minneapolis: University of Minnesota Press. . 1991. "Flexible sexism." Environment and Planning D: Society and Space 9: 31.

1984. Spatial Divisions of Labor: social structures and the geography of

production. London: MacMillan.

1983. "Industrial restructuring as class restructuring: production decentralization and local uniqueness." Regional Studies 17: 73.

Mattingly, D. and K. Falconer-Al-Hindi. 1995. "Should Women Count? A Context for the Debate." Professional Geographer 47(4).

May, J. 1999. "The Structure and Composition of Rural Poverty and Livelihoods in South Africa."

Paper presented for the Conference on "Land and Agrarian Reform in South Africa: Successes, Problems, and the Way Forward," July 26-28 ${ }^{\text {th }}$, 1999, Pretoria, South Africa.

May, J., Carter, M. and Posel, D. 1995. The Composition and Persistence of Poverty in Rural South Africa: An Entitlements Approach. Land and Agricultural Policy Center, Johannesburg.

Maynard, M. 1995. "Beyond the "big three": The development of feminist theory in the 1990s." Women's History Review 4: 259.

McDowell, L. 1997. "Women/Gender/Feminisms/: doing feminist geography." Journal of Geography in Higher Education 21: 381-400.

Routledge.

1996. “Spatializing Feminism.” In Duncan, C. ed. BodySpace. London:

. 1992a. "Multiple Voices: Speaking from inside and outside the 'Project'."

Antipode 24: 56-72.

McDowell, L. 1992b. "Doing gender: feminism, feminists, and research methods in human geography." Transactions of the Institute of British Geographers 17: 399-416. 
. 1991. "The baby and the bathwater: diversity, deconstruction, and feminist theory in geography." Geoforum 22: 123-134.

. 1986. "Beyond patriarchy: a class-based explanation of women's subordination." Antipode 18: 311. 1983. "Towards an understanding of the gender division of urban space." Environment and Planning D: Society and Space 1: 59.

McDowell, L. and Massey, D. 1984. “A women's place?” In D. Massey and J. Allen, eds. Geography Matters. Cambridge: Cambridge University Press.

McKinney, G. B. 1977. "Industrialization and Violence in Appalachia in the 1890s." In J. W. Williamson, ed. An Appalachian Symposium. Boone, N.C: Appalachian State University Press.

McLafferty, S. 1995. "Counting for Women.” Professional Geographer 47 (4).

McLaughlin, D. K., Gardner, E. L., and Lichter, D. T. 1999. "Economic Restructuring and Changing Prevalence of Female-Headed Families in America." Rural Sociology 64: 394-416.

Meer, S. 1997. Women, Land, and Authority: perspectives from South Africa. Claremont, South Africa: David Philip Publishers, Ltd.

Mencken, C. F. and Maggard, S. W. 1999. "Informal Economic Activity in West Virginia: A Descriptive and Multivariate Analysis." In B. Keith and R. Althouse, eds. Inside West Virginia: Public Policy Perspectives for the $21^{\text {st }}$ Century. Morgantown, WV: West Virginia University Press.

Miernyk, W. H. 1967a. “Appalachian Development: The Long-Run View.” Poverty and Human Resources Abstracts 2(3): 37-43.

. 1967b. "Needed: Appalachian Ghost Towns." Appalachian Review 1(4): 14-

20.

Mies, M. 1991. "Women's Research or Feminist Research? The Debate Surrounding Feminist Science and Methodology." In M. M. Fonow and J. A. Cook, eds. Beyond Methodology: Feminist Scholarship as Lived Research. Bloomington: Indiana University Press.

Miller, N. 1935. The Girl in the Rural Family. Chapel Hill: University of North Carolina Press.

Miller, R. 1991. "Selling Mrs. Consumer: advertising and the creation of suburban socio-spatial relations, 1910-1930." Antipode 23(3): 263.

. 1983. "The Hoover in the garden: middle class women and suburbanization, 18501920.” Environment and Planning D: Society and Space 1: 73. 
Millet, K. 1977. Sexual Politics. London: Virago.

Minard, R. D. 1952. "Race Relations in the Pocahontas Coal Field." Journal of Social Issues 8: $29-44$.

Minha-ha, T. T. 1989. Women, Native, Other: Writing postcoloniality and feminism. Bloomington: Indiana University Press.

Mitchell, J. 1974. Psychoanalysis and Feminism. Hammondsworth: Penguin. 1971. Women's Estate. New York: Pantheon Books.

Moffitt, R. A., Reville, R., and Winkler, A. E. 1998. "Beyond Single Mothers: Co-habitation and Marriage in the AFDC Program." Demography 35: 259-278.

Mohanty, C. T. 2004. Feminism Without Borders—Decolonizing Theory, Practicing Solidarity. Durham and London: Duke University Press.

Mohanty, C. T. 1997a. "Feminist Encounters: Locating the Politics of Experience." In L. McDowell and J. P. Sharp, eds. Space, Gender, Knowledge. London: Arnold Press. . 1997b. "Under Western Eyes: Feminist Scholarship and Colonial Discourses." In A. McClintock, A. Mufti, and E. Shohat, eds. Dangerous Liasons: Gender, Nation, and Postcolonial Perspectives. Minneapolis: University of Minnesota Press.

1991. "Cartographies of Struggle: Third World Women and the Politics of Feminism." In C.T. Mohanty, A. Russo, and L. Torres eds. Third World Women and the Politics of Feminism. Indianapolis: Indiana University.

Momsen, J. and Townsend, J. eds. 1987. Geography of Gender in the Third World. London: Hutchinson.

Molyneux, M. 1979. "Beyond the domestic labor debate." New Left Review 116: 3-27.

Morema, J. 2000. "The Influence of Ownership on Access to Land by Rural Women in the Northern Region of the Northern Province: A Case of the Kutama-Senthumule Area." In U. J. Fairhurst, A. Musyoki, T. Saidi, and G. D. H. Wilson, eds. Integrating Environment and Society: The Thohoyandou Environs, Northern Province, South Africa. Pretoria: Universities of Pretoria and Venda. 
Munro, J. 1969. "Planning the Appalachian Development Highway System: Some Critical Questions." Land Economics 45(2): 149-161.

Murray, C. 1987. "Class, Gender, and the Household: The Development Cycle in Southern Africa." Development and Change 18: 235-49.

. 1981. Families Divided: The Impact of Migrant Labor in Lesotho. Cambridge:

Cambridge University Press.

Nast, H. 1994. "Opening Remarks on 'Women in the Field'." Professional Geographer 46(1).

National Association of Community Health Centers, Inc (NACHC). 2001. "2000 Access to Community Health Care." www.nachc.com.

Nesbitt, J. T. 2000. 2000. "Ethnography and Participatory Rural Appraisal in Central Appalachia." Journal of Appalachian Studies 6 No. 1 \& 2 (Spring/Fall): 49-70.

Nel, E. and Binns, T. 2000. "Rural self-reliance strategies in South Africa: community initiatives and external support in the former black homelands." Journal of Rural Studies 16: 367-377.

Neuman, W. L. 1997. Social Research Methods: Qualitative and Quantitative Methods. Third Edition. Boston: Allyn and Bacon.

Nicholson, L. ed. 1990. Feminism/Postmodernism. New York and London: Routledge.

Nyden, P. 1979. “An Internal Colony: labor conflict and capitalism in Appalachian coal.” Insurgent Sociologist 8 (Winter): 33-43.

O’Brien, M. 1981. The Politics of Reproduction. London: Routledge and Kegan Paul.

Oberhauser, A. M. 2002. "Relocating gender and rural economic strategies." Environment and Planning A 34: 1221-1237.

. 1997. "The Home as "Field": Households and Homework in Rural

Appalachia.” In J. P. Jones, H. J. Nast, and S. M. Roberts, eds. Thresholds in Feminist Geography. Lanham: Rowman and Littlefield Publishers, Inc.

. 1995a. "Towards a Gendered Regional Geography: Women and Work in

Rural Appalachia." Growth and Change 2 (26): 217-244.

. 1995b. "Gender and Household Economic Strategies in Rural Appalachia."

Gender, Place, and Culture 2 (1): 51-70.

. 1993. "Industrial Restructuring and Women's Homework in Appalachia:

Lessons from West Virginia." Southeastern Geographer 33 (May): 23-43. 
Oberhauser, A M.., Mandel, J., and Hapke, H. 2004. "Gendered Livelihoods in Diverse Global Contexts: an introduction." In Gender, Place, and Culture: A journal of feminist geography, Special Collection on Gender and Livelihoods 11(2): 205.

Oberhauser, A. M. and Pratt, A. 2004. "Women's Collective Economic Strategies and Political Transformation in Rural South Africa." Gender, Place, and Culture 11(2): 209-228.

Oberhauser, A. M. and Pratt, A, and Turnage, A. M. 2001. "Unraveling Appalachia's Rural Economy: The Case of a Flexible Manufacturing Network." Journal of Appalachian Studies 7(1): 19-45.

Oberhauser, A. M. and Turnage, A. M. 1999. "A Coalfield Tapestry: Weaving the SocioEconomic Fabric of Women's Lives." In Neither Separate Nor Equal: Women, Race and Class in the South, ed. B. E. Smith, 109-122. Philadelphia: Temple University Press.

Oberhauser, A. M., Weiss, C. and Waugh, L. 1996. "Gender Analysis and Economic Development in West Virginia." The West Virginia Public Affairs Reporter 13(2): 13.

Obermiller, P. and Philliber, W. eds. 1994. Appalachia in International Context: CrossNational Comparisons of Development Regions. Westport, Connecticut and London: Praeger.

Opie, A. 1992. "Qualitative Research: Appropriation of the "other" and empowerment." Feminist Review 40: 52-69.

Oxford English Dictionary. 1971. Oxford: Oxford University Press.

Parisi, D., McLaughlin, D. K., Grice, S. M., Taquino, M., and Gill, D. A. 2004. "TANF Participation Rates: Do Community Conditions Matter?” Rural Sociology 68(4): 491-512.

Parker, B. L. 1940. The Coal Industry: a Study in Social Control. Washington, D.C.: American Council on Public Affairs.

Peake, L. 1993. "Race and sexuality: challenging the patriarchal structuring of urban social space." Environment and Planning D: Society and Space 11: 415.

Pearce, D. 1986. "Toil and Trouble: Women Workers and Unemployment Compensation." In B. Gelpi, N. Hartsock, C. Novak, and M. Stober, eds. Women and Poverty. Chicago: The University of Chicago Press.

Pearce, D. and McAdoo, H. 1981. Women and Children: Alone and in Poverty. Washington D. C.: National Advisory Council on Economic Opportunity.

Petty, C., Roberts, D., and Smith, S. 1987. Women's Liberation and Socialism. London and Chicago: Bookmarks. 
Phillips, M. 1994. "Habermas, Rural Studies and Critical Social Theory." In P. Cloke, M. Doel, D. Matless, M. Philips, N. Thrift, eds. Writing the Rural: Five Cultural Geographies. London: Paul Chapman.

Pickles, J. and Weiner, D. 1991. "Rural and Regional Restructuring of Apartheid: Ideology, Development Policy and the Competition for Space." Antipode 23(1): 2-32.

Pillay, P. 1985. "Women in Employment: Some Important Trends and Issues." Social Dynamics 11(2): 20-37.

Poovey, 1988. "Feminism and Deconstruction." Feminist Studies 14(1): 52-65.

Posel, D. 2001. "Who are the heads of household, what do they do, and is the concept of headship useful? An analysis of headship in South Africa." Development Southern Africa 18(5): 651-670.

Pratt, A. 1999. Rural Women and Economic Survival Strategies in the Former Bantustans of South Africa: A Case Study from Northwest Province. Master's Thesis, West Virginia University.

President's Appalachian Regional Commission. 1964. Appalachia. Washington D. C.: Government Printing Office.

Preston, V., McLafferety, S., and Hamilton, E. 1993. "The Impact of Family Status on Black, White, and Hispanic Women's Commuting." Urban Geography 14: 228.

Preston-Whyte, E. and C. M. Rogerson. eds. 1991. South Africa's Informal Economy. Cape Town: Oxford University Press.

Preston-Whyte, E. and S. Nene. 1991. "Black women and the rural informal sector." In E. Preston-Whyte and C. M. Rogerson, eds. South Africa's Informal Economy. Cape Town: Oxford University Press.

Pudup, M. B. 1990a. "Women's Work in the West Virginia Economy." West Virginia History 49: 7- 20.

. 1990b. "The limits of subsistence: agriculture and industry in Central

Appalachia." Agricultural History, 64: 61-89.

Pudup, M. B., Billings, D. and Waller, A. eds. 1995. Appalachia in the Making: The Mountain South in the Nineteenth Century. Chapel Hill: University of North Carolina Press.

Putnam Tong, R. 1998. Feminist Thought: A More Comprehensive Introduction. Boulder: Westview Press. 
Radcliffe, S. A. 1994. “(Representing) post-colonial women: authority, difference and feminisms." Area 26(1): 25-32.

Rakodi, C. and Lloyd-Jones, T. eds. 2002. Urban Livelihoods: a people-centered approach to reducing poverty. London: Earthscan Publications.

Rank, M. R. and Hirschl, T. A. 1988. "A Rural-urban Comparison of Welfare Exits: The Importance of Population Density." Rural Sociology 53: 190-206.

Rasmussen, B., 1994. Absentee Landowning and Exploitation in West Virginia, 1760-1920. Lexington: The University Press of Kentucky.

Ratner, S. 2000. "The Informal Economy in Rural Community Economic Development." Contractor Paper for TVA Rural Studies, Yellow Wood Associates, St. Albans, Vermont.

Reece, W. S. 1994. "Local Government Finance and Its Implications for West Virginia's Economic Development." In R. J. Dilger and T. S. Witt eds. West Virginia in the 1990s: Opportunities for Economic Progress. Morgantown, WV: West Virginia University Press.

Reinharz, S. 1992. Feminist Methods in Social Research. New York: Oxford University Press.

ResCare. 2005. Official Website: www.rescare.com.

Research Notes, July 10, 2001. Amy Pratt, Thohoyandou, Limpopo, South Africa.

Research Notes, July 13, 2001. Amy Pratt, Thohoyandou, Limpopo, South Africa.

Research Notes, July 16, 2001. Amy Pratt, Thohoyandou, Limpopo, South Africa.

Research Notes, April 20, 2002. Amy Pratt, Simpson, West Virginia.

Research Notes, August 9, 2004. Amy Pratt, Simpson, West Virginia.

Robinson, J. 1994. "White Women Researching/Representing "Others": From Antiapartheid to Postcolonialism?" In A. Blunt and G. Rose, eds. Writing Women and Space Colonial and Postcolonial Geographies. New York: Guilford Press.

Rocheleau, D. 1995. "Maps, Numbers, Text, and Context: Mixing Methods in Feminist Political Ecology." Professional Geographer 47(4) : 458-466.

Rogers, C., Mencken, K., and Mencken, C. F. 1995. "Female Labor Force Participation in Central Appalachia: A Descriptive Analysis." Research Paper 9532. Morgantown: Regional Research Institute, West Virginia University.

Rose, D. 1993. "On Feminism, Method, and Methods in Human Geography: An Idiosyncratic View." The Canadian Geographer 37 (1): 57-60. 
Rose, G. 1995. "The interstitial perspective: a review essay of Homi Bhabha's The Location of Culture." Environment and Planning D: Society and Space 13: 365-373.

Rowbothom, S. 1981. "The trouble with 'patriarchy." In R. Samuel, ed. People's History and Socialist Theory. London: Routledge and Kegan Paul.

Rubin, G. 1975. "The traffic in women: notes on the 'political economy' of sex." In R. Reiter, ed. Toward an Anthropology of Women. New York: Monthly Review Press.

Salstrom, P. 1996. "Appalachia's Informal Economy and the Transition to Capitalism." Journal of Appalachian Studies 2(2): 228.

Schafer, J. 2002. "Supporting livelihoods in situations of chronic conflict and political instability: overview of conceptual issues. Working Paper 183. London: Overseas Development Institute.

Scott, J. W. 1988. "Deconstructing Equality versus Difference: Or, the Uses of Poststructuralist Theory for Feminism." Feminist Studies 14(1): 32-50.

Seidman, G. 2003. "Institutional Dilemmas: Representation versus Mobilization in the South African Gender Commission.” Feminist Studies 29(3): 541-563.

Society $18(11)$.

. 1993. "No Freedom Without the Women." Journal of Women in Culture and

Seidman, A. 1989. "Towards Ending IMF-ism in Southern Africa: an Alternative Development Strategy." Journal of Modern African Studies 27 (1): 1-22.

Semple, E. C. 1910. “The Anglo-Saxons of the Kentucky Mountains: A Study in Antropogeography.” Bulletin of the American Geographical Society 42(8): 561-594.

Shannon, T. R. 1984. "Appalachia and the State." Appalachian Journal (Autumn-Winter): 143-153.

Shapiro, H. D. 1978. Appalachia on Our Mind: The Southern Mountains and Mountaineers in the American Consciousness, 1870-1920. Chapel Hill: University of North Carolina Press.

Sharlip, C. The American Friends Service Committee, and The West Virginia Economic Justice Project. 1998. A Brief Guide to Welfare Changes. Charleston, West Virginia: Charleston Gazette.

Sharp, J. and Spiegel, A. 1990. "Women and Wages: Gender and Control of Income in Farm and Bantustan Households." Journal of Southern African Studies 16(3): 527-549. 
Simkins, C. 1984. "The Distribution of the African Population of South Africa by Age, Sex, and Region Type, 1950-1980." In South African Institute of Race Relations ed. Studies in Urbanization in South Africa. Johannesburg: South African Institute of Race Relations.

Simon, R. M. 1979. The Development of Underdevelopment: the coal industry and its effects on the West Virginia Economy. Ph D Dissertation. University of Pittsburgh.

Slack, T. and Jensen, I. 2002. "Race, Ethnicity, and Underemployment in Non-Metropolitan America: A 30-year Profile.” Rural Sociology 67: 208-233.

Smith, N. 1997. "Classics in human geography revisited: commentary 2." Progress in Human Geography 21: 557.

. 1996. "Spaces of vulnerability: the space of flows and the politics of scale." Critique of Anthropology 16: 63.

491-500.

1994. "Geography, empire, and social theory." Progress in Human Geography 18:

. 1992a. "Geography, Difference, and the Politics of Scale." In J. Doherty, E.

Graham, and M. Malek, eds. Postmodernism and the Social Sciences. MacMillan Publishing.

- 1992b. "Contours of a spatialized politics: homeless vehicles and the production of geographical scale." Social Text 33: 55.

. 1987. "Dangers of the empirical turn: some comments on the CURS initiative."

Antipode 19(1): 59.

Smith, N. and Katz, C. 1993. "Grounding metaphor: towards a spatialized politics. In M. Keith and S. Pile, eds. Place and Politics of Identity. London: Routledge.

Snyder, A. R., Brown, S. I, and Condo, E. P. 2004. "Residential Differences in Family Formation: The Significance of Co-habitation." Rural Sociology 69(2): 235-260.

Snyder, A. R. and McLaughlin, D. K. 2004. "Female-headed Households and Poverty in Rural America." Rural Sociology 69: 127-149.

Soja, E. 1985. "The spatiality of social life: towards a transformative retheorisation." In D. Gregory and J. Urry, eds. Social Relations and spatial structures. London: Macmillan.

SouthAfricaInfo. 2005. "Spreading the Social Security Net." July 19, 2005. (available at: www.safrica.info/ess_info/sa_glance/social_delivery/social_grants.htm).

South Africa Social Security Agency. 2005. "You and Your Grants 2005." (available at: www.welfare.gov.za/sassa/Documents/ugrants.htm). 
Spalter-Roth, R. and H. Hartman. 1995. "Small Happinesses: The Feminist Struggle to Ingrate Social Research with Social Activism.” In H. Gottfried, ed. Feminism and Social Change:

Bridging Theory and Practice. Urbana: University of Illinois Press.

Spero, S. and Harris, A.L. 1931. The Black Worker: The Negro and the Labor Movement. New York: Columbia University Press.

Spivak, G. C. 1988. “Can the Subaltern Speak?” In C. Nelson and L. Grossberg, eds. Marxism and the Interpretation of Culture. Urbana: University of Illinois Press.

. 1987. In Other Worlds: Essays in Cultural Politics. New York:

Methuen/Routledge.

Stacey, J. 1993. "Untangling Feminist Theory." In D. Richardson and V. Robinson ed. Introducing Women's Studies. Basingstoke: Macmillan.

Staeheli, L. 1994. "Empowering political struggle: spaces and scales of resistance." Political Geography 13: 387.

Staeheli, L. and V. A. Lawson. 1994. "A Discussion of 'Women in the Field': The Politics of Feminist Fieldwork."

Statistics South Africa. 2003. "Census 2001-Census in Brief." Pretoria, South Africa. (available at: www.statssa.go v.za).

Statistics South Africa and the World Bank. 2000. "Measuring Poverty in South Africa."

Swenson, T., White, S. and Murdock, S. 2001. "Time Limit and Sanction Effects on Metropolitan and Nonmetropolitan Welfare Caseloads." Unpublished Manuscript Presented at the Annual Meetings of the Rural Sociological Society. Albuquerque, NM: August, 15-19.

Swyngedouw, E. 1997. "Excluding the other: the production of scale and scaled politics." In R. Lee and J. Wills, eds. Geographies of economies. London: Arnold.

Taylor, P. 1999. "Places, spaces, and Macy's: place-space tensions in the political geography of modernities." Progress in Human Geography 23: 7.

. 1987. “The paradox of geographical scale in Marx's politics.” Antipode 19: 287.

. 1984. "Introduction: geographical scale and political geography." In P. Taylor and J. House, eds. Political geography: recent advances and future directions. London and Sydney: Croom Helm.

. 1982. "A materialist framework for political geography." Transactions, Institute of British Geographers 7: 15. 
Thomas, J. B. 1971. Coal Country: The Rise of the Southern Smokeless Coal Industry and its Effect on Area Development, 1872-1910. Ph D Dissertation. University of North Carolina at Chapel Hill.

Thomas, W. R. 1926. Life Among the Hills and Mountains of Kentucky. Louisville: Standard Printing.

Thurmond, W. R. 1964. The Logan Coal Field of West Virginia: A Brief History. Morgantown: West Virginia University Library.

Tickamyer, A. and Duncan, C. 1990. "Poverty and Opportunity Structure in Rural America." Annual Review of Sociology 16(1): 67-86.

Tickameyer, A. and Tickameyer, C. 1986. "Gender, Family Structure and Poverty in Central Appalachia." Proceedings of the 1986 Conference on Appalachia, pp. 80-90.

Tivers, J. 1985. Women Attached: the daily lives of women with children. London: Croom Helm.

Trauger, A. 2004. "'Because they can do the work': women farmers in sustainable agriculture in Pennsylvania, USA." Gender, Place, and Culture 11(2): 289-307.

Tripp, A. 1992. "The impact of crisis and economic reform on women in urban Tanzania." In L. Beneria and S. Feldman, eds. Unequal Burden: Economic Crisis, Persistent Poverty, and Women's Work. Oxford: Westvie w Press.

Trotter, Jr. J. W. 1990. Coal, Class, and Color: Blacks in Southern West Virginia, 1915-32. University of Illinois Press.

United Nations Development Programme (UNDP). 2000. Transformation for Human Development: South Africa 2000. Pretoria: United Nations Development Programme.

United States Bureau of Labor Statistics. 1990. Employment and Earnings, States and Areas. Washington, D. C.: Government Printing Office.

United States Census Bureau. 2005. West Virginia QuickFacts. Online Document: www.quickfacts.census.gov/qfd/states/54000.html.

Document: www.census.gov. 2000a. Census 2000: Census of Population and Housing. Online 2000b. Profile of Selected Economic Characteristics: 2000.

Online Document: $\underline{w w w . f a c t f i n d e r . c e n s u s . g o v}$. 
. 2000c. Profile of General Demographic Characteristics 2000.

Online Document: www.factifinder.census.gov.

. 2000d. Census 2000 Summary File 3. Online Document:

www.factfinder.census.gov.servlet.

United States Congress. 1986. Office of Technology Assessment: Techonology and Structural Unemployment: Reemploying Displaced Adults, OTA-ITE-250. Washington D. C.: Government Printing Office.

Doc. $195,68^{\text {th }}$ Cong., $2^{\text {nd }}$ Sess. Washington, D.C.: Government Printing Office.

United States Department of Agriculture (UDA). 2005. Official Website: www.usda.gov. 1935. Economic and Social Problems and Conditions of the Southern Appalachians, Miscellaneous Publication No. 205. Washington D. C.

United States Department of Health and Human Services, (DHHS). 2005. Official Website: www.os.dhhs.gov.

. 2000. "State by State

Welfare Caseloads since 1993 (Recipients)." Washington DC: US Department of Health and Human Services, August 8, 2000. http://www.acf.dhhs.gov/news/stats/caseload.htm.

United States Department of the Interior. Census Office Population and Agricultural Statistics Tenth (1880)-Fifteenth (1930) Census. Washington D.C.: Government Printing Office.

Valentine, G. 1996. “(Re)Negotiating the 'Heterosexual Street”. In C. Duncan, ed. BodySpace. London: Routledge.

. 1992. "Images of danger: women's sources of information about the spatial distribution of male violence." Area 24(1): 22.

Vincent, G. 1898. “A Retarded Frontier.” The American Journal of Sociology 4: 1-20.

Walby, S. 1990. Theorizing Patriarchy. Oxford: Blackwell.

1986. Patriarchy at Work: Patriarchal and Capitalist Relations in Employment.

Cambridge: Polity Press.

Walker, C. 1990. Women and Gender in Southern Africa to 1945. London: James Curry.

Wallerstein, I. 1975. "Class formation in the capitalist world economy." Politics and Society 5: 367. 
Walls, M. 1976. "Central Appalachia: a peripheral region within an advanced capitalist society." Journal of Sociology and Social Welfare 4(November): 232-246.

Watson, J. 1963. The Economic and Cultural Development of Eastern Kentucky from 1900 to the present. Ph D Dissertation. Indiana University.

Watts, A. 1978. "Does the Appalachian Regional Commission really represent a region?" Southeastern Geographer 17(May): 19-36.

Weber, B., Duncan, G. J. and Whitener, L. A. 2002. Rural Dimensions of Welfare Reform. Kalamazoo, MI: W. E. Upjohn Institute for Employment Research.

Weedon, C. 1987. Feminist Practice and Poststructuralist Theory. Oxford and New York: Blackwell.

Weiner, D., Levin, R., and Chimere-Dan, O. 1997. "Understanding the Bantustans through Socio-Economic Surveys." In R. Levin and D. Weiner, eds. No More Tears...Struggles for Land in Mpumalanga, South Africa. New Jersey: Africa World Press.

West Virginia Bureau of Employment Programs (WVBEP). 2005. West Virginia -Monthly Report on the Civilian Labor Force, Employment, and Unemployment, Calendar Year 2005. Online Document: www.wvbep.org.

Summary. Charleston, West Virginia. http://www.wvbep.org.

2004. West Virginia Economic 2003. West Virginia Economic

Summary. Charleston, West Virginia. http://www.wvbep.org.

. 2001. West Virginia Employment and Unemployment Statistics, Annual Averages, 1990-1999. Online Document: www.wvbep.org. . 1999. West Virginia Economic

Summary. Charleston, West Virginia. http://www.state.wv.us/bep/lmi/SPECART/esasWV$\underline{\text { W.htm. }}$

West Virginia Child Health Insurance Program (WVCHIP). 2005. Official Website: www.wvchip.org.

West Virginia Department of Employment Security. 1990. Employment and Earnings Trends: Annual Summary. Charleston, West Virginia.

West Virginia Department of Health and Human Resources (WVDHHR). 2005. Official Website: www.wvdhhr.org. 
Whatmore, S., Marsden, T., and Lowe, P. eds. 1994. Gender and Rurality. London: David Fulton Publishers.

Whisnant, D. 1981. Modernizing the Mountaineer: people, power, and planning in Appalachia. Boone: Appalachian Consortium Press.

Whitehead, A. 1994. "Wives and mothers: Female farmers in Africa." In A. Adepoju and C. Oppong eds. Gender, Work, and Population in Sub-Saharan Africa. London: James Currey.

1979. "Some preliminary notes on the subordination of women." Institute of Development Studies Bulletin 10 (3).

Whitehead, A. and Kabeer, N. 2001. Living with uncertainty: gender, livelihoods, and pro-poor growth in rural sub-Saharan Africa. Institute of Development Studies: Working Paper 134.

Widner, R. 1990. “Appalachian Development After 25 Years: An Assessment." Economic Development Quarterly 4(4): 291-312.

Williams, C. and Windebank, J. 1998. Informal Employment in the Advanced Economies, Implications for Work and Welfare. Routledge.

Williams, J. A. 1972. "The New Dominion and the Old: Antebellum and Statehood Politics as the Background of West Virginia's Bourbon Democracy." West Virginia History 33.

Williamson, J. W. 1995. Hillbillyland: What the Movies did to the Mountains and What the Mountains did to the Movies. Chapel Hill and London: University of North Carolina Press.

Wilson, D. 2000. "Insularity in South Africa: a case study in the Northern Province." In J. Fairhurst, A. Musyoki, T. Saidi, and D. Wilson eds, Integrating Environment and Society: the Thohoyandou environs, Northern Province, South Africa. Pretoria: South Africa: Universities of Pretoria and Venda.

Wirt, William and Wilma. 1938. William and Wilma Wirt to Peggy Westerfield, 19 September, 1938. Peggy Westerfield Papers, No. 1430. Southern Historical Collection, University of North Carolina.

Wittig, M. 1992. The Straight Mind and Other Essays. Hemel Hempstead: Harvester Wheatsheaf.

Wolf, D. L. ed. 1996. Feminist Dilemmas in Fieldwork. Boulder: Westview Press.

Wolfe, G. 1916. George Wolfe to Justus Collins, 23 August, 1916. Justus Collins Papers, West Virginia University. 
Wolfe, M. R. 1975. "Aliens in Appalachia: The Construction of the Clinchfield Railroad and the Italian Experience." In E. M. Essin, ed. Appalachia: Family Traditions in Transition. Johnson City: East Tennessee State University Press.

Woolard, I. 2003. Impact of Government Programmes using Administrative Data Sets-Social Assistance Grants. Project 6.2 of the Ten Year Review Research Programme. June 19, 2003.

Wolpe, H. 1980. "Capitalism and cheap labor power in South Africa: from segregation to apartheid." In H. Wolpe ed. The Articulation of Modes of Production. London and Boston: RKP.

Women and Geography Study Group (WGSG). 1984. Geography and Gender: An Introduction to Feminist Geography. London: Hutchison.

. (WGSG) eds. 1997. Feminist Geographies: Explorations

in Diversity and Difference. England: Addison Wesley Longman Limited.

Women's National Coalition (WNC). 1994. Interim Research Report. Johannesburg, South Africa.

Wood, L. E. and Bischak, G. A. 2000. "Progress and challenges in reducing economic distress in Appalachia: an analysis of national and regional trends since 1960." Appalachian Regional Commission, Washington, D. C.

Woolard, I. 2003. "Impact of Government Programmes Using Administrative Data Sets-social assistance grants." Project 6.2 of the Ten Year Review Research Programme, June 19, 2003.

Young, I. 1980. "Socialist Feminism and the Limits of Dual Systems Theory." Socialist Review 10(2-3): 174.

Zimmerman, J., Dewees, S., Reinschmiedt, L., and Hirschl, T. 1999. Rural America and Welfare Reform: An Overview Assessment. Rural Policy Research Institute, P99-3. Columbia, MO: University of Missouri. 